\title{
CHARACTERIZATION OF MARINE NEAR-SURFACE SEDIMENTS \\ BY ELECTROMAGNETIC PROFILING
}

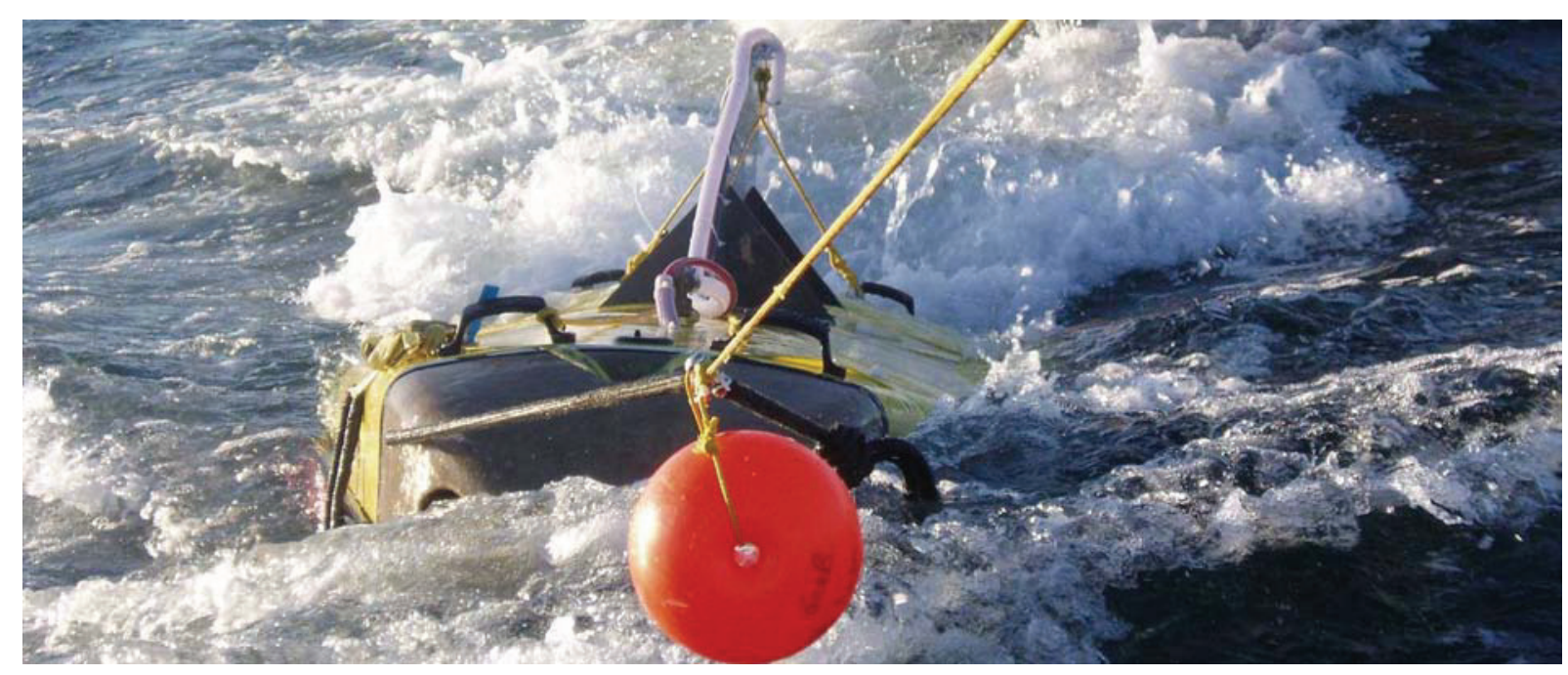

Dissertation

Eingereicht zur Erlangung des Doktorgrades der Naturwissenschaften (Dr. rer. nat.) am Fachbereich Geowissenschaften der Universität Bremen, Deutschland

In fulfillment of the requirements for the doctoral degree in natural sciences (Dr. rer. nat.) at the Department of Geosciences at Bremen University, Germany

vorgelegt von

presented by

\section{Hendrik Müller}

Bremen, Germany, November 2009 


\section{Preface}

The research, development and implementation of an electromagnetic seafloor profiler $G E M$ Shark has been made possible through the joint funding of the Center for Marine Environmental Sciences (MARUM) at the University of Bremen (research grant: Electromagnetic sensor for surveying seafloor magnetic susceptibility and electric resistivity for the investigation of sedimentary and diagenetic processes in the Ría de Vigo Estuary, NW Spain) and the Marine and Environmental Geology Group (MARGO) at the University of Vigo (research grant: PGDIT06TAM31201PR (XUGA) and CTM 2007-61227/MAR (MICINN)).

Throughout the period of this thesis the author has been the beneficiary of a doctoral student and University staff position. From November 2005 to November 2008 the doctoral student position was on the MARUM project C1 (Sedimentary signatures and diagenetic processes of ocean margin deposits) from November 2008 to November 2009 the author was employed as a member of staff at the University of Bremen.

Four survey campaigns with the RB Polarfuchs in the Western Baltic Sea were granted by IfM GEOMAR in Kiel. A survey campaign with the RB Arao in the Ría de Vigo was organized by the University of Vigo. An EM survey of the NW Iberian Shelf with the RV Poseidon was part of International Graduate School "Proxies in Earth Science" (EUROPROX) expedition P 366/3.

The thesis project has been supervised and reviewed by Prof. Dr. Tilo von Dobeneck (Dept. of Geosciences, University of Bremen). The second thesis reviewer is Prof. Dr. Tobias Mörz (Dept. of Geosciences, University of Bremen). Prof. Dr. Daniel Rey and Prof. Dr. Belén Rubio (University of Vigo) and Dr. Kay Hamer (University of Bremen) have been project partners and manuscript coauthors. The development of the hard- and software of the EM profiler was accomplished in close cooperation with Dipl.-Ing. Christian Hilgenfeldt, engineer of MARUM project C1, and support by I.J. Won, Manager of Geophex Ltd. (USA).

The main part of this cumulative thesis (Chapters 2-4) consists of three journal manuscripts (one published, two ready for submission), which are for the most part based on my own theoretical and technical developments, programming, field work and data interpretation. Laboratory data of a co-supervised diploma project by Wiebke Nehmiz (Umweltmagnetische und geochemische Untersuchungen an Grundwasseraustritten in der Eckernförder Bucht, April 2007) have been integrated into Chapter 3. 
Für

Kerstin und Theo 


\section{Content}

Abstract. 1

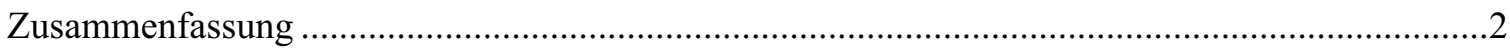

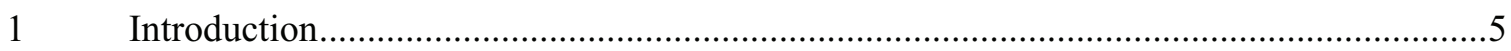

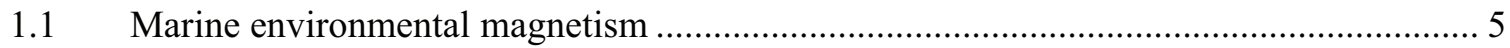

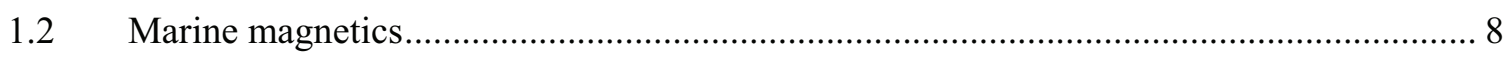

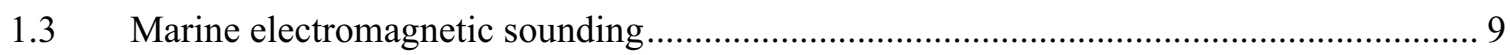

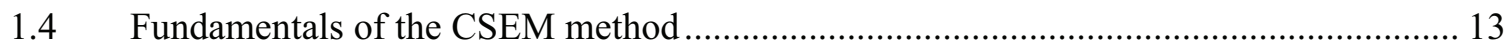

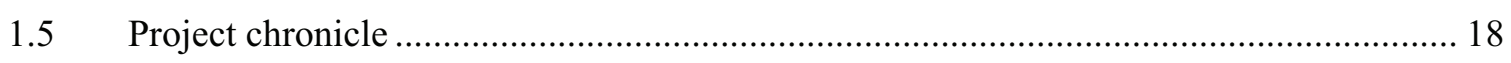

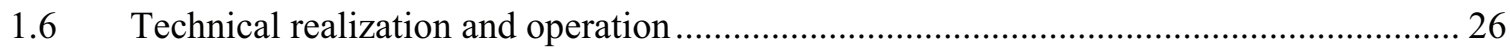

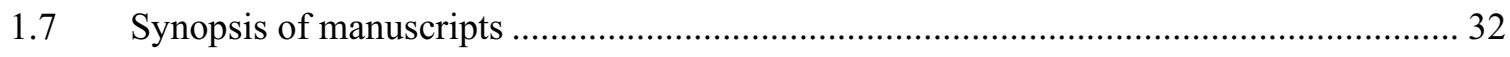

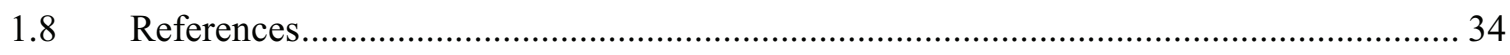

2 Mapping the magnetic and electric signatures of marine near-surface sediments by bottom-towed Controlled Source Electromagnetics ...........................................................40

3 Near-surface electromagnetic, rock magnetic and geochemical fingerprinting of submarine freshwater seepage at Eckernförde Bay (SW Baltic Sea) .................................74

$4 \quad$ Using electromagnetic sensors to estimate physical properties and environmental quality of surface sediments in the marine environment. Preliminary results ..................112

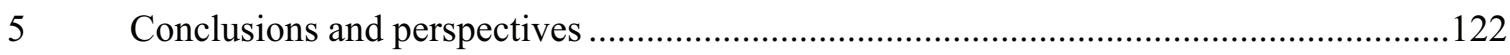

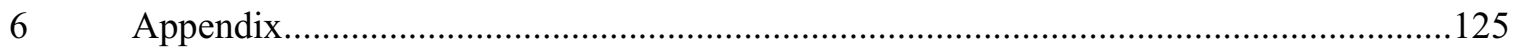

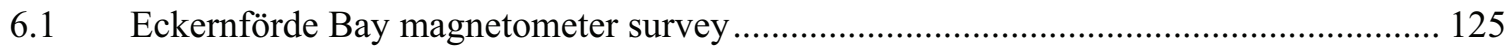

6.2 Pilot study: seafloor EM mapping in the Ria de Vigo, NW Spain ................................ 129

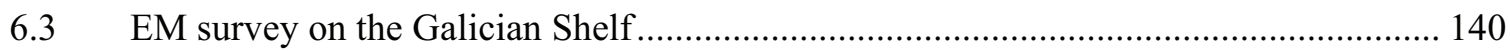

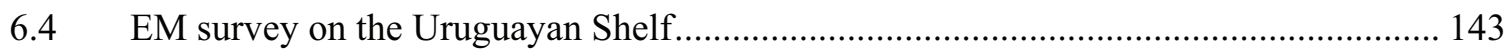

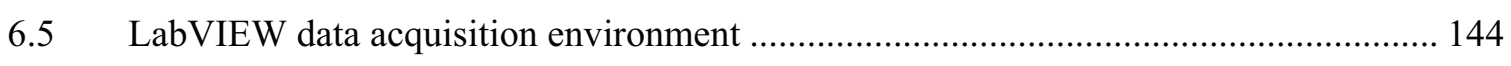

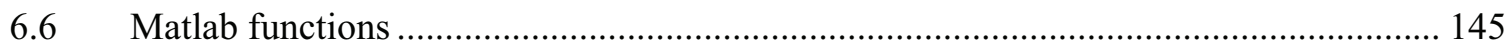

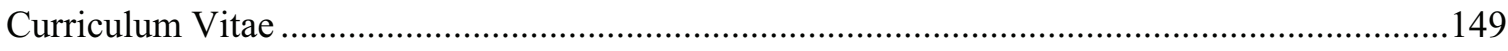

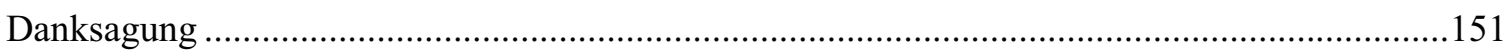




\begin{abstract}
This thesis investigates the theory, develops the technology and demonstrates the applicabilities for synchronous in-situ mapping of the magnetic and electric signatures of marine near-surface sediments. A marine electromagnetic profiler has been developed for coastal and shelf operations in 5 to $500 \mathrm{~m}$ water depths. The system was designed to resolve subtle and gradual variations in silt and clay content, porosity and diagenesis state of marine sediments at a sub-meter scale. An electromagnetic (EM) induction sensor (Geophex GEM-3) was modified for submarine operations and mounted into a special bottom-towed sled. Seafloor magnetic susceptibility and electric conductivity were calculated from the in-phase and quadrature component of the secondary electromagnetic field using a half-space inversion algorithm. Seawater conductivity was measured synchronously by an integrated conductivitytemperature-depth (CTD) probe. The electric conductivity depends on porosity, the grain-size distribution and conductivity of the pore fluid. Magnetic susceptibility was used in this study as a proxy for fine-grained terrigenous clay/silt content, diagenetically forced magnetite depletion, as well as anthropogenic contaminants.
\end{abstract}

The three attached manuscripts address different applications of the modified EM profiler. The first manuscript develops the physical and technical principles of the method and presents first results regarding the facies, early diagenesis, transport, and deposition of near-surface sediments on the NW Iberian shelf. The second manuscript combines high-resolution acoustic, magnetometric, and electromagnetic profiling with sample-based rock magnetic and geochemical analyses related to submarine groundwater discharge in a Baltic Sea estuary. The third manuscript is an application of the EM profiler to study the contamination of coastal areas by ferrous objects, organic matter and heavy metal pollution for coastal zone management of the Ría de Vigo, a NW Iberian estuary. 


\section{Zusammenfassung}

Diese Doktorarbeit erforscht die Theorie, entwickelt die Technologie und präsentiert Anwendungen zur synchronen in-situ Kartierung der magnetischen Suszeptibilität und elektrischen Leitfähigkeit mariner Sedimente. Die magnetische Suszeptibilität erfasst den Ton und Silt-Gehalt, das Ausmaß diagenetisch bedingter Magnetitlösung sowie die anthropogene Kontamination des Sediments. Die elektrische Leitfähigkeit ist ein Maß für Porosität, Korngrößenverteilung und Porenwassersalinität.

Dieses Ziel wurde durch die Entwicklung eines elektromagnetischen (EM) Meeresboden ,Profiler' realisiert, der speziell für den Schelf und Küsteneinsatz in Wassertiefen von 5 bis $500 \mathrm{~m}$ konzipiert ist. Das System ermöglicht eine hochauflösende profilierende Erfassung auch gradueller Änderungen der Lithologie und Porosität sowie der diagenetischen Alteration der Oberflächensedimente des Meeresbodens. Um dies zu realisieren wurde ein auf dem elektromagnetischen (EM) Induktionsprinzip basierender kommerzieller Sensor (Geophex GEM-3) für den marinen Einsatz modifiziert und in einen speziell für diese Anwendung konzipierten Schlitten integriert. Ein Inversionsalgorithmus ermöglicht es die magnetische Suszeptibilität und die elektrische Leitfähigkeit aus dem Realteil (In-Phase) und Imaginärteil (Quadrature) des gemessenen sekundären magnetischen Feldes zu berechnen. Neben den geometrischen Randbedingungen werden synchron zur Elektromagnetik mit einem integrierten CTD-Sensor gemessene Leitfähigkeits-, Temperatur- und Tiefendaten in die Inversion einbezogen.

Im Rahmen dreier Studien wird eine Vielzahl von Anwendungen des neuen EM-Profilers vorgestellt und diskutiert. Das erste Manuskript entwickelt die physikalischen und technischen Grundlagen der Methode und präsentiert erste Ergebnisse eines Einsatzes auf dem NW Iberischen Schelf. Anhand der magnetischen und elektrischen Signaturen lassen sich Faziestyp, Transport- und Ablagerungsmilieu der Decksedimente eindeutig abbilden. Das 
zweite Manuskript beschreibt akustische, magnetometrische und elektromagnetische Profilmessungen an submarinen Grundwasseraustritten in der Eckernförder Bucht (westliche Ostsee) in Kombination mit gesteinsmagnetischen und geochemischen Analysen an Einzelproben. Diese Untersuchungen zeigen unter anderem, dass der aus magnetischen und elektrischen Eigenschaften abgeleitete sedimentäre Fingerabdruck ein probates und schnelles Verfahren ist, um die lokale Ausprägung mariner Sedimente $\mathrm{zu}$ ermitteln und Verteilungsmuster zu kartieren. Das dritte Manuskript zeigt anhand eines Beispieldatensatzes der Ría de Vigo (NW Iberien) die Möglichkeiten des EM-Profilers auf, metallische und organische Verschmutzungen in Hafen- und Küstenregionen zu erfassen. 


\section{Introduction}

As part of the terrigenous sediment flux to the sea, magnetic trace minerals are carried by water, ice or wind to the oceans system. In coastal and shelf settings, the continental debris is subject to transport, fractionation and alteration processes by local impact of waves, currents, tides, tectonics, biota, gas and fluid seepage. Human impact, for example through trawling, mining, dredging, dumping and offshore construction, is playing a growing role in modifying sediment distribution. Early diagenesis plays an eminent role in further modifying the clastic and in particular the magnetic mineral assemblage of sediments. In consequence, shallow marine sediments show a vast spatial variability both in their lithological and magnetic properties. Magnetic exploration techniques, namely environmental magnetism, marine magnetics and electromagnetics can therefore provide important contributions in revealing naturally and anthropogenically forced sedimentation controls and their ecological and economic implications.

\subsection{Marine environmental magnetism}

Environmental magnetic techniques identify the concentration, mineralogy and grain-size of the magnetic sediment fraction by means of fast, non-destructive and sensitive measurements that require little sample preparation (Evans and Heller, 2003; Frederichs et al., 1999). In combination with geochemical major element and pore-water analysis, the magnetic properties of marine sediments are often used as proxy for paleoclimate and paleoceanography, to trace pollutants and to indicate provenance, transport and reworking of sediments. Climatic, geochemical and anthropogenic influences affect magnetic signals in various ways:

(1) Mixing of the terrigenous fraction with biogenic carbonate or silica dilutes the magnetic mineral content and reduces concentration-related magnetization parameters. Magnetic 
susceptibility and remanence signals of oxic deep-sea sediments often reflect variations of terrigenous and biogenic accumulation rates (Schmieder et al., 2000).

(2) The magnetic petrology of sediments as determined by mineral specific magnetic parameters is often characteristic of prevailing climatic conditions. Itambi et al. (2009) used rock magnetic methods to identify climatic changes related to Heinrich events, where arid periods of enhanced eolian input are reflected by higher abundances of antiferromagnetic hematite $\left(\mathrm{Fe}_{2} \mathrm{O}_{3}\right)$, while higher fluvial input during more humid conditions is mirrored in a higher abundance of ferrimagnetic magnetite $\left(\mathrm{Fe}_{3} \mathrm{O}_{4}\right)$.

(3) So-called magnetogranulometric parameters have shown potential to be used as bulk sediment grain-size proxy (Oldfield et al., 1993; Clifton et al., 1999; Zhang et al., 2001; Booth et al., 2005). Franke et al. (2007) demonstrated that magnetic particle sizes of Equatorial Atlantic sediments result from source mixing and transport sorting processes, which can be separated by environmental magnetic techniques.

(4) The site and source specificity of certain magnetic minerals can be used for magnetic fingerprinting in sediment provenance studies. This technique has been successfully applied to identify sediment sources of the Rode River (Yu and Oldfield, 1989), the Tay Estuary (Jenkins et al., 2002) and the Rias Baixas (Rubio et al., 2001).

(5) Marine heavy metal pollution can be associated with positive as well as negative anomalies in magnetic mineral concentration. Studies of stressed estuarine environments and harbors (Chan et al., 1998, Zhang et al., 2001; Versteeg et al., 1995; Pozza et al., 2004) have revealed positive correlations of magnetic susceptibility and heavy metal concentrations due to industrial combustion processes, which release both iron oxides and heavy metal particles (Beckwith et al., 1986; Hanesch and Scholger, 2002). Other studies have reported an inverse correlation of magnetic susceptibility with heavy metal content, as a consequence of 
intensified chemical diagenesis of primary iron oxides (Rey et al., 2005; Rubio et al., 2001) and heavy mineral precipitation under conditions of enhanced organic input.

(6) The alteration state of magnetic minerals is indicative of geochemical redox conditions. Early diagenesis of organic matter under reducing (suboxic) conditions frequently involves the dissolution of primary iron oxides and their transformation into magnetic and nonmagnetic iron sulfides (Karlin and Levi, 1983; Canfield and Berner, 1987; Tribovillard et al., 2002; Emiroglu et al., 2004; Reitz et al., 2004; Garmin et al., 2005; Fu et al., 2008). Rey et al. (2005) found that magnetic mineral diagenesis in the estuarine environments of the Galician Rías is mostly controlled by water depth, distribution of wave energy and hence the degree and frequency of seabed remobilization.

(7) Magnetic methods have also shown a potential to characterize seepage of methane, hydrothermal fluids and freshwater (Housen and Musgrave, 1996; Novosel et al., 2005; Tivey and Johnson, 2002).

Magnetic susceptibility is the most commonly measured magnetic parameter since it gives a rough indication of the magnetic mineral concentration and it allows for rapid measurement (Peters and Thompson, 1998). Susceptibility distribution patterns of the seafloor have often been used to clarify the provenance and transport pathways of marine sediments (e.g. Duck et al., 2001; Ellwood et al., 2006, Schmidt et al. 1999). To date, such investigations have mainly been based on laboratory analyses of grabbed or cored surface sediment samples, which strictly limits the available spatial resolution. Unfortunately core sampling and chemical analysis are prohibitively expensive and impracticable to map large structures in high detail. There always remains uncertainty whether collected sediment samples represent the full spectrum of existing seafloor conditions and yield statistically robust parameter means and distributions. In spite of the evident potential of mapping the magnetic susceptibility of 
marine near-surface sediments at high spatial resolution, the step from sample-based to in-situ measurement has not been taken because of the lack of suitable in-situ technologies.

\subsection{Marine magnetics}

Magnetic in-situ mapping of the seafloor is commonly performed with the aid of marine total field (proton precession, cesium vapor) or vector (fluxgate) magnetometers. This method makes use of spatial deflections ('anomalies') of the static earth magnetic field caused by localized induced and remanent magnetizations of rocks and sediments. Magnetometer surveys are an essential exploration method in regional mapping programs (McEnroe et al., 2001). In particular they have been utilized to detect buried mapping crustal and volcanic structures, magnetic seafloor anomalies, mineral resources, shipwrecks, cables and unexploded ordnance (UXO). Passive magnetometry can only detect relatively sharp lateral magnetization contrasts and is incapable of resolving the subtle magnetic variability of nearsurface sediments. Such as other potential-field methods, magnetometry is inherently ambiguous and lacks the capacity to define exact anomaly sources. However, it has been recognized that, under favorable conditions, marine magnetometry is capable of resolving small-scale geological features of the seafloor with relatively simple means:

(1) In a near-bottom geophysical survey on the Endeavour Segment of the Northern Juan de Fuca Ridge Tivey and Johnson (2002) showed that regions of well defined low crustal magnetization were strongly correlated with both active and extinct submarine hydrothermal vent sites. Using a magnetometer mounted on the remotely operated vehicle Jason, they identified discrete magnetization lows associated with each cluster of vents, which they interpreted as individual fluid upwelling zones with own distinct subsurface plumbing and thermal structure. These crustal magnetization patterns provided important constraints on the geometry of the subsurface plumbing beneath these hydrothermal vent systems. 
(2) Novosel et al. (2005) have shown through core based analyses of sediments from the Cascadia Accretionary Prism that prominent low magnetic susceptibility signatures within vent zones were related to high upward methane fluxes. These low magnetic susceptibility zones are capable of producing negative magnetic anomalies with a magnitude of 10-35 nT near the seafloor. Such anomalies can be detected with deep-towed magnetometers providing a means of mapping zones of methane venting.

(3) Pozza et al. (2004) estimated metal pollutant levels from core-based and magnetometer measurements in Hamilton Harbour (Canada). They found that the magnetic susceptibility of contaminated sediment layers is by one to two orders of magnitude higher than that of the uncontaminated sediment. Magnetic contrasts resulting from elevated levels of urban-source magnetic oxides are sufficient to generate total field anomaly in the order of 5-40 nT. Although being a promising precursor for comprehensive magnetometric mapping of marine pollution levels, the method is only applicable in areas where background sediments have low magnetic susceptibilities compared to highly magnetic urban-source pollutants.

Despite the fact that nearly every morphostructural element of the seafloor is also expressed in lateral material and property contrasts, the resulting magnetic contrast are generally too subtle and/or too gradual to be mapped by passive magnetometric methods. Another common problem for near-surface studies is the influence of deeper, magnetically heterogeneous substrata dominating the magnetic anomaly pattern. This is typically the case with crystalline bedrock and the strongly magnetic glacial tills of North and Baltic Sea (Gay, 2004).

\subsection{Marine electromagnetic sounding}

Marine electromagnetic methods, both passive and active, have been used to study the electric properties of the oceanic crust and mantle. Theory and instrumentation have been developed by a small number of academic groups starting from the early 1980's (Cox et al., 1971). 
Passive magnetotelluric methods have been confined to lower crust and mantle studies because of the exponential decay of the natural external source field in the conductive ocean. Active, so-called 'controlled source' electromagnetics (CSEM) has been used to sound the shallow and deep seafloor. Targets for CSEM surveys are, among others, mid-ocean ridges, hydrothermal vent systems, and gas hydrates (e.g. Baba, 2005; Edwards, 2005; Constable and Srnka, 2007).

Marine CSEM has gained attention as an exploration method by the offshore oil industry after a successful EM survey over a known oil reservoir offshore Angola in the late 1990s (Ellingsrud, 2002). Today, marine CSEM is frequently used to complement seismic methods in reservoir characterization. The electrical resistivity of hydrocarbons such as petroleum, free gas, or gas hydrate is much higher than that of the pore fluid, which is typically seawater with conductivities between 2.8 and $3.5 \mathrm{~S} / \mathrm{m}$. The electrical conductivity of hydrocarbon bearing sediments is reduced in contrast to the surroundings. Sediment conductivity can also be strongly modified by seepage of brines and freshwater which have respectively much higher and lower conductivities than seawater.

The most common set-up of a CSEM survey consists of electromagnetic receivers which are deployed on the seafloor and a dipole source that is towed behind the ship along profiles at a safety distance of about 50-100 $\mathrm{m}$ above the seafloor over the receiver array (Figure 1-1). Such systems were first developed by the marine EM group at Cambridge/Southampton, UK (e.g. Sinha et al., 1990) and the marine EMlab at Scripps, San Diego, USA (Flosadottir and Constable, 1996; Constable and Srnka, 2007). In recent years the set-up has been adapted by a number of service companies supporting the petroleum industry (e.g. OHM UK, EMGS Norway, Schlumberger, WesternGeco EM). Typical targets are hydrocarbon layers at depths of about $1000 \mathrm{~m}$ below the seafloor. In Germany, IFM-Geomar's marine EM group around Marion Jegen used magnetotellurics to investigate melt and fluid distributions along mid 
ocean ridges and subduction zones (e.g. Jegen et al., 2009). Their ocean bottom receivers were recently modified to operate in high frequency modus to collect CSEM data in conjunction with a transmitter source.

Nigel Edwards and his team at the University of Toronto have pioneered marine EM methods since the 1980s. The team designed a bottom-towed electric dipole-dipole system (Figure 1-2) to study submarine gas hydrates typically found at subbottom depths down to about $500 \mathrm{~m}$ (Edwards, 1997). First CSEM case studies were carried out by Yuan and Edwards (2000) and Schwalenberg et al. (2005) at gas hydrate deposits of the Cascadia Margin, Western Canada. The same system was used by Schwalenberg et al. (2009) to investigate the electric signature of methane seeps and gas hydrates on the Hikurangi Margin, New Zealand.

Rob Evans' group, at the Woods Hole Oceanographic Institution, and the Geological Survey of Canada have built a small scale coaxial magnetic dipole-dipole system which has been mainly used for shallow geotechnical surveys. This CSEM system measures average bulk porosity down to depths of $\sim 20 \mathrm{~m}$ below the seafloor and has been used to map buried channels on the New Jersey Margin (Evans et al., 2000) and the porosity structure within the top $20 \mathrm{~m}$ of the Eel Shelf in Northern California (Evans et al., 1999).

Other than marine magnetometers that provide means of mapping magnetic material contrasts, marine CSEM methods were so far mainly applied to detect electric resistivity (or conductivity) distribution patterns. However, the electromagnetic approach is physically and technically capable of measuring both, the magnetic susceptibility and the electric resistivity, with significantly better sensitivity and resolution than the potential-field methods. Joint interpretation of bivariate EM in-situ data in combination with advanced laboratory analytics should open new possibilities to identify and to quantify primary sediment components and reconstruct their genesis, preservation state and accumulation history. 


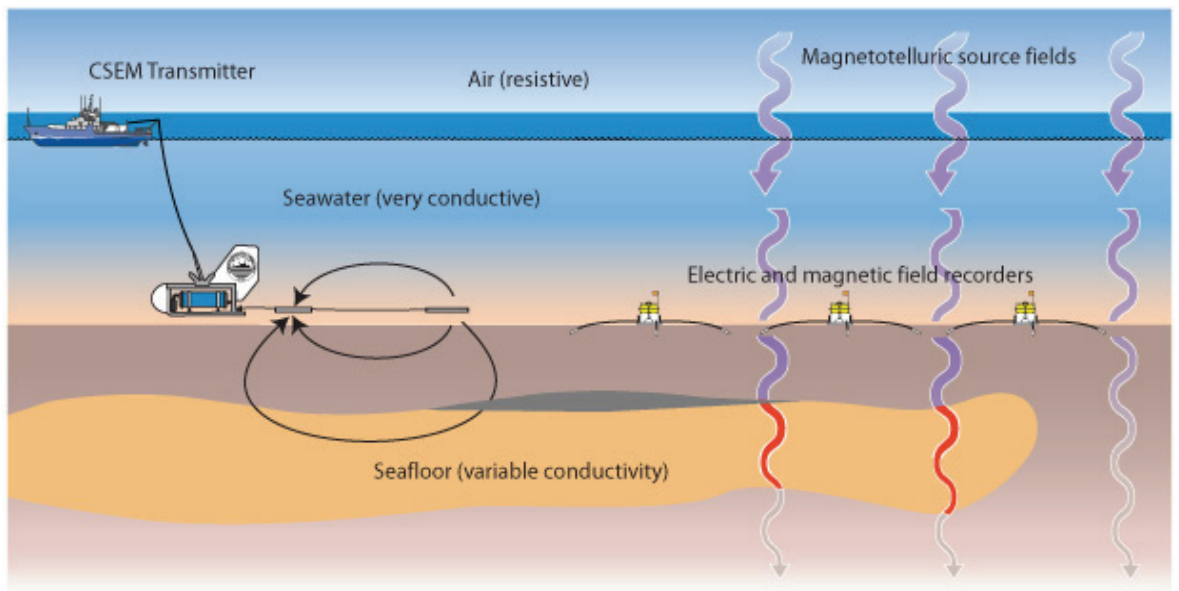

Figure 1-1. Exemplary marine CSEM set-up of towed dipole-dipole transmitter and stationary ocean bottom receivers (Constable and Srnka, 2007). An electromagnetic transmitter is towed close to the seafloor. CSEM and MT fields are recorded by instruments deployed on the seafloor at some distance from the transmitter.

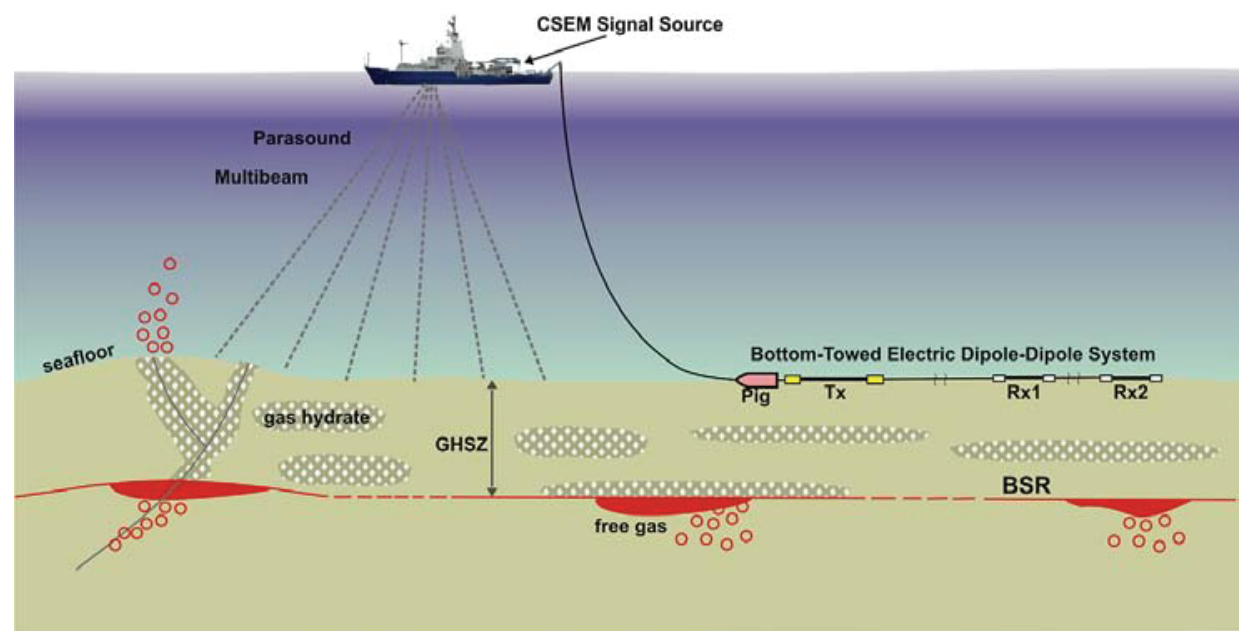

Figure 1-2. Exemplary marine CSEM set-up of the bottom-towed (inline) electric dipole-dipole system (Schwalenberg et al., 2009). A current signal is produced by an onboard transmitter and sent through the cable to the transmitter dipole Tx on the seafloor. Several receiver dipoles Rx record the signal after it passed through the seawater and the sediments (BSR - bottom simulating reflector, GHSZ - gas hydrate stability zone). 


\subsection{Fundamentals of the CSEM method}

Electromagnetic induction is based on two physical observations: (1) Ampere's Law: the flow of electric current through conductors produces a magnetic field; (2) Faradays Law: time variant magnetic fields induce current flows in media to which these magnetic fields are linked (Zhdanov and Keller, 1994).

The theory of the CSEM method is based on Maxwell's equations which govern the four vector functions: the electric field $\mathbf{E}(\mathrm{V} / \mathrm{m})$, the magnetic induction $\mathbf{B}(\mathrm{T})$, the dielectric displacement D $\left(\mathrm{C} / \mathrm{m}^{2}\right)$ and the magnetic field $\mathbf{H}(\mathrm{A} / \mathrm{m})$. Farraday's Law describes the formation of an electric field by a time-varying magnetic field:

$$
\nabla \times \mathbf{E}=-\frac{\partial \mathbf{B}}{\partial \mathrm{t}}
$$

Amperes Law states that conduction and displacement currents are sources of the magnetic field:

$$
\nabla \times \mathbf{H}=\mathbf{J}+\frac{\partial \mathbf{D}}{\partial \mathrm{t}}
$$

with current density I (A/ $\left.\mathrm{m}^{2}\right)$ (e.g. Ward and Hohmann, 1988). Maxwell's equations are coupled by the constitutive relations:

$$
\mathbf{D}=\epsilon \mathbf{E}, \quad \mathbf{B}=\mu \mathbf{H} \text { and } \mathbf{J}=\sigma \mathbf{E}
$$

where $\epsilon, \mu$ and $\sigma$ are respectively the dielectric permittivity, magnetic permeability, and electric conductivity (the reciprocal of resistivity $\rho$ ).

Magnetic susceptibility $\kappa$ is defined by $\mu=\mu_{0}(\kappa+1)$, where $\mu_{0}=4 \pi \times 10^{-7} \mathrm{H} / \mathrm{m}$ is the magnetic permeability of free space. It describes the induced magnetization per unit volume that a material acquires in a magnetic field. The relation of magnetic field and induced magnetization is linear for diamagnetic minerals (e.g. quartz, carbonate), linear, but 
temperature dependent for paramagnetic minerals (e.g. iron phyllosilicates), and non-linear, and temperature dependent for ferro-, ferri- and antiferromagnetic minerals (iron oxides, oxihydroxides and sulfides) with $\kappa_{\text {dia }}<\kappa_{\text {para }} \ll \kappa_{\text {fer }}$. In practice, sediment susceptibility is primarily a concentration measure of the ferrimagnetic mineral magnetite, the 'single most important magnetic mineral on earth' (Dunlop and Özdemir, 1997).

In CSEM problems, the transmitter is an additional source, considered by the current density $\mathbf{J}_{\mathrm{S}}$ that has to be added to Ohm's Law ( ${ }^{\text {rd }}$ relation of equations 3$)$.

$$
\mathbf{J}=\sigma \mathbf{E}+\mathbf{J}_{\mathbf{s}}
$$

The damped wave equation is then derived combining Ohm's, Ampere's and Faraday's laws:

$$
\nabla^{2} \mathbf{H}-\mu \sigma \frac{\partial \mathbf{H}}{\partial t}-\mu \epsilon \frac{\partial^{2} \mathbf{H}}{\partial t^{2}}=\mu \boldsymbol{\nabla} \times \mathbf{J}_{\mathbf{s}}
$$

The second term on the left hand side of equation (5) is energy dissipation and it describes electromagnetic diffusion; the third term is energy storage which describes wave propagation (Powers, 1997). For low frequencies $(<20 \mathrm{kHz})$ as commonly used in CSEM surveys, $|\sigma \partial \mathbf{H} / \partial t|$ is several orders of magnitude larger than $\left|\epsilon \partial \mathbf{H}^{2} / \partial t^{2}\right|$. Thus, the quasi-stationary approximation can be used, and the wave propagation term together with the dielectric permittivity $\epsilon$, can be ignored. Hence, CSEM field propagation is a purely diffusive phenomenon. The diffusion of the EM fields can be visualized by a "smoke ring" (Lamb, 1945) which moves through conductive media by induction with a velocity given by BiotSavart's Law. The conductivity of the medium is thereby responsible for the dissipation of the electromagnetic "smoke ring".

The most commonly used sensor geometries for marine resistivity mapping consist of a moving transmitter and stationary, precisely localized receivers (e.g. Sinha et al., 1990; Constable and Cox, 1996; Exxon Mobile). Alternatively several receivers are trailed in a chain behind a transmitter (e.g. Edwards, 2005; Evans, 2007; Schwalenberg et al., 2009). The 
penetration or diffusion depth of the EM signal generated by a source dipole on or close to the seafloor depends on the frequency and amplitude of the source, and the conductivity of the media. High frequency signals are quickly absorbed in conductive media, while low frequency signals propagate larger distances in resistive media. There is also an optimum transmitter-receiver-offset for target resolution. In essence the EM depth rule is similar as in seismics - the deeper the target the bigger the transmitter-receiver offset and the lower the frequency of the source signal.

CSEM surveying with very short transmitter-receiver separation can be realized by transmitter-receiver coil sensors with a third coil, the bucking coil, which is tuned to cancel the primary signal at the position of the receiver. This principle has become the state of the art for helicopter electromagnetic and for some handheld EM sensors, especially the CSEM sensor Geophex GEM-3. This is the sensor which has been used for this thesis project.

The sounding principle of the GEM-3 is based on an oscillating primary magnetic field that induces eddy currents in conductive media and magnetizes the subsurface. Given by Maxwell's equations, the electric currents generate a secondary magnetic field which depends on the conductivity distribution. Thereby, a sinusoidal primary magnetic field creates a cosinusoidal electric field (equation 1) that induces a current in the conductive media (equation 2). The resulting secondary magnetic field has a $90^{\circ}$ phase shift (cosine) with respect to the primary field. As a result of self-induction, the secondary magnetic field induces a current that is again $90^{\circ}$ phase shifted and therefore in-phase with the primary field. In other words, the diffusive induction process is equivalent to a mirroring of the transmitter current in the conductive media where upon a $90^{\circ}$ phase shift occurs at each 'reflection'. The resulting secondary magnetic field measured at the receiver coil can be written as a complex signal with in-phase (IP) and out-of-phase or quadrature (Q) components. Magnetic susceptibility is usually neglected in electromagnetic induction problems and the magnetic 
permeability $\mu$ is offset as $\mu_{0}$, the permeability of free space. This assumption is misleading at low operation frequencies where the electromagnetic in-phase signal is proportional to the magnetic susceptibility and almost unaffected by the conductive media (Won and Huang, 2004; Chapter 2). The magnetic signal is foremost a direct function of the primary magnetic field and the subsurface magnetic susceptibility distribution. The secondary magnetic field, which results from the magnetized subsurface, is frequency independent and in-phase with the primary field.

In consequence, frequency domain EM induction sensors with short transmitter - receiver coil offset record a magnetic susceptibility term that is in-phase with the transmitted field, and an electric conductivity term that contains both, a quadrature and an in-phase component (Figure 1-3). When exposed to saline marine environments, terrestrial susceptometers, such as the Bartington MS2D, measure a combination of the magnetic and electric properties of the surrounding environment. A separation of the conductivity and susceptibility related in-phase components can only be achieved by multi-frequency CSEM sounding where the low frequency in-phase component is mainly a measure of subsurface susceptibility while a high frequency quadrature signal measures primarily conductivity (for details see Chapter 2).

The marine EM induction problem differs from its terrestrial counterpart in important ways: both source and receiver are situated in a conductive medium and the electrical and magnetic structure both below and above the sensor takes part in the induction process (Chave et al., 1991). The signal of vertical magnetic field sensors with coplanar, concentric coils, like the GEM-3, depends on both medias' conductivity (Cheesman et al., 1987). Here, the separation of the seawater and seafloor signals is realized by correcting CSEM measurements with independent seawater conductivity measurements using an oceanographic CTD probe. However, the electric eddy current (or "smoke ring") prevails in the conductive seawater layer and propagates faster through the less conductive subsurface (Figure 1-4). 


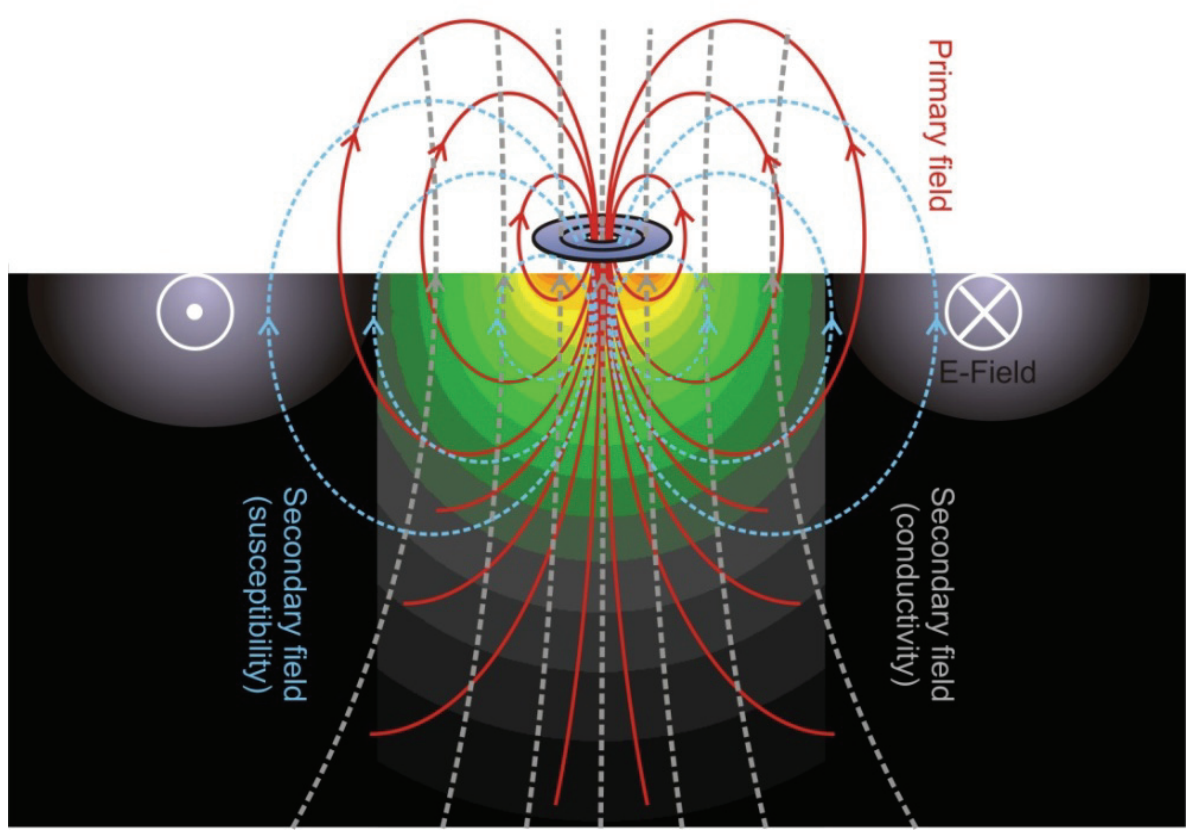

Figure 1-3. Schematic GEM-3 sub-surface sounding principle: the primary magnetic field of the transmitter induces a magnetization (proportional to susceptibility) and an electric current (proportional to conductivity) in the subsurface. The receiver records superimposed secondary magnetic fields related to conductivity and susceptibility.
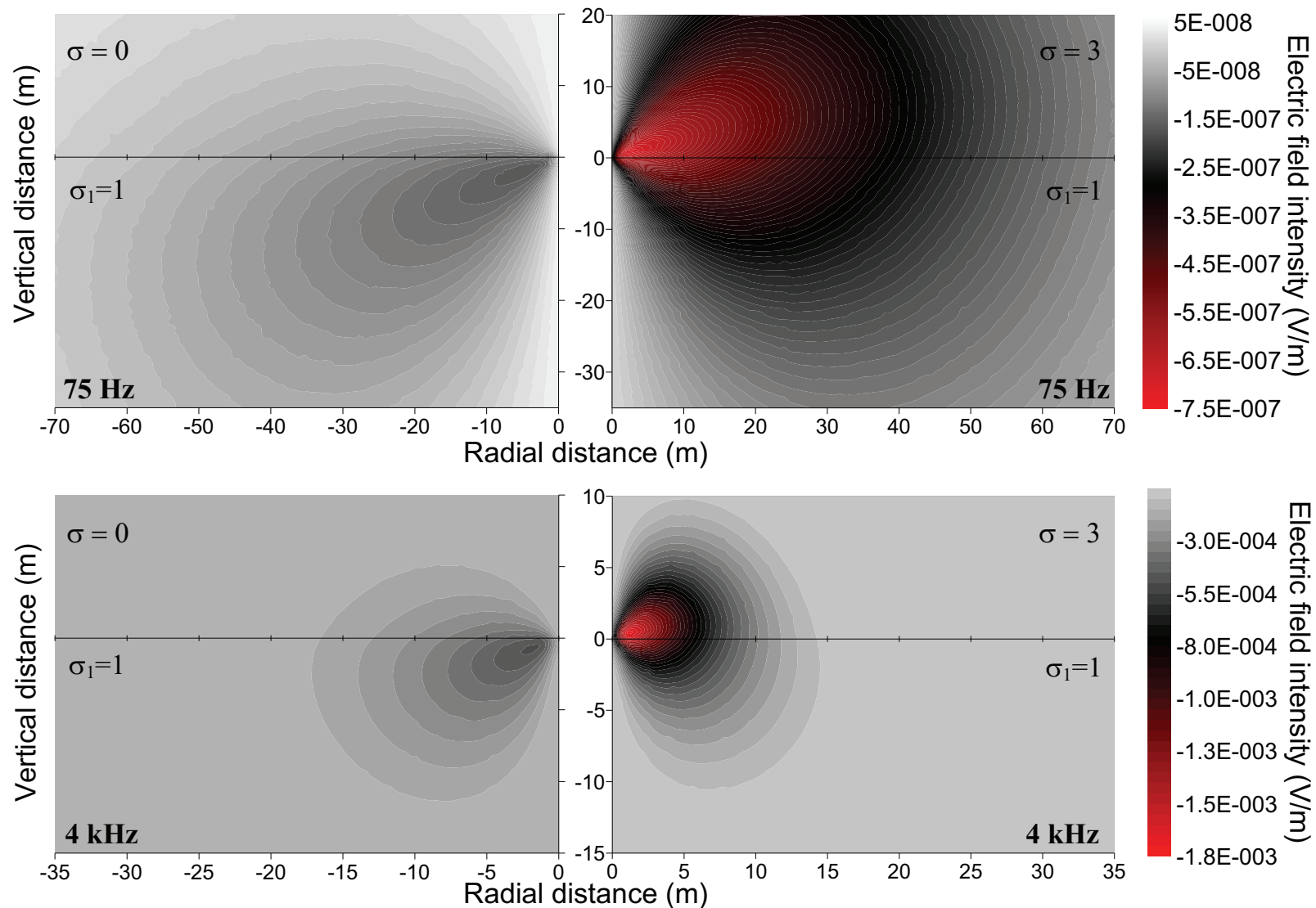

Figure 1-4. Primary electric field (quadrature component) of the GEM-3 when situated in air (left figures) and seawater (right figures). Frequency has a strong effect on the lateral dimension of the electric eddy current (upper figures: electric field at $75 \mathrm{~Hz}$; lower figures: electric field at $4 \mathrm{kHz}$ ). 
In terms of signal formation the subsurface response on the primary field has to be taken into account. In an axial symmetric model the conductivity related secondary magnetic field of discrete rings $(1 \mathrm{~cm}$ height, $1 \mathrm{~cm}$ width and radius $R$ ) at the center of the receiver coil is calculated using Biot Savart's Law, using the ambient electric field strength and the electric conductivity. The magnetic field, due to the subsurface susceptibility, is calculated by a magnetic dipole equation (e.g. Hansen et al., 2005). As a result of the toroidal shape of the electric primary field and dipolar shape of the magnetic primary field the sensitivity is at maximum near the coil axis for susceptibility and around the transmitter coil for quadrature conductivity (Figure 1-5). The footprint of quadrature conductivity is therefore a few times larger than that of susceptibility. In the case of in-phase conductivity, the footprint is much wider due to diffusive nature of the in-phase electric field (for details see Chapter 2).
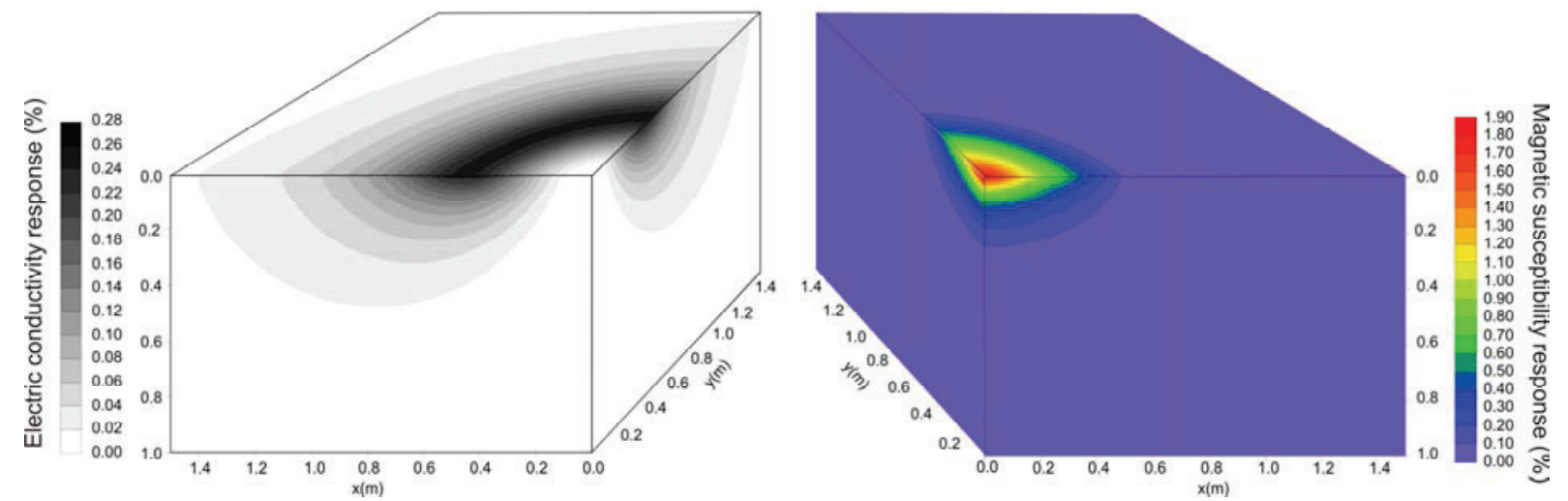

Figure 1-5. Left: Spatial response of a conductive lower half-space, illuminated by the quadrature component of the primary electric field (transmitted by the GEM-3 at $5 \mathrm{kHz}$ in seawater of $3 \mathrm{~S} / \mathrm{m}$, above a subsurface of $1 \mathrm{~S} / \mathrm{m}$ ). Right: Spatial response of a magnetic lower half-space on the primary magnetic field (transmitted at $75 \mathrm{~Hz}$, modeling the subsurface with $0.001 \mathrm{SI}$ ). Each response is normalized to the total secondary field measured in the center of the receiver coil.

\subsection{Project chronicle}

Developing a fundamentally new marine research platform is a complex, time-consuming and expensive endeavor, which cannot be adequately represented by scientific journal articles. This section narrates the history of this thesis project in chronological order. Some interim 
results and background explanations have been inserted as required to complement the decision and development process. As documented in Table 1, the total research and development time of the GEM Shark marine CSEM profiler from feasibility study (November 2005) to first prototype operability (August 2007) was 20 months. From then the system completed one pilot study and two full successful scientific missions on the NW Iberian Shelf and in the Western Baltic Sea.

In addition to the design of the GEM Shark, the specification and linkage of the sensors, the writing of the MARUM funding proposal for the Geophex GEM-3 sensor, the organization and execution of the Eckernförde Bay fieldwork and my participation in three survey cruises have all been essential parts of this $\mathrm{PhD}$ work. Some additional results that are not or just partly covered by the three so far finalized journal manuscripts are enclosed in the Appendix.

The technical project aims were realized in close cooperation of four members of the Bremen Marine Geophysics Section. The group's development engineer Dipl.-Ing. Christian Hilgenfeldt conceptualized the data acquisition and communication units and assembled and connected all the underwater and shipboard components. Laboratory Manager Dr. Thomas Frederichs helped to develop the control and navigation software. Section Head Prof. Dr. Tilo von Dobeneck moderated the decision processes and took part in manufacturing the sled platform. Our Spanish project partners Prof. Dr. Belén Rubio and Prof. Dr. Daniel Rey were extremely supportive in developing the operational concept. They raised decisive technological funding from the Galician Regional Government and helped organize a four week testing phase in the Ría de Vigo where they participated in the first full-scale mission of GEM Shark on the Galician shelf. 
Table 1. Project timetable

\begin{tabular}{|c|c|}
\hline Pre-PhD phase & \\
\hline Oct. - Nov. 2004 & Magnetic pollution study in the Schlei River \\
\hline Aug. 2005 & Magnetic mineral distribution in the Baltic Sea close to the Schlei Mouth \\
\hline PhD phase & \\
\hline $\begin{array}{l}\text { Nov. } 2005- \\
\text { Feb. } 2006\end{array}$ & $\begin{array}{l}\text { Feasibility study of marine in-situ magnetic susceptibility measurements by finite } \\
\text { element (COMSOL) and numerical modeling of the GEM-3 (Geophex) }\end{array}$ \\
\hline Feb. 2006 & $\begin{array}{l}\text { Visit at Geophex Ltd. and test measurements with the GEM-3 in Lake Wheeler } \\
\text { recreation area (Raleigh, North Carolina, USA) }\end{array}$ \\
\hline March 2006 & $\begin{array}{l}\text { Grant proposal to the DFG-Research Center Ocean Margins (RCOM) "Unforeseen } \\
\text { Project" to build a EM sea-bottom profiler }\end{array}$ \\
\hline Aug. 2006 & $\begin{array}{l}\text { Magnetic seepage study in Eckernförde Bay } \\
\text { (deep towed magnetometry and high resolution seafloor sampling) }\end{array}$ \\
\hline Nov. 2006 & Grant from RCOM to buy a modified GEM-3 sensor for underwater operation \\
\hline Dez. 2006 & $\begin{array}{l}\text { Grant from the Xunta de Galicia (The Council for Innovation and Technology of the } \\
\text { Galician Province) to build a platform for seabottom EM measurements and application } \\
\text { in the Ria de Vigo (Spain) }\end{array}$ \\
\hline Feb. 2007 & $\begin{array}{l}\text { Field excursion to test and compare the GEM-3 with the Barington MS2D susceptibility } \\
\text { meter in Madeira (Portugal) }\end{array}$ \\
\hline Feb. - Aug. 2007 & $\begin{array}{l}\text { Design and in house assembly of the GEM Shark platform, sensor integration and } \\
\text { software development }\end{array}$ \\
\hline July 2007 & Test and video analysis of GEM Shark platform in Kiel Bay \\
\hline Sept. 2007 & First marine EM survey in the Ria de Vigo \\
\hline Apr. 2008 & $\begin{array}{l}\text { EM survey of Eckernförde Bay seeps } \\
\text { (surveying failed due to motor damage on the RB Polarfuchs) }\end{array}$ \\
\hline June 2008 & EM survey of the Galician Shelf (RV Poseidon cruise P366/3) \\
\hline Aug. 2008 & EM survey of Eckernförde Bay seeps \\
\hline June 2009 & EM survey on the Uruguayan Shelf (RV Meteor cruise M78/3a) \\
\hline
\end{tabular}


The Bremen Marine EM project was inspired by the M.Sc. project of Sarah Forté (2005) which aimed to link magnetic susceptibility and pollution patterns of the upper Schlei Inlet (Schleswig-Holstein). A Bartington MS2D field susceptometer mounted into a non-magnetic underwater pressure housing was operated from our survey zodiac RB Neridis (NERItic DIScoverer). The device was lowered by hand to the ground of the inlet (1-8 $\mathrm{m}$ water depths). Three repeat measurements were taken at a total of 1227 stations. The readings which varied by more than $2 \times 10^{-5}$ SI were rejected. In spite of frequent leakage problems, the Bartington MS2D seemed to function correctly in the low saline upper Schlei environment. However, a first offshore survey in front of the Schlei Mouth in August 2005 clearly demonstrated the unacceptable deficiencies of the Bartington MS2D when operating on a rough seafloor and in a more saline environment. As noted by Lecoanet et al. (1999), the signal of the Bartington MS2D sensor only refers to the top $8 \mathrm{~cm}$ of the subsurface and is therefore strongly influenced by ripples and rocks on the seafloor. The sensor also lacks the required robustness and temperature stability. The main deficiency of this sensor in marine studies is a strong bias of the susceptibility measurement by the varying conductivity of the sourrounding seawater and sediment. As a consequence, the repeatability of the measurements could not meet the previously defined quality criterion.

Benech and Marmet (1999) have demonstrated the influence of a conductive subsurface on the susceptibility measurement of conventional field susceptometers by modeling their response to a material with constant susceptibility, but varying resistivity. The two instrument types most commonly use for terrestrial field work, the Slingram and the coincident loop configuration (like the Bartington MS2D) both show a strong and systematic impact of subsurface resistivity on the susceptibility measurement. In consequence, none of the established land susceptibility meters are suitable for marine operations with typical seawater 
and sediment resistivities of $0.2-0.4 \Omega \mathrm{m}$ and $0.8-1.5 \Omega \mathrm{m}$, respectively (Schwalenberg et al., 2009).

A solution to overcome these technical limitations had been published by Won and Huang (2004), who proposed a method to separate magnetic susceptibility and electric conductivity contributions on the basis of multi-frequency measurements. Other than the Bartington MS2D system, which operates at a single frequency of $975 \mathrm{~Hz}$, their CSEM sensor GEM-3 offers a frequency range from $25-40.000 \mathrm{~Hz}$. In addition several transmitter frequencies can be superimposed to generate a complex EM waveform enabling synchronous measurements of magnetic susceptibility at a low and electric conductivity at a high frequency. The standard sensor diameters of 40 to $96 \mathrm{~cm}$, developed primarily for military purposes, have been successfully applied in unexploded ordnance (UXO) surveys not just on land, but also in shallow marine settings ( $<10 \mathrm{~m}$ depth).

A central part of the early $\mathrm{PhD}$ project phase was therefore to conduct a feasibility study of all available electromagnetic sounding technologies and instrumentation using finite element EM modeling and numerical simulations of sensor geometries and environmental conditions. A personal visit to Geophex Ltd (Raleigh, North Carolina, USA) for technical discussions and field trials with the GEM-3 system in the Lake Wheeler recreation area helped to round up the decision in favor of this system. A first grant proposal to the DFG-Research Center Ocean Margins (RCOM) to build an EM sea-bottom profiler was approved, but was later postponed because of the high costs of $\sim 50.000 €$ for the full system.

To provide additional support of the proposal I designed a scientifically promising pilot EM project associated with MARUM project E1 (Structure and dynamics of cold seeps, associated communities and mineral precipitates) in Eckernförde Bay (Western Baltic Sea). This estuary is well known for freshwater seepage (Marczinek and Piotrowski, 2002) within localized depressions (Jensen et al., 2002). In May 2006, a precursory magnetometer survey 
with two marine GSM 19 Overhauser magnetometers (GEM Systems) was conducted. An area of $4 \times 4 \mathrm{~km}^{2}$ was covered by $22 \mathrm{~N}-\mathrm{S}$ profiles using RB Neridis (Figure 6-1) as unmanned sensor platform and RB Polarfuchs (IFM-GEOMAR, Kiel) as towboat (see Chapter 6-1).

In August 2006 the resolution of magnetometer measurements was enhanced by installing one overhauser magnetometer on a stainless steel video sled towed in bottom contact and another trawled $4 \mathrm{~m}$ above the seafloor. The purpose of this experiment was also to collect experience with sled concepts for future EM susceptibility measurements. The field measurements were performed during four days and accompanied by 15 days of field work in conjunction with a Bremen diploma thesis project of Wiebke Nehmiz. In total 32 short gravity cores $(20-60 \mathrm{~cm})$ and 146 Van Veen grab samples were taken (for details see Chapter 3).

In late 2006, a renewed MARUM Unforeseen Project Grant of $25.000 €$ in combination with a $30.000 €$ technology grant by the Xunta de Galicia (Council for Innovation and Technology of the Galician Province) made it possible to envisage the realization of dedicated nonmagnetic sensor platform for seabottom EM measurements. First trials in the Galician Ría de Vigo (NW Spain) were scheduled for summer 2007. A joint Bremen-Vigo planning meeting and first field trials with the GEM-3 sensor were performed on Madeira Island in February 2007. GEM-3 and reference Bartington MS2D susceptibility profiles over contrasting volcanic rocks (dykes, tuffs and basalts) and soils turned out to be in good agreement despite the very different frequencies and integration volumes of the two sensors (Figure 1-6). 


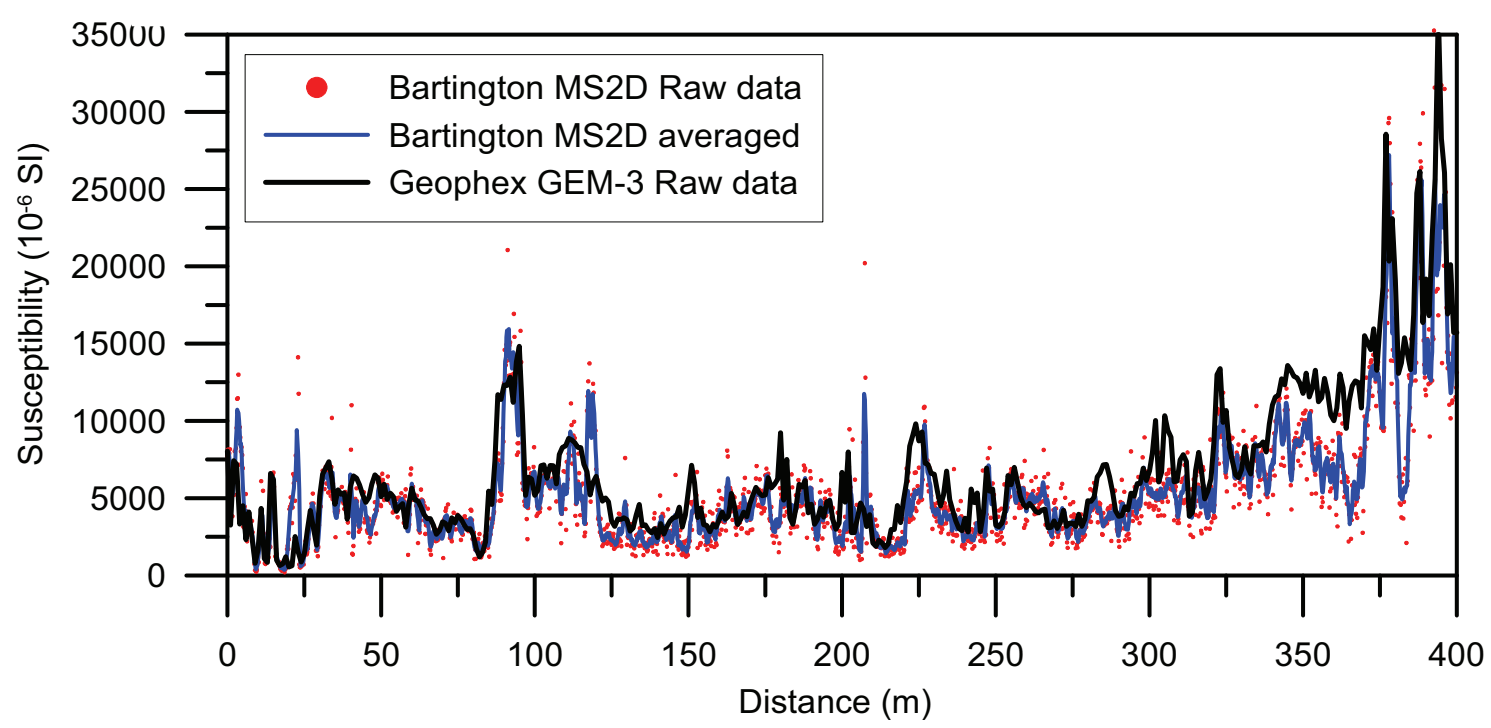

Figure 1-6. Comparison of Geophex GEM-3 EM sensor and Bartington MS2D susceptometer (Madeira 2007).

The outcome of this first geo-scientific application of the GEM-3 was also used to validate the vertical sensitivity of the sensor and to validate theoretically developed concepts to calculate the magnetic susceptibility and electric conductivity from the sensors measured electromotive force (voltage). Numerical models based on the published formulas by Won et al. (1997) were developed to include a conductive saltwater environment and layered subsurface; 3D effects were examined by finite element models.

Over the following months, a non-magnetic and non-conductive submarine platform named GEM Shark was developed using the 3D CAD software Solid Edge. The sled was built to encase a CTD, to track bathymetry and seawater conductivity, navigation sensors and an inflatable lift bag, to dive and rise the sled autonomously. An Ethernet structure allows realtime data transmission to the towboat and a modular LabView software package was programmed for online data visualization and storage.

In July 2007, four month later, the empty GEM Shark sled, only equipped with pressure housing, navigation (pitch, roll and heading), altimeter and speed sensor, was ready to dive in Kiel Bight. Power and Ethernet cables of GEM Shark were connected with RB Neridis and both sled and zodiac towed behind RB Polarfuchs. The sled's gliding qualities were 
monitored by scientific divers who shot underwater videos in $8 \mathrm{~m}$ water depth while the sled was moving at 1-2 knots over sandy and rocky seafloor. As a result of this video and motion sensor analyses the sled was equipped with a rubber covered base and a fin to minimize roll in the water. Data and power cable were connected and the tow point was raised to stabilize the pitch.

The first electromagnetic surveys with GEM Shark were performed in the NW Iberian Ría de Vigo in September 2007 in cooperation with the University of Vigo MARGO Group. A major aim of the joint Vigo-Bremen project was to test whether magnetic profiling is suitable to map seafloor contamination by heavy metals, organic matter and ferrous objects (see Chapter 4 and 6-2). Field EM data were of excellent quality and matched well with existent sedimentological maps and reference cores. However, frequent collisions with unmarked (illegal) fishing nets and various obstacles (wrecks, anchor stones and rocks) hampered the survey progress. These collisions also caused damage to the first internal fiberglass frame supporting sensor and electronics pressure housing.

In the following six months of the project, GEM Shark was modified for shelf surveys with RV Poseidon. These modifications involved a more autonomous concept for the sled involving an independent power source (deep-sea battery). A DSL communication link via the ship's standard armored coaxial tow cable was established. In addition to more robust internal sensor fixations, a rescue strategy for underwater collisions was implemented.

In the RV Poseidon cruise P366/3 on the NW Iberian Shelf in June 2008 (see Chapter 6-3), GEM Shark's performance was excellent even under rough weather conditions. In total during ten 6-8 hour deployments in water depths of 50 to $270 \mathrm{~m}$, more than $300 \mathrm{~km}$ of high resolution magnetic susceptibility and electric conductivity profiles were collected with a typical data point spacing of just $10-15 \mathrm{~cm}$. Two W-E EM profiles are presented in Chapter 2. In his B.Sc. thesis, Bastian Wichand compared two N-S EM profiles with rock magnetic, 
sedimentological and geochemical sample data. Three further W-E profiles were analyzed by Johannes Brock as part of a student undergraduate project in 2009. A joint journal publication of all EM survey results combined with shore-based studies is currently in a planning stage.

Shortly after the successful Iberian Shelf expedition, GEM Shark was used to map the pockmarks in Eckernförde Bay in August 2008 (see Chapter 3). Data handling, processing and visualization was optimized according to industrial standards with the professional magnetic database and processing software Oasis Montaj (Geosoft). A number of additional system features were added comprising improvements of the Labview data acquisition and real-time visualization environment used to control platform status and data quality. An optimized water flow through the GEM Shark hull and a sophisticated, streamlined radio and flashlight rescue buoy were fixed via three tons tear-resistant Kevlar rope to the GEM Shark.

The final EM survey project of this PhD phase was scheduled with RV Meteor on the Shelf of Uruguay in June 2009 (see Chapter 6-4). The new software concept and the profiler worked successfully. However, the short timeline, bad weather conditions and a collision with an underwater outcrop resulted in a unrecoverable loss of the platform in $50 \mathrm{~m}$ water depth.

\subsection{Technical realization and operation}

This section outlines the latest-state technical configuration and operational concept of the GEM Shark EM profiler. Centerpiece of the system is the already mentioned frequency domain, concentric, coplanar CSEM sensor Geophex GEM-3. This commercial system has been primarily intended for portable minesweeping on land and it therefore has been optimized for minimal weight. Two modifications adopt the sensor for marine applications:

(1) Deep-sea sensor coil: Coils are wound onto a massive, pressure-resistant PVC carrier disk and have been enclosed in a circular oil-filled PVC casing $(\varnothing 100 \mathrm{~cm} \times 5 \mathrm{~cm})$. The sensor 
and control unit have been furnished with SubConn underwater connectors for simple detachment.

(2) High power amplification: $48 \mathrm{~V}$ instead of standard $24 \mathrm{~V}$ amplification of the transmitter signal results in two-fold increase in the amplitude of the receiver signal and therefore a higher signal-to-noise ratio.

The technical setup of the specialized marine GEM-3 sensor and its digital transmitter and receiver circuits are shown in Figures 1.7-1.9. The outer transmitter coil $(\varnothing 96 \mathrm{~cm})$ is driven in series with a bucking coil $(\varnothing 54 \mathrm{~cm})$ of inverse polarity tuned to produce a magnetic cavity (compensation of the transmitter field) in the center of the coils. The receiver coil within the magnetic cavity does not see the primary signal and is therefore capable of measuring the minute secondary electromagnetic response field over a wide dynamic range. The high power transmitter is achieved with a 21 A pulse-width modulation (PWM) driver that allows up to 12 frequencies to be combined to build a broadband transmitter waveform. This is technically realized by generating a bitstream of 384000 digital $+1,0$, or -1 commands per second that controls the switches (1-4) of the H-bridge circuit (Figure 1-8) to build the (primary) transmitter waveform. The digital signal formation by the PWM technique also minimizes power consumption and size of the waveform generator.

The secondary EM field of the surrounding formation, related to subsurface conductivity, susceptibility and seawater conductivity, induces an alternating current in the receiver coil. The voltage measure of the receiver and reference coil is digitized in a 24bit AD converter within the sensor head. The reference coil has the function to measure the primary field and thereby compensates temperature and environmental conductivity or susceptibility related resistivity changes of the transmitter coils. A digital signal processor (DSP) applies a discrete Fourier transform to the time-series of the receiver and reference output and uses a sine transform to deduce the in-phase component and a cosine transform to deduce the quadrature 
component of the receiver $(\mathrm{Rx})$ and reference (Ref) signal. The raw output of GEM-3 is the ratio of receiver and reference signals given in units of parts per million (ppm) with a sampling rate of $25 \mathrm{~Hz}$.

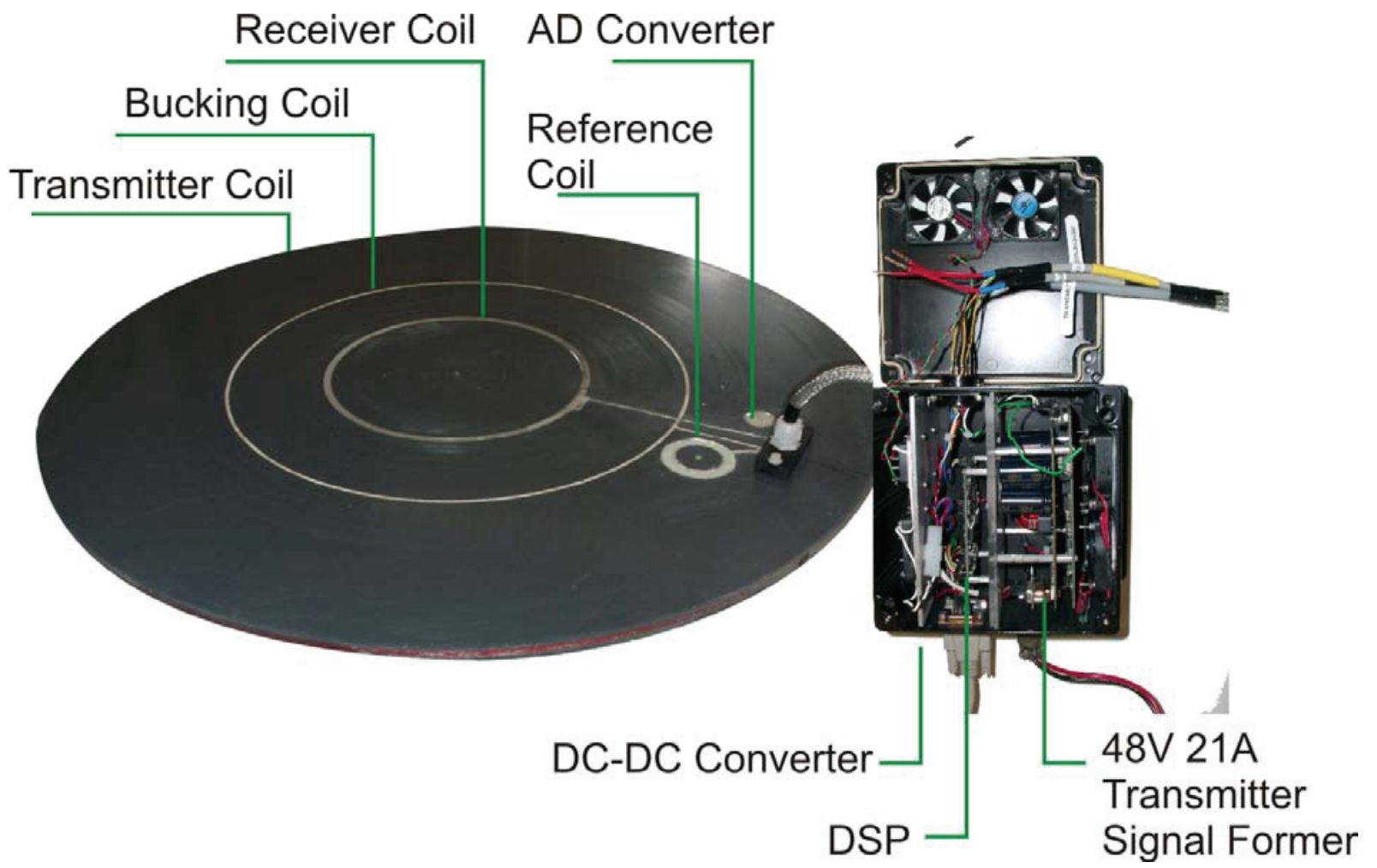

Figure 1-7. Customized marine GEM-3 configuration. Left: sensor head with transmitter, bucking and receiver coil. Right: GEM-3 control unit with 24V-48V DC-DC converter, digital signal processor (DSP) and amplifier.

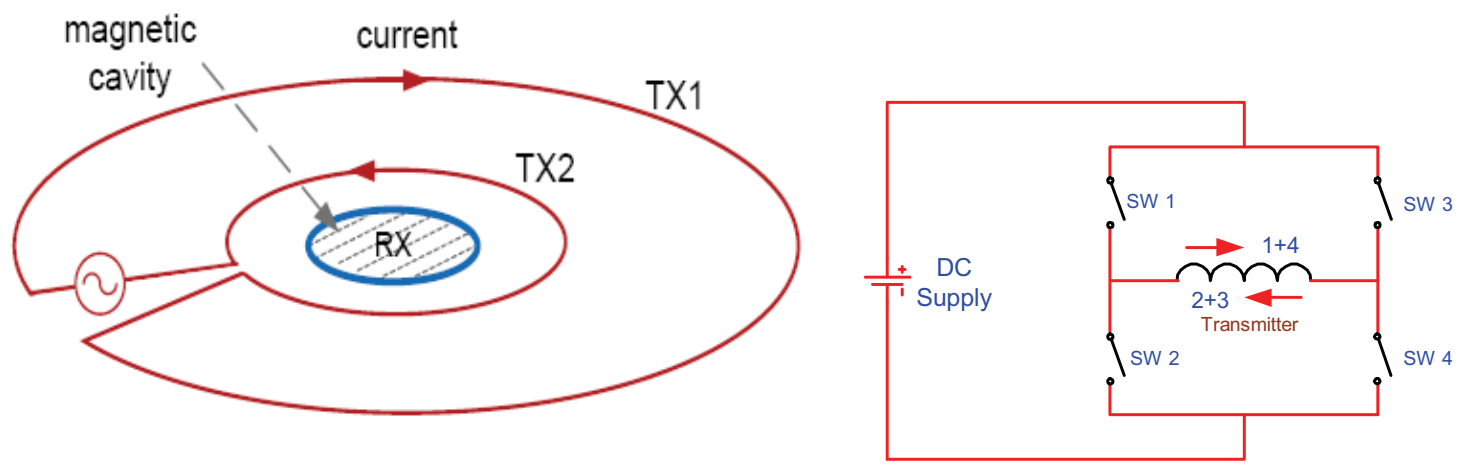

Figure 1-8. Schematic of sensor coils and primary waveform generator. Left: Coils TX1 and TX2 form the primary transmitter and bucking configuration. The smaller, reversely wound inner coil TX2 partly compensates the primary field of TX1 creating a neutral "magnetic cavity" region in the center where the receiver coil RX is located; this allows measuring the secondary field with a largest possible dynamic range. Right: H-bridge circuit to build arbitrary multi-frequency waveforms. (I. J. Won, personal communication). 


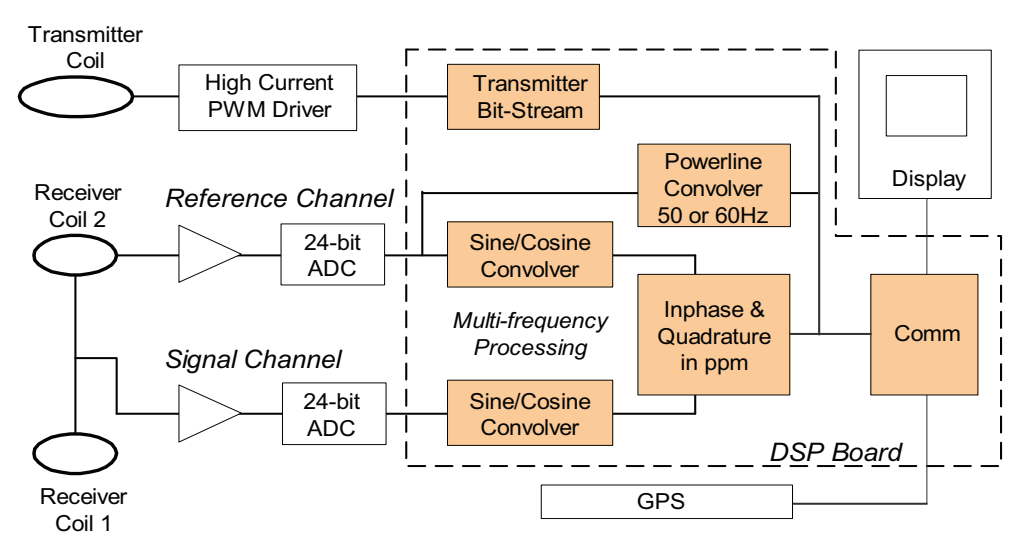

Figure 1-9. Schematic of Digital Signal Processor (DSP). The DSP performs a real-time Fourier transform for each operation frequency. Sine convolution: in-phase (IP) signal, Cosine convolution: - Quadrature (Q) signal. (I. J. Won, personal communication).

All electronic units of GEM Shark (GEM-3 console, embedded PC, DSL link, Aositilt EZCompass pitch, roll and heading sensor with tilt-compensated 3-axial magnetometer) are installed in a semi-evacuated Vitrovex glass benthos sphere (Figure 1-10). All external sensors, the GEM-3 coil, a Seabird SBE 16 CTD, a Sea-and-Sun 24 V deep-sea battery and the coax tow and communication cable are connected via SubConn underwater connectors to the pressure housing. High-speed data transmission (192 kbit/s to $2.3 \mathrm{Mbit} / \mathrm{s})$ between profiler and tow ship are driven by a Westermo SHDSL extender for 10/100BaseTX (Ethernet) networks via the standard $11 \mathrm{~mm}$ armored coax-cable enabling lengths of up to $10 \mathrm{~km}$. The Ethernet network integrity of all serial devices (GEM-3, CTD, motion sensor, optional Altimeter) is achieved with an iolan SDS 4 Serial to an Ethernet device server enabling full sensor control by virtual communication ports on the tow ship's control PC. As a backup system for data recording, the internal industrial PC-104 with a CF memory card is accessed by remote control software (e.g. Virtual Network Computing, VNC). 


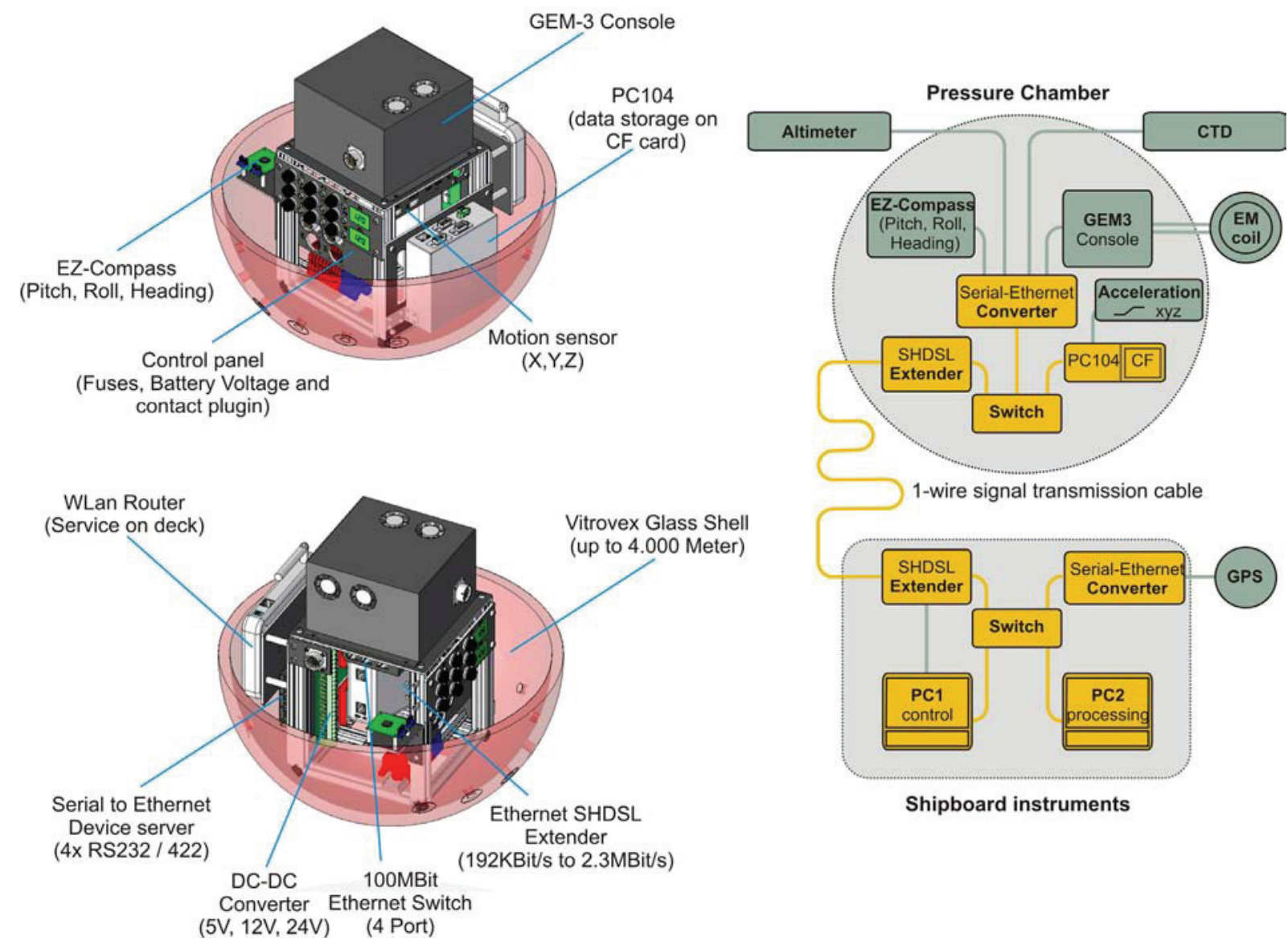

Figure 1-10. Left: Electronic sensor and control units inside the Vitrovex glass pressure housing (shown without connectors). Right: communication scheme of GEM Shark and shipboard instrumentation.

The GEM Shark sled encloses the sensitive instruments in a ruggedized, non-magnetic, nonconductive fiberglass body of $3.2 \mathrm{~m}$ length, which is continuously flushed with ambient seawater. The sled is equipped with a $24 \mathrm{~V}$ deep sea battery which allows for mission durations of about 8-12 hours. The robust design with concrete nose and runners was essential for bottom-towed operations at speeds of 3-4 knots in various seafloor environments. Bottom contact is necessary to maintain a short $(20 \mathrm{~cm})$ and very constant ground distance of the GEM-3 sensor.

For deployment, the profiler is lifted with the ship's A-frame winch above its center of gravity by means of a bridle. The moment the profiler touches the sea surface, the bridle is released and the system is held only by the tow-cable. A stable dive and soft landing is achieved by adjusting the winch slack to ship speed. Stable ground contact is indicated by a steady course 
(typically $\left.\pm 1^{\circ}\right)$, low pitch $\left( \pm 2^{\circ}\right)$ and roll $\left( \pm 1^{\circ}\right)$ angles and a pressure signal that follows bathymetry. Contact is maintained by dynamically adjusting ship speed and tow cable length. Typically, the ratio of required cable length to water depth is in the order of 3-4 depending on bottom conditions. Exemplary data of the landing procedure are given in the Appendix (Figure 6-10).
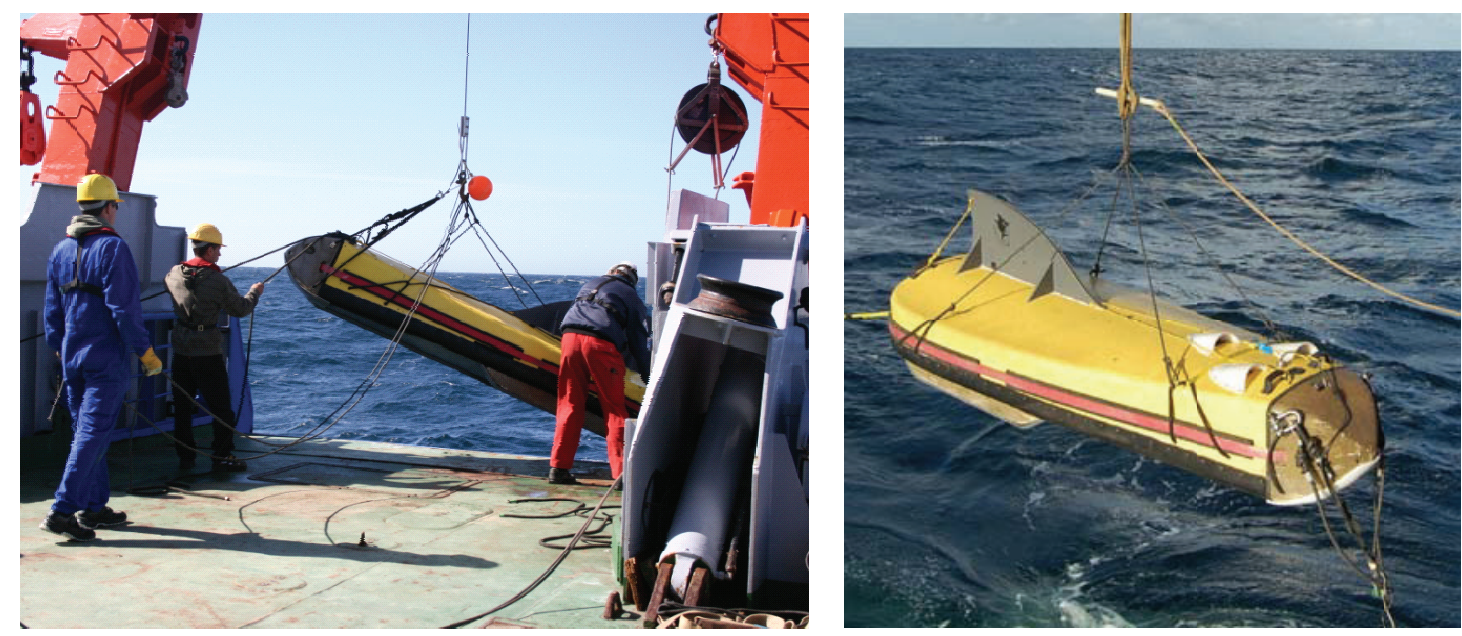

Figure 1-11. Deployment of the GEM Shark CSEM profiler by RV Poseidon and RV Meteor.

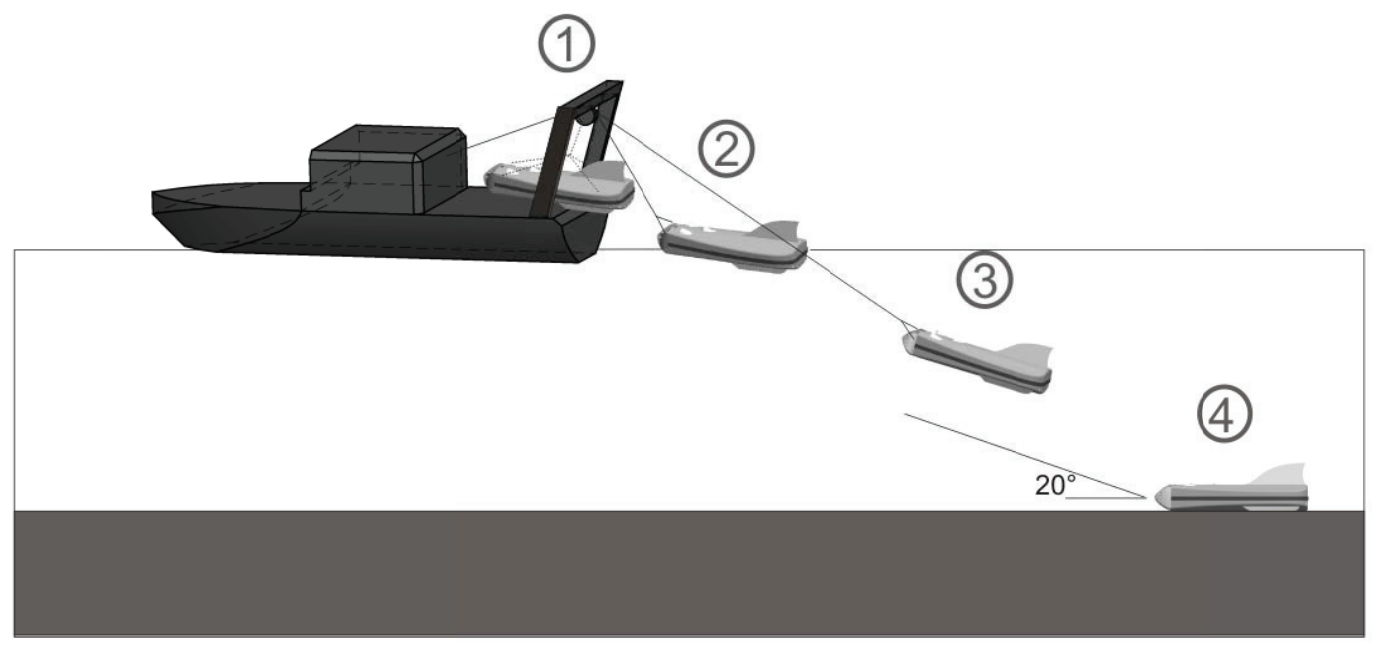

Figure 1-12. Deployment procedure: (1) lifting the GEM Shark profiler above the center of gravity by means of a bridle; (2) disembarkation of the profiler to the sea-surface, releasing the bridle and slacking the tow-cable; (3) when flooded, the profiler sinks with a $\sim 15^{\circ}$ pitch angle and lands on the seafloor at a tow-cable length of about 2.5 times the water depth; (4) stable bottom contact profiling is assured at about 3 knots (s.o.g.) and a tow angle of about $20^{\circ}$ (indicated by $<2^{\circ}$ oscillation of pitch, roll and heading). 


\subsection{Synopsis of manuscripts}

Three manuscripts discuss the development and applications of a Controlled Source Electromagnetic (CSEM) sled - the GEM Shark. The first two manuscripts are first author papers based on my thesis work, which is ready for submission to international journals. I provided the electromagnetic data, figures and interpretational contributions as co-author for the third manuscript which was published in Geotemas in 2008.

The first manuscript 'Mapping the magnetic and electric signatures of marine near-surface sediments by bottom-towed Controlled Source Electromagnetics' investigates the physical theory and technical realization of combined magnetic susceptibility and electric conductivity in-situ profiling. The conceptual design of sensor's application and sensing characteristics are discussed on the basis of electromagnetic (EM) induction theory, which has been revised for marine magnetic investigations, and theoretical models. This manuscript delineates the fundamental concepts and the setup of the new rugged, non-magnetic and non-conductive CSEM profiler the GEM Shark that integrates sensor and electronics into a platform manageable for shallow and deep marine operations. This bottom-towed platform is equipped with heading and bearing sensors and provides real-time communication. Two examples demonstrate the potential of combined susceptibility and conductivity surveying to classify sediments on the Galician Shelf in unmatched lateral resolution and sensitivity.

The second manuscript 'Near-surface electromagnetic, rock magnetic and geochemical fingerprinting of submarine freshwater seepage at Eckernförde Bay (SW Baltic Sea)' investigates the alteration of Holocene marine sediments by freshwater seepage. This is a fjord-like setting located in the Kiel Bight of the Western Baltic Sea, where a wide variety of sediments and sedimentation regimes under shallow water conditions can be found (Nittrouer et al., 1998). An intense diagenesis has occurred during early burial and several freshwater seeps have already been reported in literature (Wever et al., 1998; Whiticar, 2002). A multi 
method approach which combines high-resolution EM mapping, magnetometric acoustic subbottom profiling, with detailed environmental magnetic and geochemical laboratory analyses of core and grab samples. The results of the EM survey provide a first order fingerprint of advective or diffusive fluid seepage and sediment composition.

The third manuscript 'Using electromagnetic sensors to estimate physical properties and environmental quality of surface sediments in the marine environment', published in 2008, summarizes the results of the pilot study with the GEM Shark profiler in the Ria de Vigo (NW Spain). This relatively short Spanish manuscript draws the line from the first expedition to highly significant CSEM classification in shelf and coastal sediments. This project highlighted the positive cooperation of the Center for Marine Environmental Sciences (MARUM) Marine Geophysics Group at the University of Bremen and the Marine and Environmental Geology Group at the University of Vigo. This important cooperation has been crucial for the financing of the project and it also created the frame of the two major working areas - the Rìa de Vigo and the Galician Shelf. 


\subsection{References}

Beckwith, P. R., J. B. Ellis, D. M. Revitt, and F. Oldfield, 1986, Heavy metal and magnetic relationships for urban source sediments: Physics of the Earth and Planetary Interiors, 42, 67-75.

Baba, K., 2005, Electrical structure in marine tectonic settings: Surveys in Geophysics, 26, 701-731.

Benech, C., and E. Marmet, 1999, Optimum Depth of Investigation and Conductivity Response Rejection of the Different Electromagnetic Devices Measuring Apparent Magnetic Susceptibility: Archaeological Prospection, 6, 31-45.

Booth, C. A., J. Walden, A. Neal, and J. P. Smith, 2005, Use of mineral magnetic concentration data as a particle size proxy: A case study using marine, estuarine and fluvial sediments in the Carmarthen Bay area, South Wales, U.K.: Science of the Total Environment, 347, 241-253.

Canfield, D. E., and R. A. Berner, 1987, Dissolution and pyritization of magnetite in anoxic marine sediments: Geochimica et Cosmochimica Acta, 51, 645-659.

Chan, L. S., C. H. Yeung, W. W. S. Yim, and O. L. Or, 1998, Correlation between magnetic susceptibility and distribution of heavy metals in contaminated sea-floor sediments of Hong Kong Harbour: Environmental Geology, 36, 77-86

Chave, A. D., S. Constable, and R. N. Edwards, 1991, Electrical Exploration Methods for the Seafloor, in M. N. Nabighian, ed., Electromagnetic Methods Vol. 2: Applications: Society of Exploration Geophysicists, Tulsa, 931-966.

Cheesman, S. J., R. N. Edwards, and A. D. Chave, 1987, On the theory of seafloor conductivity mapping using transient electromagnetic systems: Geophysics, 52, 204-217.

Clifton, J., P. McDonald, and A. Plater, 1999, Deviation of a grain size proxy to aid the modeling and prediction of radionuclide activity in salt marshes and mud flats of the Eastern Irish Sea: Estuarine, Coastal and Shelf Science, 48, 511-518.

Constable, S., and L. J. Srnka, 2007, An introduction to marine controlled-source electromagnetic methods for hydrocarbon exploration: Geophysics, 72, WA3-WA12.

Constable, S., and C. Cox, 1996, Marine controlled source electromagnetic sounding 2. The PEGASUS experiment: Journal of Geophysical Research, 101, 5519-5530.

Cox, C. S., J. H. Filloux, and J. C. Larsen, 1971, Electromagnetic studies of ocean currents and electrical conductivity below the ocean-floor, in A. Maxwell, ed., The Sea: Wiley, New York, Vol.4, part 1, 637 693.

Dunlop, D. J., and Ö. Özdemir, 1997, Rock Magnetism. Fundamentals and Frontiers: Cambridge University Press, Cambridge, 573 pp.

Duck, R. W., J. S. Rowan, P. A. Jenkins, and I. Youngs, 2001, A multi-method study of bedload provenance and transport pathways in an estuarine channel: Physics and Chemistry of the Earth, 26 (9), 747-752. 
Edwards, R. N., 1997, On the resource evaluation of marine gas hydrate deposits using sea-floor transient electric dipole-dipole method: Geophysics, 62, 63-74.

Edwards, R. N., 2005, Marine Controlled Source Electromagnetics: Principles, Methodologies, Future Commercial Applications: Surveys in Geophysics, 26, 675-700.

Ellingsrud, S., T. Eidesmo, S. Johansen, M. C. Sinha, L. M. MacGregor, and S. Constable, 2002, Remote sensing of hydrocarbon layers by seabed logging (SBL): Results from a cruise offshore Angola: The Leading Edge, 21, 972-982.

Ellwood, B. B., W. L. Balsam, and H. H. Roberts, 2006, Gulf of Mexico sediment sources and sediment transport trends from magnetic susceptibility measurements of surface samples: Marine Geology, 230, $237-248$.

Emiroglu, S., D. Rey, and N. Petersen, 2004, Magnetic properties of sediment in the Ría de Arousa (Spain): dissolution of iron oxides and formation of iron sulphides: Physics and Chemistry of the Earth, 29, 947959.

Evans, M. E., and F. Heller, 2003, Environmental Magnetism: Principles and Applications of Eviromagnetics: Academic Press, San Diego, 299 pp.

Evans, R. L., 2007, Using CSEM techniques to map the shallow section of seafloor: From the coastline to the edges of the continental slope: Geophysics, 72, WA105-WA116.

Evans, R. L., L. K. Law, B. Louis, and S. J. Cheesman, 2000, Buried Paleo-Channels on the New Jersey Continental Margin: Channel Porosity Structures from Electromagnetic Surveying: Marine Geology, 170, 381-394.

Evans, R.L., L. K. Law, B. St. Louis, S. Cheesman, and K. Sananikone, 1999, The shallow porosity structure of the Eel Shelf, northern California: Results of a towed electromagnetic survey, Marine Geology, 15, 211226.

Flosadottir, A. H., and S. Constable, 1996, Marine controlled source electromagnetic sounding 1. Modeling and experimental design: Journal of Geophysical Research, 101, 5507-5517.

Forté, S.A., 2005, Combined environmental magnetic and geochemical survey of pollution patterns in the Schlei inlet, Northern Germany: Master Thesis, FB Geowissenschaften, Universität Bremen, 110 pp.

Franke, C., T. von Dobeneck, M. R. Drury, J. D. Meeldijk, and M. J. Dekkers, 2007, Magnetic petrology of equatorial Atlantic sediments: Electron microscopy results and their implications for environmental magnetic interpretation: Paleooceanography, 22, DOI: 10.1029/2007PA001442.

Frederichs, T., U. Bleil, K. Däumler, T. von Dobeneck, and A. Schmidt, 1999, The Magnetic View on the Marine Paleoenvironment: Parameters, Techniques and Potentials of Rock Magnetic Studies as a Key to Paleoclimatic and Paleoceanographic Changes, in G. Fischer and G. Wefer, eds., Use of Proxies in Paleoceanography: Examples from the South Atlantic: Springer-Verlag, Berlin, Heidelberg, 575-599. 
Fu, Y., T. von Dobeneck, C. Franke, D. Heslop, and S. Kasten, 2008, Rock magnetic identification and geochemical process models of greigite formation in Quaternary marine sediments from the Gulf of Mexico (IODP Hole U1319A): Earth and Planetary Science Letters, 275, 233-245.

Garming, J. F. L., U. Bleil, and N. Riedinger, 2005, Alteration of magnetic mineralogy at the sulfate methane transition: analysis of sediments from the Argentine continental slope: Physics of the Earth and Planetary Interiors, 151, 290-308.

Gay, S. P., 2004, Glacial Till: A Troublesome Source of Near-Surface Magnetic Anomalies: The Leading Edge, $23,542-547$.

Hanesch, M., and R. Scholger, 2002, Mapping of heavy metal loadings in soils by means of magnetic susceptibility measurements: Environmental Geology, 42, 857-870.

Hansen, R. O., L. Racic, and V. J. S. Grauch, 2005, Magnetic Methods in Near-Surface Geophysics, in D. K. Butler, ed., Near-surface geophysics: SEG, Investigations in Geophysics, 13, 301-356.

Housen, B. A., and R. J. Musgrave, 1996, Rock-magnetic signature of gas hydrates in accretionary prism sediments. Earth and Planetary Science Letters, 139, 509-519.

Itambi, A. C., T. von Dobeneck, S. Mulitza, T. Bickert, D. Heslop, 2009, Millennial-scale North West African droughts related to $\mathrm{H}$ Events and D-O cycles: evidence in marine sediments from off-shore Senegal: Paleoceanography, 24, doi:10.1029/2007PA001570.

Jegen M. D., R. W. Hobbs, P. Tarits and A. Chave, 2009, Joint inversion of marine magnetotelluric and gravity data incorporating seismic constraints: Preliminary results of sub-basalt imaging off the Faroe Shelf: Earth and Planetary Science Letters, 282, 47-55.

Jensen, J. B., A. Kuijpers, O. Bennike, T. Laier, and F. Werner, 2002, New geological aspects for freshwater seepage and formation in Eckernförde Bay, western Baltic: Continental Shelf Research, 22, 2159-2173.

Karlin, R. and S. Levi, 1983, Diagenesis of magnetic minerals in Recent haemipelagic sediments: Nature, 303, 327-330.

Lamb, H., 1945, Hydrodynamics, 6th Edition, Dover Publications, New York, 738pp.

Lecoanet, H., F. Leveque, and S. Seguna, 1999, Magnetic susceptibility in environmental applications: comparison of field probes: Physics of the Earth and Planetary Interiors 115, 191-204.

McEnroe, S., P. Robinson, and P. Panish, 2001, Aeromagnetic anomalies, magnetic petrology, and rock magnetism of hemo-ilminite- and magnetite-rich cumulate rocks from Sokndal region, South Rogaland, Norway: American Mineralogist, 86, 1447-1468.

Marczinek, S., and J. A. Piotrowski, 2002, Grundwasserströmung und -beschaffenheit im Einzugsgebiet der Eckernförder Bucht, Schleswig-Holstein: Grundwasser - Zeitschrift der Fachsektion Hydrogeologie, 101110.

Nittrouer, C. A., G. R. Lopez, L. D. Wright, S. J. Bentley, A. F. D'Andrea, and C. T. Friedrichs, 1998, Oceanic processes and the preservation of sedimentary structure in Eckernförde Bay, Baltic Sea: Continental Shelf Research, 18, 1689-1714. 
Novosel, I., G. D. Spence, and R. D. Hyndman, 2005, Reduced magnetization produced by increased methane flux at a gas hydrate vent. Marine Geology, 216, 265-274.

Oldfield F., N. Richardson, P. G. Appleby, and L. Yu, 1993, 241Am and 137Cs activity in fine grained saltmarsh sediments from parts of the NE Irish Sea shoreline: Journal of Environmental Radioactivity, 19, 1- 24.

P. Jenkins, R. Duck, J. Rowan, and J. Walden, 2002, Fingerprinting of bed sediment in the Tay Estuary, Scotland: an environmental magnetism approach: Hydrology and Earth System Sciences, 6 (6), $1007-$ 1016.

Peters, C. and R. Thompson, 1998, Magnetic identification of selected natural iron oxides and sulphides: Journal of Magnetism and Magnetic Materials, 183, 365-374.

Powers, M.H., 1997, Modeling frequency-dependent GPR: The Leading Edge, 16, 1657-1662.

Pozza, M. R., J. I. Boyce, and W.A. Morris, 2004, Lake-based magnetic mapping of contaminated sediment distribution, Hamilton Harbor, Lake Ontario, Canada: Journal of Applied Geophysics, 57, 23-41.

Reitz, A., C. Hensen, S. Kasten, J. A. Funk, G. J. de Lange, 2004, A combined geochemical and rock-magnetic investigation of a redox horizon at the last glacial/interglacial transition: Physics and Chemistry of the Earth, 29, 921-931.

Rey, D., K. J. Mohamed, A. Bernabeu, B. Rubio, F. Vilas, 2005, Early diagenesis of magnetic minerals in marine transitional environments: Geochemical signatures of hydrodynamic forcing: Marine Geology, $215,215-236$.

Rubio, B., K. Pye, J. E. Rae, and D. Rey, 2001, Sedimentological characteristics, heavy metal distribution and magnetic properties in subtidal sediments, Ria de Pontevedra, NW Spain: Sedimentology, 48, 1277-1297.

Schmidt, A. M., T. von Dobeneck, and U. Bleil, 1999, Magnetic characterization of Holocene sedimentation in the South Atlantic: Paleoceanography, 14, 465-481.

Schmieder, F., T. von Dobeneck, and U. Bleil, 2000, The mid-Pleistocene climate transition as documented in the deep South Atlantic Ocean; initiation, interim state and terminal event: Earth and Planetary Science Letters, 179 (3-4), 539-549.

Schwalenberg K., M. Haeckel, J. Poort, and M. Jegen, 2009, Evaluation of gas hydrate deposits in an active seep area using marine controlled source electromagnetics: Results from Opouawe Bank, Hikurangi Margin, New Zealand: Marine Geology, doi:10.1016/j.margeo.2009.07.006.

Schwalenberg, K., E. Willoughby, R. Mir, and R. N. Edwards, 2005, Marine Gas Hydrate Electromagnetic Signatures in Cascadia and their Correlation with Seismic Blank Zones: First Break, 23, 57-63.

Sinha, M. C., P. D. Patel, M. J. Unsworth, T. R. E. Owen, and M. R. G. Maccormack, 1990, An Active Source Electromagnetic Sounding System for Marine Use: Marine Geophysical Researches, 12, 59-68.

Tivey, M. A., and H. P. Johnson, 2002, Crustal magnetization reveals subsurface structure of Juan de Fuca Ridge hydrothermal vent fields: Geology Boulder, 30, 979-982. 
Tribovillard, N., O. Averbuch, A. Bialkowski, and J. F. Deconinck, 2002, Early diagenesis of marine organicmatter and magnetic properties of sedimentary rocks: the role of iron limitation and organic-matter source organisms: Bulletin de la Societe Geologique de France, 173 (4), 295-306.

Versteeg, J. K., W. A. Morris, and N. A. Rukavina, 1995, Mapping Contaminated Sediment in Hamilton Harbour, Ontario: Environmental Geology of Urban Areas, 241-248.

Ward, S. H., and G. W. Hohmann, 1988, Electromagnetic theory for geophysical applications, in M. N. Nabighian, ed., Electromagnetic methods in applied geophysics: Society of Exploration Geophysicists, 130-311.

Wever, T. F., F. Abegg, H. M. Fiedler, G. Fechner, and I. H. Stender, 1998, Shallow gas in the muddy sediments of Eckernförde Bay, Germany: Continental Shelf Research, 18, 1715-1739.

Whiticar, M. J., 2002, Diagenetic relationships of methanogenesis, nutrients, acoustic turbidity, pockmarks and freshwater seepages in Eckernförde Bay: Marine Geology, 182, 29-53.

Won, I. J., D. A. Keiswetter, D. R. Hanson, E. Novikova, and T. M. Hall, 1997, GEM-3: A Monostatic Broadband Electromagnetic Induction Sensor: Journal of Environmental and Engineering Geophysics, 2, 53-64.

Won, I. J., and H. Huang, 2004, Magnetometers and electro-magnetometers: The Leading Edge, 23, 448-451.

Yu, L., and F. Oldfield, 1989, A multivariate mixing model for identifying sediment sources from magnetic measurements, Quaternary Research, 32, 168-181.

Yuan, J., and R. N. Edwards, 2000, The assessment of marine hydrates through electrical remote sounding: Hydrate without a BSR?: Geophysical Research Letters, 27, 2397-2400.

Zhang, W., L. Yu, S. M. Hutchinson, 2001, Diagenesis of magnetic minerals in the intertidal sediments of the Yangtze Estuary, China, and its environmental significance. Science of the Total Environment, 266, 16075 .

Zhdanov, M. S., and G. V. Keller, 1994, The Geoelectrical Methods in Geophysical Exploration, Methods in Geochemistry and Geophysics, 31: Elsevier, New York, 884 pp. 


\section{Mapping the magnetic and electric signatures of marine near- surface sediments by bottom-towed Controlled Source Electromagnetics}

Hendrik Müller ${ }^{1}$, Tilo von Dobeneck ${ }^{1}$, Christian Hilgenfeldt ${ }^{1}$, Daniel Rey ${ }^{2}$, Belen Rubio ${ }^{2}$

(1) Fachbereich Geowissenschaften, Universität Bremen, 28359 Bremen, Germany

(2) Facultad de Ciencias del Mar, Universidad de Vigo, 36310 Vigo, Spain

Manuscript for submission to Geophysics, published by the Society of Exploration Geophysicists (www.seg.org) 


\subsection{Introduction}

Coastal and shelf sedimentary systems are sedimentologically complex interim deposits in the transport chain from land to ocean. Storage and release, production and alteration of sediment particles at and near the seafloor depend on their physical and chemical material properties and the local impact of waves, currents, tides, tectonics, biota, gas and fluid seepage. The very dynamic nature of shallow marine settings finds its geological expression in vast lateral variability and frequent discontinuity of the sediment body. Human impact, e.g. by trawling, mining, dredging, dumping and off-shore construction plays an increasing role in modifying sediment distribution. In order to understand the geological, ecological and economical implications of these natural and anthropogenic processes and make model predictions on future system changes, precise knowledge of the near-surface architecture of coastal and shelf sediments is required, including quantitative and high-resolution data on the composition, porosity, granulometry as well as mechanical and chemical stability of the seafloor.

Geophysical exploration methods can provide the lateral resolution, vertical penetration and parameterization required to image sedimentary patterns in their full spatial complexity. In particular acoustic backscatter and seismic reflection methods have been intensely used in this context. Both methods excel in resolving bottom topography and sub-bottom stratification, but are limited and often ambiguous, when it comes to determine sediment properties and map surface heterogeneities. As shown, e.g. by Evans (2001), electromagnetic imaging of seafloor resistivity is a promising method to gather quantitative information on sediments porosity, an expression of grain-size and consolidation. Radiometric mapping of seafloor radionuclides $(\mathrm{K}, \mathrm{U}, \mathrm{Th})$ is an alternative approach capable of discerning mud and sands from various provenances (De Meijer et al., 1996; van Wijngaarden et al., 2002). 
Magnetic properties of shallow marine sediments have been equally exploited in shallow marine studies, but mainly on collected samples. Magnetic trace minerals, especially ironoxides, have source-specific rock magnetic and elemental signatures that can be detected by mineral and grain-size specific bulk measurements. The environmental specificity and available instrumental sensitivity of laboratory rock magnetic analytics lends iron oxides an excellent potential as markers of sediment origin, transport, hydrodynamics, diagenesis and pollution in coastal and shelf systems (Ellwood et al., 2006; Rey et al., 2005; Emiroglu et al., 2004; Zhang et al., 2001; Funk et al., 2004; Tribovillard et al., 2002). Owing to its commonly fine crystal size in magmatic rocks, detrital (titano-)magnetite tends also to enrich in the fine fraction of sediments providing a means to quantify terrigenous clay and silt content from bulk magnetic susceptibility (Booth et al., 2005; Ellwood et al., 2006).

In spite of the promises of using magnetic susceptibility measurements in the mapping of marine sediment distribution, the step from sample based to in-situ measurement has not been taken because of inherent instrumental difficulties. Standard alternating field susceptometers (e.g. Bartington MS2 type) do not operate properly in the highly conductive seawater environment (Benech and Marmet, 1999). Passive marine magnetometry can only detect relatively sharp lateral magnetization contrasts and does not resolve the subtle magnetic variability of near-surface sediments, especially in presence of magnetically more prominent deeper geological structures (Gay, 2004). The best available technology for in-situ susceptometry is Controlled Source Electromagnetic (CSEM) induction. By combining high and low transmitter frequencies, precise geometry control and an independent measurement of ambient seawater conductivity, the electric conductivity $\sigma$ and magnetic susceptibility $\kappa$ of marine near-surface sediments can be separately determined.

This measurement concept was realized with a new bottom-towed marine profiler GEM Shark (Figure 2-1) based on the commercial frequency domain CSEM sensor Geophex GEM-3 
(Won and Huang, 2004) and was developed in close cooperation and co-funding of the MARUM Center for Marine Environmental Sciences at University of Bremen (Germany) and the MARGO Marine and Environmental Geology Group at University of Vigo (Spain) (Rey et al., 2008). The system has been devised for coastal and shelf operations down to $500 \mathrm{~m}$ water depth, targeting essentially the topmost $50 \mathrm{~cm}$ of the seafloor.

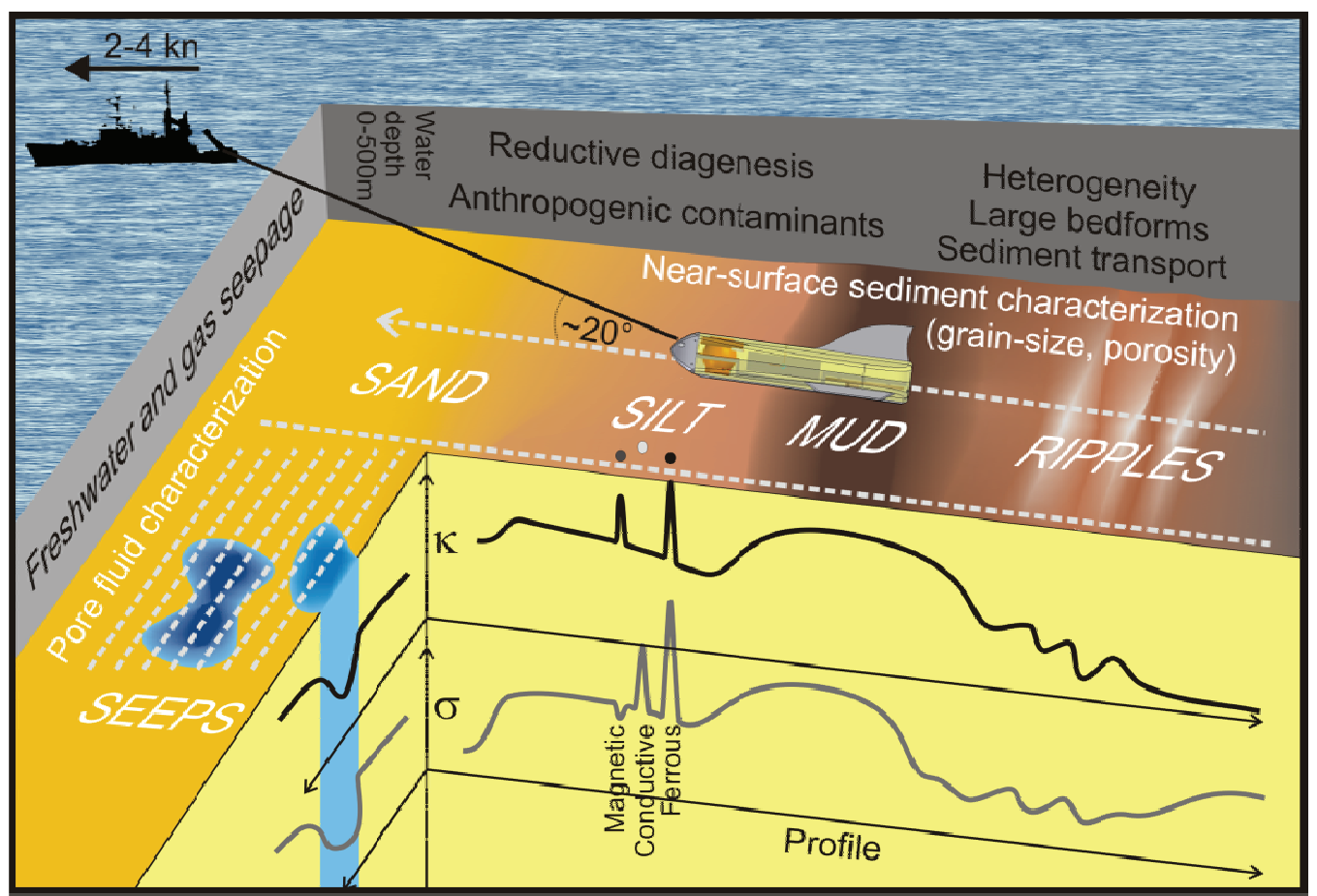

Figure 2-1. 3D conceptual model of combined susceptibility and conductivity near-surface electromagnetic profiling and mapping. The two investigated topics of near-surface sediment characterization and freshwater or gas seepage (pore fluid characterization) can be characterized by their electric conductivity $\sigma$ and magnetic susceptibility $\kappa$ signatures.

For the purpose of mapping shallow marine sediment characteristics, seepage effects and metallic contaminants, it is essential to consider the spatial variability of the solid sediment matrix as well as of the fluid-filled pore space. The two parameters $\kappa$ and $\sigma$ derived from CSEM provide just that: The magnetic susceptibility of sediment depends on its ferro-, paraand diamagnetic mineral content, hence on lithology and grain-size. The electric conductivity of marine sediment is controlled by pore water salinity, temperature and mainly by porosity, a result of the packing structure determined by grain size and shape, sorting and compaction. As 
the conceptual $\kappa$ and $\sigma$ profiles of Figure 2-1 suggest, both parameters offer related, but also complementary information on primary and secondary geological processes.

This paper presents the specific physical principles, technical realization and first successful scientific applications of the new marine EM profiler. In particular, we will discuss

(1) implications of the sensor geometry,

(2) consequences of the conductive saltwater environment

(3) lithological and morphological controls of susceptibility and conductivity

(4) design and operation of the bottom-towed platform

Two 33 and $19 \mathrm{~km}$ long cross-profiles of the NW Iberian shelf illustrate the applicability of this novel seafloor mapping tool and highlight the eminent potential of combining magnetic and electric information for quantitative seabed characterization.

\subsection{EM measurements in a conductive saltwater environment}

So far, most CSEM-based studies of marine sediments were exclusively interested in the subsurface conductivity, and there is a range of publications addressing the specific problems created by the influence of the conductive saltwater environment (e.g. Edwards, 2005; Chave et al., 1991; Cheesman et al., 1987). Contrary to land based CSEM surveys, the subsurface is generally less conductive than the seawater. Specific constraints must be met by sensor type and geometry to measure subsurface conductivity without apriority knowledge of seawater conductivity (e.g. Cheesman et al., 1987). Especially in shallow waters, the EM subsurface signal can be significantly biased by air waves (that travel to and along the air-water boundary and back to the receiver) or by current driven water turbulences and wave motion (Chave et al., 1991; Manoj et al., 2006). Due to the damping of the EM signal in the water column sensitive EM measurements must be performed close to the seafloor where obstacles of various types (e.g. wracks, rocks, terraces, cables, fishing gear) hold risks for the 
instrumentation and survey success. Some benefit is provided by low-pass filtering of cultural noise and spherics by the conductive seawater drape (Chave et al., 1991).

\subsubsection{Primary and secondary EM signal}

EM field instruments capable of measuring magnetic susceptibility differ fundamentally by the arrangement of transmitter and receiver coil (Benech and Marmet, 1999). 'Slingram' type or bistatic sensor geometries, where the receiver coil is apart from the transmitter coil enable greater depths of investigation and are less influenced by a conductive subsurface. However, they are much less sensitive for susceptibility and therefore not useful for the earlier depicted purpose, where precisions in the order of $10^{-6} \mathrm{SI}$ are required. As the magnetic dipole-field decays by the inverse cube to the distance, the highest amplitude of the secondary magnetic field due to a magnetized body is gained by a receiver loop which is concentric and coplanar with the transmitter coil. The broadband CSEM sensor GEM-3 (Won et al., 1997) applies this principle and is capable of separating magnetic susceptibility and electric conductivity by combining low- and high-frequency signals (Won and Huang, 2004). Its sensitivity for magnetic susceptibility was determined as $7 \times 10^{-7}$ SI in a low noise environment at $5 \mathrm{~Hz}$ sampling rate. The base period of the transmitter waveform is $25 \mathrm{~Hz}(30 \mathrm{~Hz}$ in $60 \mathrm{~Hz}$ power environment), which defines the minimum operation frequency and maximum sampling rate. Up to ten frequencies of $25 \mathrm{~Hz}$ to $50 \mathrm{kHz}$ can be combined to build a complex waveform using a pulse-width modulation technique (Won et al., 1996).

An outstanding advantage of the GEM-3 sensor is its method of 'bucking' the otherwise dominant primary magnetic source field of the transmitter coil $\mathrm{T}_{\mathrm{x}}(\varnothing 96 \mathrm{~cm})$ in the central socalled 'magnetic cavity' area enclosed by the receiver coil $R_{x}(\varnothing 30 \mathrm{~cm})$. This is realized by adding a third, equally concentric 'bucking coil' $\mathrm{B}_{\mathrm{x}}(\varnothing 53 \mathrm{~cm})$ in series with the transmitter coil, but with reverse winding and lesser reach. The bucking coil is tuned so that it cancels the transmitter moment within the cavity area by its corresponding, but inverse signal (Figure 
2-2a). Ideally, the receiver coil does not 'see' the primary transmitter signal and therefore only registers the secondary subsurface response.

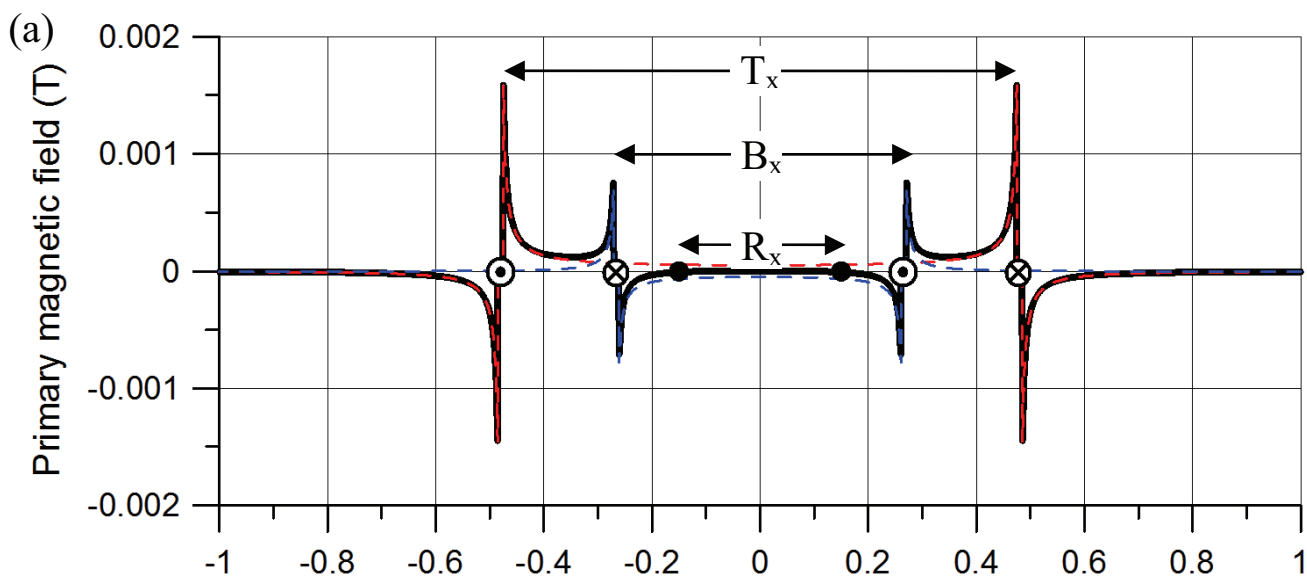

(b)

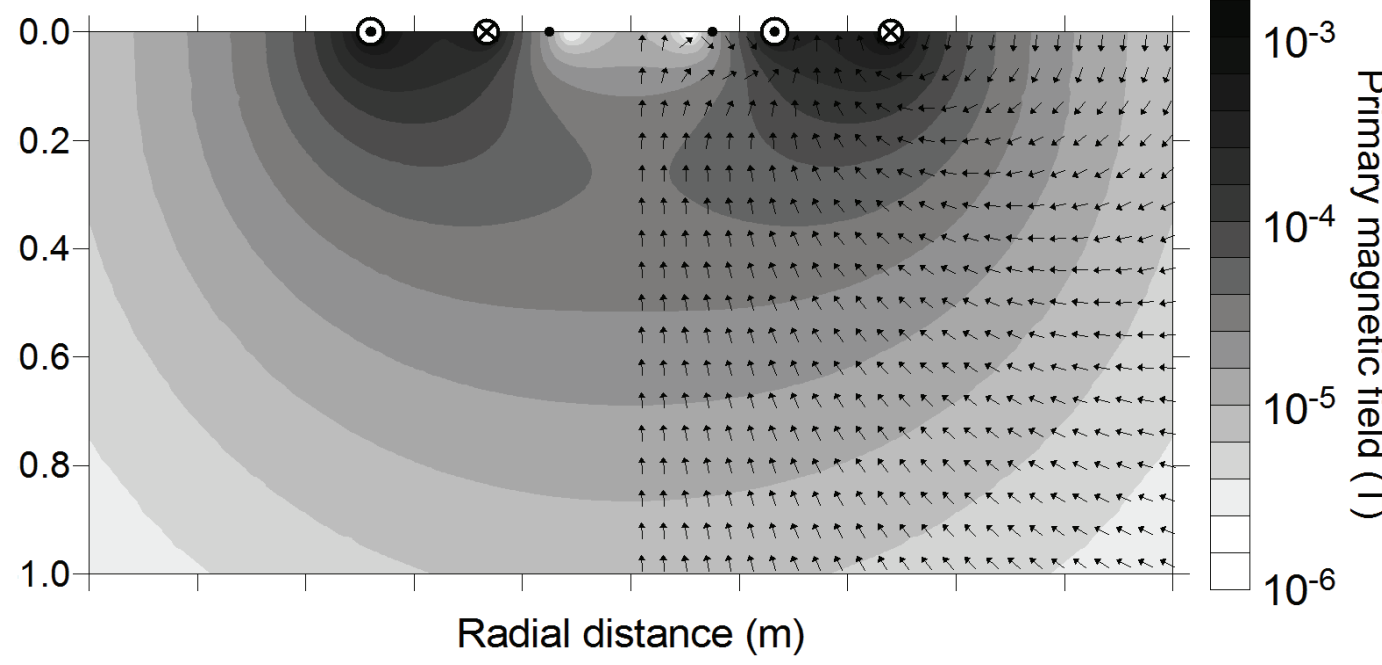

Figure 2-2. Primary magnetic field intensity distribution of GEM-3 sensor (96 cm coil) in (a) sensor plane and (b) vertical cross section. Vectors indicate field directions; dots represent the positions of transmitter $\left(\mathrm{T}_{\mathrm{x}}\right)$, bucking $\left(B_{x}\right)$ and receiver $\left(R_{x}\right)$ coil and momentary sense of the alternating primary current.

Due to the interference of transmitter and bucking field, the primary field in the sensor plane changes polarity at the positions of $T_{x}$ and $B_{x}$ and approaches zero inside $R_{x}$ (Figure 2-2a, b). However at a vertical distance of $20 \mathrm{~cm}$, the transmitter coil starts to dominate the primary field and positive polarity predominates; a dipolar characteristic can be assumed at depths greater than $40 \mathrm{~cm}$. In consequence of the primary and resulting secondary field geometries, the total sensitivity of the sensor reaches its maximum when the sensor is placed $20 \mathrm{~cm}$ above the ground which defines the optimum elevation for surface sediment measurements. 
To understand the fundamentals of the received signal, we expand the analytical half-space equation of the sensor given by Won et al. (1997) (based on Ward and Hohmann, 1988) by adding the terms for a conductive upper half-space and a magnetic subsurface. The received signal is expressed by the ratio $\mathrm{T}$ of the secondary magnetic field $H_{s}$ recorded by the receiver coil relative to the primary field $H_{p}$ sent by the transmitter coil in the response function

$$
\begin{aligned}
& T=\frac{H_{s}}{H_{p}}=r^{2} \int_{0}^{\infty} \frac{u_{s e d}-u_{w}}{u_{s e d}+u_{w}} \lambda e^{-2 h\left(\mu_{w} u_{w}\right)} J_{1}(\lambda r) d \lambda+T_{w}\left(\varpi \mu_{w} \sigma_{w}\right), \\
& u_{\text {sed }, w}=\frac{1}{\mu_{s e d, w}} \sqrt{\lambda^{2}+i \varpi \mu_{0} \mu_{s e d, w} \sigma_{s e d, w}}
\end{aligned}
$$

with electric conductivity $\sigma_{s e d, w}$, magnetic permeability $\mu_{s e d, w}$ (magnetic susceptibility $\kappa=\mu-1)$, angular frequency $\varpi(\varpi=2 \pi f)$, sensor elevation $h$, and transmitter coil radius $r$. The complex ratio $\mathrm{T}$ is given in units of parts-per-million (ppm) and can be split into a real (in-phase) and an imaginary (quadrature) component. The conductive seawater can be expressed by the additive term $T_{w}$, controlled by frequency, seawater conductivity and permeability. In practice, the seawater conductivity $\sigma_{w}$ is determined with an oceanographic conductivity-temperature-depth (CTD) probe, which has been integrated into the GEM Shark profiler. As the diamagnetic susceptibility of seawater $\kappa_{w}$ is a temperature-independent constant, a literature value of $-9 \times 10^{-6}$ SI (Collinson, 1983) is assumed.

The voltage output of the EM sensor, the so-called electromotive-force (emf), equals the surface integral of the response function (equation 1) over the area enclosed by the receiver coil (here simplified by a point receiver in the coil axis). The resulting two additive terms seafloor $S$ and water $W$ can be written as radial symmetric receiver function with transmitter coil radius $\left(R_{T}\right)$, bucking coil radius $\left(R_{B}\right)$ and the number of respective turns $\left(n_{T}\right.$ and $\left.n_{B}\right)$ : 


$$
\begin{aligned}
& S=R_{T}^{2} \cdot \int_{0}^{\infty}\left[J_{1}\left(\lambda R_{T}\right)-\frac{n_{B} R_{B}}{n_{T} R_{T}} J_{1}\left(\lambda R_{B}\right)\right] \cdot \frac{\lambda^{2}}{\mu_{w} u_{w}} \cdot e^{-2 h \cdot \mu_{w} u_{w}} \cdot\left[\frac{u_{\text {sed }}-u_{w}}{u_{\text {sed }}+u_{w}}\right] d \lambda \\
& W=R_{T}^{2} \cdot \int_{0}^{\infty}\left[J_{1}\left(\lambda R_{T}\right)-\frac{n_{B} R_{B}}{n_{T} R_{T}} J_{1}\left(\lambda R_{B}\right)\right] \cdot \lambda \cdot\left[1-\frac{\lambda}{\mu_{w} u_{w}}\right] d \lambda \\
& \text { emf }=S+W
\end{aligned}
$$

The geometrical constraints of the receiver function (equation 2) can be summarized in the (real) geometry term:

$$
G(h)=R_{T}^{2} \cdot \int_{0}^{\infty}\left[J_{1}\left(\lambda R_{T}\right)-\frac{n_{B} R_{B}}{n_{T} R_{T}} J_{1}\left(\lambda R_{B}\right)\right] \cdot \lambda e^{-2 h \lambda} d \lambda
$$

The first order Bessel-Function $J_{l}$ describes the primary field strength in close vicinity to the transmitting coils (small $h$ ). Expansion of term $G$ for vertical distances much higher than the transmitter radius $\left(h \gg R_{T}\right.$ ) leads to a dipolar characteristic of the primary field with $1 / h^{3}$ proportionality.

Low frequency expansion of the receiver function (equation 2) represents the 'resistive limit' conditions, where the conductive seawater and subsurface surrounding behave like a perfect resistor. Thus, the primary and the secondary field are in phase (real) and seawater term and subsurface conductivity effects can be neglected. Under these conditions, the measured emf is proportional to the magnetic susceptibility $\kappa$, described by the resistive limit equation:

$$
e m f \cong-\frac{1}{2} \kappa \cdot G
$$

Magnetic susceptibility has a negative contribution to the recorded EM in-phase signal. Frequency dependence of the susceptibility signal can arise from superparamagnetic magnetite (Buselli, 1982; Dearing et al., 1996) or subsurface magnetization by secondary EM fields (Zhang and Oldenburg, 1997). However, currents in marine sediments will usually not exceed $1 \mathrm{~A}$ inducing a maximum secondary magnetic field $<1 \mu \mathrm{T}$, which is at least two orders of magnitude lower than the primary magnetic field at this position. The measured magnetic susceptibility is hence by more than $99 \%$ related to primary EM field magnetization. 
Sediment electric conductivity $\sigma_{\mathrm{s}}$ is commonly interpreted as a measure of (connected) porosity. The empirical relation of sediment conductivity, pore water conductivity $\sigma_{\mathrm{w}}$ and porosity $\phi$ is given by Archie's law (Archie, 1942):

$$
\sigma_{s}=a \cdot \sigma_{w} \phi^{m} S_{w}^{n}
$$

The constants $m$ (the cementation factor), $a$ and $n$ can be determined from own reference samples or literature values for the respective sediment type. Typical values for marine sands are $m=1.5-1.8$ and $a=1$ (Evans, 2007). The water saturation factor $S_{w}\left(0 \leq S_{w} \leq 1\right)$ is only relevant for marine sediments that include free gas.

Sediment magnetic susceptibility $\kappa_{s}$, depends primarily on magnetic mineral content, which is expressed by the porosity-independent susceptibility of the sediment matrix $\kappa_{m}$. However, $\kappa_{s}$ bears also a dilutional effect by porosity as shown by the equation:

$$
\kappa_{s}=(1-\phi) \kappa_{m}+\phi \kappa_{w} ; \kappa_{w}<0<<\kappa_{m}
$$

Matrix susceptibility can be used to separate source specific sediment properties against textural effects and susceptibility reduction due to a diagenetic overprint against dilution by increasing water content. By substituting equation 5 into equation 6 , we can determine the apparent matrix susceptibility $\kappa_{m}$ from the conductivity and susceptibility measurements.

\subsubsection{Representation of a homogenous seafloor}

Although inappropriate for stratified marine deposits, the assumption of a homogeneous sediment half-space is conclusive in defining fundamental constraints of EM signal formation. For this simple case, the conversion of secondary EM in-phase and quadrature components into susceptibility and conductivity data is realized by a look-up table, solving the Hankel transformation of the response function (equation 2) with coefficients given by Anderson (1979). Both real (in-phase) and imaginary (quadrature) components of the secondary field can be used to determine subsurface conductivity provided that the conductivity of the upper 
half-space (i.e. seawater) is precisely known, in our case from synchronous CTD readings. The CTD point measurement is only representative if quasi-homogeneous bottom water conditions within the sensitive volume of the GEM-3 sensor can be assumed. Heterogeneous (e.g. freshwater plumes) or layered water masses (e.g. close to the thermocline or sea surface) give rise to systematic errors in the determination of subsurface conductivity.

Figure 2-3 shows the influence of the sea surface on GEM-3 conductivity measurements. Obviously, the overlying water depth is uncritical for susceptibility measurements as the replacement of diamagnetic water by non-magnetic air has just minute effects of $<4 \times 10^{-6} \mathrm{SI}$ even for extremely shallow settings. In contrast, the conductivity measurement is strongly affected by the water surface. As shown by our model results, the required water cover to justify the assumption of homogenous seawater half-space crucially depends on operation frequency and mode. For our typically applied frequencies of 525, 2025, 4775 and $16025 \mathrm{~Hz}$, the respective critical minimum water depths are $6,4,3$ and $2 \mathrm{~m}$ for quadrature conductivity and $12,8,5$ and $3 \mathrm{~m}$ for in-phase conductivity unless special corrections are applied.

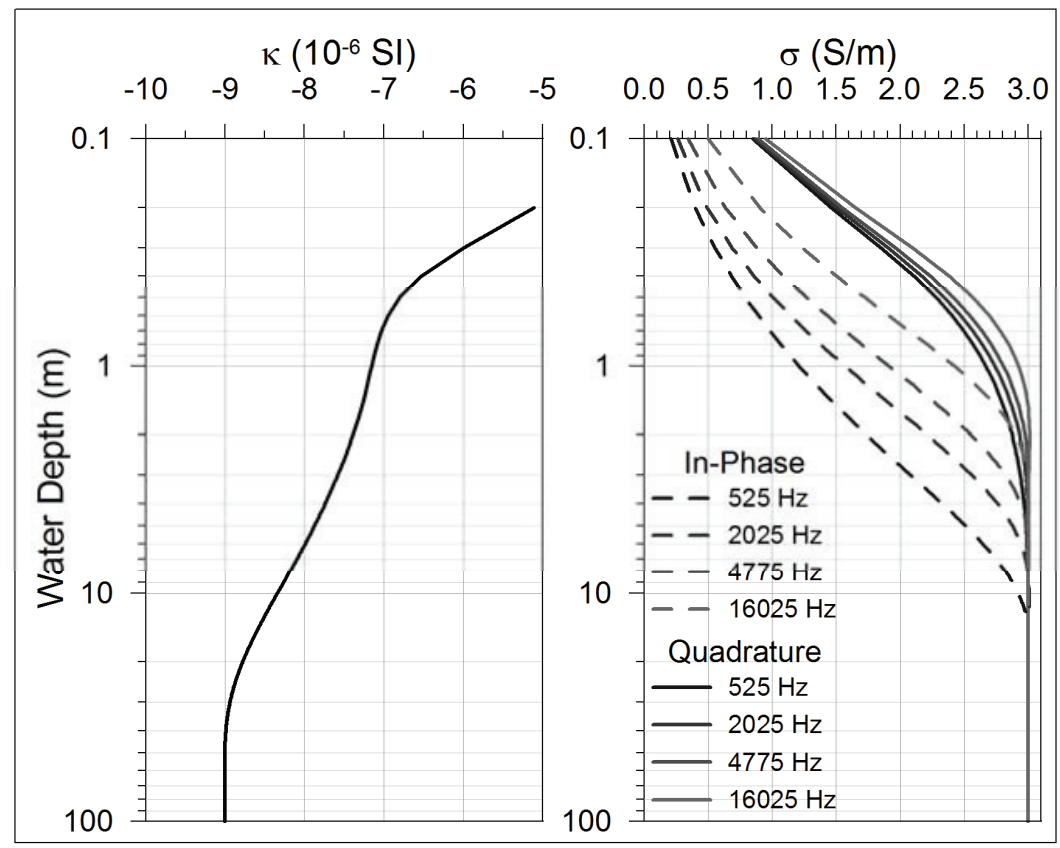

Figure 2-3. GEM-3 susceptibility and conductivity measurements under decreasing water cover. This model result assumes that the sensor emerges from an infinite seawater halfspace $\left(\kappa_{\mathrm{w}}=-9 \times 10^{-6} \mathrm{SI}\right.$ and $\left.\sigma_{\mathrm{w}}=3 \mathrm{~S} / \mathrm{m}\right)$. 
In practice, magnetic susceptibility can be exclusively determined from low frequency EM sounding (Won and Huang, 2004). Figure 2-4a shows the relative contributions of susceptibility and conductivity to in-phase response in function of the product of subsurface conductivity and operation frequency. Close to resistive limit conditions, the magnetic signal dominates by far and conductivity effects can be easily eliminated computationally or even neglected with little consequence. When measuring at $75 \mathrm{~Hz}$ over a seafloor of $1.2 \mathrm{~S} / \mathrm{m}$ in seawater of $3 \mathrm{~S} / \mathrm{m}$, less than $1 \%$ of a susceptibility value of $100 \times 10^{-6}$ SI is related to subsurface conductivity while for weakly magnetic sediments with susceptibilities below $10 \times 10^{-6}$ SI, a measurement without numeric conductivity compensation would be significantly biased .

In return, the susceptibility of marine sediments has negligible effects on the determination of quadrature conductivity (Huang and Won, 2003) and can be subtracted from the in-phase component prior to conductivity conversion. The precision of the conductivity determination is therefore only related to the noise floor. During static measurements on the sea bottom, noise was found to be less than 1 ppm for in-phase and quadrature components in the frequency range of $200-20000 \mathrm{~Hz}$. The conductivity equivalent of $1 \mathrm{ppm}$ (the noise floor) is shown in Figure 2-4b, assuming seawater and seafloor conductivities of $3 \mathrm{~S} / \mathrm{m}$ and $1 \mathrm{~S} / \mathrm{m}$. At $5000 \mathrm{~Hz}$, we can assume a resolution of about $1 \mathrm{mS} / \mathrm{m}$ in quadrature and $8 \mathrm{mS} / \mathrm{m}$ in in-phase conductivity, corresponding to porosity changes of $<0.1 \%$ and ca. $0.2 \%$, respectively, while at $500 \mathrm{~Hz}$ resolution is $13 \mathrm{mS} / \mathrm{m}$ in quadrature and $205 \mathrm{mS} / \mathrm{m}$ in-phase conductivity equivalent to porosity variations of ca. $0.4 \%$ and $5.9 \%$. 

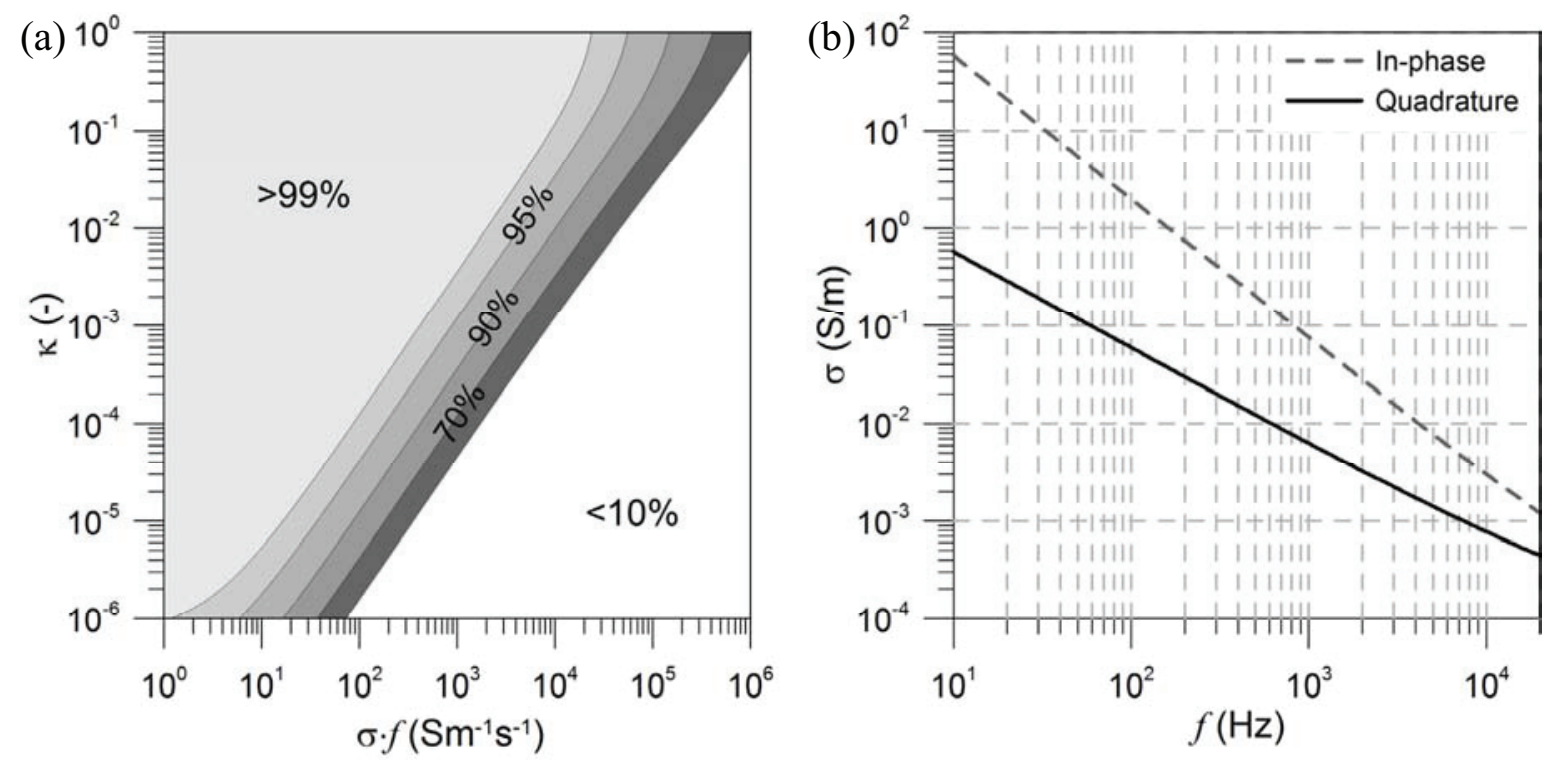

Figure 2-4. (a) Relative contribution of the magnetic (complementary to the electric) response to total in-phase signal in function of operation frequency, sediment susceptibility and conductivity (modified after Won and Huang, 2004); (b) Frequency-dependence of of in-phase and quadrature conductivity noise floor $\left(\sigma_{\mathrm{w}} 3 \mathrm{~S} / \mathrm{m}\right)$.

\subsubsection{Representation of a heterogeneous seafloor}

For typical sedimentary coastal and shelf settings, the assumption of a homogenous seafloor is not adequate. Magnetic and electric properties of near-surface sediments vary both in the vertical (e.g. by stratification, consolidation, diagenesis, free gas, freshwater aquifers) and in the horizontal dimension (e.g. lateral facies changes, point and line anomalies, seeps). In this section, we will treat the two idealized cases of a vertically and a radially varying seafloor.

In order to calculate the EM response of a stratified seafloor of $n$ layers, we expand the receiver function for a homogeneous subsurface (equation 2) to vertically layered subsurface substituting $u_{\text {sed }}$ against a recursive series introduced by Ward and Hohmann (1988) where any layer $k(1 \leq k<n)$ is characterized by its specific magnetic permeability $\mu_{k}$, electric conductivity $\sigma_{k}$ and thickness $z_{\mathrm{k}}$.

$u_{k}=\hat{u}_{k} \frac{u_{k+1}+\widehat{u}_{k} \tanh \left(\hat{u}_{k} \mu_{k} z_{\mathrm{k}}\right)}{\widehat{u}_{k}+u_{k+1} \tanh \left(\hat{u}_{k} \mu_{k} z_{\mathrm{k}}\right)}$ with $\hat{u}_{k}=\mu_{k}^{-1} \sqrt{\lambda^{2}+i \varpi \sigma_{k} \mu_{0} \mu_{k}}$

The $\mathrm{n}^{\text {th }}$ layer is given by $u_{n}=\hat{u}_{n}$. 
In order to model the response of the $G E M-3$ sensor to vertical susceptibility and conductivity distributions, respective sensor characteristics or 'weighting functions' are required. Apparent seafloor conductivity and susceptibility values determined by EM profiling then correspond to a convolution the vertical distribution function of these sediment properties and the respective weighting functions. Following Evans (2001), these functions were numerically determined by simulating a thin anomalous horizontal layer shifting through a uniform sediment halfspace. The lower half-space was discretized into layers of $1 \mathrm{~mm}$, which were consecutively perturbed by $0.1 \%$ of their background value. The sensor's response to the perturbed relative to the unperturbed model delineates its characteristic vertical distance sensitivity. To derive the weighing functions, the change in response was normalized, such that the integral over the entire sediment half-space equals one. Figure 2-5a,b depicts the resulting weighting functions of in-phase susceptibility and quadrature conductivity modeled with a seawater conductivity of $3 \mathrm{~S} / \mathrm{m}$, sediment susceptibility of $100 \times 10^{-6} \mathrm{SI}$, sediment conductivity of $1 \mathrm{~S} / \mathrm{m}$ and sensorground distance of $0.2 \mathrm{~m}$. The cumulative curves quantify the contribution of the sediment volume between seafloor and a given depth plane to total sensor response.

The characteristics for in-phase susceptibility and quadrature conductivity (4775 Hz) differ mainly within the water half-space, while their decay within the sediment half-space is rather similar. The sensitivity for conductivity (or susceptibility, respectively) reduces to $50 \%$ at a depth of $16 \mathrm{~cm}(17 \mathrm{~cm})$ and to $10 \%$ at a depth of $71 \mathrm{~cm}(48 \mathrm{~cm})$. In cumulative terms, the upper $0-21 \mathrm{~cm}(0-14 \mathrm{~cm})$ of sediment corresponds to $50 \%$ and the upper $0-92 \mathrm{~cm}(0-50 \mathrm{~cm})$ to $90 \%$ of the signal. If the sensor-ground distance falls below $0.13 \mathrm{~m}$, the susceptibility signal diminishes due to the increasing predominance of the magnetic inverse field of the bucking coil. The quadrature conductivity signal is not influenced by this bucking effect, but values would still decrease since bottom water is replaced by less conductive sediment. 
The good geometric coincidence of both sensor characteristics and hence measured sediment volumes permits to combine in-phase susceptibility and quadrature conductivity values in interpretations and calculations. Frequency has no influence on the shape of the susceptibility response function and only little effect on the shape of the quadrature response function. On the contrary, the vertical characteristic of in-phase conductivity is substantially controlled by the operation frequency (Figure 2-5c) and does obviously not correspond to the sensitive area of the susceptibility signal. In many EM systems, frequency dependence of the vertical sensor characteristics forms the base for depth inversion of conductivity. However, this approach concerns deeper strata and is not applicable to the near-surface studies dealt within this paper.
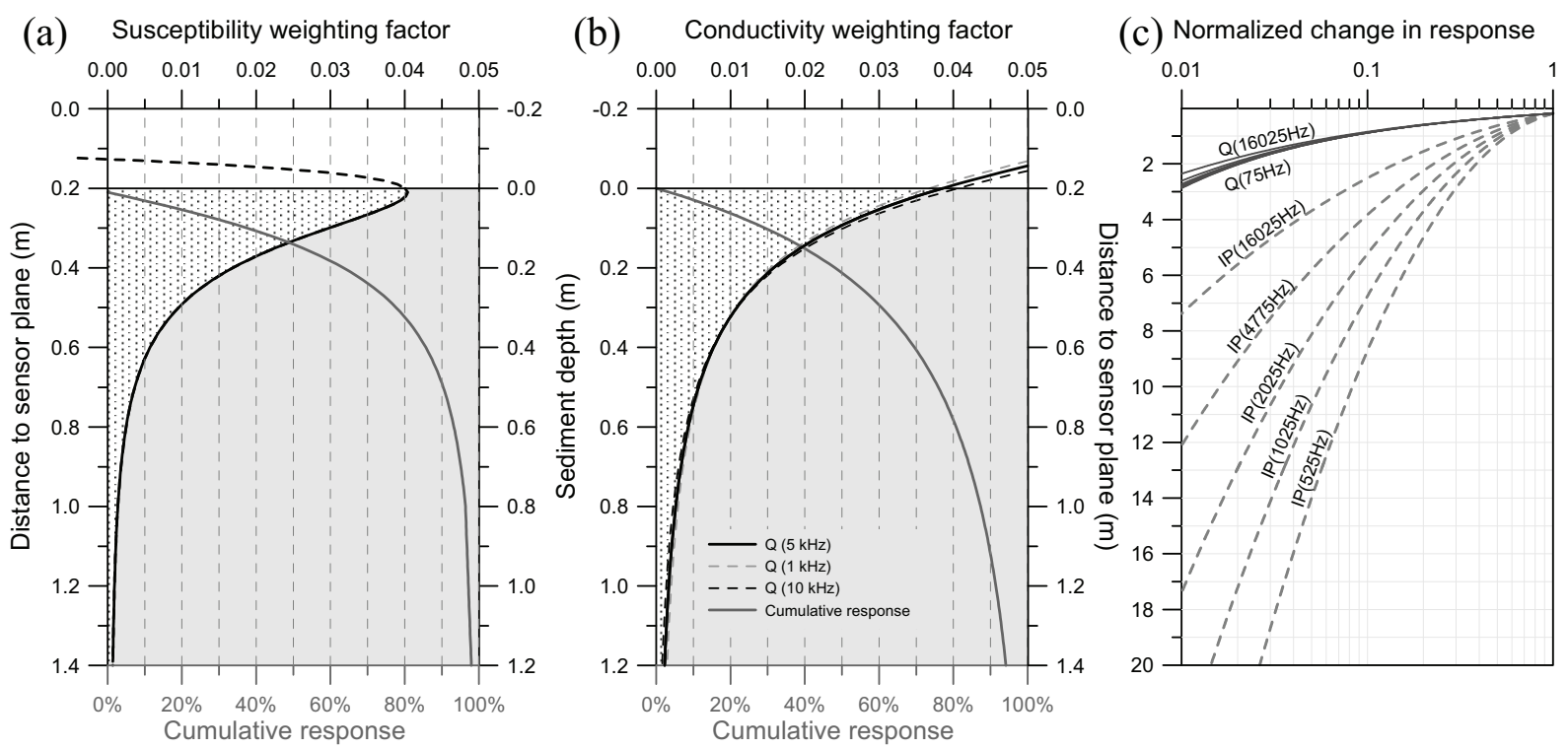

Figure 2-5. Vertical sensor characteristics of GEM-3 (96 cm coil) for (a) in-phase susceptibility and (b) quadrature conductivity given as weighting functions and cumulative subsurface response. (c) In-phase (IP) and quadrature $(\mathrm{Q})$ responses of $G E M-3$ sensor at various operation frequencies. The models are based on $0.1 \%$ perturbations of a homogenous seafloor model with seawater (and sediment) conductivities / susceptibilities of $3 \mathrm{~S} / \mathrm{m}$ and $-9 \times 10^{-6} \mathrm{SI}\left(1 \mathrm{~S} / \mathrm{m}\right.$ and $\left.100 \times 10^{-6} \mathrm{SI}\right)$.

In analogy to a definition of Liu and Becker (1990), the horizontal footprint of the secondary EM field (Figure 2-6) was numerically calculated as the diameter of a semi-infinite cylinder that provides $90 \%$ of the total secondary signal with identical model settings. The primary electric field was determined by a finite element model (COMSOL Multiphysics); Biot Savart's law was used to calculate the contribution of discrete rings $(1 \mathrm{~cm}$ height, $1 \mathrm{~cm}$ width 
and radius $R$ ) to the total secondary magnetic field at the center of the receiver coil. The respective footprint diameter for a given frequency and phase was determined by adding up the contributions of cylinder shells with increasing radii until $90 \%$ of the total signal were attained.
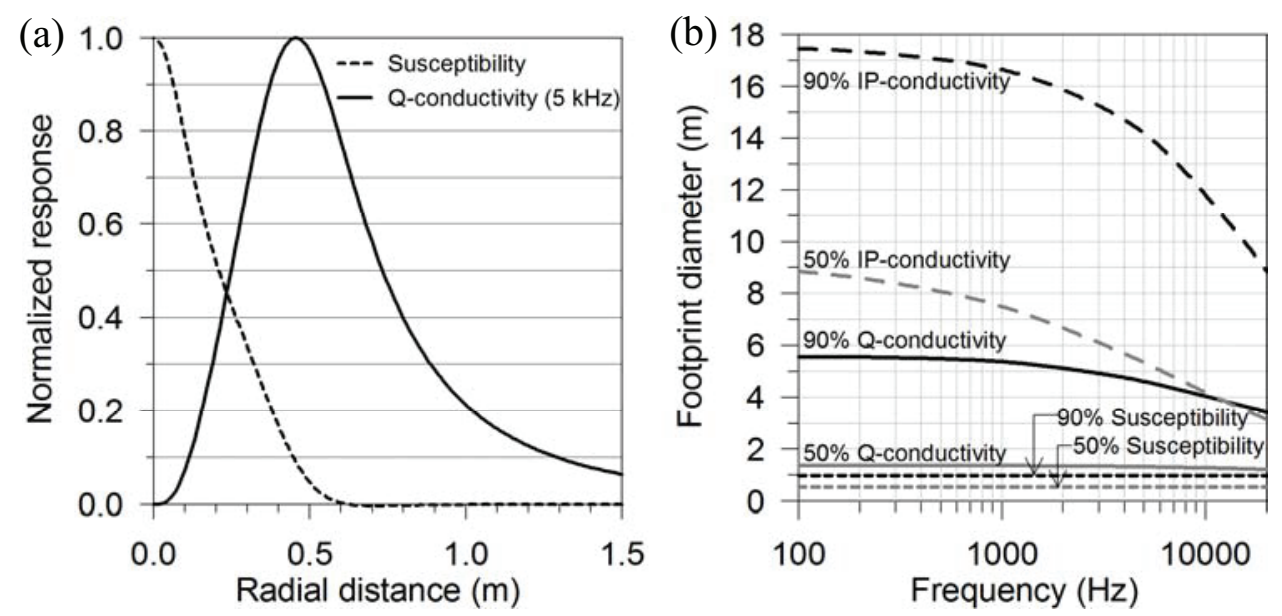

(c)

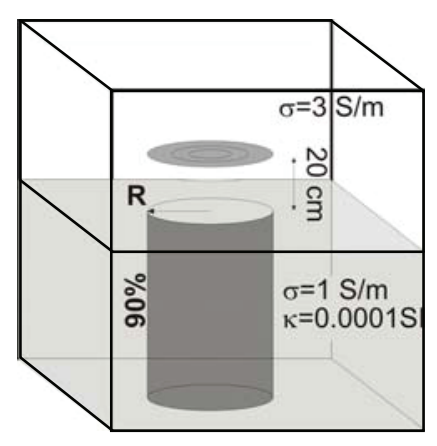

Figure 2-6. (a) Lateral response of GEM-3 sensor (96 cm coil) for susceptibility and $5 \mathrm{kHz}$ quadrature conductivity on homogeneous seafloor normalized to peak values and (b) horizontal footprint diameter (90\% of the total signal) and half-with (50\%) of susceptibility, quadrature (Q) and in-phase (IP) conductivity; (c) model settings: sensor elevation $0.2 \mathrm{~m}$, seawater (seafloor) susceptibility $-9 \times 10^{-6}\left(100 \times 10^{-6} \mathrm{SI}\right)$ and conductivity $3 \mathrm{~S} / \mathrm{m}(1 \mathrm{~S} / \mathrm{m})$.

This simulation demonstrates that the sensitive volumes of susceptibility and in-phase and quadrature conductivity differ more in the lateral than in the vertical dimension. Due to the dipolar shape of the magnetic and toroidal shape of the electric primary fields, sensitivity is at maximum near the coil axis for susceptibility and around the transmitter coil for quadrature conductivity (Figure 2-6a). The footprint of quadrature conductivity is therefore 3.5 to 5.5 larger (half-width of 1.3 to $1.5 \mathrm{~m}$ ) than that of susceptibility $(1.0 \mathrm{~m}$ footprint and $0.5 \mathrm{~m}$ halfwidth). In the case of in-phase conductivity, the footprint is much wider (9 to $17 \mathrm{~m}$; halfwidth of 3 to $9 \mathrm{~m}$ ) due to lateral wave propagation (Figure 2-6b). The frequency dependence of footprint size has the potential for the coverage of off-track conductivity anomalies (e.g. seeps, metal objects).

Combining all investigated aspects of sensing geometry as well as phase- and frequencydependence, we can conclude, that 
(1) Magnetic susceptibility is preferentially determined from low frequency in-phase signal. Depth penetration is shallow (ca. $0.5 \mathrm{~m}$ ) and essentially determined by sensor geometry.

(2) The $1-10 \mathrm{kHz}$ quadrature conductivity signal provides the highest $\mathrm{S} / \mathrm{N}$ ratio, the highest lateral resolution and the best spatial compatibility with the susceptibility measurement.

(3) The $1-10 \mathrm{kHz}$ in-phase conductivity signal has a much wider footprint and much deeper, frequency-dependent penetration (up to $9 \mathrm{~m}$ radius and depth). It is suitable for mapping deeper strata, e.g. the thickness of mud layers or the depth of erosional contacts.

(4) Under ideal conditions, the GEM-3 sensor can resolve susceptibility changes of $1 \times 10^{-6} \mathrm{SI}$ and conductivity changes $1 \mathrm{mS} / \mathrm{m}$ (corresponding to a porosity change of $0.1 \%$ )

EM data collected with various frequencies, sensor diameters and phases open interesting possibilities to determine vertical susceptibility and porosity transitions and gradients as demonstrated by the model examples of Figure 2-7: The first model (Figure 2-7a) represents a sand layer dipping below a muddy drape of higher susceptibility and conductivity. The sand facies contributes significantly to the magnetic susceptibility signal at a mud thickness $<1 \mathrm{~m}$. In the $5 \mathrm{kHz}$ quadrature conductivity signal the sand remains detectable under a mud cover of $<2.5 \mathrm{~m}(<5 \mathrm{~m}$ at $0.5 \mathrm{kHz})$. The second model (Figure 2-7b) deals with the loss of magnetic susceptibility associated with pervasive magnetite dissolution (pyritization) in the sulfidic zone. Magnetite depletion was assumed to set in at depths of $0.2-0.8 \mathrm{~m}$ and to be completed $0.2 \mathrm{~m}$ deeper. By combining various available $G E M-3$ sensor sizes $(96,64$ and $40 \mathrm{~cm})$, one could reasonably estimate the depth of the iron redox boundary. 

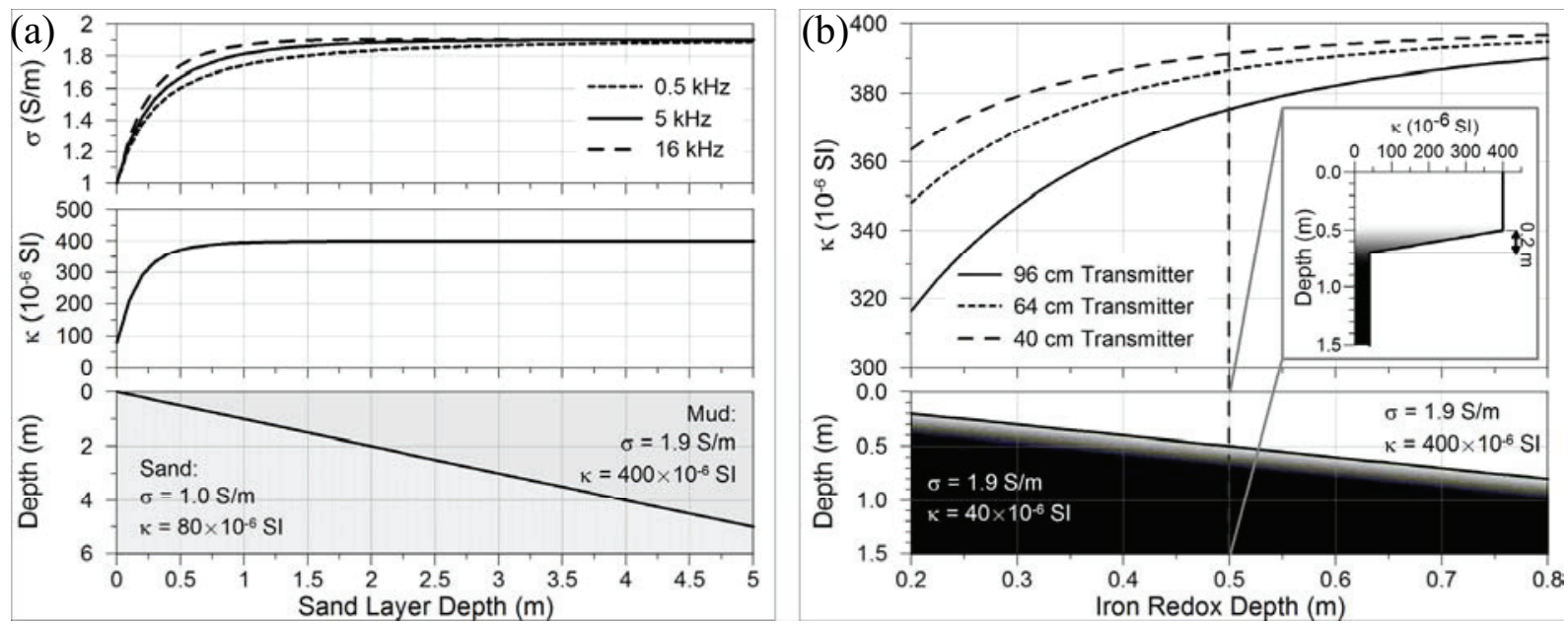

Figure 2-7. Simulations of (a) apparent susceptibility and conductivity profiles of a dipping mud/sand boundary (b) apparent susceptibility profiles by various available sensor sizes of dipping sulfidic (magnetite-reducing) zone (assumption: magnetite dissolution sets in at depths of 0.2-0.8 $\mathrm{m}$ and is completed $0.2 \mathrm{~m}$ deeper).

\subsection{GEM Shark design and operation}

As outlined in the previous chapters, the sensor's ground distance is confined to $20 \mathrm{~cm}$ and must be maintained at a precision of $\sim 1-2 \mathrm{~cm}$. For a moving, continuously profiling system, such narrow tolerance in distance control can only be achieved with a bottom contact platform with excellent hydrodynamic and gliding properties, rigidity and sufficient inert mass. The platform has to tolerate a tow line drag of up to 3 tons (load of rupture), withstand abrasive ground friction and endure collisions with such obstacles as boulders, plant and mussel cover, fishing gear and human waste. It must protect the enclosed sensors and other electronic components from shock and silting up, while allowing free passage of the ambient bottom water. All structural parts have to be non-conductive and non-magnetic, hence non-metallic, in order not to bias or perturb the primary and secondary EM fields. To enable a wide range of coastal to open ocean survey concepts, the system should be operational with various ship classes ( $\sim 10$ to $100 \mathrm{~m}$ size), winches and cranes. Real-time communication is of vital importance in permanently controlling the platform's motion (heading, water depth, roll and pitch, ground contact) and the quality of the acquired EM and hydrographic data. 
The design of the GEM Shark EM profiler (Figure 2-8 and Table 2) accounts for all the above requirements. The streamlined hull consists of two symmetric epoxy fiberglass/Kevlar shells with openings in front and stern providing a continuous flow-through of ambient water. A tapered concrete ram bow clears obstacles, absorbs shocks and compensates the upward pull of the tow line. Three PVC skids (a central of $2.8 \mathrm{~m}$ and two lateral of $0.8 \mathrm{~m}$ length) provide a steady course (typically $\left.\pm 1^{\circ}\right)$ and low pitch $\left( \pm 2^{\circ}\right)$ and roll $\left( \pm 1^{\circ}\right)$ angles. A stable dive, soft landing is achieved by adjusting winch slack to ship speed. A stable ground contact (zero pitch) can be maintained at tow speeds of 2-4 knots. The tow cable length is dynamically adjusted to about 3.5 times water depth. In the case of a collision with large obstacles, a break point at the bow releases the tow cable. Subsequently, the sled can be recovered by a trailed Kevlar safety line with head buoy.

Table 2. Technical specifications of GEM Shark profiler

\begin{tabular}{|l|l|}
\hline Total dimensions & $\begin{array}{l}\text { Length: } 3.2 \mathrm{~m} \text {, width: } 1.2 \mathrm{~m}, \\
\text { height: } 0.6 \mathrm{~m} \text { (without fin) }\end{array}$ \\
\hline Total weight & $420 \mathrm{~kg}$ (in air), $120 \mathrm{~kg}$ (in water) \\
\hline Transmitter moment & $61 \mathrm{Am}^{2}$ peak $(48 \mathrm{~V} / 21 \mathrm{~A})$ \\
\hline Power & $24 \mathrm{VDC}$ (deep sea battery with $40 \mathrm{Ah})$ \\
\hline Tow speed & $2-4$ knots \\
\hline Tow cable length & 3.5 times water depth $\left(20^{\circ}\right.$ tow angle $)$ \\
\hline Sampling rate & EM $(25 \mathrm{~Hz})$, CTD $(1 \mathrm{~Hz})$, motion $(5 \mathrm{~Hz})$ \\
\hline Mission duration & $8 \mathrm{~h}\left(61 \mathrm{Am}^{2}\right), 12 \mathrm{~h}\left(43 \mathrm{Am}{ }^{2}\right)$ \\
\hline
\end{tabular}

The original GEM-3 sensor had to be adapted to underwater operation. Coils were wound onto a massive, pressure-resistant carrier disk and enclosed in a circular oil-filled PVC casing. All electronic units (GEM-3 console, embedded PC, DSL link, Aositilt pitch and roll sensor with tilt-compensated 3-axial magnetometer) were installed in a semi-evacuated Vitrovex glass benthos sphere with five Subconn connectors. EM sensor, Seabird SBE 16 CTD, deep- 
sea battery, and pressure housing were attached to the hull via transverse, rubber-damped fiberglass profiles, keeping the distance between sensor head and electronics $1.2 \mathrm{~m}$ apart. High-speed data transmission (192 kbit/s to $2.3 \mathrm{Mbit} / \mathrm{s})$ between profiler and tow ship was realized by using standard $11 \mathrm{~mm}$ armored coax-cable and a Westermo SHDSL extender for 10/100BaseTX (Ethernet) networks .

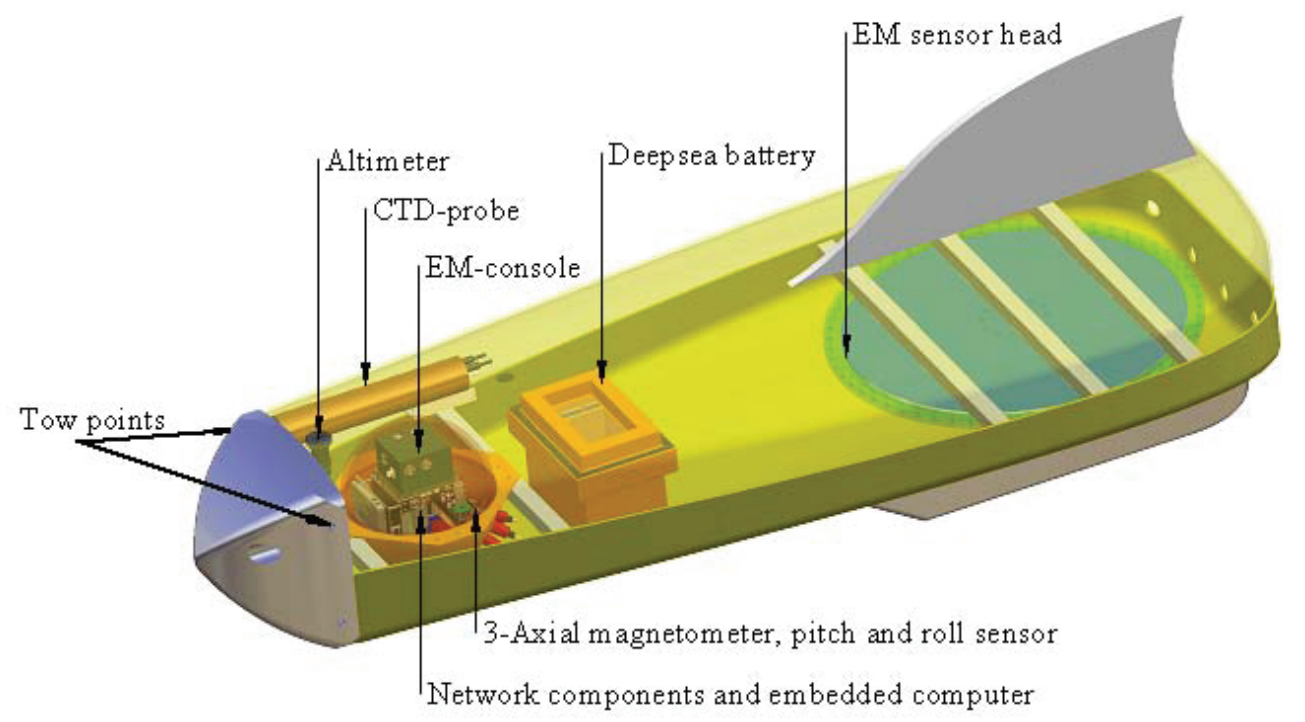

Figure 2-8. Virtual 3D view of GEM Shark profiler (lid shown transparent).

In-phase and quadrature component of the secondary EM field are recorded at a sampling rate of $25 \mathrm{~Hz}$ for each of the frequencies in use $(75,175,525,1025$ and $4775 \mathrm{~Hz}$ in examples). GEM-3, CTD and motion sensor are synchronized by the GPS time pulse (delay $<100 \mu \mathrm{s}$ ), that is provided via the high speed Ethernet link from the ship. The position of the sled is determined from its heading and horizontal layback relative to the tow ship's DGPS position. All measurement, navigation and system status data are graphically and numerically displayed in real time by means of a specific Labview-based control software.

During post-processing, the hydrographic and navigation data are interpolated and resampled to the GEM-3 clock. EM sensor intrinsic noise is filtered by applying a $5 \mathrm{~Hz}$ lowpass filter to in-phase and quadrature data. CTD conductivity is used to measure and correct bucking offset 
(zeroing) and drift of the EM sensor when the sled is descending or ascending through the water column before and after each profile. The corrected EM data are converted to electric conductivity (4775 Hz quadrature) and magnetic susceptibility (75 Hz in-phase) with a lookup table method based on the receiver function (equation 2). The conductivity signal was used to subtract its potential contribution to the in-phase signal prior to susceptibility calculation.

\subsection{Applications in coastal and shelf research}

As practical examples for CSEM surveying in coastal and shelf research, we present here some summarized results of our first marine surveys with GEM Shark. Ground truthing of the EM system was performed by correlation with core material during first trials in the Ría de Vigo, a NW Iberian estuary, in 2007. Shelf data were collected off NW Iberia in 2008. The first example addresses sediment distribution in transition regions of mud, siliceous sands and glauconite sands across a $30 \mathrm{~km}$ wide section of the NW Iberian shelf in water depths of 50 $270 \mathrm{~m}$. The second example from the same region takes a close-up at a $10 \mathrm{~km}$ wide bottomcurrent induced sand wave field on the outer shelf and investigates the relations of bedform morphology and sediment composition. A pilot study on sediment and scrap metal distribution in the Galician Riá der Vigo (Rey et al. 2008) and a further, very detailed survey of groundwater seeps in Eckernförde Bay, western Baltic Sea, (Müller et al., subm.) were separately published.

\subsubsection{Ground truthing}

As a means of ground truthing the first measured in-situ data, we compared porosity and susceptibility values measured by EM profiling and piston coring over a range of sandy to muddy sediments in the Ría de Vigo (Figure 2-9). Core lengths of 20 to $40 \mathrm{~cm}$ were taken with a piston corer and subsampled at $2 \mathrm{~cm}$ intervals into $6.2 \mathrm{~cm}^{2}$ plastic cubes. Sediment porosity was determined both from EM conductivity using Archie's law (equation 5) and 
from weight loss during the drying of the samples. Sediment susceptibility was measured with a Agico Kappa Bridge laboratory susceptometer. Downcore data were averaged with the respective weighting functions (Figure 2-5a, b) in order to correspond to the EM data.
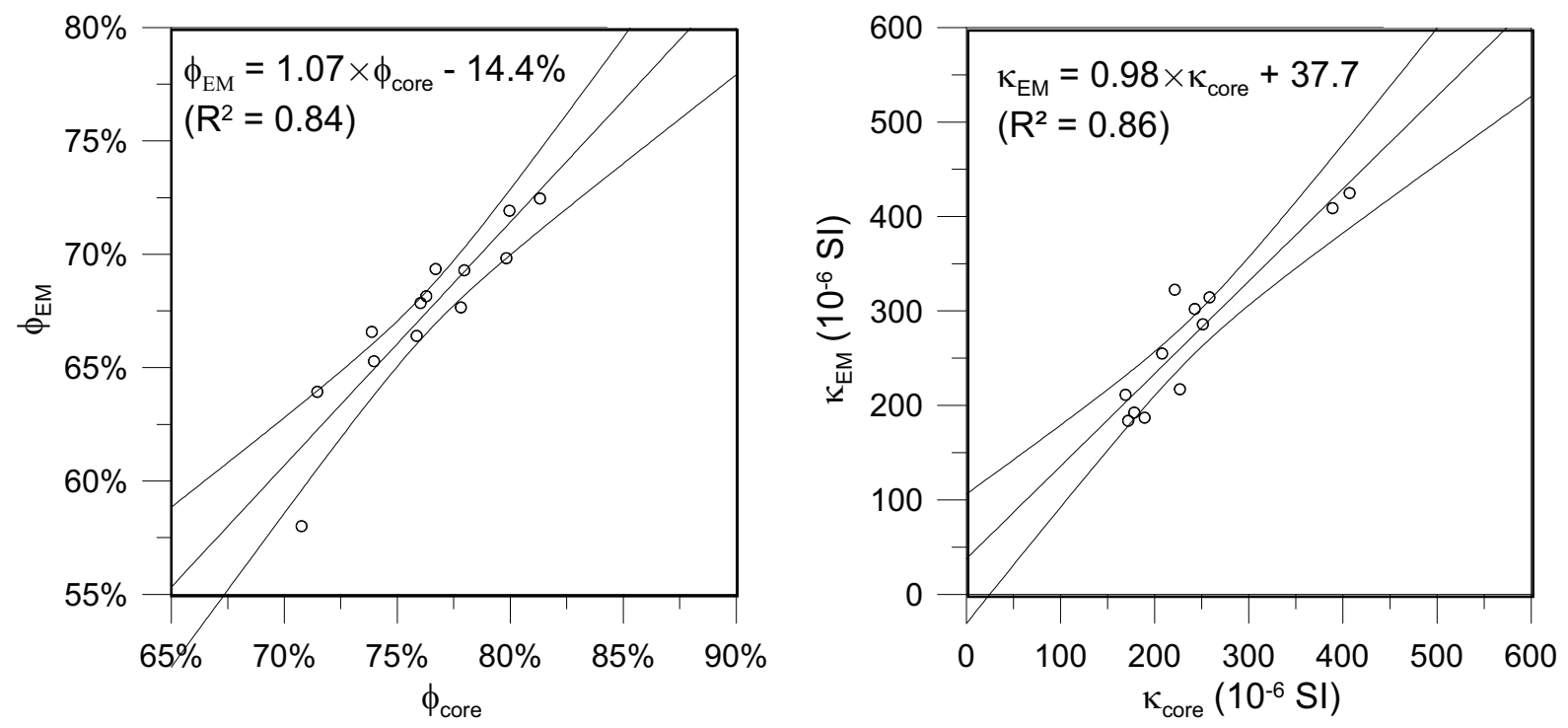

Figure 2-9. Correlation of EM and sediment core porosity and magnetic susceptibility.

The apparent porosity and susceptibility values measured closest to the locations of the cores are in good agreement with the core values (Figure 2-9). Deviation from the linear regression curve is in the order of $1.0 \%\left(24 \times 10^{-6} \mathrm{SI}\right)$, i.e. well within the limits of analytics. A linear slope close to one demonstrates the reliability of EM derived susceptibility. Offsets of the regression curves are reasonably explained by imprecision of the sensor's elevation above ground. It is likely that the skids of the profiler carve a few centimeters into softer sediments. This would explain why some EM porosities appear lower and susceptibility38 $\times 10^{-6} \mathrm{SI}$ higher than predicted by the core material. In a future modification of the system, the sensor's elevation above ground will be controlled by a suitable device.

\subsubsection{Sediment distribution on shelves}

The NW Iberian platform (Figure 2-10b,c) is a high energy, low accumulation non-glaciated shelf of generally narrow width $(25$ to $50 \mathrm{~km})$ and a large variety of surface sediment types and patterns (Dias et al., 2002a ,b; Lantzsch et al., 2009). EM surveying in this area had the 
objective to classify the facies and textures of the near-surface sediments and to map their distribution at meter-scale spatial resolution with a special focus on transitional effects.

Four major sediment facies were defined from cored material (Odin and Lamboy, 1988; Lantzsch et al., submitted):

(1) The mud facies comprises fine-grained, mostly muddy Holocene high-stand sediments originating mainly from the Duoro and Minho rivers and deposited in two coast-parallel mud belts of $\sim 50 \mathrm{~km}$ length, 2-3 km width at water depths of 110-120 m (Figure 2-10c) by northward currents. (Mohamed et al., in press);

(2) The mixed sand facies consists of relict and reworked siliceous and carbonaceous sands deposited at moderate hydrodynamic regimes (Lantzsch et al., submitted);

(3) The glaucony facies consists of mostly relict, late Miocene (5-6 Ma) sands containing up to $50 \%$ paramagnetic glaucony (Odin and Lamboy, 1988). This facies is indicative of slow to arrested sediment accumulation on the outer shelf;

(4) The gravel facies is dominated by shell fragments and coarse silicates (Odin and Lamboy, 1988) and represents low-stand shoreface and storm deposits.

Sediment composition of the upper slope varies with supplied material, local hydrodynamic conditions and morphology. In particular, re-suspended sediments from the mud patches are believed to be carried off the shelf when storm events coincide with downwelling conditions (Dias et al., 2002a). However, more than $70 \%$ of the modern sediments supplied to the Iberian margin are stored on the shelf (Jouanneau et al., 2002).

During RV Poseidon cruise P366/3, the GEM Shark profiler surveyed the Galician shelf on more than $300 \mathrm{~km}$ total profile length during 11 successful 5-7 hour dives. The Galician mud belt was crossed at $41^{\circ} 45^{\prime} \mathrm{N}$ and $42^{\circ} 10^{\prime} \mathrm{N}$ by the two WE-oriented EM profiles (Figure 
2-10a,d), which are shown in compilation with the depth and salinity logs of the internal CTD and coincident boomer profiles collected by Hanebuth et al. (2007).

The boomer sections of the northern and southern profile (Figure 2-10a,d) depict the modern Galician mud belt as an up to $6 \mathrm{~m}$ thick stratified Holocene mud lens deposited on top of older transgressive sand deposits (Rey, 1993). In the EM profiles, the mud-belt is represented by concurrent, slightly asymmetric susceptibility and porosity highs. Confinement of mud and sand is most distinct in the southern profile (Figure 2-10d), where the shapes of susceptibility and porosity profiles closely reflect the distribution of silt and clay described by Dias et al. (2002b). Apparent magnetic susceptibility rises westward from 520 to 630 and back to $300 \times 10^{-6} \mathrm{SI}$; apparent porosity rises from $59 \%$ to $63 \%$ and back to $53 \%$ along this track.

The northern profile (Figure 2-10a) is more complex as it contains several sediment facies and bedforms, shelf break and upper slope. Apparent magnetic susceptibility increases from $490 \times 10^{-6} \mathrm{SI}$ at $\mathrm{km} 1$ to $640 \times 10^{-6} \mathrm{SI}$ at $\mathrm{km} 6$ of the profile and slightly decays to a local minimum at $580 \times 10^{-6} \mathrm{SI}$ at $\mathrm{km} 6.8$ while apparent porosity rises from $58 \%$ in the east to $61 \%$ at $\mathrm{km} 5.2$ and returns to $52 \%$ at $\mathrm{km} 7$. This structure corresponds to the mud belt as shown by acoustics and suggested by Dias et al. (2002b) based on high silt and clay contents.

At water depths between 130 and $165 \mathrm{~m}(\mathrm{~km} 7$ to 19), the profile transects a mega ripple (sediment wave) field documented by undulations in bathymetry as well as in susceptibility and porosity (see also the following section). Although the mean susceptibility of $660 \times 10^{-6} \mathrm{SI}$ in this section is as high as on the mud belt, a joint interpretation with relatively low porosity of about $46 \%$ clearly indicates poorly sorted glaucony sands (Figure $2-11$ ). A material change to weakly magnetic, well sorted siliclastic sands occurs west of km 19 in 160 to $175 \mathrm{~m}$ water depth. This section represents the shelf break, where a boundary current system causes strong to gradual winnowing of the fine fraction. The adjacent upper slope $(\mathrm{km} \mathrm{26-} \mathrm{;} \mathrm{>205} \mathrm{m} \mathrm{water}$ depth) is characterized by a fining of the sediments and less saline bottom water. 
Cross-plots of sediment and matrix susceptibility against porosity demonstrate the lithostratigraphic potential of EM sediment classification (Figure 2-11). The joint interpretation of both EM parameters allows distinct separation of the main structural elements given by the mud, glaucony and sand facies as well as reworked and thereby magnetically reduced slope deposits. Transitional environments between the sediment units cover several hundreds of meters within the profiles and are discriminative for facies end-members in the cross-plots.

\subsubsection{Bedforms}

The EM measurements of the northern profile (Figure 2-10a) cross the axis of long wavelength sediment waves (1-3 km in length, 0.5-2 $\mathrm{m}$ height) on the outer Galician shelf. As visible in the detailed section (Figure 2-12), local minima in porosity and maxima in magnetic susceptibility are co-located with local topographic highs. Porosity is $8-12 \%$ lower than near the two easternmost ridges. The morphology of these ridges is almost symmetric although porosity shows steeper slopes at the eastern flanks. Comparable sand wave structures form by slope currents or internal waves where crests are oriented perpendicular to the main current direction (Hulscher, 1996). A ridge normal current will result in coarser grained and well sorted sediments on the upstream flank (e.g., Smith, 1969; Swift et al., 1978) and fine grained material on the downstream flank unless the winnowed sediments are transported out of the region. The asymmetry of the porosity indicates a westward current, which corresponds to storm driven downwelling in this area (Dias et al., 2002a). The magnetic susceptibility signal generally mirrors the porosity undulation. This finding is contrary to the relations of porosity, susceptibility and grain-size observed in the southern profile (Figure 2-11d) and indicates that glaucony concentration is enhanced on the crests of higher current energy.

The general structure of the major sediment waves is overlain by ridges of smaller wavelength and amplitude, showing a complex pattern of local deposition (preferably on western flanks: 
$11.8 \mathrm{~km}$ ) and erosion. The relationship among morphology, porosity and susceptibility terminates below $145 \mathrm{~m}$ water depth in the western part of the section.

a)

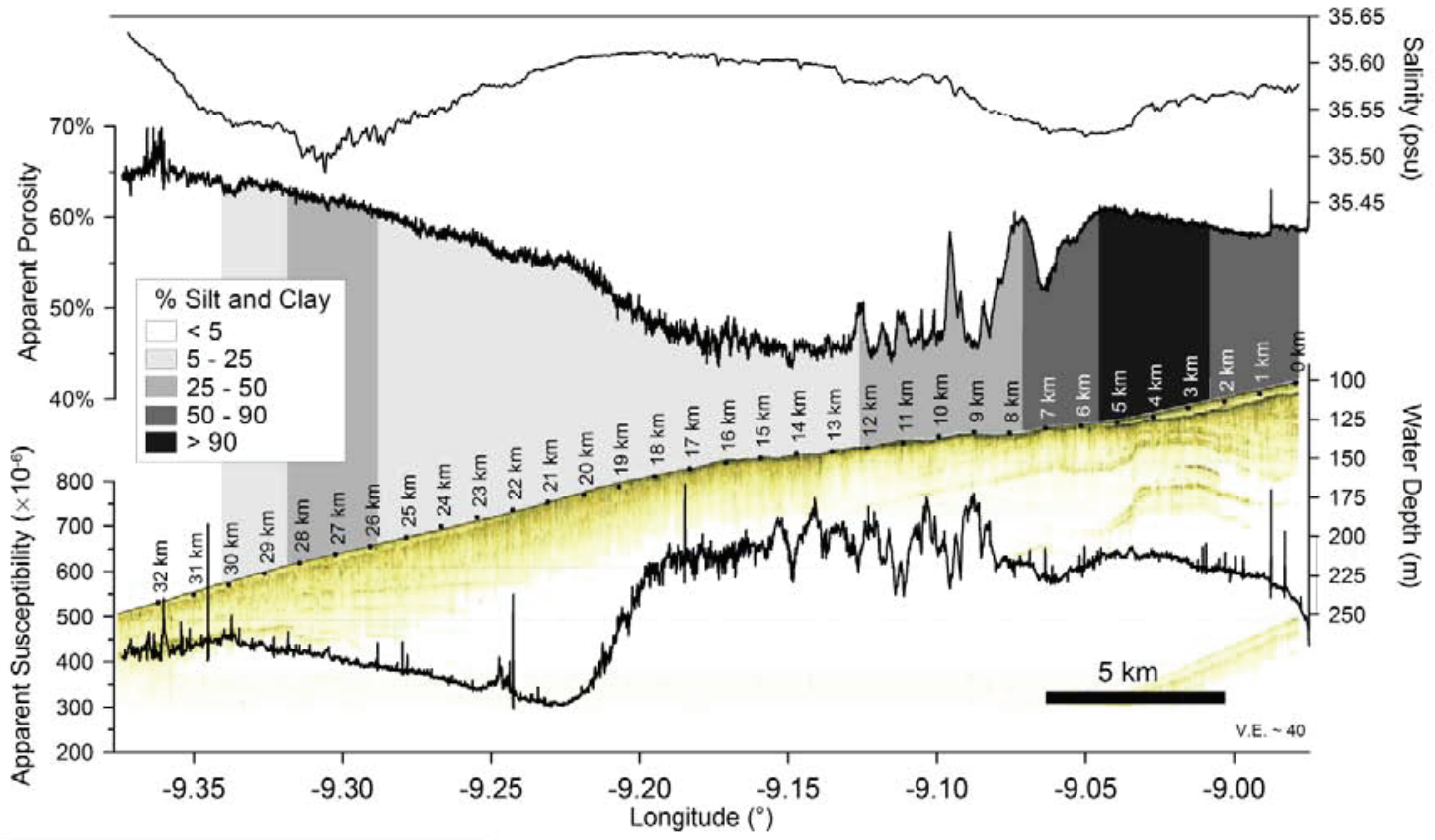

b)

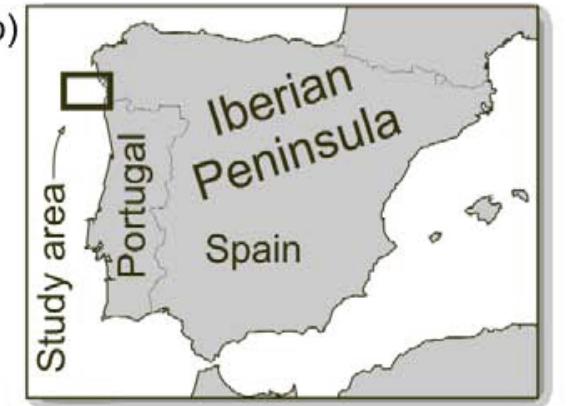

c)

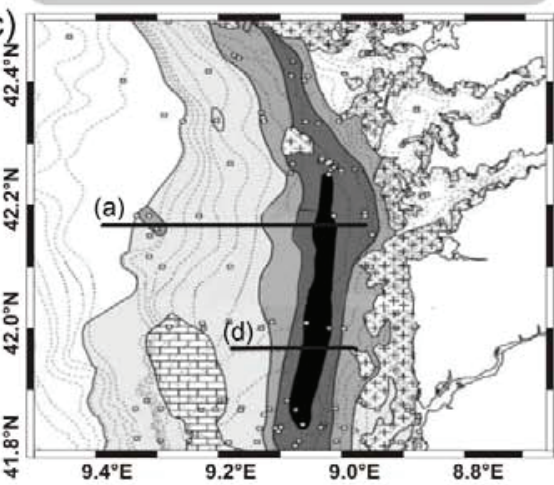

d)

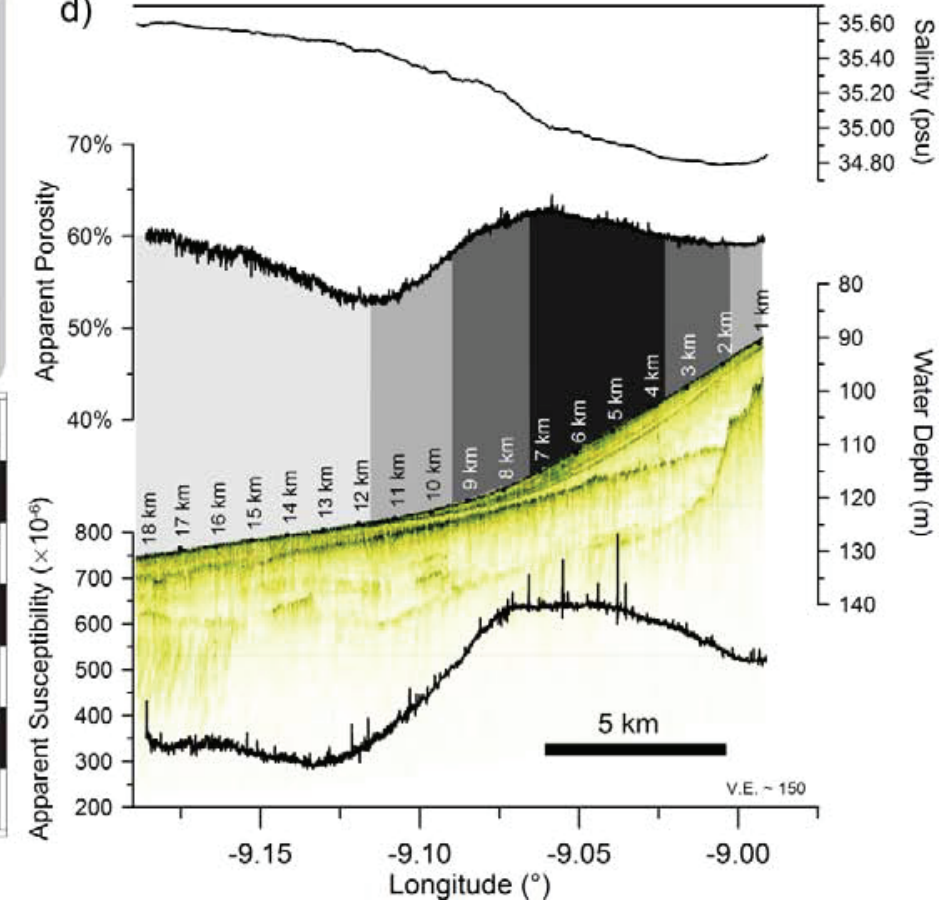

Figure 2-10. GEM Shark profiles GeoB 130124 and 130106 on the NW Iberian Shelf. Figures a) and d) show CSEM based porosity and magnetic susceptibility profiles in combination with CTD depth and salinity transects. Acoustic boomer profiles delineate mud belt extension and bathymetry. Background colors show the core based sediment classification based on the silt and clay distribution map (Figure c) according to Dias et al. (2002b). 

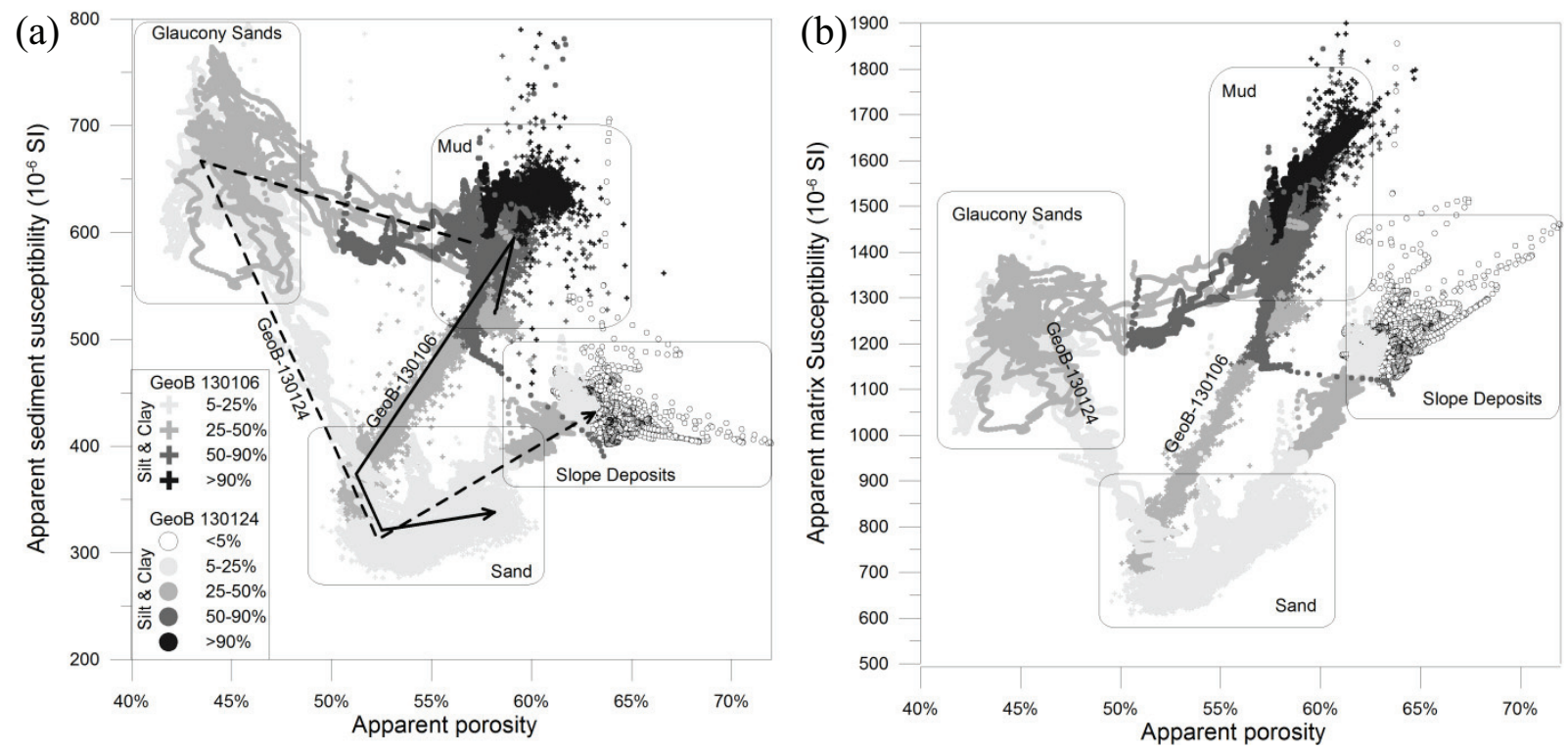

Figure 2-11. Main sediment facies (clusters) and transition zones (tracks) of GEM Shark profiles GeoB 130124 and 130106 visualized by combining susceptibility and conductivity data. Biplots of (a) sediment and (b) matrix susceptibility against porosity show the decisive influence of grain size and compaction state on susceptibility.

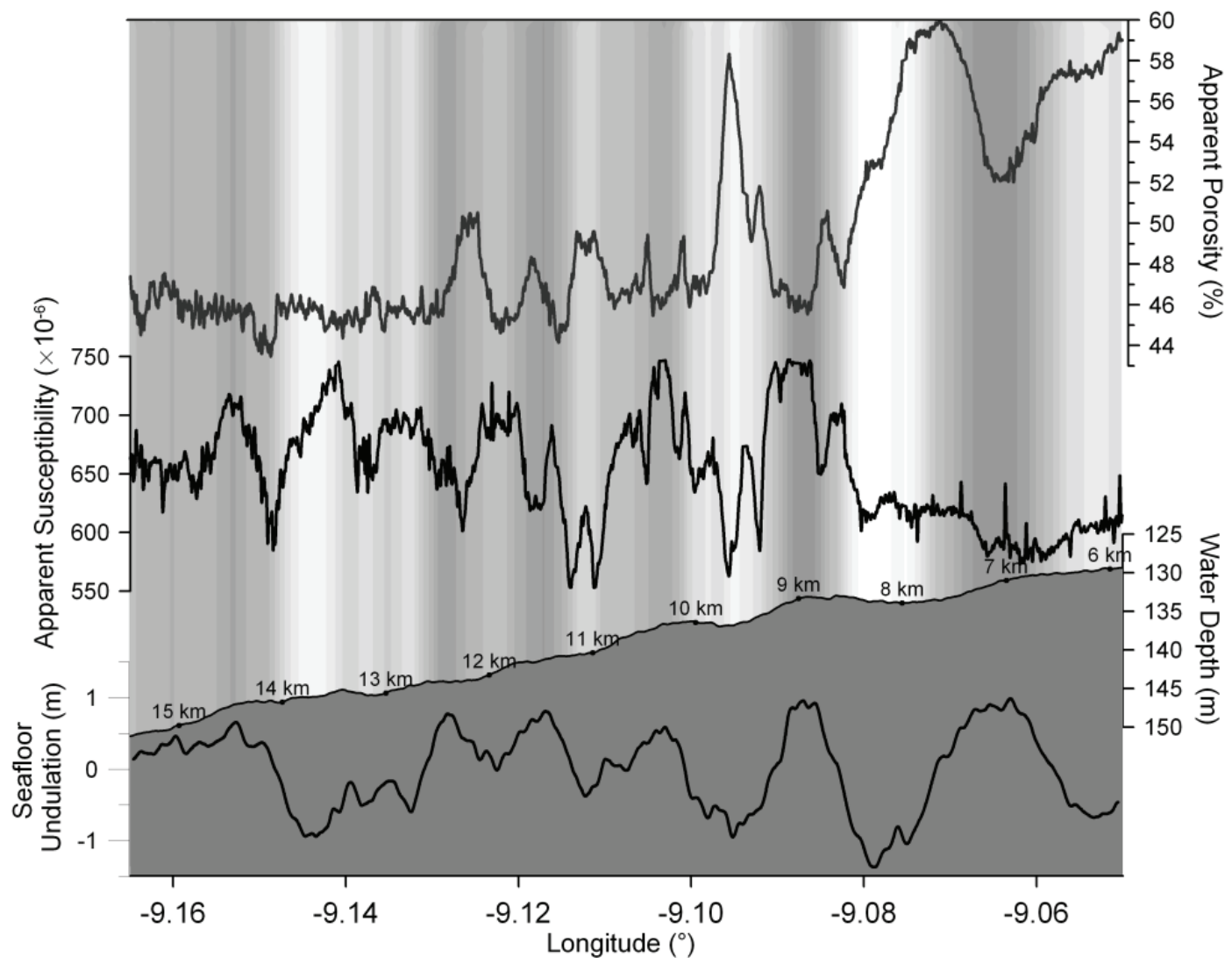

Figure 2-12. Sediment wave section of the northern profile (Figure 2-11a). The seafloor undulation parameter is derived by high pass filtering ( $3 \mathrm{~km}$ cut off) bathymetry and gives background colors (dark: crest, bright: valley). 


\subsection{Conclusions and summary}

Our theoretical and practical investigations demonstrate that Controlled Source Electromagnetic Imaging can be successfully applied for submarine in-situ mapping of sediment electric conductivity and magnetic susceptibility. All presently available data sets show excellent suitability to classify types, provenance, grain-size and redox state of marine sediments and to assess climatic, hydrodynamic, diagenetic and anthropogenic patterns of shelf and coastal sedimentary deposits. The two physical properties derived from marine electromagnetics differ fundamentally insofar as electric conductivity relates to the fluid-filled pore space and magnetic susceptibility to the solid sediment matrix. Electric conductivity is controlled by pore water salinity, porosity, and temperature, while magnetic susceptibility depends on ferro-, para- and diamagnetic mineral content.

Both parameters can be derived from combined frequency CSEM soundings with the commercial broadband coincident coil sensor GEM-3 (Geophex) when accounting for the following major constraints:

(1) Bottom-water conductivity has to be measured by an oceanographic CTD;

(2) Magnetic susceptibility must be derived from the low frequency $(<100 \mathrm{~Hz})$ in-phase component of the secondary EM field in order to avoid a conductivity related bias in the magnetic signal;

(3) Electric conductivity can be derived from the quadrature component of the secondary field at higher frequencies $(1-10 \mathrm{kHz})$;

(4) Ground clearance of about $0.2 \mathrm{~m}$ is necessary to provide high resolution measurements and to minimize the bias by the field of the bucking coil in the susceptibility signal;

(5) Sensor drift is compensated by subsequent background measurements where the sensitive volume of the sensor is filled with homogeneous (CTD characterized) water; 
(6) Sensor characteristics must be considered to account for lateral and vertical seafloor heterogeneity.

The sensor's characteristic spatial sensitivity has been investigated by theoretical models to determine the vertical penetration and horizontal footprint. The resulting weighting functions can be convolved with available core-based conductivity and susceptibility data to validate the in-situ measurements. In the vertical perspective, $90 \%$ of the magnetic signal is related to the top $48 \mathrm{~cm}$ and the $5 \mathrm{kHz}$ (quadrature) electric conductivity is related to the top $71 \mathrm{~cm}$ of the seafloor. The conductivity derived from the in-phase component of the secondary field provides a depth penetration of up to $9 \mathrm{~m}$ but has a lower $\mathrm{S} / \mathrm{N}$ ratio. The sensitive volumes of susceptibility, in-phase and quadrature conductivity differ more in the lateral than in the vertical dimension due to the different shapes of the magnetic and electric primary fields.

Based on a conceptual study, the new bottom-towed marine EM profiler GEM Shark was developed. This sled carries the GEM-3 sensor, CTD, battery power, navigation sensors and an embedded PC and provides real-time communication over standard coaxial tow cables via industrial Ethernet / DSL technology. Sizes, arrangement and operation frequencies of the EM sensor coils were optimized for synchronous magnetic susceptibility and electric conductivity measurement of the near-surface sediment. GEM Shark reaches thereby lateral sub-meter resolution at sampling rates of 25 samples per second and tow speeds of 3-4 knots.

Exemplary data from surveys on the NW Iberian coast and shelf demonstrate the discriminative potential, the robustness and the capability of the system to map sediment physical properties in shallow $(0-50 \mathrm{~m})$ and deeper water $(50-300 \mathrm{~m})$ operations. It is shown, that a joint interpretation of magnetic and electric parameters evades the ambiguity of interpreting each parameter individually. Susceptibility vs. porosity cross-plots of two exemplary shelf profiles identify the main sedimentary units and transitional phases. Detailed information on small scale features or bedforms (e.g. sand waves) can be easily studied by detailed 
examination of the meter-scale resolution profiles of susceptibility and conductivity, porosity in combination with CTD-based hydrographic bottom-water profiles.

The system can be further improved by measuring and correcting small variations in the EM sensor's ground elevation, by depth inversion of frequency and phase dependent conductivity data and by inversion of susceptibility data measured with two or more transmitter diameters. The results of this study strongly suggest to combine lateral EM surveying with acoustic and hydrographic surveying, to concentrate seafloor coring on EM defined centers of sedimentary units and to use EM mapping to understand the heterogeneity, the dynamics and the pollution of marine sedimentary deposits.

\subsection{References}

Anderson, W. L., 1979, Numerical integration of related Hankel transforms of orders 0 and 1 by adaptive digital filtering: Geophysics, 44, 1287-1305.

Archie, G. E., 1942, The electrical resistivity log as an aid in determining some reservoir characteristics: Journal of Petroleum Technology, 5, 1-8.

Benech, C., and E. Marmet, 1999, Optimum Depth of Investigation and Conductivity Response Rejection of the Different Electromagnetic Devices Measuring Apparent Magnetic Susceptibility: Archaeological Prospection, 6, 31-45.

Booth, C. A., J. Walden, A. Neal, and J. P. Smith, 2005, Use of mineral magnetic concentration data as a particle size proxy: A case study using marine, estuarine and fluvial sediments in the Carmarthen Bay area, South Wales, U.K.: Science of the Total Environment, 347, 241-253.

Buselli, G., 1982, The effect of near-surface superparamagnetic material on electromagnetic measurements: Geophysics, 47, 1315-1324.

Chave, A. D., S. C. Constable, R. N. Edwards, 1991, Electrical Exploration Methods for the Seafloor. In M.N. Nabighian, ed., Electromagnetic Methods Vol. 2: Applications: Society of Exploration Geophysicists, 931-966.

Cheesman, S. J., R. N. Edwards, and A. D. Chave, 1987, On the theory of seafloor conductivity mapping using transient electromagnetic systems: Geophysics, 52, 204-217.

Collinson, D. W., 1983, Methods in Rock Magnetism and Palaeomagnetism: Chapman Hall. 
De Meijer, R. J., I. C. Tánczos, and C. Stapel, 1996, Radiometry as a technique for use in coastal research. in M. de Batist, P. Jacobs, eds., From Geology of Siliciclastic Shelf Seas: Geological Society Special Publication 117, 289-297.

Dearing, J. A., R. J. L. Dann, K. Hay, J. A. Lees, P. J. Loveland, B. A. Maher and K. O'Grady, 1996, Frequencydependent susceptibility measurements of environmental materials: Geophysical Journal International, 124, 228-240

Dias, J. M. A., J. M. Jouanneau, R. Gonzalez, M. F. Araújo, T. Drago, C. Garcia, A. Oliveira, A. Rodrigues, J. Vitorino, and O. Weber, 2002a, Present day sedimentary processes on the northern Iberian shelf: Progress in Oceanography, 52 (2-4): 249-259.

Dias, J. M. A., R. Gonzalez, C. Garcia, and V. Diaz-del-Rio, 2002b, Sediment distribution patterns on the Galicia-Minho continental shelf: Progress in Oceanography, 52 (2-4), 215-231.

Edwards, R. N., 2005, Marine Controlled Source Electromagnetics: Principles, Methodologies, Future Commercial Applications: Surveys in Geophysics, 26, 675-700.

Ellwood, B. B., W. L. Balsam, and H. H. Roberts, 2006, Gulf of Mexico sediment sources and sediment transport trends from magnetic susceptibility measurements of surface samples: Marine Geology, 230, 237-248.

Emiroglu S., N. Petersen, and D. Rey, 2004, Magnetic properties of sediment in the Ría de Arousa (Spain): Dissolution of iron oxides and formation of iron sulphides: Physics and Chemistry of the Earth, 29, 947959.

Evans, R. L., 2001, Measuring the shallow porosity structure of sediments on the continental shelf: A comparison of an electromagnetic approach with cores and acoustic backscatter: Journal of Geophysical Research, 106, 27047-27060.

Evans, R. L., 2007, Using CSEM techniques to map the shallow section of seafloor: From the coastline to the edges of the continental slope: Geophysics, 72 (2): WA105-WA116.

Funk, J. A., T. von Dobeneck, and A. Reitz, 2004, Integrated Rock Magnetic and Geochemical Quantification of Redoxomorphic Iron Mineral Diagenesis in Late Quaternary Sediments from the Equatorial Atlantic, in G. Wefer, S. Mulitza, and V. Ratmeyer, eds., The South Atlantic in The Late Quaternary: Reconstruction of Material Budgets and Current Systems: Springer Verlag, 237-260.

Gay, S. P., 2004, Glacial Till: A Troublesome Source of Near-Surface Magnetic Anomalies: The Leading Edge, 23, $542-547$.

Hanebuth, T., V. Bender, S. Bujan, M. Elvert, T. Frederichs, B. Kockisch, S. Krastel-Gudegast, H. Lantzsch, Á. Mena Rodríguez, F. Schmidt, F. Strozyk, and M. Wagner Friedrichs, 2007, Report and first results of the Poseidon cruise P342 GALIOMAR, Vigo-Lisboa (Portugal), Distribution pattern, residence times and export of sediments on the Pleistocene/Holocene Galician Shelf (NW Iberian Peninsula): Berichte, Fachbereich Geowissenschaften, University of Bremen 255.

Huang, H., and I. J. Won, 2003, Detecting metal objects in magnetic environments using a broadband electromagnetic method: Geophysics, 68, 1877-1887. 
Hulscher, S. J. M. H., 1996, Tidal induced large-scale regular bed form patterns in a three-dimensional shallow water model: Journal of Geophysical Research, 101, 20727-20744.

Lantzsch, H., T. Hanebuth, and V. B. Bender, 2009, Holocene evolution of mud depocentres on a high-energy, low-accumulation shelf (NW Iberia): Quaternary Research, 72 (3), 325-336.

Lantzsch, H., T. Hanebuth, and R. Henrich, (submitted), Reconfiguration of a high-energy, low-accumulation sedimentary shelf system since the Last Glacial Maximum (NW Iberia): Continental Shelf Research.

Liu, G., and A. Becker, 1990, Two-dimensional mapping of sea ice keels with airborne electromagnetics: Geophysics, 55, 239-248.

Manoj, C., A. Kuvshinov, S. Maus, and H. Lühr, 2006, Ocean circulation generated magnetic signals: Earth Planets Space, 58, 429-437.

Mohamed, K., D. Rey, B. Rubio, F. Vilas, and T. Frederichs, 2009, Interplay between detrital and diagenetic processes since the LGM on the NW Iberian continental shelf: Quaternary Research, in press.

Odin, G. S., and M. Lamboy, 1988, Glaucony from the Margin off Northwestern Spain. in G.S. Odin, ed., Green Marine Clays. Developments in Sedimentology 45: Elsevier, 249-275.

Rey Salgado, J., 1993, Relación morfosedimentaria entre la plataforma continental de Galicia y las Rías Bajas y su evolución durante el Cuaternario: Publicaciones Especiales, Instituto Español de Oceanografía 17, 1233.

Rey D., K. J. Mohamed, A. Bernabeu, B. Rubio, and F. Vilas, 2005, Early diagenesis of magnetic minerals in marine transitional environments: Geochemical signatures of hydrodynamic forcing: Marine Geology, 215, 215-236.

Rey, D., H. Müller, B. Rubio, T. von Dobeneck, F. Vilas, C. Hilgenfeldt, T. Frederichs, A. Bernabeu, S. Fernandez, K. J. Mohamed, and Grupo GEOMA, 2008, Using electromagnetic sensors to estimate physical properties and environmental quality of surface sediments in the marine environment. Preliminary results: Geotemas, 10, 651-654.

Smith, J. D., 1969, Geomorphology of a sand ridge: Journal of Geology, 77, 39-55.

Swift, D. J. P., and G. L. Freeland, 1978, Current lineations and sand waves on the inner shelf, Middle Atlantic Bight of North America: Journal of Sedimentary Petrology, 48, 1257-1266.

Tribovillard, N., O. Averbuch, A. Bialkowski, and J. F. Deconinck, 2002, Early diagenesis of marine organicmatter and magnetic properties of sedimentary rocks: the role of iron limitation and organic-matter source organisms: Bulletin de la Societe Geologique de France, 173 (4): 295-306.

van Wijngaarden, M., L. B. Venema, and R. J. De Meijer, 2002, Radiometric sand mud characterisation in the Rhine-Meuse Estuary Part B. In situ mapping. Geomorphology 43, 103-116.

Ward, S. H., and G. W. Hohmann, 1988, Electromagnetic theory for geophysical applications, in M. N. Nabighian, ed., Electromagnetic methods in applied geophysics: Society of Exploration Geophysicists, $130-311$. 
Won, I. J., D. A. Keiswetter, G. R. A. Fields, and L. C. Sutton, 1996, GEM-2: A new multifrequency electromagnetic sensor: Journal of Environmental and Engineering Geophysics, 1 (2), 129-138.

Won, I. J., D. A. Keiswetter, D. R. Hanson, E. Novikova, and T. M. Hall, 1997, GEM-3: A Monostatic Broadband Electromagnetic Induction Sensor: Journal of Environmental and Engineering Geophysics, 2 (1), 53-64.

Won, I. J., and H. Huang, 2004, Magnetometers and electro-magnetometers: The Leading Edge, 23, 448-451.

Zhang, Z., and D. W. Oldenburg, 1997, Recovering magnetic susceptibility from electromagnetic data over a one-dimensional earth: Geophysical Journal International, 130, 422-434.

Zhang, W., L. Yu, and S. M. Hutchinson, 2001, Diagenesis of magnetic minerals in the intertidal sediments of the Yangtze Estuary, China, and its environmental significance. Science of the Total Environment, 266, $160-175$. 


\section{Near-surface electromagnetic, rock magnetic and geochemical fingerprinting of submarine freshwater seepage at Eckernförde Bay (SW Baltic Sea)}

Hendrik Müller $^{1}$, Tilo von Dobeneck ${ }^{1}$, Wiebke Nehmiz ${ }^{2}$, Kay Hamer ${ }^{1}$

(1) Fachbereich Geowissenschaften, Universität Bremen, Klagenfurter Strasse, 28359 Bremen, Germany

(2) FILAX Gesellschaft für Wissenschaftliche Datenverarbeitung mbH, 27568 Bremerhaven, Germany

Manuscript for submission to Geo-Marine Letters Springer Berlin / Heidelberg 


\subsection{Introduction}

Freshwater seepage from terrestrial aquifers contributes significantly to the mass exchange of coastal seas. Especially inlets with minor river input such as the Eckernförde Bay (Northern Germany, SW Baltic Sea) study area can receive $40 \%$ or more of their freshwater influx from submarine groundwater discharge (Moore 1996; Schlüter et al. 2004). Beside water balance and chemistry, sedimentary redox states and element cycles are strongly influenced by freshwater advection or chemical reactions coupled to the recirculation of seawater through a coastal aquifer system (Burnett et al. 2001).

On shore, aerogeophysical methods, especially Helicopter EM (HEM), are comprehensively used to map aquifer structures, delineation of soil and groundwater salinization, salt-water intrusion into coastal aquifers and the geology of northern German coastal areas (e.g. Siemon 2006; Steuer et al. 2007; BurVal Working Group 2006). However, off shore mapping of the spatial patterns of submarine freshwater expulsion is mainly the domain of acoustic methods. Focused fluid flow through the seabed produces characteristic geomorphologic expressions such as pockmarks, distorted stratification, impedance contrasts and backscatter effects (Hovland 2003; Jensen et al. 2002). Ground truthing is typically performed with schlieren optics (Karpen et al. 2004), benthic habitat mapping, in-situ seepage-meters and pore water sampling and analysis (Burnett et al. 2006). These techniques are restricted to sites with favorable geological and hydrological conditions.

Hoefel and Evans (2001) could demonstrate that electromagnetic (EM) induction methods are also suitable to image sub-seafloor freshwater seeps and aquifers due to their much lower salinity and electric conductivity $\sigma$. The complex response of a sedimentary half-space to an electromagnetic (EM) field is composed of an out-of-phase (or quadrature) signal representing electric pore water conductivity $\sigma$ and an in-phase signal driven by the magnetic permeability 
$\mu$ (or magnetic susceptibility $\kappa$ with $\kappa=\mu-1$ ) of the sedimentary matrix. At very low operating frequencies $f(\sim 25-100 \mathrm{~Hz})$, the contribution of conductivity to this in-phase signal can be neglected (Won and Huang 2004; Farquharson et al. 2003). Controlled source electromagnetic sounding allows the separation of magnetic and electric signal components from the low- and high-frequency parts of a single multi-frequency EM measurement at high sensitivity.

In rocks and sediments, the magnetic susceptibility $\kappa$ is primarily controlled by their content of strongly (ferri-)magnetic oxic and sulfidic iron mineral phases such as (titano-)magnetite $\left(\mathrm{Fe}_{3-\mathrm{x}} \mathrm{Ti}_{\mathrm{x}} \mathrm{O}_{4}\right)$ and greigite $\left(\mathrm{Fe}_{3} \mathrm{~S}_{4}\right)$ (Thompson et al. 1980; Verosub and Roberts 1995). Such 'magnetic minerals' are unique in owing themselves as well to rapid rock magnetic bulk sediment analytics with paleomagnetic laboratory equipment as to various magnetic distance detection methods used in geophysical ore exploration.

The magnetic petrology of marine deposits is indicative of sediment provenance, grain-size and redox state, and often mirrors climatic, hydrodynamic and/or anthropogenic influences (Ellwood et al. 2006; Rey et al. 2005; Emiroglu et al. 2004; Zhang et al. 2001; Funk et al. 2004; Tribovillard et al. 2002). Depletion of redox-sensitive iron oxides under reducing, especially sulfidic conditions is a widely observed early diagenetic phenomenon. Ti-poor magnetite and at slower pace hematite $\left(\mathrm{Fe}_{2} \mathrm{O}_{3}\right)$ dissolve under sub- and anaerobic, in particular under sulfidic conditions (Dillon and Bleil 2006) to reprecipitate either as weakly paramagnetic $\left(\mathrm{FeS}, \mathrm{FeS}_{2}\right)$ or as strongly ferrimagnetic $\left(\mathrm{Fe}_{3} \mathrm{~S}_{4}, \mathrm{Fe}_{7} \mathrm{~S}_{8}, \mathrm{Fe}_{9} \mathrm{~S}_{11}\right)$ iron sulfides (Rowan and Roberts 2006; Fu et al. 2008). Magnetic enhancement and depletion by remineralization has therefore been identified as a tracer of hydrothermal venting (Tivey and Johnson 2002) and methane accumulation in sediments (Housen and Musgrave 1996; Novosel et al. 2005). However, little is known a magnetic mineral alterations and related susceptibility changes caused by submarine groundwater discharge and their potential detectability by geophysical methods. 
Conventional laboratory alternating field susceptometers do not operate properly in a highly conductive seawater environment (Benech and Marmet 1999; Müller 2009). Passive marine Overhauser or Cesium magnetometers require relatively sharp lateral magnetization contrasts and cannot resolve the subtle magnetic anomalies of hydrogeologically altered Holocene subsurface sediments from the more prominent background signals created by heterogeneous deeper glacial strata or the crystalline basement (Gay 2004).

To overcome these technical problems, a new bottom-towed marine EM profiler GEM Shark carrying the commercial multi-frequency sensor GEM-3 was developed in co-operation of the MARUM Center for Marine Environmental Sciences at the University of Bremen and the Marine and Environmental Geology Group (MARGO) at the University of Vigo (Rey et al. 2008; Müller 2009). Sizes, arrangement and operation frequencies of the EM sensor coils were optimized for synchronous magnetic susceptibility and electric conductivity measurement of the near-surface sediment ( $90 \%$ signal from 0-50 $\mathrm{cm}$ subbottom depth). GEM Shark reaches lateral sub-meter resolution at sampling rates of 25 samples per second and tow speeds of 3-4 knots both in shallow (0-50 m) and deep water $(50-500 \mathrm{~m})$ operation.

The Eckernförde Bay case study has been conducted in a previously well-studied cold seep area with numerous characteristic pockmark structures. Besides high-resolution EM profiling and sampling, detailed rock magnetic and geochemical analyses of near-surface sediments were performed to validate the sea-floor measurements, expand them by analytical geochemical and rock magnetic parameters and clarify relevant geological signal formation processes.

Specifically, this study aims to

(1) investigate the impact of focused and diffuse submarine groundwater seepage on porosity, pore water conductivity and magnetic mineralogy of marine surface sediments,

(2) document, how electric conductivity and magnetic susceptibility data can be combined to distinguish and characterize hydraulic and diagenetic regimes, 
(3) test the performance of the novel electromagnetic profiler GEM Shark in a logistically simple, but geologically complex near-shore setting,

(4) and demonstrate the potential of combining high-resolution electromagnetic mapping with detailed environmental magnetic and geochemical laboratory analytics.

\subsection{Working area}

Eckernförde Bay is a $16 \mathrm{~km}$ long and $2-6 \mathrm{~km}$ wide funnel-shaped inlet of glacial origin situated on the east coast of Schleswig-Holstein (Northern Germany) in the southwestern Baltic Sea (Fig. 3-1). Medium-fine to fine sands predominate on the slopes above the wave base at $22 \mathrm{~m}$ water depth, while the center of the 26 to $28 \mathrm{~m}$ deep bay is covered by fine mud with a median grain size of 15 to $20 \mu \mathrm{m}$ and low hydraulic permeabilities of $10^{-13}$ to $10^{-15} \mathrm{~m}^{2}$ (Schlüter et al. 2004). High sedimentation rates of $1.4 \mathrm{~mm} /$ year and organic loading of $4-5 \%$ lead to the formation of anoxic conditions within the topmost centimeters of bottom sediments and of extensive zones of sulfate reduction and methanogenesis in the Holocene mud layer (Whiticar 2002). Several pockmark depressions of 1-2 $\mathrm{m}$ depths with lateral extents of 50-300 $\mathrm{m}$ were identified on the southern bay slope and the 'Mittelgrund', an elongated moraine sill in the center of the bay (Jensen et al. 2002). Sediments within the pockmark structures show low chloride concentrations and gently undulating sediment-water interfaces (Schlüter et al. 2004). Vertical pore water salinity gradients carry non-steady state characteristics indicating episodic freshwater seepage (Whiticar 2002).

The hydrogeologic setting is characterized by two connected aquifers confined in a Miocene lignite sand and a Pleistocene glacio-fluviatile sand horizon embedded between till complexes; the hydrostatic head is 1-2 m above sea level (Marczinek and Piotrowski 2002). Heavy rain falls as well as strong westerly offshore winds can trigger episodic groundwater outflow by overbalancing the hydraulic state of the aquifers (Smith et al. 2008), while tides 
are negligible in the Baltic Sea. The interplay of fluid seepage and bottom currents are considered responsible for the formation and preservation of the pockmarks (Whiticar and Werner 2002; Harrington 1985; Schlüter et al. 2004). Due to long flow paths from its southern sources, the groundwater arrives in a highly reduced chemical state (Marczinek and Piotrowski 2002). The intermixing of the groundwater and the brackish seawater of the SW Baltic Sea (mean chloride concentration of $12 \%$, up to $14 \%$, Whiticar 2002) is assumed to occur close to the sediment-water interface. Deep-towed CTD profiling in a previous study (Schlüter et al. 2004), however could not find freshwater plumes in the water column.

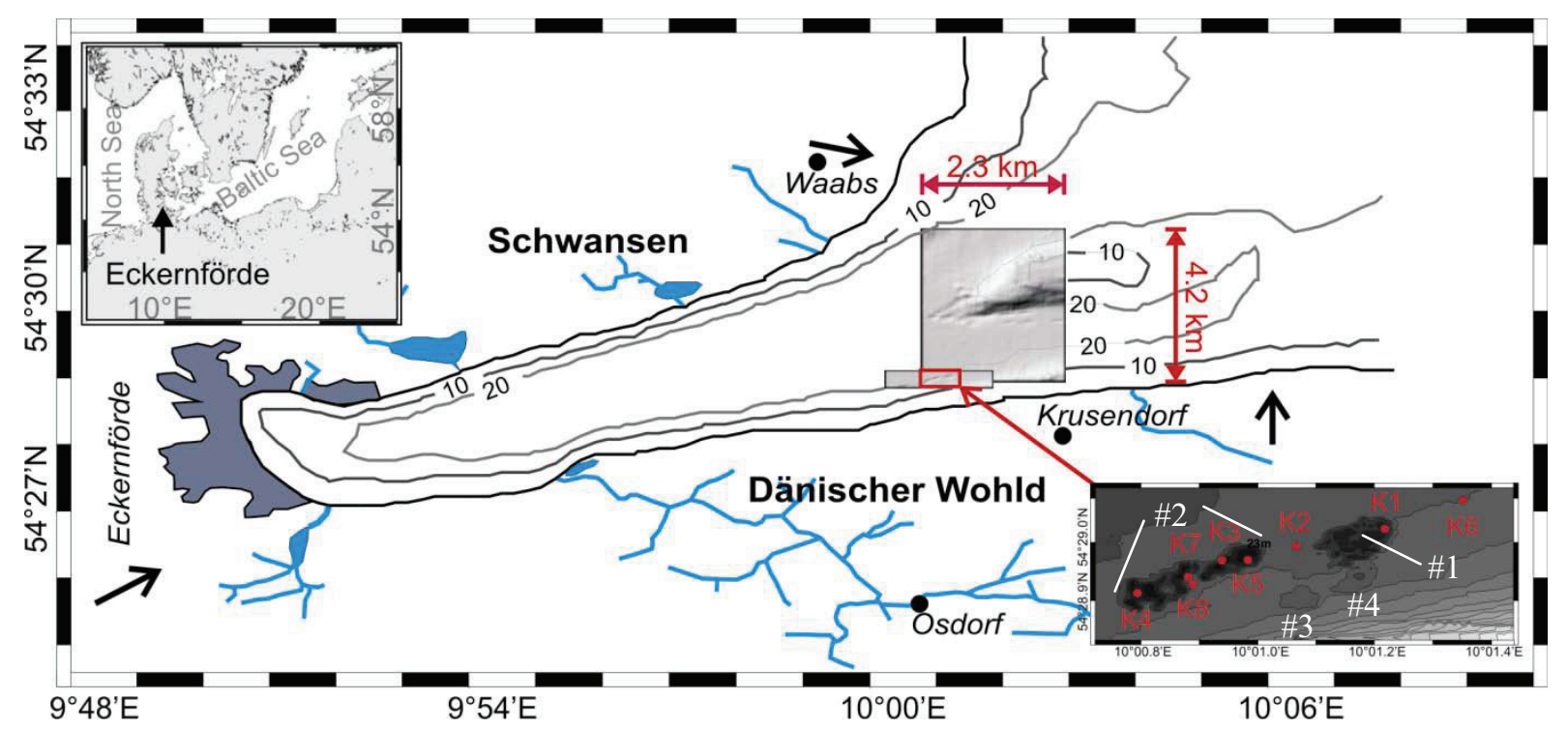

Fig. 3-1. Map of the Eckernförde Bay with $10 \mathrm{~m}$ and $20 \mathrm{~m}$ isobaths and more detailed bathymetries of the 'Mittelgrund' and southern bay slope freshwater seepage area (shaded relief maps). Freshwater feeders (blue lines) and groundwater flow directions (black arrows) were drawn according to Marczinek and Piotrowski (2002). The close-up at lower right depicts the bathymetry of the study area with core locations K1-K8 and major pockmarks (pockmark \#1 around core K1 and pockmark \#2 around cores K3-5, K7-8). Two smaller and shallower depressions \#3 and \#4 are located south of core K2 and pockmark \#1.

\subsection{Materials and methods}

Three dedicated sampling and survey campaigns with RB Polarfuchs (IFM-GEOMAR, Kiel) were performed in the summers of 2006 and 2008. A first survey in May 2006 was addressed to hydroacoustic and magnetic mapping of two known pockmarks areas (Jensen et al. 2002) 
along the Mittelgrund (50 $\mathrm{m}$ spaced NS profiles and $250 \mathrm{~m}$ spaced EW tie-lines within a $4.2 \mathrm{~km} \times 2.3 \mathrm{~km}$ area) and the southern bay slope $(25 \mathrm{~m}$ spaced EW profile-lines and $125 \mathrm{~m}$ spaced NS tie-lines covering an area of $1.2 \mathrm{~km} \times 0.4 \mathrm{~km}$ ). Sediment samples were taken in the southern working area during a second campaign in August 2006 (Nehmiz 2007). Electromagnetic and hydrographic surveys with the new bottom-towed profiler GEM Shark were performed within three days in July 2008. Two overlapping grids in a $1.4 \mathrm{~km} \times 0.5 \mathrm{~km}$ plot were covered with $25 \mathrm{EW}$ profiles of $20 \mathrm{~m}$ line spacing and 4 unequally spaced NS tielines at typical tow speeds of 2 to 3.5 knots.

\section{Hydroacoustic and magnetic surveys}

Hydroacoustic and marine magnetic surveys were performed in the same area to establish a high-resolution bathymetry of the Holocene mud drape and underlying glacial substratum. A $10 \mathrm{kHz}$ SyQuest StrataBox ${ }^{\mathrm{TM}}$ acoustic Sub-Bottom Profiler was towed in an unmanned nonmagnetic zodiac with DGPS positioning at 100-120 m distance behind RB Polarfuchs. A GEM systems GSM-19 marine Overhauser magnetometer was alternatively (1) mounted in the zodiac, (2) towed at ca. $4 \mathrm{~m}$ above ground or (3) bottom-towed on a nonmagnetic sledge. In modes (2) and (3), magnetometer and zodiac had identically adjusted laybacks permitting to determine the position and depth of the magnetometer from the DGPS and echosounder on the zodiac.

Seafloor and sub-bottom reflector depths were picked from the Sub-Bottom Profiler sections and gridded with a Geosoft Oasis Montaj 7.1 Minimum Curvature algorithm. Magnetic data were corrected for diurnal drift with a shore-based Proton magnetometer station, resampled at $1 \mathrm{~m}$ spacing, bandpass filtered in the periodicity range of $30-4000 \mathrm{~m}$, leveled and inverted to apparent subsurface magnetizations using the method of Hussenoeder et al. (1995). 


\section{Electromagnetic and hydrographic surveys}

The application of Controlled Source Electromagnetics (CSEM) in shallow marine studies is relatively new and has been restricted to the detection of metallic objects such as unknown ordnance by Won and Huang (2004). We used their Geophex GEM-3 broadband, frequency domain electromagnetic induction sensor (Won et al. 1997) in a submarine modification where the concentric and coplanar transmitter coil $(\varnothing 96 \mathrm{~cm})$, bucking coil $(\varnothing 53 \mathrm{~cm})$ and receiver coil (Ø $30 \mathrm{~cm}$ ) were wound into an oil-filled PVC casing (Müller 2009). The bucking coil compensates the direct signal of the transmitter coil at the position of the receiver coil in order to exclusively record the weak secondary electromagnetic fields of the currents induced to the conductive seawater and seafloor surroundings (quadrature signal) and the induced magnetizations of magnetic subsurface minerals and objects (in-phase signal).

The GEM-3 sensor was mounted into the custom-built non-magnetic and non-conductive GEM Shark fiberglass sled (Fig. 3-2). Positioned at a distance of $20 \mathrm{~cm}$ above the seafloor, the sensitivity of the sensor decays exponentially with sub-bottom depth such that $90 \%$ signal integrates over the uppermost $50 \mathrm{~cm}$. The sled is further equipped with two CTDs, an internal Seabird SBE 16 and external Sea\&Sun CTD 48 (0.75 m above ground), electronic compass, roll and pitch motion sensors, embedded PC and lead-battery power supply. Real-time data transmission to the tow boat was realized by DSL network telemetry via the armored coax tow cable. The position of GEM Shark was determined with an estimated precision of $5 \mathrm{~m}$ from the tow boat's DGPS position, the horizontal layback and the compass course of the sled. The applied lag distance was verified from reverse control profiles.

The multi-frequency transmitter waveform was created by superimposing frequencies of 75 , 175, 525, 1025 and $4775 \mathrm{~Hz}$ with a pulse-width modulation technique (Won et al. 1997) and amplified to a transmitter current of $21 \mathrm{~A}$. EM data were gathered at $25 \mathrm{~Hz}$ sampling rate and low-pass filtered at $5 \mathrm{~Hz}$ to reduce intrinsic noise. Towed at speeds of 2-3.5 knots, the system 
achieves an effective lateral resolution of ca. 20-35 cm. EM sensor drift was corrected by interpolating between water-column background measurements taken after every second profile.

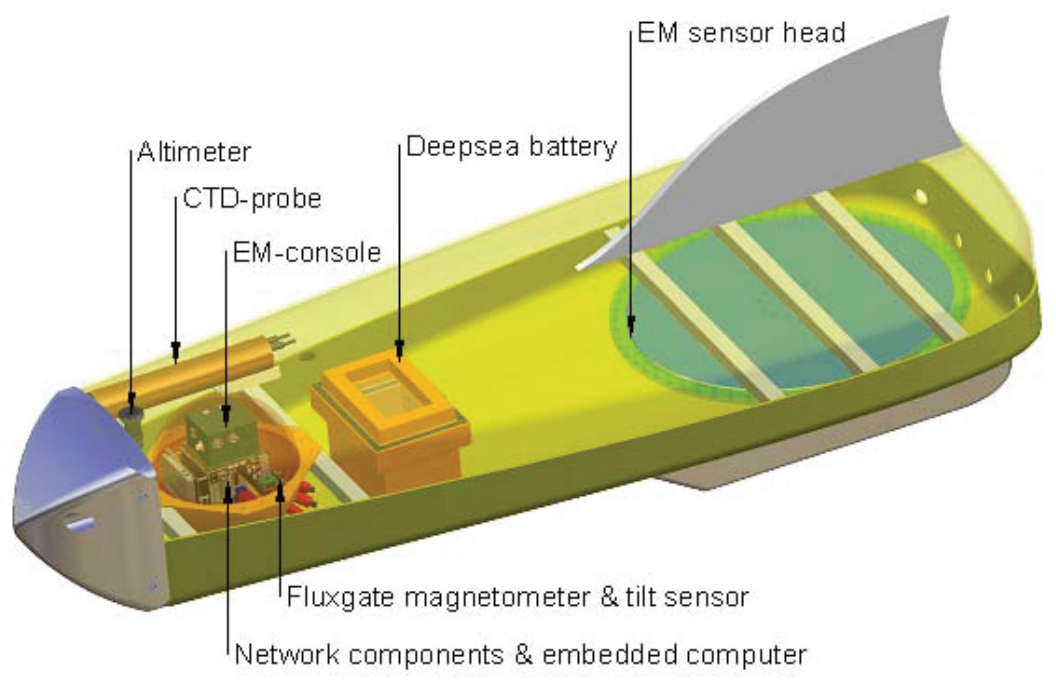

Fig. 3-2. Set-up of the GEM Shark EM profiler. The $3.6 \mathrm{~m}$ long, $1.2 \mathrm{~m}$ wide and $0.6 \mathrm{~m}$ high (fin: $1.0 \mathrm{~m}$ ) high sled consists of two symmetrical fiberglass shells (upper is drawn transparent), a concrete nose, concrete vats with PVC runners and a PVC fin. The concentric coplanar EM coils are located in a solid disc in the back. A spherical glass pressure housing, internal CTD and 24VDC battery are located in the bow of the profiler; seawater flushes through vents in nose and stern.

The electric conductivity and magnetic susceptibility of the subsurface were calculated with a half-space model algorithm (see Müller 2009) based on seawater conductivity data of the internal CTD. Conductivity was determined from the $4775 \mathrm{~Hz}$ quadrature component of the secondary electromagnetic field, susceptibility from the $75 \mathrm{~Hz}$ in-phase component. The subsurface conductivity signal was used to subtract its (minor) contribution to the in-phase signal. $4 \mathrm{~Hz}$ conductivity, temperature and pressure data of the external CTD were used to calculate bottom water salinity and to establish a cm-resolution along-track bathymetry.

\section{Sediment sampling}

Eight gravity cores $\mathrm{K} 1-\mathrm{K} 8$ of 30 to $60 \mathrm{~cm}$ lengths were taken with a Rumohr gravity corer along a transect across the pockmarks \#1 and \#2 of the southern study area (Fig. 3-1 and 
3-3h). The cores were cold-stored $\left(4^{\circ} \mathrm{C}\right)$ and within 24 hours sub-sampled at $2 \mathrm{~cm}$ intervals into $6.2 \mathrm{~cm}^{3}$ plastic cubes for laboratory rock magnetic analytics. The remainder of the sediment was prepared for element and organic carbon analytics. Pore water from the bottom of each core was extracted with rhizone samplers (Seeberg-Elverfeldt et al. 2005) for laboratory salinity determination with a $\operatorname{sen} \operatorname{SION} 5$ conductivity-meter calibrated to $\mathrm{NaCl}$ standards.

146 samples of at least $500 \mathrm{~cm}^{3}$ were collected from the uppermost $5-6 \mathrm{~cm}$ of the seabed with a $25 \mathrm{~cm}$ Van Veen grab sampler on a $25 \mathrm{~m}$ mesh grid covering an area of $270 \mathrm{~m} \times 270 \mathrm{~m}$ around pockmark \#2 (Fig. 3-3h). The specimens were filled into $500 \mathrm{~cm}^{3}$ plastic bottles for bulk magnetic susceptibility measurement using a Bartington MS2C loop sensor, which was calibrated for the specific bottle size with a $\mathrm{MnCl}$ standard. A subset of 15 surface samples covering the NE part of pockmark \#2 and its surroundings were homogenized by stirring and sampled for rock magnetic and geochemical analyses in analogy to the core samples.

\section{Rock magnetic analyses}

Bulk rock magnetic measurements were applied to all gravity cores at $2 \mathrm{~cm}$ intervals and the surface sample subset. Low field magnetic susceptibility $(\kappa)$ was measured with a Bartington MS2D susceptibility meter. Isothermal Remanent Magnetization (IRM) was imparted at 5 incremental steps up to $700 \mathrm{mT}$ peak field in a $2 G$ Enterprises $755 R$ DC SQUID pass-through cryogenic magnetometer. The IRM at this maximum field was considered as Saturation Isothermal Remanent Magnetization (SIRM) and used together with the $300 \mathrm{mT}$ IRM in calculating the Hard Isothermal Remanent Magnetization (HIRM) representing the content in the high-coercive antiferromagnetic minerals hematite and goethite (King and Channel 1991; Bloemendal et al. 1992; Maher and Thompson 1999). In the same instrument, Anhysteretic Remanent Magnetization (ARM) was imparted in a $100 \mathrm{mT}$ AF field and $40 \mu \mathrm{T}$ DC biasing field and subsequently AF demagnetized in 11 steps to determine its Median Destructive Field 
(MDF). ARM is used as concentration indicator of sub-micron magnetite (Thomson and Oldfield 1986; King et al. 1982; Oldfield and Yu 1994). The ARM/SIRM ratio quantifies the relative concentration of the clay-size single domain (SD) fraction and is widely used for magnetic granulometry (Evans and Heller 2003). The SIRM/ $/$ ratio is also used in magnetic granulometry, but focuses more on grain-size variations of the silt-size multi domain (MD). The $\mathrm{S}_{0.3 \mathrm{~T}}$ ratio given by the equation $\mathrm{S}_{0.3 \mathrm{~T}}=\mathrm{IRM}_{0.3 \mathrm{~T}} / \mathrm{SIRM}$ measures variations in the relative content in high- and low-coercive minerals in a range of 0-1 (King and Channel 1991; Maher and Thompson 1999).

Magnetic hysteresis and backfield measurements at $300 \mathrm{mT}$ peak field were performed with a PMC M2900 Alternating Gradient Force Magnetometer to determine saturation magnetization $\mathrm{M}_{\mathrm{s}}$, remanent saturation magnetization $\mathrm{M}_{\mathrm{rs}}$, coercive force $\mathrm{B}_{\mathrm{c}}$ and remanent coercivity $\mathrm{B}_{\mathrm{cr}}$, all specifying the characteristics of the ferrimagnetic mineral components.

\section{Geochemical analyses}

Element analyses were performed on freeze-dried and finely ground samples of $\sim 3 \mathrm{~g}$ using a SPECTRO XEPOS Energy Dispersive Polarization X-ray Fluorescence Analyzer (EDP-XRF) calibrated to an alluvial mud standard, representative for the sampling area. Total organic carbon (TOC) was quantified on $600 \mathrm{mg}$ subsamples treated twice with $12.5 \% \mathrm{HCl}$ using a LECO CS-200 Carbon/Sulfur Determinator.

\subsection{Results}

\section{Acoustic, hydrographic and electromagnetic profiling}

The survey area in the depth range of 18-25 m encloses the transition from the muddy central basin to the gently inclined (ca. $2^{\circ}$ ) and more sandy southern slope of outer Eckernförde Bay (Fig. 3-3a). The depicted $600 \mathrm{~m} \times 500 \mathrm{~m}$ bathymetric section contains four discrete, morphologically distinct pockmarks \#1 to \#4. Pockmark \#1 in the NE has the structure of a roundish 
trough, a size of $160 \mathrm{~m} \times 95 \mathrm{~m}$ and maximum depth of $2 \mathrm{~m}$ below the surrounding seafloor. Pockmark \#2 in the SW is of elongated, ENE-SWS striking shape, has a size of $340 \mathrm{~m} \times$ $100 \mathrm{~m}$ and maximum relative depth of $1.5 \mathrm{~m}$. Two smaller and shallower $(0.7 \mathrm{~m})$ depressions \#3 and \#4 are located south of pockmark \#1 on the foot of the slope (rise). To give a better idea of the structural details, an expanded WE section of pockmark \#1 is shown in Fig. 3-4a.

Bottom water conductivities given by the external CTD of the EM profiler (Fig. 3-3b) vary by some $2 \%$ between $2.61-2.66 \mathrm{~S} / \mathrm{m}$ and systematically increase with water depth. Several localized highly negative conductivity anomalies of peak values up to $-250 \mathrm{mS} / \mathrm{m}$ were observed especially in the eastern parts of pockmarks \#1 and \#2 (Fig. 3-3b, 3-4b) indicating freshwater admixture by active groundwater seepage. The preferred orientation of the lowconductivity anomalies at the eastern margins of the pockmarks may either result from a groundwater flow from SE or else from a western bottom current.

A high-amplitude acoustic sub-bottom reflector marks the boundary of the Holocene mud drape (Fig. 3-3c) and glacial sand (Fig. 3-3d). The reflector depth could be well determined from the $10 \mathrm{kHz}$ sub-bottom profiles except for the NW corner of the survey area, where acoustic turbidity by free gas limits sound penetration to 2-3 mbsf. The thickness of the Holocene drape averages at 3-4 $\mathrm{m}$ and reaches a maximum of $5 \mathrm{~m}$ in the NW of the survey area (Fig. 3-3c). Inside the pockmarks, the mud layer is considerably thinner $(0.3-1.5 \mathrm{~m}$ as verified by gravity coring) and undulates slightly, while the underlying sand formation bulges up to $3 \mathrm{~m}$ above its surrounding level (Figs. 3-3d, 3-4c). The lateral extent of this 'sand high' in pockmark \#1 follows largely the shape of the depression except for the southern end of the structure. In contrast, sand highs of pockmark \#2 are not as coherent and seem to form a chain of separate subunits, which may correspond to adjacent seeps. As the bulging of the sand reflector is always over-compensated by the thinning of the mud layer, the resulting seafloor relief remains negative. 
The EM-based electric conductivity of the seafloor (Fig. 3-3e, 3-4d) is principally controlled by pore water salinity and temperature as well as by the sediment's (grain-size related) porosity. The background value increases by $30 \%$ from 0.8 to $1.1 \mathrm{~S} / \mathrm{m}$ within the investigated depth range pointing at a fining of the sediment matrix with shore distance. Inside the pockmarks, subsurface conductivity values drop to less than $0.4 \mathrm{~S} / \mathrm{m}$ (Fig. 3-3e). The resistive anomalies of pockmarks \#1 and \#2 strictly follow their morphologies while the signatures of the smaller pockmarks \#3 and \#4 seem more diffuse. A fifth conductivity minimum of confined shape is situated on the sandy lower slope in the SE corner of the survey area. The absence of a pockmark depression related to this potential seep site could result from the absence of a mud cover. The expanded WE section (Fig. 3-4d) illustrates the local character of the subsurface conductivity minima and points to the existence of separate groundwater vents at typical lateral distances of $\sim 10-15 \mathrm{~m}$. The slightly negative value of the easternmost conductivity peak is a processing artifact resulting from the very heterogeneous seawater halfspace.

The EM-based magnetic susceptibility map (Fig. 3-3f) outlines the above described structures surprisingly well by virtue of contrasting magnetic iron mineral contents and an excellent sensitivity of the EM sensor. As a general trend, susceptibility decreases from 160 to $70 \times 10^{-6}$ SI) with shore distance. Numerous small positive point anomalies (spikes) are believed to reflect metallic subsurface contaminants. Sediments inside the pockmarks have up to $50 \%$ lower susceptibilities than the surrounding basin (Fig. 3-3d). The susceptibility minimum of pockmark \#1 is uniform and conforms well to the shape of the bathymetric low, while the anomaly of pockmark \#2 is composed of several smaller and less pronounced minima. The expanded WE section (Fig. 3-4e) shows a general reduction of susceptibility in and around the pockmarks, while internal signal undulations are counter-phased with conductivity suggesting iron precipitation at the vent sites. 
The filtered anomaly pattern detected by deep-towed passive magnetometry (Figs. 3-3g, 3-4f) shows smoother and basically inverted anomaly features. The broad and positive anomalies over the pockmarks should therefore correspond to deeper, more strongly magnetic bodies, which seem to coincide with the observed glacial sand highs, but also with deeper structures.

The magnetic susceptibility map determined from the surface sample measurements (Fig. 3-3h) is strikingly consistent with the electromagnetic image (Fig. 3-3f) both in terms of relative and absolute values. This finding is not self-evident because of the different sediment depths $(0-5 \mathrm{~cm}$ vs. $0-50 \mathrm{~cm})$ represented by both methods. The main distinction of the samplebased from the EM-based map is the total lack of positive spikes (to be explained by the negligible chance of recovering small metallic objects by grab sampling) and the lower spatial resolution (due to the wider sampling grid). Again, susceptibility values within pockmark \#2 are $35-50 \%$ below adjacent areas indicating localized magnetic depletion of the Holocene mud under the influence of anoxic groundwater seepage. 

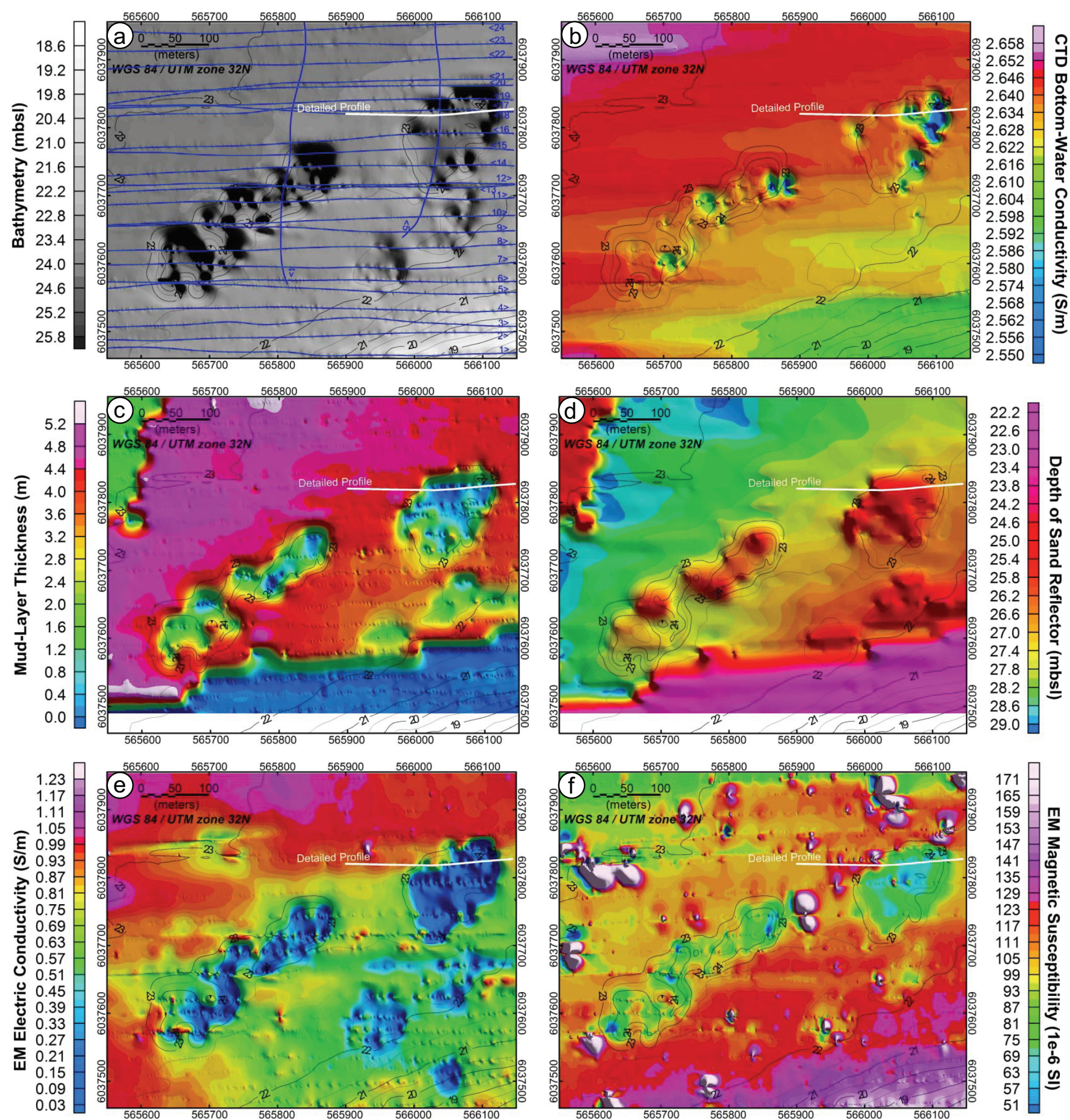

Fig. 3-3a-f. Acoustic, hydrographic and electromagnetic maps of the southern bay slope survey area. All data were gridded with a minimum curvature algorithm and are shown with linear color scales shaded from NE. Bathymetric contour lines with $0.5 \mathrm{~m}$ spacing are overlain for reference; the section of Fig. 3-4a-f is shown as a white line. (a) Bathymetry by CTD pressure data and EM profile lines (blue); (b) Bottom-water electric conductivity measured by GEM Shark's external CTD; (c) Mud layer thickness and (d) sand reflector, both determined from $10 \mathrm{kHz}$ sub-bottom profiles; (e) Apparent electric conductivity and (f) apparent magnetic susceptibility, calculated from the $4.8 \mathrm{kHz}$ quadrature and $75 \mathrm{~Hz}$ in-phase EM signals, respectively. 

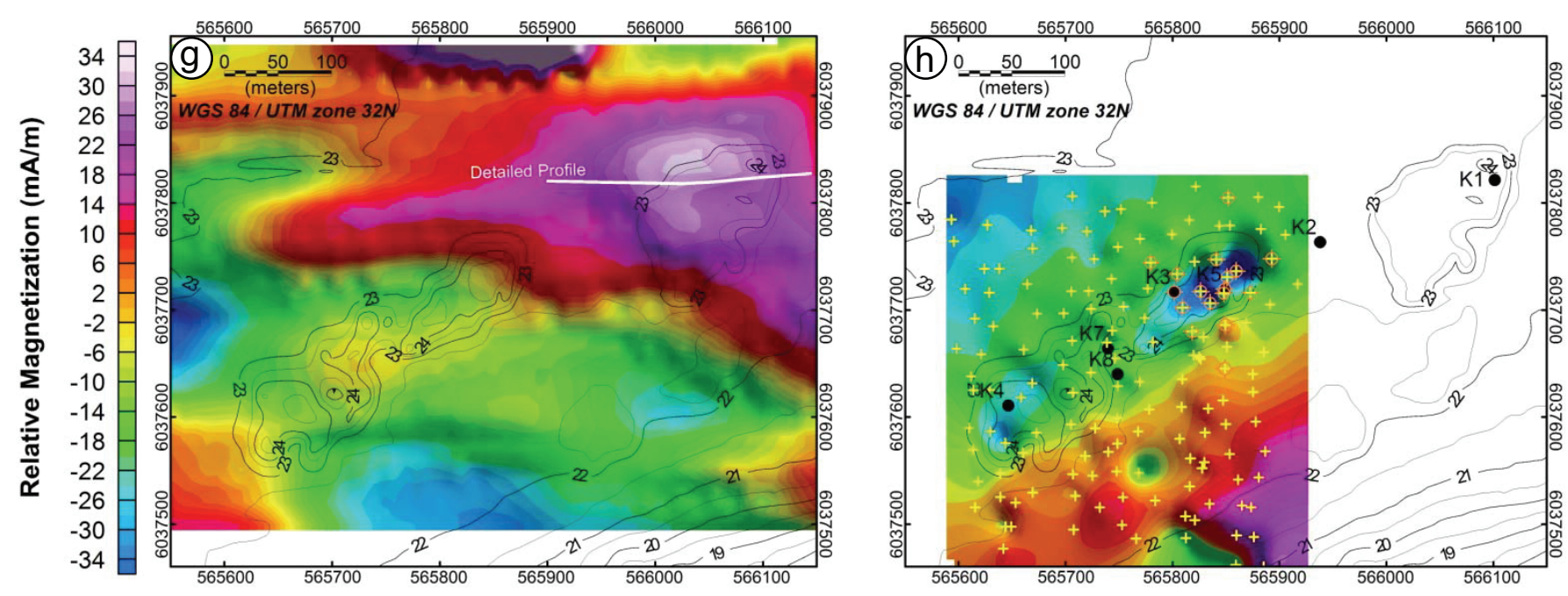

Fig. 3-3g-h. Deep towed passive Overhauser magnetometry and surface sample maps of the survey area. (g) Magnetization of the subsurface related to a virtual layer of $10 \mathrm{~m}$ thickness. (h) Magnetic susceptibility of 146 surface grab samples (yellow crosses). Orange circles subscribe the 17 sample locations taken for detailed rock magnetic and geochemical investigations. Gravity core locations are marked by black dots and labeled from K1 to $\mathrm{K} 8$ (K6 is located NE of K1, out of the map area).

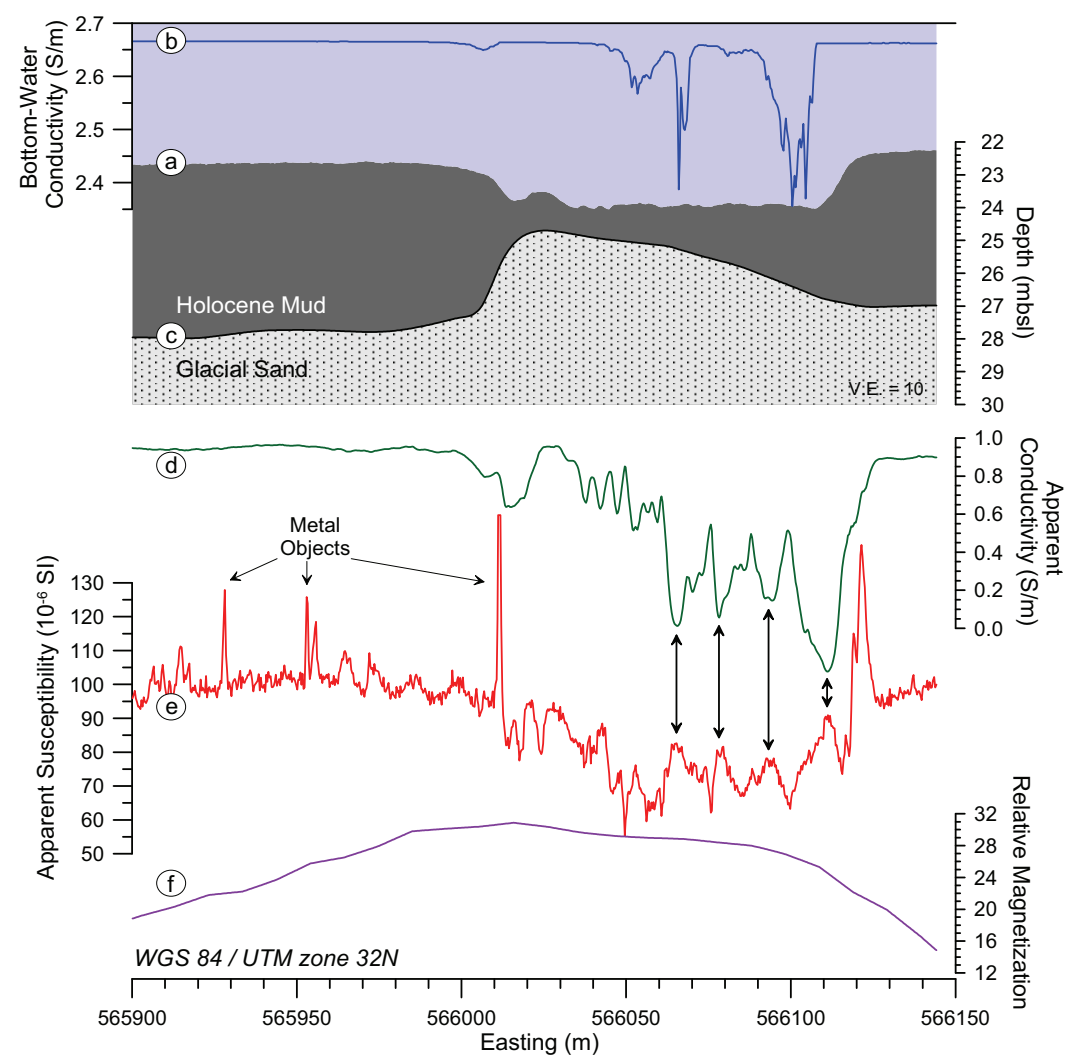

Fig. 3-4. EW-Profile crossing pockmark \#1 (see Fig. 3-3a-g). Bathymetry (a) and bottom-water conductivity (b) are given by the external CTD's pressure and conductivity sensors; the depth of the glacial sand reflector (c) was extracted from the Fig. 3-3d. Apparent electric conductivity (d) and apparent magnetic susceptibility (e) were calculated from EM signals, counter-phase conductivity lows and susceptibility highs are marked by black arrows. Ferromagnetic metal objects clearly peak out from magnetic susceptibility data. The relative subsurface magnetization (f) deduced by numerical inversion from Overhauser magnetometry has a positive anomaly below pockmark \#1 and is therefore inverse to the subsurface susceptibility signal. 


\section{Rock magnetic and geochemical analyses}

In order to interpret the obtained electromagnetic images of freshwater seepage correctly, all the physical and chemical sedimentary processes that contribute to the formation of the EM signal must be clarified. Three previously mentioned hypothetic mechanisms were investigated by detailed laboratory rock-magnetic and geochemical analyses:

(1) reductive depletion of magnetite in and around pockmarks,

(2) iron and magnetic mineral precipitation near groundwater seeps, and

(3) high susceptibility contrasts of Holocene muds and glacial sands,

We present surface samples from a very heterogeneous section of the NE part of pockmark \#2 (Fig. 3-3h) where three pronounced low conductivity spots coincide with susceptibility lows of remarkably different amplitudes (Figs. 3-6a-c), suggesting an interplay of the above effects. Down-core plots (Figs. 3-5c-j) and surface maps (Figs. 3-6a-c, f-i) are derived from selected diagnostic rock magnetic parameters and element contents of the 15 surface samples $(0-5 \mathrm{~cm})$ and 3 cores with distal (K2), proximal (K3) and central (K5) positions with respect to this pockmark. The vertical perspective is more insightful in terms of signal formation processes, while the horizontal depiction clarifies spatial and structural aspects. The downward change of susceptibility and conductivity is also crucial for the volume- and hence depth-integrating EM signal. In mathematical terms, the conductivity and susceptibility values derived by EM profiling correspond to a convolution of the applicable depth characteristic of the sensor and the true vertical distribution of these physical sediment properties.

The design and geometry of the sensor coils entail distinct depth characteristics for quadrature and in-phase (Figs. 3-5a, b) signal components. Assuming a 100\% response at the sedimentwater interphase, the sensitivity for conductivity (or susceptibility, respectively) reduces to $50 \%$ at a depth of $16 \mathrm{~cm}(17 \mathrm{~cm})$ and to $10 \%$ at a depth of $71 \mathrm{~cm}(48 \mathrm{~cm})$. In cumulative terms, the weight-averaged properties of the upper $0-21 \mathrm{~cm}(0-13 \mathrm{~cm})$ correspond to $50 \%$ and 
the upper $0-92 \mathrm{~cm}(0-48 \mathrm{~cm})$ to $90 \%$ of the signal. No significant attenuation or reflection of the electromagnetic signal occurs in the relevant depth windows because of sufficiently low sediment conductivities and operating frequencies ('quasi-static approximation'). As the quadrature characteristic sensitivity changes marginally with frequency at the given sensing geometry, frequency domain depth inversion of the subsurface conductivity is excluded.

Sediment conductivity $\sigma_{\text {sed }}$ as described by Archie's Law (Archie 1942) $\sigma_{\text {sed }}=a \sigma_{\text {water }} \phi^{m}$ (with material constants a, m) is a physical expression of water-saturated sediment porosity $\phi$ and pore water conductivity $\sigma_{\text {water }}$, which itself is controlled by salinity and temperature. Salinity and chloride content of pore water are nearly proportional. Dry bulk $\mathrm{Cl}^{-}$content hence combines vertical porosity and salinity changes (Figs. 3-5c, 3-6a). While the gentle decline of the distal core $\mathrm{K} 2$ can possibly result from compaction alone, the strong curvature of the proximal and even more the central profile are typical results of an interplay of episodic upward freshwater advection vs. steady downward seawater diffusion (Whiticar 2002; Schlüter et al. 2004). Low chloride concentrations near the sediment surface indicate strong and/or recent seepage. From comparison of the quadrature sensitivity and $\mathrm{Cl}^{-}$content curves, we estimate that the EM conductivity signal within the pockmarks integrates over $20-30 \%$ seawater and $70-80 \%$ freshwater saturated sediment which should correspond to a conductivity decline by a factor of 3-5 with regard to the non-infiltrated surroundings. This estimate complies nicely with the here observed EM conductivities of ca. $0.9 \mathrm{~S} / \mathrm{m}$ outside and $0.2-0.5 \mathrm{~S} / \mathrm{m}$ inside the pockmarks (Fig. 3-6a). Supernatant bottom water and core bottom pore water conductivities of all eight investigated gravity cores are compared in Tab. 1. Relative to the uniform bottom water conductivities of 3.63-3.72 S/m, all extracted pore water samples show systematically reduced conductivities at 30-60 cm depth. Pore water salinities decrease with proximity to the center of the pockmarks and reach minimum values of $0.05 \mathrm{~S} / \mathrm{m}$ in the penetrated sand highs. The data suggest that freshwater has infiltrated the entire Holocene mud 
drape of the survey area: by advection inside the pockmarks and by diffusive and advective flow outside the pockmarks. Non-linear $\mathrm{Cl}$ profiles in Fig. 3-5c indicate non-steady state conditions inside pockmarks. Freshwater advection disturbs diffusion processes due to (1) episodically changing hydraulic pressure gradients, (2) seasonally variations of bottom water salinity (Marcinek and Piotrowski 2002) as well as (3) short time, e.g. wind induced, sea-level changes (Whiticar 2002). Focused seepage seems to be indicated by localized conductivity minima of bottom and pore water (Figs. 3-3b, 3-6d) as well as by chloride minima of the surface sediment (Fig. 3-6a).

Tab. 1. Supernatant bottom water and core bottom pore water conductivities of investigated gravity cores.

\begin{tabular}{|c|c|c|c|c|c|c|}
\hline Core & $\begin{array}{c}\text { Position } \\
\text { relative to } \\
\text { pockmark }\end{array}$ & $\begin{array}{c}\text { Water } \\
\text { Depth }[\mathrm{m}]\end{array}$ & $\begin{array}{c}\text { Bottom-Water } \\
\text { Conductivity } \\
{[\mathrm{S} / \mathrm{m}]}\end{array}$ & $\begin{array}{l}\text { Core } \\
\text { Length } \\
{[\mathrm{cm}]}\end{array}$ & $\begin{array}{c}\text { Pore-Water } \\
\text { Conductivity } \\
{[\mathrm{S} / \mathrm{m}]}\end{array}$ & $\begin{array}{c}\text { Conductivity } \\
\text { Decrease over } \\
\text { Core Length }\end{array}$ \\
\hline $\mathrm{K} 1$ & Center & 24.5 & 3.72 & 34 & 0.05 & $99 \%$ \\
\hline $\mathrm{K} 2$ & Distal & 23.2 & 3.71 & 52 & 1.27 & $66 \%$ \\
\hline $\mathrm{K} 3$ & Proximal & 23.0 & 3.72 & 54 & 0.13 & $97 \%$ \\
\hline K4 & Proximal & 24.2 & 3.69 & 50 & 1.47 & $60 \%$ \\
\hline K5 & Central & 24.2 & 3.60 & 50 & 0.06 & $98 \%$ \\
\hline K6 & Distal & 23.0 & 3.77 & 58 & 1.19 & $68 \%$ \\
\hline K7 & Proximal & 23.4 & 3.63 & 60 & 0.13 & $96 \%$ \\
\hline K8 & Proximal & 23.0 & 3.69 & 56 & 0.60 & $84 \%$ \\
\hline
\end{tabular}

In contrast to chloride, the dry bulk iron and sulfur (Figs. 3-5d, e) contents of the distal and proximal cores are almost constant with depth $(0.48$ and $0.53 \mathrm{~mol} / \mathrm{kg}$ for Fe and 0.30 and 0.35 $\mathrm{mol} / \mathrm{kg}$ for $\mathrm{S}$, respectively). The central core has higher contents of $0.70 \mathrm{~mol} / \mathrm{kg} \mathrm{Fe}$ and $0.42 \mathrm{~mol} / \mathrm{kg} \mathrm{S}$ in the Holocene mud and much lower contents of $0.28 \mathrm{~mol} / \mathrm{kg} \mathrm{Fe}$ and $0.21 \mathrm{~mol} / \mathrm{kg} \mathrm{S}$ in the glacial sand. Fe/S ratios of 1.59 for the distal, 1.52 for the proximal and 1.67 (mud) and 1.34 (sand) for the central core show that only some $30-60 \%$ of the iron can occur in a ferrous $\left(\mathrm{Fe}^{2+}\right)$ sulfidic form as pyrite $\left(\mathrm{FeS}_{2}\right)$ or mackinawite $(\mathrm{FeS})$. Additionally, partly ferric $\left(\mathrm{Fe}^{3+}\right)$ oxide, oxyhydroxide or silicate iron minerals should be present, which can serve as electron acceptors for organic carbon remineralization. An increase of Fe content towards the center of the pockmark can be observed (Fig. 3-6b), but these can be associated 
with lateral lithology variations, e.g. finer grain-sizes and higher clay contents in the pock marks. There are no obvious indications of prominent $\mathrm{Fe}$ depletion, mobilization or precipitation by a freshwater source.

The TOC profiles (Fig. 3-5f) are strikingly similar to the Fe and S profiles. The observed mean values of $3.1 \%$ for the distal, $3.9 \%$ for the proximal and $5.4 \%$ (mud) and $0.5 \%$ (sand) for the central core comply with earlier described TOC contents of Eckernförde Bay muds of $4-5 \%$ at $0-200 \mathrm{~cm}$ depth and some $7 \%$ below $200 \mathrm{~cm}$ (Whiticar 2002). Like Fe and S, the TOC content of the surface nearly doubles towards the center of the pockmark (Fig. 3-6c). Following Whiticar's results, this trend could be due to different organic carbon preservation. Organic carbon remineralization requires downward transport of sulfate, nitrate or oxygen, which is inhibited by anoxic freshwater advection from below; only the distal core developed a vertical TOC gradient, an indication of top-down oxidation, not disturbed by advection.

The down-core magnetic susceptibility profiles (Fig. 3-5g) of the distal, proximal and central core show seafloor values of $\sim 95,70$ and $40 \times 10^{-6}$ SI, respectively, i.e. decreasing values with seep distance as EM- and sample-based surface susceptibility plots (Figs. 3-6e, f) imply. In the vertical continuation, the distal core shows a linear susceptibility decrease with depth from 95 down to $35 \times 10^{-6} \mathrm{SI}$, while the proximal core's values fluctuate around their mean of $70 \times 10^{-6} \mathrm{SI}$. The central core shows a more complex succession: After a gentle down-core rise from 40 to $50 \times 10^{-6} \mathrm{SI}$ in the upper $0-30 \mathrm{~cm}$, susceptibility drops to $25 \times 10^{-6} \mathrm{SI}$ just above the $\mathrm{mud} / \mathrm{sand}$ boundary at $43 \mathrm{~cm}$ and rises more than tenfold to a stable level of $\sim 350 \times 10^{-6} \mathrm{SI}$ in the glacial sand facies. Given the sensitivity characteristic of the EM sensor (Fig. 3-5a), 84\% of the EM-based susceptibility signal relates to the weakly magnetic Holocene mud and just $16 \%$ to the strongly magnetic glacial base. As a consequence, the positive contribution of glacial sand to the integral EM-based susceptibility signal is not large enough to reverse the 
negative surface trend, but is reflected in the discrepant susceptibility values of EM and surface sample.

The rock magnetic concentration measure for the coarser magnetite fraction $(>1 \mu \mathrm{m})$ SIRM (not shown) shows nearly the same characteristics as $\kappa$ both in depth and in the plain. Coarse, also not shown, hysteresis ratios of $\mathrm{M}_{\mathrm{rs}} / \mathrm{M}_{\mathrm{s}} \leq 0.1$ and $\mathrm{B}_{\mathrm{cr}} / \mathrm{B}_{\mathrm{c}}$ (Day et al. 1977) emphasize, that the so-called multi-domain (MD) fraction is clearly dominant and should be the main carrier of susceptibility. The down-core concentration of the finer $(0.03-1 \mu \mathrm{m})$ single domain (SD) magnetite fraction is represented by the ARM plots (Figs. 3-5h, 3-6g). In contrast to IRM and $\kappa$ depth variations, the ARM profiles of all three cores show a sharp drop by some $60-80 \%$ within the top $5 \mathrm{~cm}$ of the sediment column. This well-known decrease of submicron magnetite at shallow depths is generally attributed to reductive dissolution of ferric Fe oxides below the $\mathrm{Fe}(\mathrm{II}) / \mathrm{Fe}(\mathrm{III})$ redox boundary and therefore marks the upper limit of the suboxic zone (Berner 1981). This magnetite depletion is driven by the relatively high TOC content of the Holocene mud.

The coincident shifts of the concentration-independent magnetic grain size estimate ARM/IRM (Figs. 3-5i, 3-6h) and the magnetite/hematite ratio $\mathrm{S}_{0.3 \mathrm{~T}}$ (Figs. 3-5j, 3-6i) support these findings (Dillon and Bleil 2006). The ARM/IRM and $\mathrm{S}_{0.3 \mathrm{~T}}$ levels of the central core K5 remain constantly low throughout the mud/sand boundary suggesting that the main magnetic carrier of both facies is coarse detrital (titano-)magnetite of glacial origin, however at much lower concentration in the Holocene mud. The distal core $\mathrm{K} 2$ seems to have undergone the most pervasive diagenesis at depths below $30 \mathrm{~cm}$ as reflected by the lowest $\kappa$ and IRM values, the largest shifts in $\mathrm{S}_{0.3 \mathrm{~T}}$ and a reversing ARM/SIRM trend. This suggests that even the coarse detrital magnetite fraction is dissolving and only fine-grained magnetite inclusions in silicate matrix, as well as Ti-rich (hence $\mathrm{Fe}^{3+}$-poor and reduction-resistant) Fe oxides can survive (Dillon and Bleil 2006). We can reasonably deduct from the concurrent results, that all muddy 
sediments of the deeper bay should be sub- to anoxic and Fe-reducing below 5-10 $\mathrm{cm}$ depth irrespective of the seepage action.

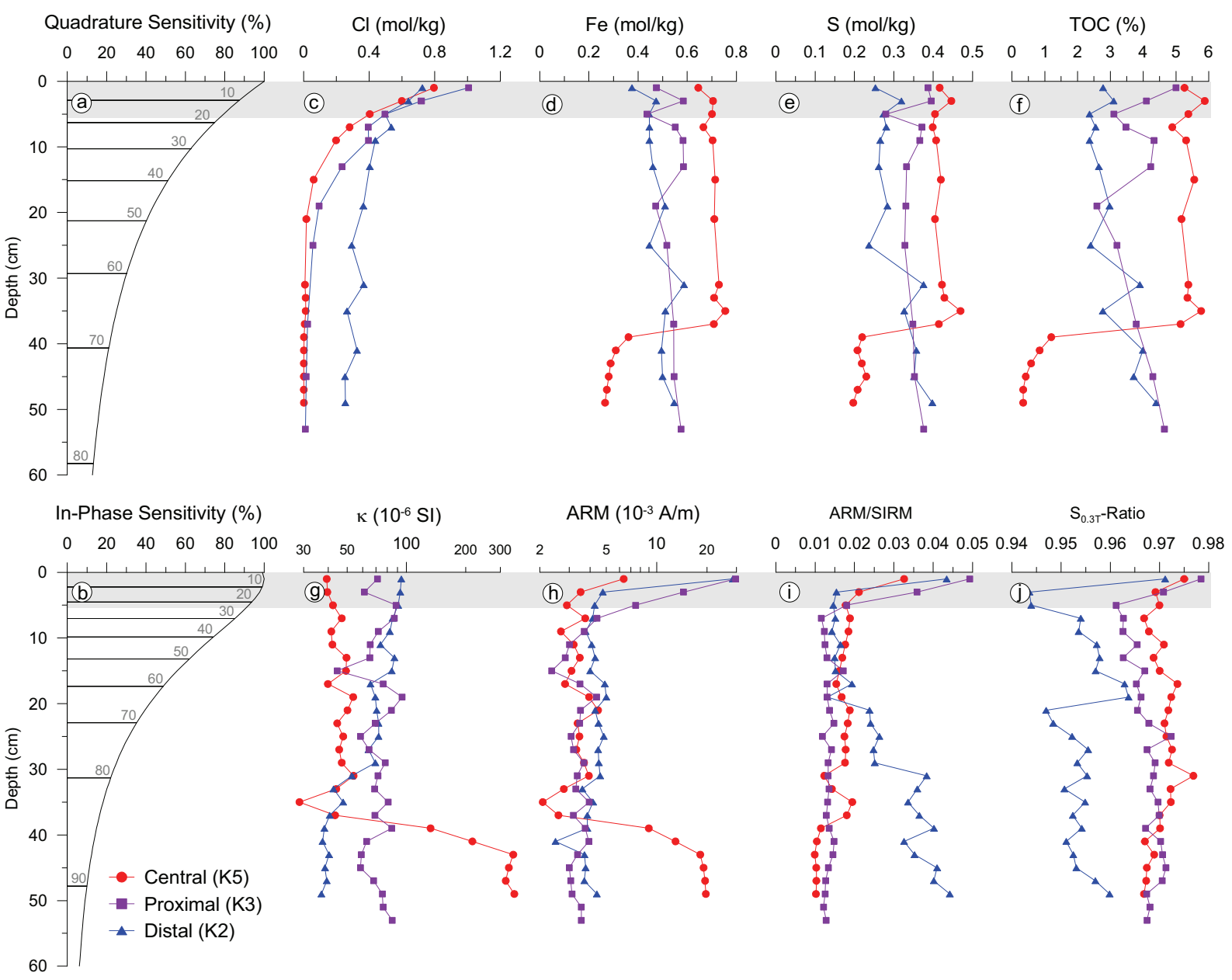

Fig. 3-5. Selected down-core element contents (c-f) and rock magnetic parameters (g-j) of 3 representative cores with distal (K2), proximal (K3) and central (K5) positions with respect to a pockmark. The grey area marks the oxic surface layer. EM sensitivity characteristics of the $4.8 \mathrm{kHz}$ quadrature (a) and $75 \mathrm{~Hz}$ in-phase (b) component define the weighting of the subsurface conductivity and susceptibility signal respectively. Therein, labeled horizontal lines mark the depth integrals that correspond from $10 \%$ to $90 \%$ of the EM signal. 


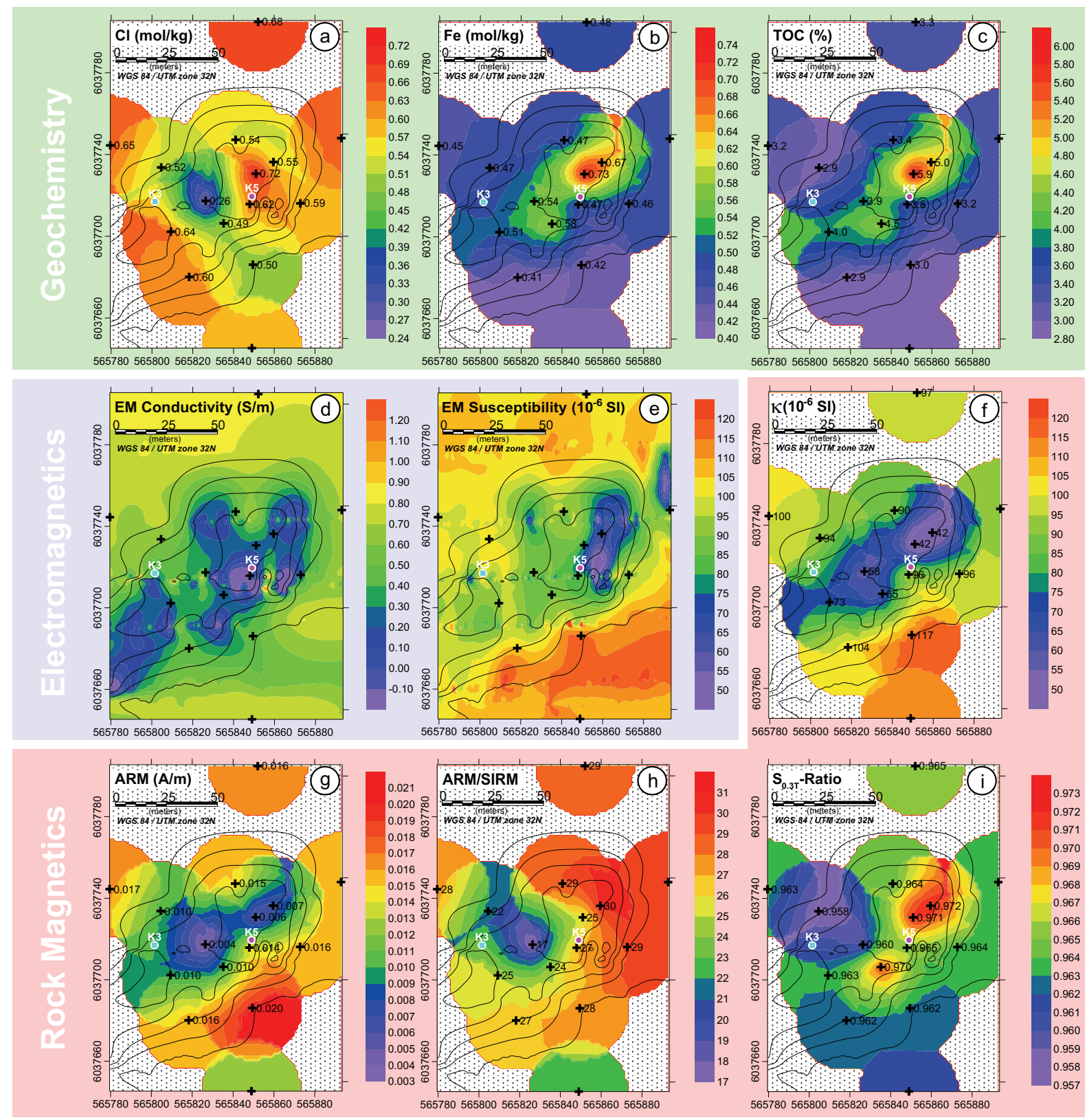

Fig. 3-6. Surface maps of element contents (a-c) and rock magnetic parameters (f-i) of 15 grab samples (crosses) and EM conductivity (d) and susceptibility (e) for the NE part of pockmark \#2. Core locations (K3 and K5) are marked for reference. EM data were gridded by minimum curvature algorithm, sample data by kriging algorithm with $25 \mathrm{~m}$ search radius. 


\subsection{Discussion}

\section{Controlling factors of sediment conductivity and susceptibility}

The two physical property measurements derived from marine electromagnetics differ fundamentally insofar as electric conductivity relates to the fluid-filled pore space and magnetic susceptibility to the solid sediment matrix. Conductivity is controlled by pore water salinity, porosity, and temperature while susceptibility depends on ferro-, para- and diamagnetic mineral content. Obviously, the only parameter affecting both properties directly is porosity, which correlates positively with conductivity

$$
\sigma_{\text {sed }} \cong \sigma_{\text {water }} \phi^{m} ; 1.5<m<3
$$

and negatively with volume susceptibility

$$
\kappa_{\text {sed }}=(1-\phi) \kappa_{\text {matrix }}+\phi \kappa_{\text {water }} ; \kappa_{\text {water }}<0<<\kappa_{\text {matrix }}
$$

For sediments with constant pore water conductivity and matrix susceptibility, but varying porosity an inverse nonlinear relation of sediment conductivity and susceptibility should be expected:

$$
\frac{\kappa_{\text {sed }}}{\kappa_{\text {matrix }}} \approx 1-\left(\frac{\sigma_{\text {sed }}}{\sigma_{\text {water }}}\right)^{1 / m}
$$

The observed decrease of pore water conductivity by $60 \%$ to $99 \%$ from between top and bottom of our eight gravity cores (Tab. 1) clearly rules out the assumption of constant pore water salinity in the study area. This finding is supported by the electric conductivities measured by the EM sensor at pockmark \#2 sampling locations, that are much lower than expected (Eq. (1)) for the given porosity of the surface samples (Fig. 3-7a). Surface susceptibilities correlate negatively with porosity (Fig. 3-7b), but do not follow a single linear trend, implying that the assumption of constant bulk susceptibility is also inappropriate here. Indeed, matrix (=dry bulk) susceptibilities of these samples vary by a factor more than 2 
between 250 and $600 \times 10^{-6}$ SI. Samples from the pockmark centers have systematically lower bulk susceptibilities and higher porosities than proximal and distal samples suggesting alteration of the ferrimagnetic mineral fraction by freshwater seepage and a fining of the sediment matrix within the pockmark. Magnetic particles are preferentially enriched in finer grain-size fractions (Booth et al. 2005, Ellwood et al. 2006), which typically also have higher porosities. Porosity, grain-size and diagenesis should therefore be controlling factors of sediment susceptibility.

So far, we have regarded the simple case, where the mud layer is taken as a homogeneous halfspace. The Eckernförde Bay setting is better described by a two-layer model composed of a finite Holocene mud-layer of 0-5 m thickness on top of a semi-infinite glacial base.

In the two cores reaching the glacial base the pore water conductivity at the core bottom has a near freshwater value of $0.05 \mathrm{~S} / \mathrm{m}$, porosity is about $50 \%$ and susceptibility $350 \times 10^{-6} \mathrm{SI}$. The Holocene mud was modeled (two layer model, Müller 2009) with pore water conductivities ranging from 0.05 to $2.6 \mathrm{~S} / \mathrm{m}$, sediment susceptibilities from 20 to $100 \times 10^{-6} \mathrm{SI}$ and a mean porosity of $80 \%$ (Figs. 3-7c, d). The two sets of curves model the EM response for discrete mud conductivities and susceptibilities as a function of mud layer thickness. With diminishing thickness of the Holocene drape, the contrasting glacial base shifts the surface conductivities towards lower values and susceptibilities towards higher values. The base starts to have a noticeable influence on EM measurements at depths above $3 \mathrm{~m}$, becomes critical above $1 \mathrm{~m}$ and dominant above $50 \mathrm{~cm}$ depth. This effect is mainly owed to the relatively large transmitter coil diameter of $96 \mathrm{~cm}$. It could be reduced by decreasing the coil size, however at the cost of higher noise by seafloor roughness.

By plotting real EM data of pockmarks \#1 and \#2 onto both model curves (Figs. 3-7c, d), some important conclusions can be drawn: 
(1) The EM conductivity data shows larger scatter and hence higher lateral variability than the EM susceptibility data. There may be various reasons for this effect: Firstly, pore water salinity near freshwater seeps can change by several orders of magnitude, whereas sediment susceptibility cannot be reduced by so much due to mineralogical limitations. Secondly, conductivity mirrors the current, spatially complex and temporally dynamic hydrological system while alteration of the magnetic mineral fraction is a slower chemical processes averaging over long periods of time. Salinity change is reversible, magnetic mineral depletion is not. Thirdly, focused freshwater flow has high impact on (local) conductivity, while magnetic mineral reduction occur with focused as well as with diffuse flow.

(2) Model curves are curvilinear at the top and converge to constant mud values at ca. $3 \mathrm{~m}$ in depth, while the magnetic EM data trends are nearly linear throughout the $5 \mathrm{~m}$ depth range and show a pronounced gradient. With decreasing mud layer thickness, susceptibilities shift towards more reduced states. It is also noteworthy, that the trends of pockmarks \#1 and \#2 have different dips and keep changing below $3 \mathrm{~m}$ in depth, the theoretical detection limit of the glacial base.

(3) EM conductivities shift in general towards freshwater saturation with decreasing mud layer thickness, although localized conductivity minima, i.e. seep centers, are not restricted to areas of least mud thickness. Hydraulic gradients and sub-bottom conduits may be more decisive for their localization.

The shifting of $\sigma$ and $\kappa$ with mud thickness is therefore not a direct geometrical effect, but rather the result of an indirect geological process: A thinner and therefore more permeable mud layer facilitates freshwater infiltration from the basal aquifer. As a result, mud porosity increases and susceptibility decreases. The theoretical scenario of positive susceptibility anomalies over (near) outcropping sand highs is not observed in practice. 

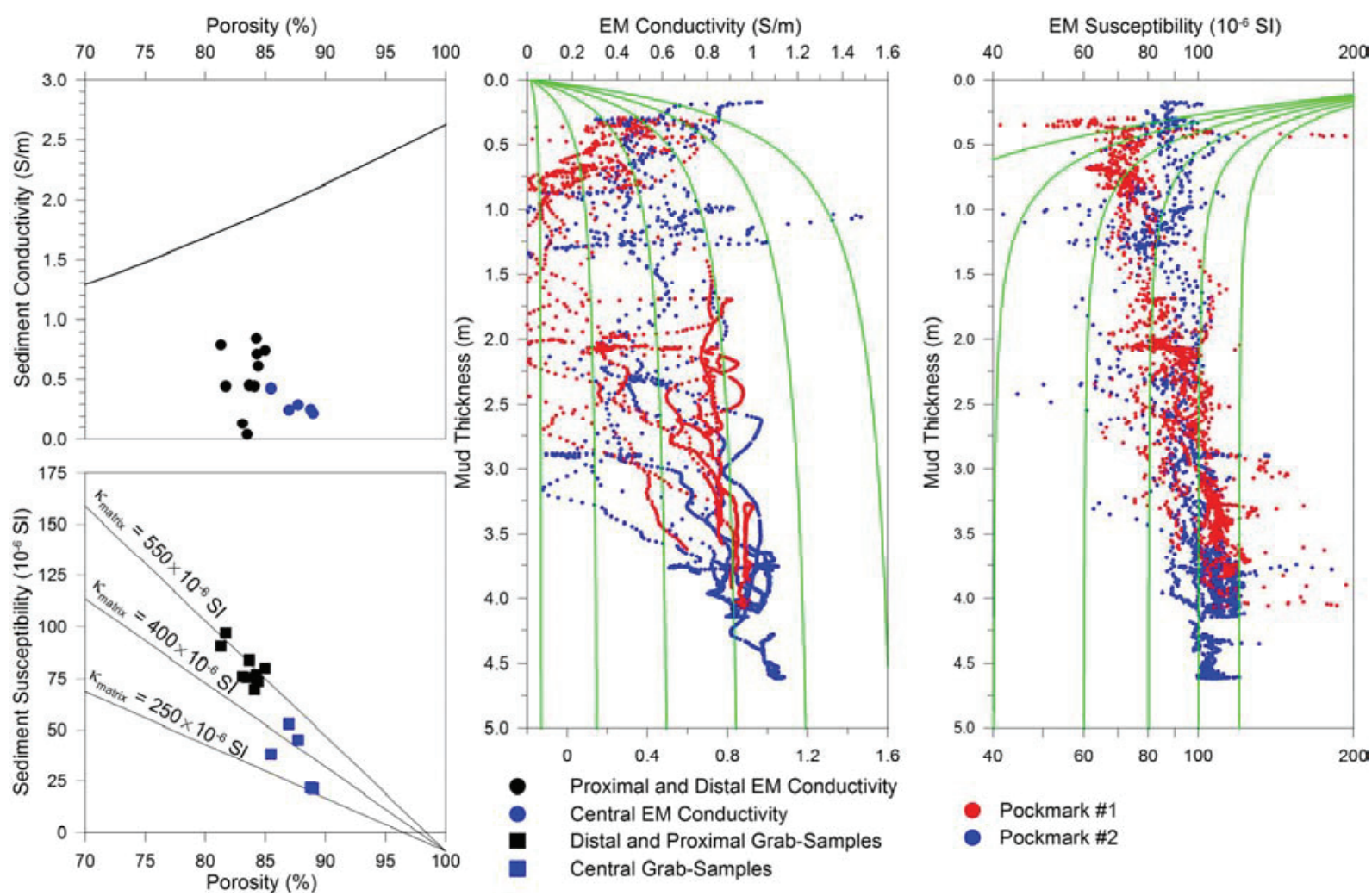

Fig. 3-7. (a) For given surface sample porosities, the expected values of sediment electric conductivity, calculated by Eq. (1) $\left(\sigma_{\text {water }}\right.$ sampled from Fig. $\left.3-3 b ; m=2\right)$, are generally higher than those determined by the EM sensor at the sampling position. (b) Susceptibility values of proximal and distal samples scatter around the theoretical curve for $\kappa_{\text {matrix }}=550 \times 10^{-6}$ SI (Eq. (2)) while low central pockmark susceptibilities could not be explained by the reduced porosity. EM conductivity (c) and susceptibility (d) of pockmark \#1 and \#2 increases with Holocene mud thickness. Two layer models of various mud properties $\left(\sigma_{\text {mud }}\right.$ and $\left.\kappa_{\text {mud }}\right)$ over sand $(\phi=50 \%$, $\left.\kappa=350 \times 10^{-6} \mathrm{SI}\right)$ are shown by green lines.

\section{Freshwater seepage and magnetic mineral diagenesis}

The previously shown geochemical and rock magnetic data of our surface and core samples

(Figs. 3-5, 3-6) could provide qualitative evidence that grain-size and diagenesis effects were the main causes for negative susceptibility anomalies of Eckernförde Bay pockmarks. We now present rank-order correlation statistics of magnetic susceptibility with selected geochemical and rock magnetic parameters (Fig. 3-8) to substantiate and expand our earlier statements:

The presented theory and statistical data analysis (Fig. 3-7) suggest that larger porosities of the pockmark sediments should at least partly account for the lowering of susceptibility. Porosity is indeed negatively correlated with susceptibility while chloride content is rated 
insignificant, most likely because salinity fluctuations due to advective and diffusive processes are magnetically irrelevant. The highly significant positive correlation of susceptibility with SIRM (magnetite) and anti-correlation with Fe content (paramagnetic iron) identifies magnetite without ambiguity as the decisive carrier of the susceptibility signal. The positive significant correlation of $\kappa$ and $\mathrm{Si} / \mathrm{Al}$ detects higher magnetite concentrations in the coarser quartz-rich and lower in the finer clay-rich sediments. Clay minerals conserve a larger pore space, which 'dilutes' also the magnetic fraction and reduces volume susceptibility.

Higher TOC contents within the pockmarks can result from calmer settling conditions as well as from better preservation in the surface sediment due to lesser oxygenation and remineralization. TOC has a high negative correlation with susceptibility. Reactive organic carbon, methane and sulfate drive the suboxic and/or sulfidic dissolution of ferrimagnetic Fe oxides and the precipitation of paramagnetic Fe sulfides (Berner 1981; Fu et al. 2009) by the following reactions:

$2 \mathrm{Fe}_{3} \mathrm{O}_{4}+\mathrm{CH}_{2} \mathrm{O}+11 \mathrm{H} \rightarrow 6 \mathrm{FE}_{(\mathrm{aq})}^{2+}+\mathrm{HCO}_{3}^{-}+\mathrm{H}_{2} \mathrm{O}$ (magnetite dissolution by organic matter)

$\mathrm{CH}_{4}+\mathrm{SO}_{4}^{2-} \rightarrow \mathrm{HCO}_{3}^{-}+\mathrm{H}_{2} \mathrm{O}+\mathrm{HS}^{-}$(formation of hydrogen sulfide from methane and sulfate)

$\mathrm{Fe}_{3} \mathrm{O}_{4}+\mathrm{HS}^{-}+7 \mathrm{H}^{+} \rightarrow 3 \mathrm{Fe}_{(\text {aq })}^{2+}+\mathrm{S}_{(\mathrm{s})}^{0}+4 \mathrm{H}_{2} \mathrm{O}$ (Magnetite dissolution by hydrogen sulfide)

$\mathrm{Fe}_{(\mathrm{aq})}^{2+}+\mathrm{HS}^{-} \rightarrow \mathrm{FeS}_{(\mathrm{s})}+\mathrm{H}^{+}$(Precipitation of dissolved iron by hydrogen sulfide)

Total Fe and the (porosity-independent) diagenesis indices $\mathrm{Fe} / \mathrm{Al}$ (Fe precipitation) and $\mathrm{S} / \mathrm{Al}$ (pyritization) are therefore elevated within the pockmarks, but correlate negatively with $\kappa$, suggesting that only paramagnetic Fe species are precipitated from the anoxic, $\mathrm{Fe}^{2+}$-rich (ca. $2 \mathrm{mg} / \mathrm{l}$, Marczinek and Piotrowski 2002) freshwater. The precipitation of the weakly magnetic secondary iron minerals by diagenesis and seepage hence does not contribute significantly to magnetic susceptibility. As in many other reductive marine environments (e.g. Zhang et al. 
2001; Emiroglu et al. 2004; Tribovillard et al. 2002), diagenetic dissolution of the strongly magnetic primary magnetite phase is the predominant, statistically most significant process.

The hardest evidence for magnetite dissolution is delivered by rock magnetic parameters. The total loss of fine-grained magnetite below the Fe redox boundary detected by the ARM/IRM (Figs. 3-5i, 3-8b) correlates significantly with the susceptibility decrease. Better preservation of hematite vs. magnetite $\left(\mathrm{S}_{0.3 \mathrm{~T}}\right)$ and shifts in the proportion of para- and ferrimagnetic iron $(\mathrm{Fe} / \chi)$ are recognized fingerprints of magnetite depletion (Funk et al. 2004). This process proceeds within the entire Holocene drape, but is more pervasive in and near the pockmarks.
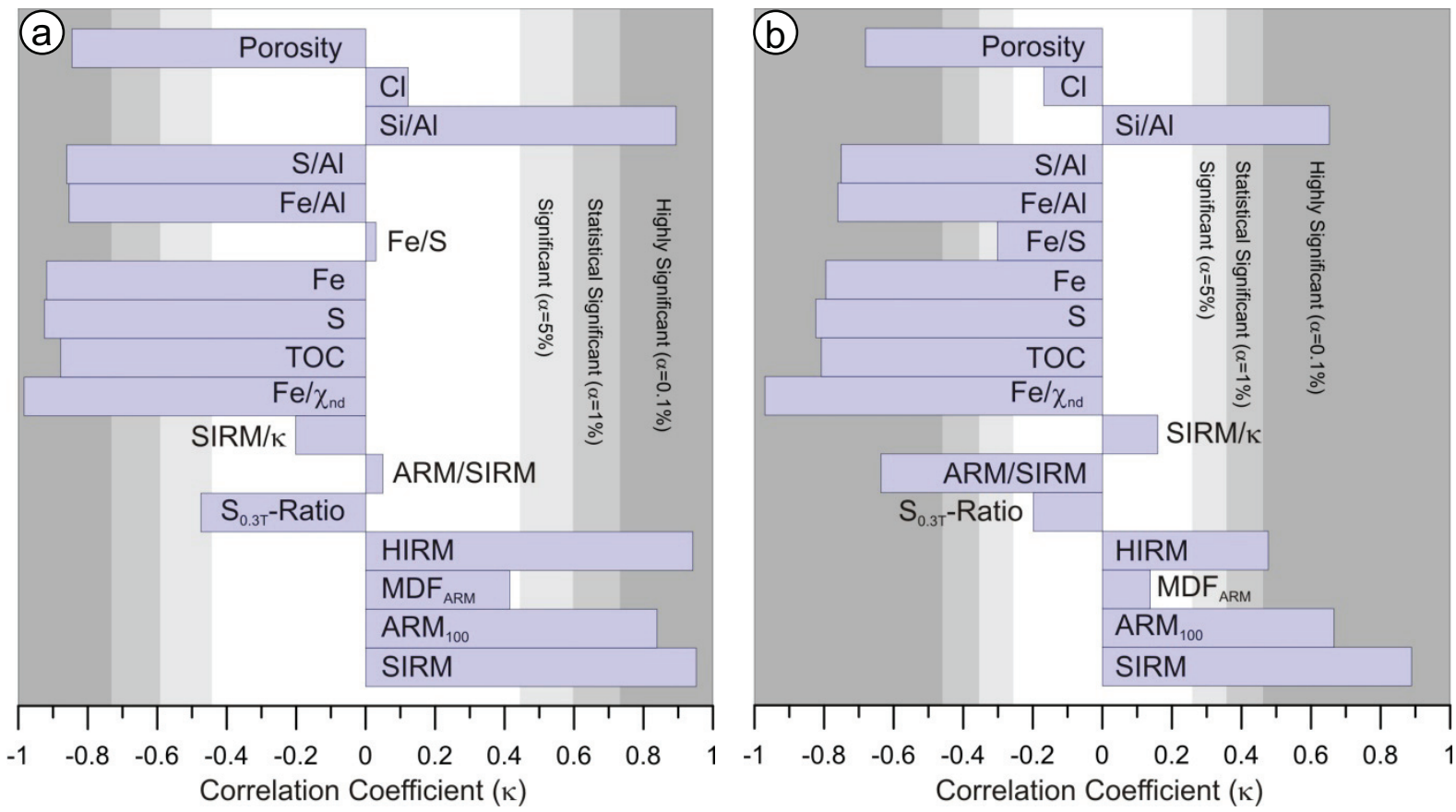

Fig. 3-8. Spearman rank-order correlation statistics of magnetic susceptibility with a set of geochemical and rock magnetic proxy parameters of surface samples (a) and core samples (b). 


\section{Electromagnetic fingerprinting of freshwater seepage and sediment lithology}
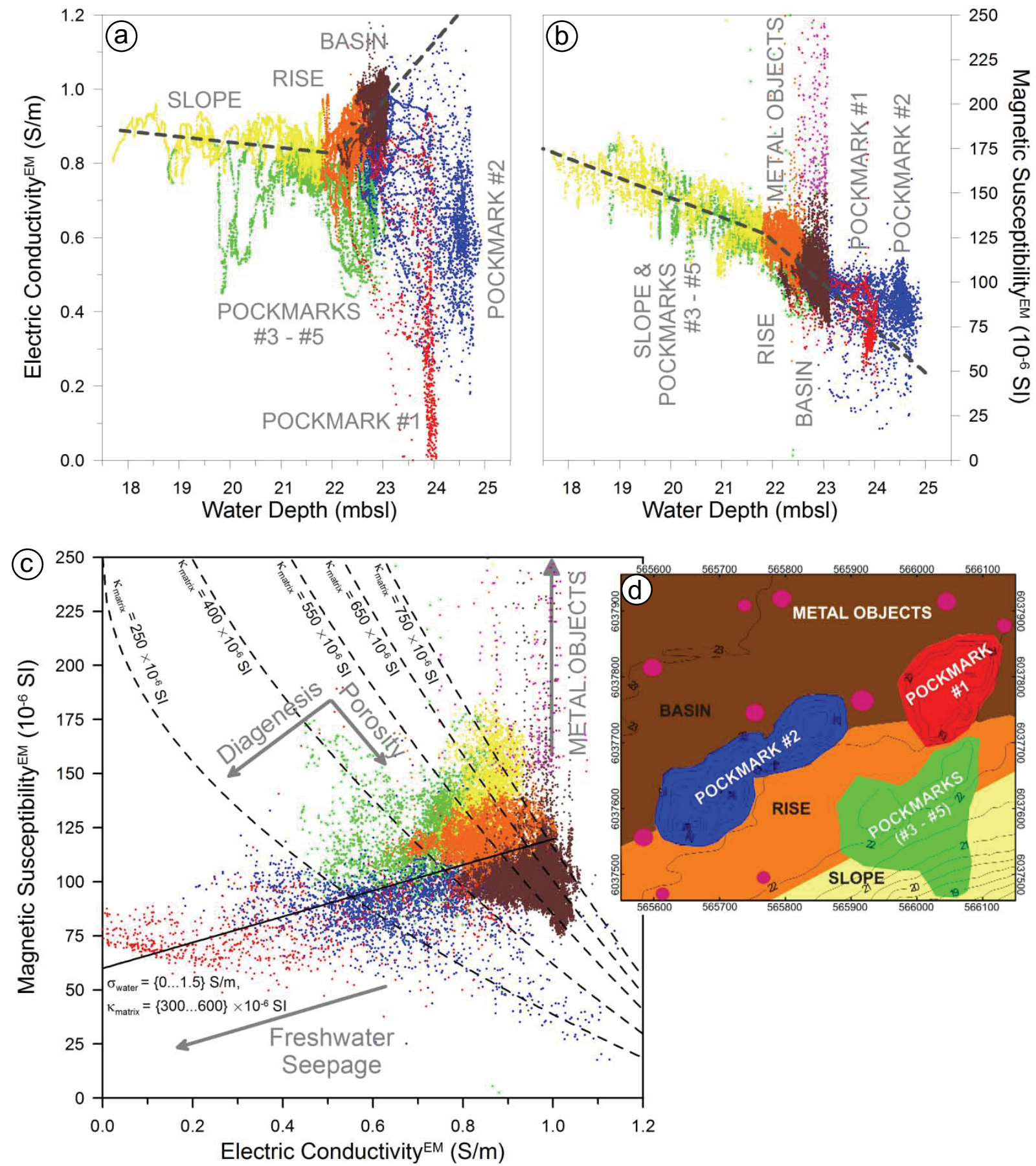

Fig. 3-9. EM fingerprinting of sediments in the study area. The main structural elements (basin, rise, slope and pockmarks \#1 - \#5) were depicted in the bathymetric map (d) and color coded. Ferrous metal objects were identified and grouped by a threshold method. Linear trends are given for the conductivity to depth (a) and susceptibility to depth (b) relation of slope, rise and basin sediments (dashed lines). Sediments group in the susceptibility versus conductivity crossplot (c) showing porosity trends (dashed) of constant pore water conductivity of $1.4 \mathrm{~S} / \mathrm{m}$ and varying values for matrix susceptibility $\kappa_{\text {matrix }}$ following Eq. (3) $(\mathrm{m}=2)$. The freshwater trend (solid) is given by the parametric equations in analogy to Eq. (1) \& (2): $\sigma(\mathrm{t})=(1-100 / 550)^{2} \mathrm{t}$ and $\kappa(t)=200(t+1.5)(1-0.8) ; t=\{0 \ldots 1.5\}$. 
The high data quality and excellent consistency of acoustic pockmark morphologies with the electromagnetic conductivity and susceptibility images (Fig. 3-3), supported by our reasoning for signal formation invoking an interaction of episodic freshwater advection and long-term iron mineral diagenesis, form a solid framework to use EM data for sediment classification. In order to demonstrate the lithostratigraphic potential of EM fingerprinting, the main structural elements of the Eckernförde Bay study area (basin, rise, slope and pockmarks \#1 - \#5) have been grouped and color-coded (Fig. 3-9d). Dispersed metal objects (e.g. scrap metal, ordnance) deviate from the geological background by their unusually high susceptibility (Figs. 3-3f, 3-9b, c) and were identified and grouped by a threshold method.

When plotted against water depth (Fig. 3-9a), background conductivity is uniform at the slope (yellow) and increases just slightly with porosity toward the rise (orange) and basin (brown). Pockmarks \#1 (red, 24 m), \#2 (blue, 23-25 m), \#3 and \#4 (green 22-23 m) and \#5 (green, 19$21 \mathrm{~m}$ ) protrude sharply from the main trend by their reduced conductivities due to freshwater infiltration. In the same representation (Fig. 3-9b), background susceptibility shows much higher sensitivity for sediment lithology, i.e. magnetic mineral content, grain-size and porosity. Metallic contaminants are easily identified as positive outliers, while the negative scatter by early diagenetic alteration appears quite modest when choosing linear axis scaling. Given by the susceptibility to depth trend (dashed line in Fig. 3-9b), susceptibility values within pockmarks are even higher than basin sediments of comparable depths. Thus, susceptibility alone is not capable of classifying the sediment correctly. The bivariate scatter plot of susceptibility against conductivity (Fig. 3-9c) greatly expands the discriminative power of EM imaging. Three main trends can be discerned:

(1) The lithological variability of the Holocene drape sediment is determined by clay content, which determines grain-size and porosity. Under the specific local settings, sediment fining is associated with a pronounced decrease of susceptibility and a somewhat lesser 
rise of conductivity in accordance with Eq. 1. This signal formation process is responsible for the discrimination of slope, rise and basin sediments (Figs. 3-3e, f, h and 3-9c, d) and the depth dependence of $\kappa$ and $\sigma$ (Figs. 3-9a, b).

(2) Freshwater seepage is represented by a major decline of conductivity (salinity) along with a minor decrease of susceptibility (diagenesis) (Fig. 3-9c). According to these trends, the pockmark structures \#1, \#2 and \#3-\#5 differ in grain size (e.g. \#2 is muddier than \#3-\#5) and freshwater saturation (e.g. \#1 is less saline than \#2) as well as in the pervasiveness of magnetite depletion. Freshwater advection therefore reduces sediment susceptibility by a combination of pore water injection and magnetite depletion.

(3) Ferromagnetic metal objects along or aside the sled tracks have 4-6 orders of magnitude higher intrinsic susceptibilities and conductivities than the surrounding sediment. Because of geometry and frequency effects, metal detection by the $75 \mathrm{~Hz}$ susceptibility measurement is found much more efficient than by the $4.8 \mathrm{kHz}$ conductivity measurement (Figs. 3-3e-f, 3-9a-c). Depending on the volume and distance of metallic objects, apparent susceptibilities rise locally by more than $400 \times 10^{-6} \mathrm{SI}$.

\subsection{Conclusion and summary}

Seepage of reactive groundwater in Eckernförde Bay has a major effect on the magnetic mineralogy and electric conductivity of marine surface sediments. The affinity of electric conductivity to pore water salinity and temperature constitutes this electromagnetically determined parameter to resolve the recent freshwater impact on the sediment, controlled by vertical advection and lateral diffusion processes. The magnetic susceptibility on the contrary, is controlled by the solid phase mineralogy of the sediment, and reflects the impact of reactive fluid seepage over a certain time interval that is necessary to dissolve the primary magnetic 
minerals. Magnetic susceptibility minima within pockmarks are found to maintain their position relative to sand highs underneath.

The conceptual hydrogeological model of the survey area (Fig. 3-10) summarizes the main findings of this study:

(1) Freshwater penetrates the sediment pore-space of the Holocene mud sediments in the whole study are by diffuse and focused advection

(2) Pockmarks are characterized by focused freshwater seepage, underlying sand highs, reduced mud thickness, higher porosity, fining of grain-size and anoxic conditions

(3) Depletion of Fe oxides, especially magnetite, is amplified within pockmarks due to enhanced organic and sulfuric reaction partners

(4) Freshwater advection reduces sediment susceptibility by a combination of pore water injection and magnetite depletion

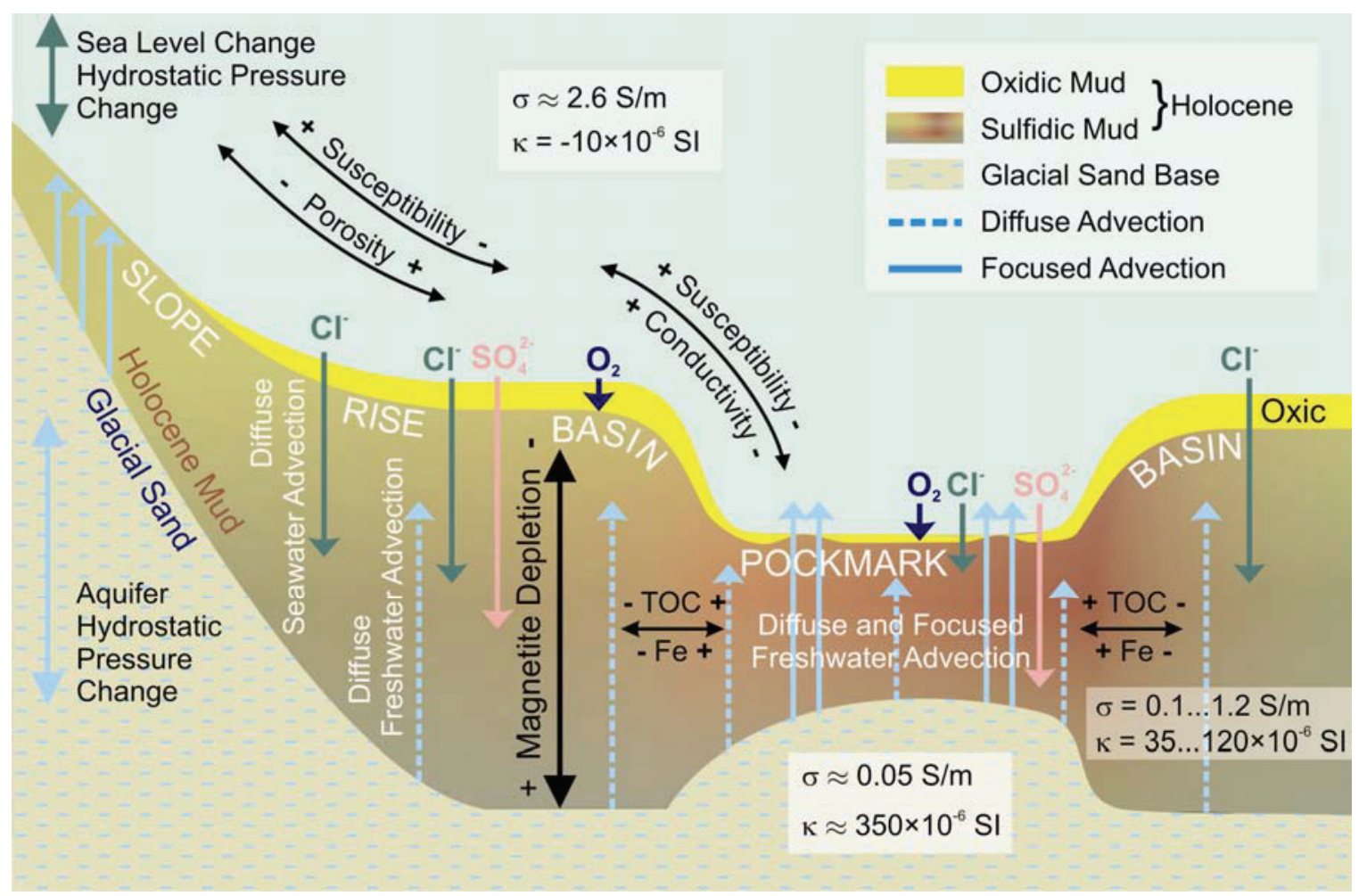

Fig. 3-10. Conceptual hydrogeological model of sedimentary units, freshwater advection, element exchange and Fe oxide depletion. Focused and diffusive freshwater advection within pockmarks reduces the magnetic sediment susceptibility by a combination of pore water injection and magnetite depletion. Seepage and subsequent pockmark formation is related to thinned Holocene mud drape above glacial sand highs. 
Core results depict the enrichment of magnetite in the surface layer and its depletion at the iron redox boundary in depths of 5-10 cm. Pervasive diagenesis in the sulfidic zone of the Holocene mud causes the dissolution of coarse detrital magnetite while fine-grained matrix inclusions could survive. Magnetite depletion within pockmarks is controlled by reactive organic carbon although the susceptibility decay is part wise carried by increased porosity.

The spatial interpretation of punctual sediment samples is prone to misleading interpolation errors and unrecognized outliers. Continuous data can fill these gaps of information and also depict the transition zones. Electromagnetic mapping with the GEM Shark profiler has attested it's capability to provide a continuous image of surface sediment alteration due to freshwater seepage. Bivariate plots of EM susceptibility versus conductivity data clearly separate between the lithologic units of the slope, rise and basin and sediments within pockmarks. However, classic sediment core analysis enrolls process chains that are poorly represented by integral electromagnetic measurements and the down-core perspective is essential to fully understand the involved signal formation processes.

The results of this study imply that near surface electromagnetic profiling can highly improve our understanding of the heterogeneity of submarine groundwater discharge and the patchiness of surface sediment properties. Further work should include high resolution depth inversion of electromagnetic conductivity and susceptibility data to provide a down-core perspective that offers to quantify the advective and diagenetic processes in more detail by high resolution, fast and cost effective in-situ profiling. 


\subsection{References}

Archie GE (1942) The electrical resistivity log as an aid in determining some reservoir characteristics. Journal of Petroleum Technology 5:1-8

Benech C, Marmet E (1999) Optimum Depth of Investigation and Conductivity Response Rejection of the Different Electromagnetic Devices Measuring Apparent Magnetic Susceptibility, Archaeological Prospection 6:31-45

Berner RA (1981) A new geochemical classification of sedimentary environments. Journal of Sedimentary Petrology 51:359-365

Bloemendal J, King JW, Hall FR, Doh SJ (1992) Rock magentism of late Neogene and Pleistocene deep-sea sediments: relationship to sediment source, diagenetic processes, and sediment lithology. Journal of Geophysical Research 97:4361-4375

Booth CA, Walden J, Neal A, Smith JP (2005) Use of mineral magnetic concentration data as a particle size proxy: A case study using marine, estuarine and fluvial sediments in the Carmarthen Bay area, South Wales, U.K. Science of the Total Environment 347:241-253

Burnett WC, Taniguchi M, Oberdorfer J (2001) Measurement and significance of the direct discharge of groundwater into the coastal zone. Journal of Sea Research 46:109-116

Burnett WC, Aggarwal PK, Aureli A et al (2006). Quantifying submarine groundwater discharge in the coastal zone via multiple methods. Science of the Total Environment 367:498-543

BurVal Working Group (2006) Groundwater resources in buried valleys - a challenge for geosciences. In: Kirsch R, Rumpel HM, Scheer W, Wiederhold H (eds) Leibniz Institute for Applied Geosciences, Hannover

Day R, Fuller M, Schmidt VA (1977) Hysteresis properties of titanomagnetites: grain-size and compositional dependence. Physics of the Earth and Planetary Interiors 13:260-266

Dillon M, Bleil U (2006) Rock magnetic signatures in diagenetically altered sediments from the Niger deep-sea fan. Journal of Geophysical Research 111. B03105. doi:10.1029/2004JB003540

Ellwood BB, Balsam WL, Roberts HH (2006) Gulf of Mexico sediment sources and sediment transport trends from magnetic susceptibility measurements of surface samples. Marine Geology 230:237-248

Emiroglu S, Petersen N, Rey D (2004) Magnetic properties of sediment in the Ría de Arousa (Spain): Dissolution of iron oxides and formation of iron sulphides. Physics of the Earth and Planetary Interiors 29:947-959

Evans ME, Heller F (2003) Environmental Magnetism, Principles and Applications of Eviromagnetics. Academic Press, Elsevier Science, USA

Farquharson CG, Oldenburg DW, Routh PS (2003) Simultaneous 1D inversion of loop-loop electromagnetic data for magnetic susceptibility and electrical conductivity. Geophysics, 68:1857-1869. 
Frederichs T, Bleil U, Däumler K, von Dobeneck T, Schmidt A (1999) The Magnetic View on the Marine Paleoenvironment: Parameters, Techniques and Potentials of Rock Magnetic Studies as a Key to Paleoclimatic and Paleoceanographic Changes. In: Fischer G, Wefer G (eds) Use of Proxies in Paleoceanography: Examples from the South Atlantic. Springer-Verlag, Berlin, Heidelberg, pp 575-599

Fu Y, von Dobeneck T, Franke C, Heslop D, Kasten S (2008) Rock magnetic identification and geochemical process models of greigite formation in Quaternary marine sediments from the Gulf of Mexico (IODP Hole U1319A). Earth and Planetary Science Letters 275:233-245

Funk JA, von Dobeneck T, Reitz A (2004) Integrated Rock Magnetic and Geochemical Quantification of Redoxomorphic Iron Mineral Diagenesis in Late Quaternary Sediments from the Equatorial Atlantic. In: Wefer G, Mulitza S, Ratmeyer V (eds) The South Atlantic in the Late Quaternary: Reconstruction of Material Budget and Current Systems. Springer-Verlag, Berlin, Heidelberg, pp 237-260

Gay SP (2004) Glacial Till: A Troublesome Source of Near-Surface Magnetic Anomalies, The Leading Edge $23: 542-547$

Harrington PK (1985) Formation of Pockmarks by Pore-Water Escape. Geo-Marine Letters 5:193-197

Hoefel FG, Evans RL (2001) Impact of low salinity pore water on seafloor electromagnetic data: A means of detecting submarine ground water discharge? Estuarine, Coastal and Shelf Science 52:179-189

Housen BA, Musgrave RJ (1996) Rock-magnetic signature of gas hydrates in accretionary prism sediments. Earth and Planetary Science Letters 139:509-519

Hovland M (2003) Geomorphological, geophysical, and geochemical evidence of fluid flow through the seabed. Journal of Geochemical Exploration 78-79:287-291

Hussenoeder SA, Tivey MA, Schouten H (1995) Direct inversion of potential fields from an uneven track with application to the Mid-Atlantic Ridge. Geophysical Research Letters 22 (23):3131-3134

Jensen JB, Kuijpers A, Bennike O, Laier T, Werner F (2002) New geological aspects for freshwater seepage and formation in Eckernförde Bay, western Baltic. Continental Shelf Research 22:2159-2173

Karpen V, Thomsen L, Suess E (2004) A new 'schlieren' technique application for fluid flow visualization at cold seep sites. Marine Geology 204:145-159

King JW, Channel JET (1991) Sedimentary magnetism, environmental magnetism, and magnetostratigraphy. Reviews of Geophysics, Supplement, 358-370

King J, Banerjee SK, Marvin J, Özdemir Ö (1982) A comparison of different magnetic methods for determining the relative grain size of magnetite in natural materials: Some results from lake sediments. Earth and Planetary Science Letters 59:404-419

Maher BA, Thompson R (1999) Quaternary climates, environments and magnetism. Cambridge University Press: Cambridge, New York

Marczinek S, Piotrowski JA (2002) Grundwasserströmung und -beschaffenheit im Einzugsgebiet der Eckernförder Bucht, Schleswig-Holstein. Grundwasser - Zeitschrift der Fachsektion Hydrogeologie, 101110 
Moore WS (1996) Large groundwater inputs to coastal waters revealed by ${ }^{226} \mathrm{Ra}$ enrichment. Nature 380:612614

Müller H (2009) Characterization of marine near-surface sediments by electromagnetic profiling. Dissertation, Univertität Bremen

Nehmiz W (2007) Umweltmagnetische und geochemische Untersuchungen an Grundwasseraustritten in der Eckernförder Bucht. Diplomarbeit, Universität Bremen

Novosel I, Spence GD, Hyndman RD (2005) Reduced magnetization produced by increased methane flux at a gas hydrate vent. Marine Geology 216:265-274

Oldfield F, Yu L (1994) The influence of particle-size variations on the magnetic properties of sediments from the N.E. Irish Sea. Sedimentology 41:1093-108

Rey D, Mohamed KJ, Bernabeu A, Rubio B, Vilas F (2005) Early diagenesis of magnetic minerals in marine transitional environments: Geochemical signatures of hydrodynamic forcing. Marine Geology 215:215236

Rey D, Müller H, Rubio B et al (2008) Using electromagnetic sensors to estimate physical properties and environmental quality of surface sediments in the marine environment. Preliminary results. Geotemas 10:651-654

Rowan CJ, Roberts AP (2006) Magnetite dissolution, diachronous greigite formation, and secondary magnetizations from pyrite oxidation: unravelling complex magnetization in Neogene marine sediments from New Zealand. Earth and Planetary Science Letters 241:119-137

Schlueter M, Sauter EJ, Andersen CE, Dahlgaard H, Dando PR (2004) Spatial distribution and budget for submarine groundwater discharge in Eckernforde Bay (western Baltic Sea). Limnology and Oceanography 49:157-167

Seeberg-Elverfeldt J, Schlüter M, Feseker T, Kölling M (2005) Rhizon sampling of porewaters near the sediment-water interface of aquatic systems. Limnology and Oceanography 3:361-371

Siemon B (2006) Airborne techniques. In: R. Kirsch (Eds.), Groundwater Geophysics - A tool for Hydrogeology. Springer, Heidelberg, pp 348-362

Steuer A, Siemon B, Auken E (2007) A comparison of helicopter-borne electromagnetics in frequency- and time-domain at the Cuxhaven valley in Northern Germany. Journal of Applied Geophysics 67 (3):194-205

Smith JWN, Bonell M, Gibert J et al (2008) Groundwater-surface water interactions, nutrient fluxes and ecological response in river corridors: Translating science into effective environmental management. Hydrological Processes 22:151-157

Thompson R, Bloemendal J, Dearing JA et al (1980) Environmental apllications of magnetic measurements. Science 207:481-486

Thompson R, Oldfield F (1986) Environmental Magnetism. Allen and Unwin

Tivey MA, Johnson HP (2002) Crustal magnetization reveals subsurface structure of Juan de Fuca Ridge hydrothermal vent fields. Geology Boulder 30:979-982 
Tribovillard N, Averbuch O, Bialkowski A, Deconinck JF (2002) Early diagenesis of marine organic-matter and magnetic properties of sedimentary rocks: the role of iron limitation and organic-matter source organisms. Bulletin de la Societe Geologique de France 173 (4):295-306

Verosub KL, Roberts AP (1995) Environmetnal magnetism: past, present, and future. Journal of Geophysical Research 100:2175-2192

Whiticar MJ, Werner F (1981) Pockmarks: Submarine vents of natural gas or freshwater seeps? Geo-Marine Letters 1:193-199

Whiticar MJ (2002) Diagenetic relationships of methanogenesis, nutrients, acoustic turbidity, pockmarks and freshwater seepages in Eckernförde Bay. Marine Geology 182:29-53

Won IJ, Keiswetter DA, Hanson DR, Novikova E, Hall TM (1997) GEM-3: A Monostatic Broadband Electromagnetic Induction Sensor. Journal of Environmental and Engineering Geophysics 2:53-64

Won IJ, Huang H (2004) Magnetometers and electro-magnetometers. The Leading Edge 23:448-451

Zhang W, Yu L, Hutchinson SM (2001) Diagenesis of magnetic minerals in the intertidal sediments of the Yangtze Estuary, China, and its environmental significance. Science of the Total Environment 266:160-75 


\section{Using electromagnetic sensors to estimate physical properties and environmental quality of surface sediments in the marine environment. Preliminary results}

D. Rey ${ }^{1}$, H. Müller ${ }^{2}$, B. Rubio ${ }^{1}$, T. von Dobeneck ${ }^{2}$, F. Vilas ${ }^{1}$, C. Hilgenfeldt ${ }^{2}$, A. Bernabeu $^{1}$, T. Frederichs ${ }^{2}$, S.Fernández ${ }^{1}$, K.J. Mohamed ${ }^{1}$ y Grupo GEOMA ${ }^{1 *}$

(1) Dpto. Geociencias Marinas, Facultad de Ciencias del Mar, Universidad de Vigo,36310 Vigo. danirey@uvigo.es

(2) Research Center "Ocean Margins", University of Bremen. Postfach 330440 D-28331 Bremen. Alemania.

$\left(^{*}\right) \quad$ Grupo GEOMA (P. Abilleira, P. Álvarez-Iglesias, A. Andrade, A. Ares, I. Pérez, I.R. Germade)

English translation of the Spanish original (Chapter 6.3): "Uso de sensores electromagnéticos para la estimación de las propiedades físicas y calidad ambiental de sedimentos superficiales en el medio marino. Resultados preliminares", published in GEO-TEMAS 10, 2008 (ISSN: 1567-5172), p. 651-654 


\begin{abstract}
The coastal systems are often subjected to high anthropogenic pressure, which makes it necessary to develop new techniques to assess the environmental impacts caused by such human activity. This manuscript presents the first results obtained during the development and implementation of a new equipment of submarine geophysics survey oriented to integrated coastal zone management (ICZM). It is based on the drag of a submarine in contact with the sea-bottom. The submarine is equipped with an electromagnetic sensor which allows the measurement of the magnetic susceptibility and electrical conductivity of the surface sediments continuously and to a depth of sediment of $40 \mathrm{~cm}$. This system, once improved, will allow us to obtain valuable information for monitoring the environmental quality of coastal areas.
\end{abstract}

Key words: Marine pollution, susceptibility, electromagnetic sensor. 


\subsection{Introduction}

The Rías of Galicia, a series of fjord-like inlets of the NW-Iberian coast, represent some unique marine spaces of great natural as well as economic richness, which have attracted considerable urban settlement and industrial activity. Some $40 \%$ of Galicia's population live nearby the shores of the Rías and principal industrial complexes are situated close to the harbor areas. Associated with these activities and aggravated by the newly implemented aquacultures is a notable deterioration of the water and sediment quality due to a steady input of organic matter and metal contaminants. These potentially nocent developments call for the use and improvement of adequate instrumentation permitting to monitor, evaluate and eventually manage environmental pollution.

The chemistry, biogeodynamics and bioavailability of metals in coastal marine ecosystems is especially interesting from the viewpoint of control and prevention of harmful effects of these contaminants. Data of evidence are generally acquired by chemical and geochemical techniques which are costly and laborious. It therefore seems necessary to develop other cheaper and faster techniques which allow defining contamination levels and assessing their possible dispersion patterns with higher temporal frequency and spatial resolution. This would allow to evaluate their temporal evolution at short and midterm with higher spatio-temporal precision. In this respect, certain magnetic properties such as magnetic susceptibility $(\kappa)$ and saturation remanence (SIRM) are of interest, which can be measured rapidly, economically and non-destructively and which show significant correlations with metals contents in the fine fraction of sediments (Scoullos and Olfield, 1985; Chan et al., 2001; Spassov et al., 2004). Such associations are explained by the roles which sedimentary grain-size and Fe oxide content play in the control of metal concentrations, conferring on them a considerable value as tool in the assessment of environmental quality. 
Here we present the development of a new device to measure magnetic susceptibility and conductivity in situ, which, once perfectioned, will permit to indirectly assess several physical and chemical key parameters of environmental quality within a specific zone. This device is configured as submarine sled equipped with an electromagnetic (EM) sensor which determines the magnetic susceptibility and electric conductivity while it is towed over the ground of the study area. The Ría de Vigo was selected as test area because it has been profoundly investigated in magnetochemical terms (Rubio et al., 2001; Emiroglu et al., 2004; Rey et al., 2005). These studies have manifested relations between susceptibility and metal concentrations where lower values of susceptibility coincide with areas of greater sensitivity for the accumulation and bioavailability of metals.

The development of this system is a result of close cooperation between the RCOM of Bremen University, realizing the technological base and the GEOMA group of Vigo University applying it to environmental problems. It is aspired to transform the platform into a key element in what we call "Integrated Coastal Zone Management" (ICZM) providing a suitable approach to detect and monitor contaminations of the sea's littoral zones. Likewise, the approach will at longer term allow to assess the susceptibility of these zones to pollution. This will contribute to the establishment of objective techniques for environmental impact risk assessment in such settings with a promising commercial perspective.

\subsection{Study area}

The Ría de Vigo is the southernmost of the Rías Baixas of Galicia. It has the shape of a triangle with a bisectrix of $33 \mathrm{~km}$ length striking in NE (apex) - SE (base) direction. Water depth increases lengthwise from $7 \mathrm{~m}$ in the inner zone up to $53 \mathrm{~m}$ in the outer zone. The western end is defined by a structural high which gives origin to the Islas Cíes. These islands act as a barrier against the Atlantic storms and thereby condition the wave energy distribution 
in the interior of the ría, and, in consequence, the distribution of surface sediments (Vilas et al., 1995). Along general lines, the coarser sediments with high contents of bioclastic carbonate gravels are concentrated at the margins and the external zone of the ría. The finer sediments are preferentially deposited in the central trough, in deeper parts and towards the inner zones (Vilas et al., 1995).

Previous studies in the area (López-Rodríguez et al., 2000; Rey et al., 2000) suggest that the distribution of the magnetic susceptibility of the surface sediment has been predominantly determined by the interrelation of hydrodynamic and textural characteristics of the ría. The lower values of this parameter are therefore found at the margins and shallower parts, which are richer in coarser carbonatic sediments of biogenic origin. Higher levels are, on the contrary, found in the muddy central trough, where biogenic carbonates are less abundant and in the outermost zone with more oxic conditions. Values along the length axis diminish towards the inner zones.

\subsection{Materials and methods}

Here we present first results from the testing of a novel mapping tool to be used in the integrated management of the shallow marine sediments of contaminated coastal zones. This equipment consists of a bottom-towed submarine sensor platform equipped with a Geophex GEM 3 electromagnetic sensor, which is capable of determining the magnetic susceptibility and conductivity of the sediment surface down to $20-40 \mathrm{~cm}$. This permits to evaluate the environmental quality of seafloor sediments at high spatial resolution.

The hull of the submarine is made from an aramid-reinforced epoxy compound, protected with rubber and aluminum at zones which are most exposed to shocks and wear during the bottom-tow. The interior bears a CTD to determine the conductivity of the surrounding seawater, an altimeter providing the actual depth of the submarine, an inflatable rescue bag 
which also acts as a floating system, a pressurized benthos sphere, which contains the navigation sensors for heading, heave, roll and pitch (compass and inclinometer), velocity as well as the power electronics of the EM sensor. In the posterior part of the platform an insulated PVC casing carries the coils in charge of transmitting and the receiving the electromagnetic field used to determine the susceptibility and conductivity.

The submarine has assistance from the surface by a light rubber zodiac of $5.4 \mathrm{~m}$ length, which carries the compressed air cylinders to operate the floaters of the submarine, lead batteries for its power supply and a differential GPS system for its positioning. An onboard computer acquires data from the submarine's electromagnetic multifrequency sensor (GEOPHEX GEM 3) and relays them by wireless LAN to the tugboat. Dinghy and submarine are connected via an umbilical cable which transmits power and acquired data and an air hose to operate the flotation bag.

The arrangement is completed by a tugboat which is in charge of towing the dinghy and the submarine and which is equipped with echosounder, winch, WLAN for communication with the dinghy and DGPS for navigation. This tow formation advances at not more than two knots during survey operation of the equipment while the submarine is kept perpendicular to the dinghy at every moment.

To set out for a marine EM survey, once all equipment is set afloat, the submarine and dinghy are towed in line at some $180 \mathrm{~m}$ distance behind the towboat to the starting point of the profile. After the air valves of the submarine are opened, the air bag deflates and the profiler submerges. The survey commences as soon as the submarine reaches ground and the required tow speed has been attained. In measurement operation, the electromagnetic sensor transmits and receives signals at frequencies of 75,175 and $4725 \mathrm{~Hz}$. For each of these frequencies series of in-phase and quadrature data are obtained, which deliver the values of susceptibility and conductivity, respectively. 
Test surveys were realized by a series of transects, which were localized according to suitable seafloor characteristics. We preferentially considered zones where no rocks existed (which could have damaged the submarine) and where muddy sediments were present and enhanced susceptibility values were to be expected, allowing to validate the measures of the equipment. For this reason, the initial measurements were oriented along two perpendicular transects. The first (Track 1) in W-E direction is parallel to the central axis of the ría, while the second (Track 2) in N-S direction near the mouth of the ría is transversal to the latter (Figure 4-1).

The campaign consisted of eight day cruises during which seven profiles in E-W direction along Track 1 and two in N-S direction in a more external zone following Track 2, resulting in a total of 16:48 h of measurements and a total profile length of $35,177 \mathrm{~km}$.

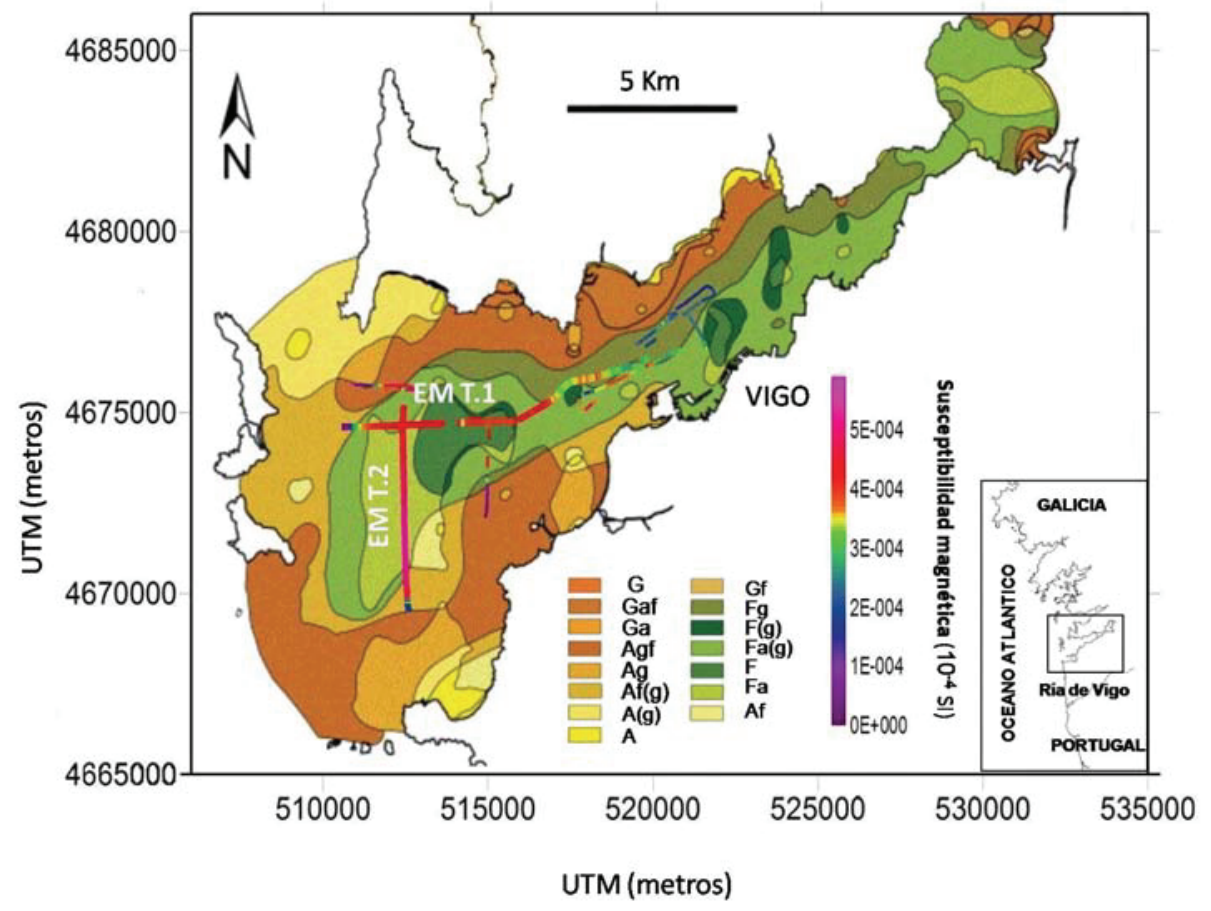

Figure 4-1. Distribution map of surface sediments and magnetic susceptibility in the Ría de Vigo, taken from Vilas et al. 2005. The perpendicular lines mark the EM tracks of this study. 


\subsection{Results and discussion}

The obtained susceptibility values of the EM sensor increase from east to west and thereby with distance from the sources of organic matter and metals (Figure 4-2). In the inner parts of the muddy zones along the central axis of the ría a reduction in susceptibility is observed, which is attributed to diagenetic reduction of the magnetic minerals, owing to the more reducing conditions provoked by the enhancement of organic carbon in this region. The results are consistent with the model of susceptibility distribution in the Ría de Vigo which has been proposed by López-Rodríguez et al., (2000) and Rey et al., (2000) based on the measurement of discrete samples.

The susceptibility data of the proximal zones show high noise levels owing to the presence of metallic residues, submarine cables and electromagnetic noise of the local port industry. This anthropogenic impact diminishes towards the west at the measure by which we leave the city and harbor behind. The conductivity measures express changes in the porosity of the surface sediments, where higher conductivity values are associated with larger porosity and vice versa. This parameter provides information on the variations of grain-size. The conductivity data feature sharp drops which are attributed to the presence of gravel or rubble materials along the trajectory of the submarine (Figure 4-2).

Susceptibility and conductivity show differences in their behavior at the lithological transitions of mud and sand in such way that these lithological variations are indicated by abrupt changes in the conductivity values while susceptibility is marked by a gradual descent. This results, in the case of conductivity, from the differences in porosity which the distinct lithologies present. For susceptibility, the variations are motivated by mixing of different grain-sizes which provoke a gradual descent in magnetic mineral content. 


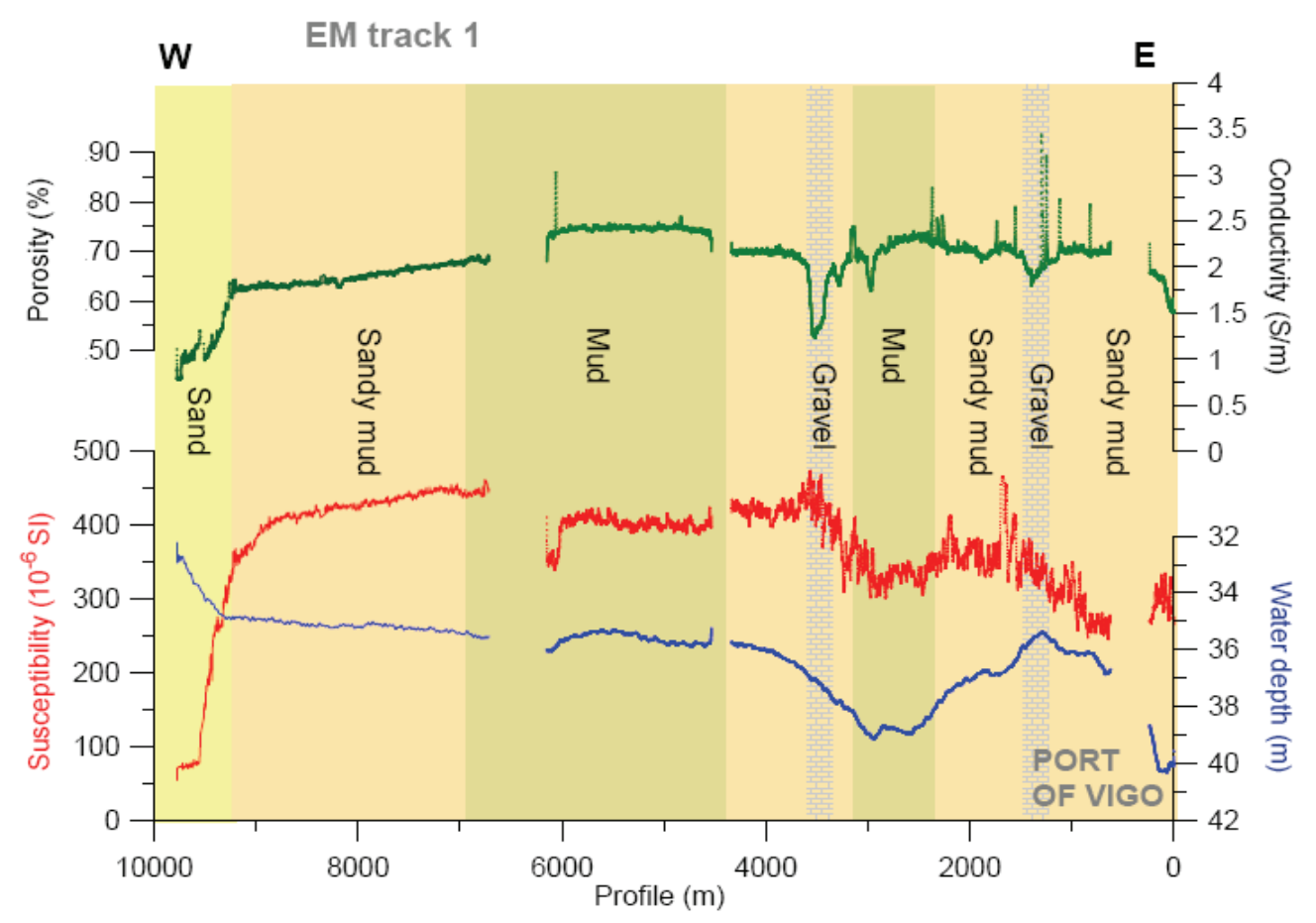

Figure 4-2. Conductivity (S/m) and susceptibility $\left(10^{-6} \mathrm{SI}\right)$ data of transects along the central axis of the Ría.

\subsection{Conclusions and future perspectives}

In this work, a new methodology is introduced, based on a submarine with the electromagnetic sensor Geophex GEM 3, as a new tool to acquire data on the magnetic properties of surface sediments in coastal zones. This will allow to elaborate maps with relevant environmental information. These Data are obtained in larger quantity and more rapid than by traditional methods. Once this technique is fully perfectioned we will be able to correlate the data obtained in this way with dates on heavy metal concentration determined by usual geochemical methods, in the objective to validate these results and to thereby define a relation of EM signals and environmental quality. Their future use in combination with data from hydrodynamic models will turn them into an excellent management tool. This will even allow to determine the iron redox state and its subsurface boundaries in 3-D. Thereby we will be able to distinguish zones, where a detected pollutant can be safely remineralized or where it is in contrary subject to secondary transformation processes, which favor its incorporation into the food chain. 


\subsection{References}

Chan, L.S., Ng, S.L., Davis, A.M., Yim, W.W.S. y Yeung, C.H. (2001): Magnetic properties and heavy-metal contents of contaminated seabed sediments of Penny's Bay, Hong Kong. Marine Pollution Bulletin. 42(7), $569-583$.

Emiroglu, S., Petersen, N. y Rey, D., (2004). Magnetic properties of sediments in the Ría de Arousa (Spain): Dissolution of iron oxides and formation of iron sulphides. Physics and Chemestry of the Earth. 29 (13-14 SPEC.ISS.), 947-959.

Lopez-Rodríguez, N., Rey, D., Rubio, B. y Vilas, F. (2000). Correlación negativa entre susceptibilidad magnética y el contenido en metales pesados de origen antropogénico en un medio litoral. Geotemas. 1, 111-116.

Rey, D., López-Rodríguez, N., Rubio, B., Vilas, F., Mohamed, K., Pazos, O. y Bógalo, M.F. (2000). Propiedades magnéticas de los sedimentos de tipo estuarino. El caso de las Rías Baixas. Cuadernos de Geología Ibérica. 26, 115-126.

Rey, D., Mohamed, K.J., Bernabeu, A., Rubio, B., y Vilas, F., (2005). Early diagenesis of magnetic minerals in marine transitional environments: Geochemical signatures of hydrodynamic forcing. Marine Geology. 215 $(3-4), 215-236$.

Rubio, B., Pye, K., Rae, J.E., y Rey, D. (2001) Sedimentological characteristics heavy metal distribution and magnetic properties in subtidal sediments, Ria de Pontevedra, NW Spain. Sedimentology. 48 (6), 12771296.

Scoullos, M. y Oldfield, F. (1985). Heavy metal-magnetic relationships in particulates and sediments. 5th Heavy Metals in the Environment International Conference. 2, 363-365.

Spassov, S., Egli, R., Heller, F., Nourgaliev, D.K. y Hannam, J. (2004). Magnetic quantification of urban pollution sources in atmospheric particulate matter. Geophysical Journal International. 159(2), 555-564.

Vilas, F., Nombela, M.A., García-Gil, E., García-Gil, S., Alejo, I., Rubio, B. y Pazos, O. (1995). Cartografía de Sedimentos Submarinos. La Ría de Vigo. Escala 1:50.000. Memoria y Mapas. Xunta de Galicia, Consellería de Pesca, Marisqueo e Acuicultura, Madrid. 40 p. 


\section{Conclusions and perspectives}

This doctoral thesis project has developed the great potential of Controlled Source Electromagnetic (CSEM) imaging for submarine in-situ mapping of sediment electric conductivity and magnetic susceptibility. The theoretical and practical investigations have documented the excellent suitability of this new profiling method to classify types, provenance, grain-size and redox state of marine sediments from combined frequency CSEM soundings with the commercial broadband coincident coil sensor Geophex GEM-3.

The physical mandatory near-bottom operation of the sensor at water depths down to several hundred meters entailed the development of a very robust, non-magnetic and non-conductive EM profiling platform. This bottom-towed GEM Shark sled carries the GEM-3 sensor, a conductivity-temperature-depth (CTD) probe, and a sophisticated Ethernet and DSL network allowing real-time communication with the tow-ship. GEM Shark reaches lateral sub-meter resolution at sampling rates of 25 samples per second and tow speeds of 3-4 knots.

Data examples from surveys on the NW Iberian Shelf and Ria de Vigo have demonstrated the high discriminative potential, great robustness and striking ability of the system to map sediment physical properties both in shallow $(5-50 \mathrm{~m})$ and deep $(50-300 \mathrm{~m})$ neritic settings.

A multi-proxy approach has been taken to characterize sediment structures and alteration related to submarine groundwater discharge in Eckernförde Bay, Baltic Sea. Seepage of anoxic groundwater was shown to have major effects on the magnetic mineralogy and electric conductivity of marine surface sediments. It was also demonstrated that combined electromagnetic, acoustic, geochemical and rock magnetic investigations are capable of delivering a detailed and conclusive fingerprint of sedimentary properties and processes. While the spatial interpretation of point samples is prone to interpolation errors and unrecognized outliers, the quasi-continuous profiling data not only fill these information gaps, 
but also detect isolated features and transition zones. Bivariate plots of EM susceptibility versus conductivity data showed great potential to differentiate the main lithologic units and delineate the diagenetic impact on sediment magnetic properties.

The results of this doctoral study suggest that near-surface electromagnetic profiling has significant potential to improve the understanding of the natural diversity of marine sediment deposits. It can also deliver information concerning their contamination by human activities. The results presented clearly show that high sampling resolution is one of the key aspects to successfully identify sedimentary signals of environmental changes in their full scope. This is especially the case when they are combined with other geoscientific information, such as hydroacoustics, hydrographics and laboratory based sediment analytics, EM near-surface sediment profiling has potential to become a routine technique in marine environmental research, mineral exploration, or the assessment of seafloor contamination.

The development the GEM Shark EM profiler as documented in this work has generated a fully functional technological precursor. The logical next step will be to overcome the prototype stage and build easily reproducable and deployable, compact and affordable EM profilers, which are operational from various ship types and platforms. The insights and practical experiences of this study will lead to substantial recommendations concerning mission safety, survey preparation and additional sensor and sampler integration concepts expanding GEM Shark into a mission-specific multi-sensor and multi-method profiling platform. 


\section{Appendix}

\subsection{Eckernförde Bay magnetometer survey}

In may 2006, hydroacoustic and marine magnetic surveys were performed within a study area of $10 \mathrm{~km}^{2}$ in the Eckernförde Bay to establish a high resolution bathymetry of the Holocene mud drape and underlying glacial substratum. The project was set out to test whether passive magnetometry can capture magnetic susceptibility variations related to freshwater seepage. Various ground distances of the magnetometers and 'state of the art' data processing and inversion methods were applied to produce a detailed magnetometric seafloor map combined with hydroacoustic sub-bottom profiles.

A $10 \mathrm{kHz}$ SyQuest StrataBox ${ }^{\mathrm{TM}}$ acoustic Sub-Bottom Profiler and a DGPS beacon receiver were towed in the unmanned non-magnetic zodiac RB Neridis (Figure 6-1) at 100-120 m distance behind RB Polarfuchs. A GEM systems GSM-19 marine Overhauser magnetometer was alternatively (1) mounted in the zodiac, (2) towed at ca. $4 \mathrm{~m}$ above ground or (3) bottomtowed on a nonmagnetic sledge. In modes (2) and (3), the magnetometer and zodiac had identically adjusted laybacks permitting to determine the position and depth of the magnetometer from the DGPS and echosounder on the zodiac. A proton magnetometer was installed on-shore (ca. $5 \mathrm{~km}$ from the survey area), to correct diurnal variations of the earth magnetic field.

A regional magnetic field based on the 2006 International Geomagnetic Reference Field (IGRF) and adjusted for the survey date was removed from the observed total field data. The residual magnetic anomalies were interpolated at $2 \mathrm{~m}$ intervals along the profiles using a nearest-neighbor algorithm (Smith and Wessel, 1990). To correct the measured magnetic field for varying magnetometer elevations above seafloor (given by the bathymetry in Figure 6-2a), the data were inverted to apparent seafloor magnetizations, by an inversion method of Hussenoeder et al. (1995). Thereby, a constant-thickness of the sediment layer that is assumed to be the source of the magnetic signal is chosen at $10 \mathrm{~m}$, which is representative for the mean Holocene mud thickness in the central Eckernförde Bay (Jensen et al. 2002). 


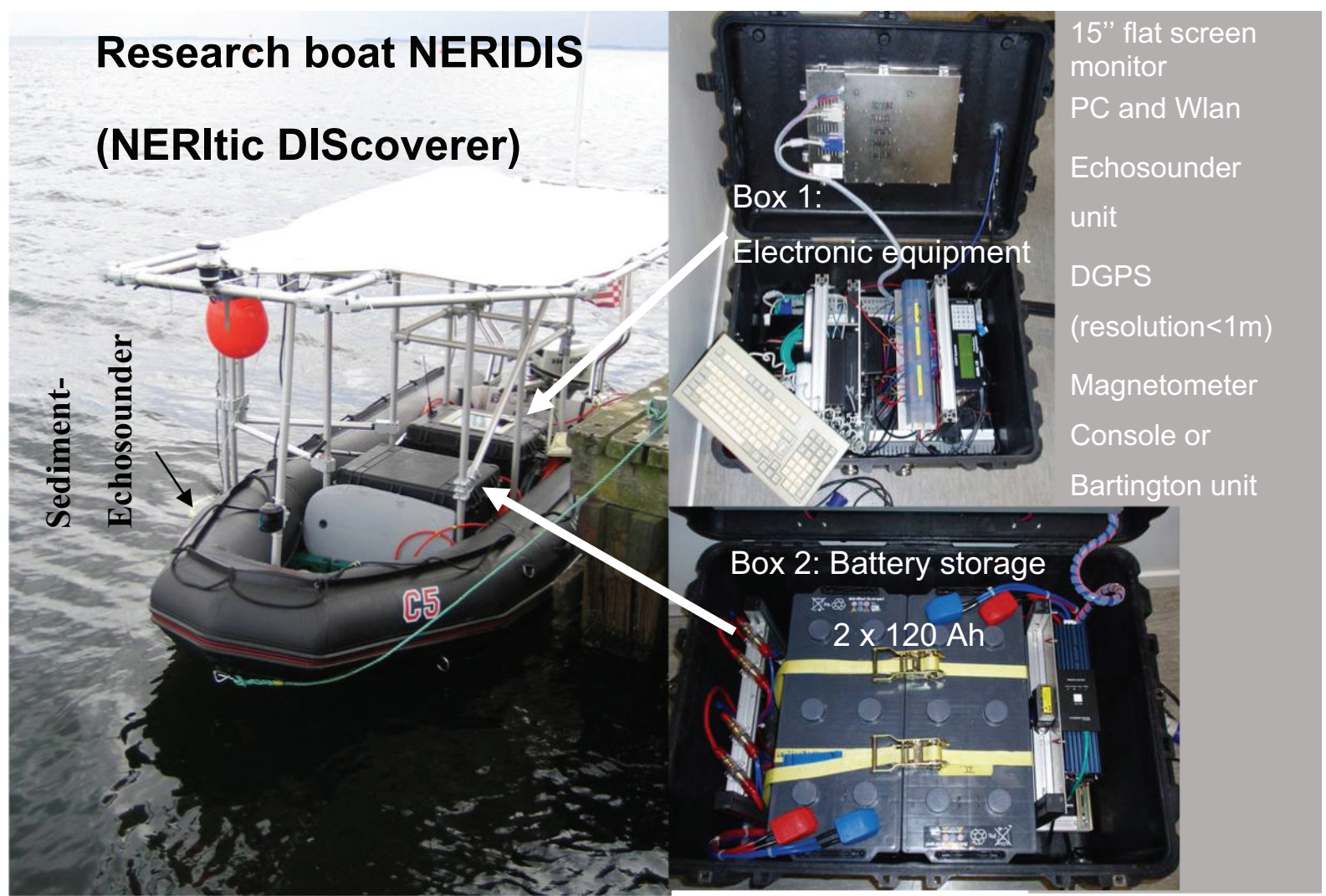

Figure 6-1. NERitic DIScoverer

The resolved apparent seafloor magnetization was bandpass filtered (pass-band 50 to $2000 \mathrm{~m}$ ) to remove residual noise and long wavelength subsurface structures (Figure 6-2b). The resolved magnetization map nicely resolves structures of the glacial basement (Gay, 2004). However, the magnetometers could not allocate a susceptibility change according to the freshwater seepage in direct matter, neither in the total field (inversion of the deep towed magnetometer), nor in the gradiometer configuration (difference between deep and surface towed magnetometer).
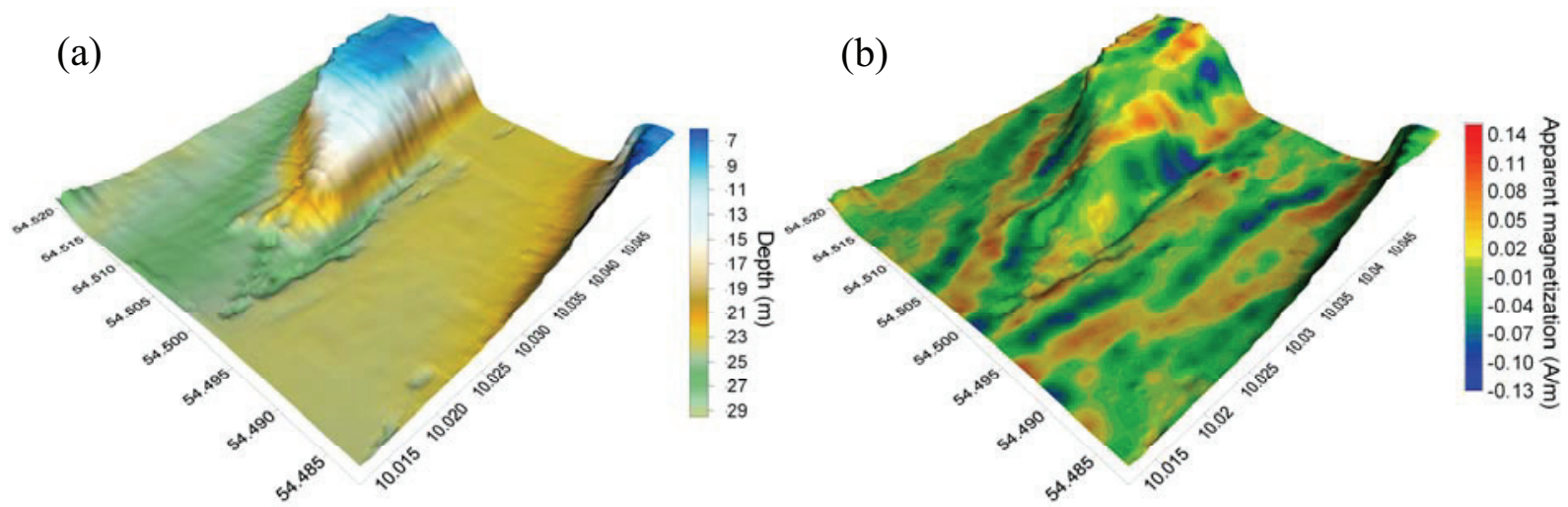

Figure 6-2. Bathymetry (a) and apparent magnetization (b) of the survey area around Mittelgrund. Magnetization is derived from inversion of total field data, considering a $10 \mathrm{~m}$ mud drape responsible for the signal $\left(2^{\text {nd }}\right.$ order butterworth bandpass-filter and minimum curvature gridding of $100 \mathrm{~m}$ spaced NS profiles). 


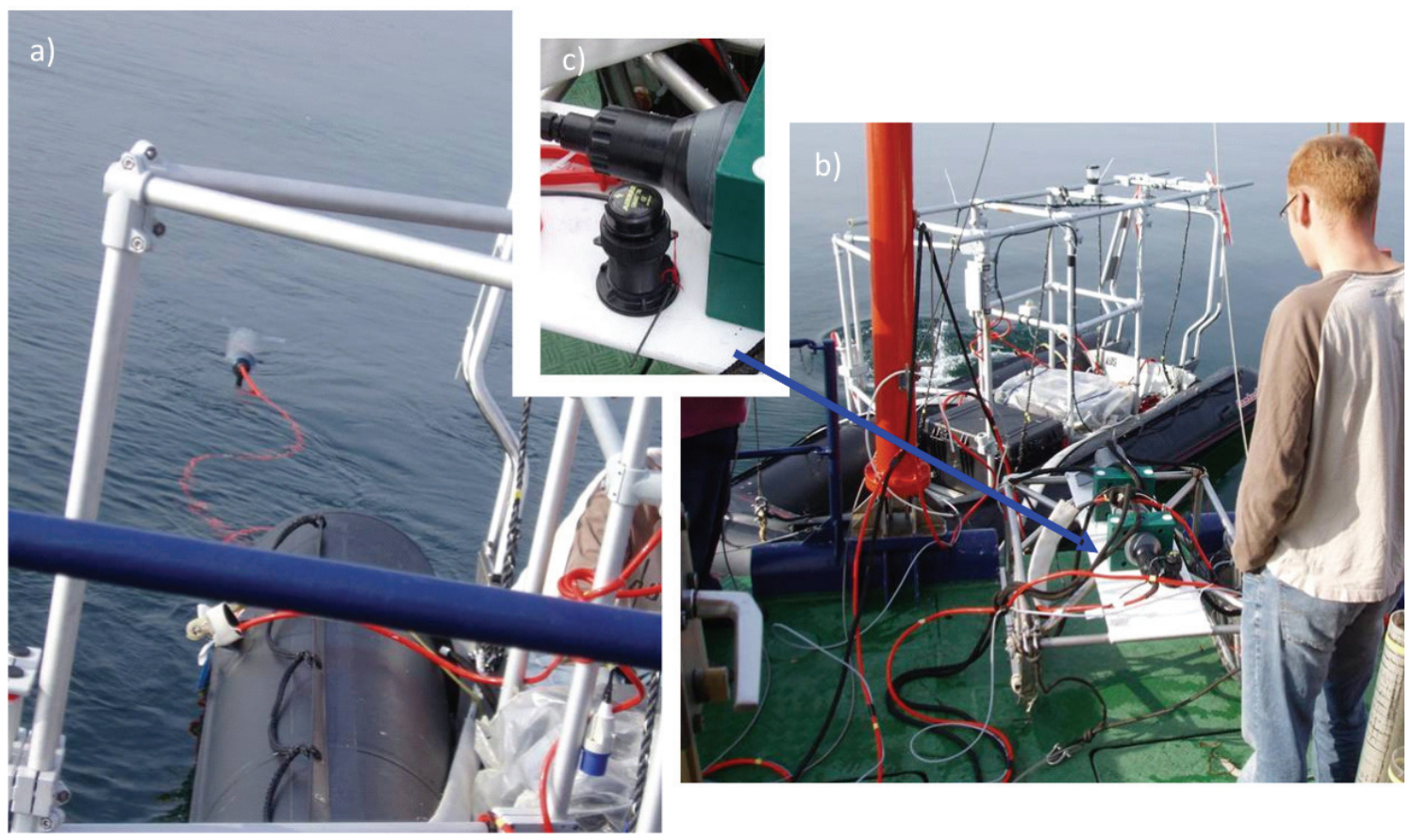

Figure 6-3. Magnetometer configuration for bottom-towed operations. One magnetometer was towed on the sea surface (a) and a second on a stainless steel sled (b) with altimeter (c). Data acquisition and positioning of the sled was performed from unmanned RB Neridis, both systems trailed at equal distance behind RB Polarfuchs.

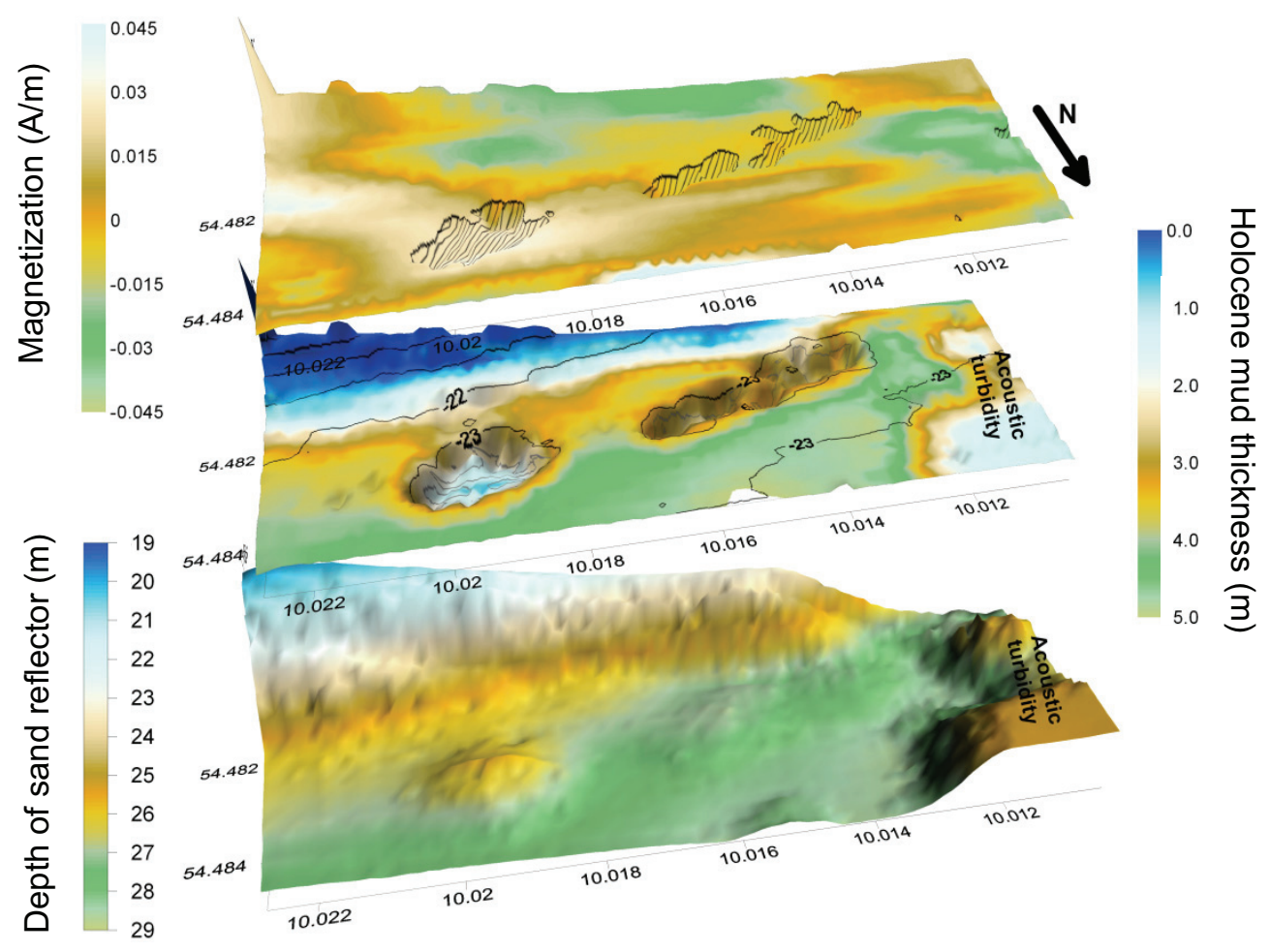

Figure 6-4. Results of deep towed magnetometry and acoustic sub-bottom profiling; (top) apparent magnetization of the depicted survey area with marked (dashed) pockmark locations; (centre) color scaling of the mud thickness, overlain on the bathymetry; (bottom) the sand reflector was extracted from the acoustic images (minimum curvature grids of $25 \mathrm{~m}$ spaced EW profiles). 


\subsubsection{References}

Smith, W.H.F., and P. Wessel, 1990, Gridding with continuous curvature splines in tension: Geophysics, 55, 293-305.

Hussenoeder, S. A., M. A. Tivey, and H. Schouten, 1995, Direct inversion of potential fields from an uneven track with application to the Mid-Atlantic Ridge: Geophysical Research Letters 22 (23), 3131-3134.

Jensen, J. B., A. Kuijpers, O. Bennike, T. Laier, and F. Werner, 2002, New geological aspects for freshwater seepage and formation in Eckernförde Bay, western Baltic: Continental Shelf Research, 22, 2159-2173.

Gay, S. P., 2004, Glacial Till: A Troublesome Source of Near-Surface Magnetic Anomalies: The Leading Edge, $23,542-547$. 


\subsection{Pilot study: seafloor EM mapping in the Ria de Vigo, NW Spain}

The small vessel tow concept relies on limited deployment and handling facilities. Collisions with fishing nets or obstacles are frequent. Batteries and a major control system (including an embedded computer) are placed in an unmanned zodiac, together with 151 diving bottles to inflate a lift bag within the sea bottom towed system (the GEM Shark). Communication with the zodiac is realized using Wireless LAN technology while data transfer between sledge and zodiac is based on the Ethernet LAN technology. All serial interfaces are converted to the Ethernet IPv6 standard and managed in real-time via virtual communication ports over an $80 \mathrm{~m}$ power and communication cable.
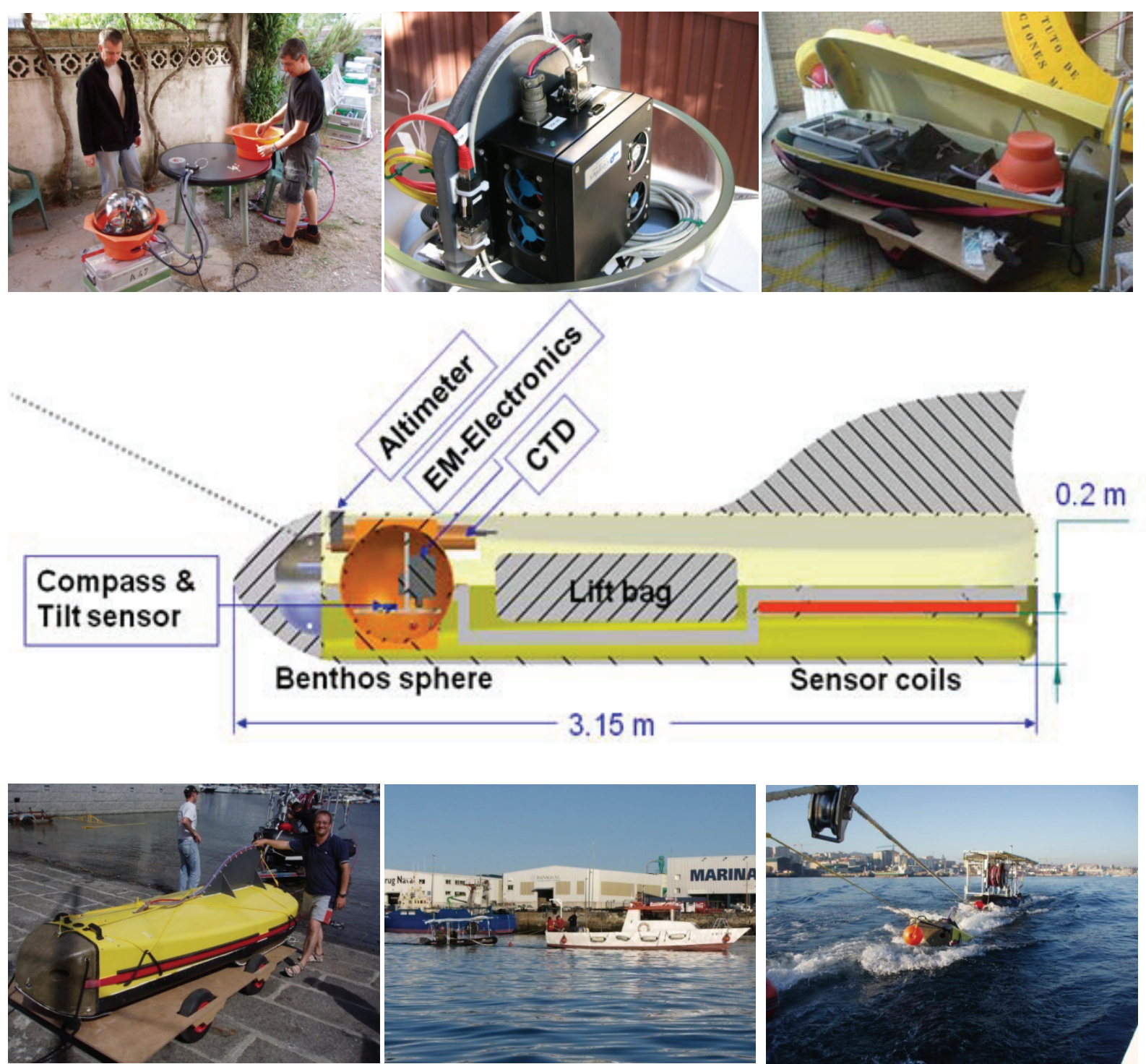

Figure 6-5. Schematic GEM Shark set-up and exemplary pictures of system configuration, deployment and tow concept. 


\section{Electromagnetic and hydrographic field work}

The broadband transmitter waveform was created by superimposing frequencies of 75,175 , 525, 1025 and $4775 \mathrm{~Hz}$ with a pulse-width modulation technique (Won et al. 1997) and amplified to a transmitter current of $21 \mathrm{~A}$. EM data were gathered at $25 \mathrm{~Hz}$ sampling rate and low-pass filtered at $5 \mathrm{~Hz}$ to reduce intrinsic noise. Towed at speeds of 2-3.5 knots, the system achieves an effective lateral resolution of ca. 20-35 cm. EM sensor drift was compensated by interpolating among water-column background measurements.

The electric conductivity and magnetic susceptibility of the subsurface were calculated with a half-space model algorithm considering seawater conductivity data of the CTD. Conductivity was determined from the quadrature component of the $4775 \mathrm{~Hz}$ secondary electromagnetic field, susceptibility from the $75 \mathrm{~Hz}$ in-phase component. The conductivity signal of the subsurface was used to subtract its (minor) contribution to the in-phase signal. A $5 \mathrm{~Hz}$ low pass filter was used to subtract sensor intrinsic noise. Porosity $\phi$ is calculated according to Archies Law (Archie, 1942) by dividing seawater conductivity $\sigma_{\mathrm{CTD}}$ through subsurface conductivity $\sigma_{\mathrm{EM}}$ :

$$
\phi \approx\left(\sigma_{\mathrm{CTD}} / \sigma_{\mathrm{EM}}\right)^{-1 / \mathrm{m}}
$$

The exponent $\mathrm{m}$ was taken at the literature value $\mathrm{m}=1.8$ for marine sands (Cheesman et al. 1993). $4 \mathrm{~Hz}$ conductivity, temperature and pressure data of the CTD were also used to calculate bottom water salinity and to establish a sub-meter resolution along-track bathymetry.

\section{Sediment sampling}

Twelve cores of 20 to $40 \mathrm{~cm}$ lengths were taken with a small piston corer in the Ria de Vigo study area. The cores were subsampled at $2 \mathrm{~cm}$ intervals into $6.2 \mathrm{~cm}^{3}$ plastic cubes and measured in a Kappa Bridge laboratory susceptibility meter at the University of Vigo; porosity was determined by relating wet bulk density to dry mass and a water density of $1025 \mathrm{~kg} / \mathrm{m}^{3}$. A weighted mean is calculated for magnetic susceptibility and porosity core data by a convolution of the applicable depth function of the sensor and the true vertical distribution of these physical sediment properties. 


\subsubsection{Results}

Figure 6-6 presents an exemplary result of a west to east track through the Ria de Vigo, done in autumn 2007, trailing the sea bottom towed GEM Shark in combination with a surface towed zodiac by a $12 \mathrm{~m}$ research vessel, equipped with DGPS, wireless LAN access point, winch and sediment echosounder. The high environmental noise spectrum and increased abundance of ferrous and conductive objects in the eastern section could be observed close to the international harbor and adjacent industries, and the town of Vigo. The magnetic susceptibility signal has its minimum at $70 \cdot 10^{-6} \mathrm{SI}$ in sands at the western part of the profile, close to the Cies islands, and its maximum at $480 \cdot 10^{-6} \mathrm{SI}$ in the central part of the Ria. In the east, the susceptibility decreases stepwise: first, following the bathymetry, to $320 \cdot 10^{-6} \mathrm{SI}$ and to $280 \cdot 10^{-6} \mathrm{SI}$ in the inner part of the Ria, close to the port of Vigo. Gaps in the profile mark collisions with fishing nets, wrecks or obstacles. The decreased susceptibility in the west is likely to be representative for the incorporation of organic matter and heavy metals into the sediment texture, causing diagenetic reduction of iron oxides, such as magnetite and maghemite, which dominate the magnetic signal. According to Rey et al. (2005) two essential factors control the redoxomorphic conditions in the Galician Ria and shelf environment and thus the rise of the magnetic signal to the west: (1) greater distance to sources of pollutant agents associated with the river, town and industrial input, and (2) bottom water oxygenation and degree of mixing in the upper sediment layer, controlled by local water depth, hydrodynamic forces and sediment texture.

Sharp transitions in the conductivity signal (and respectively in apparent porosity) were found due to buried metallic objects and local heterogeneities (e.g. gravel and shale deposits), mud to sand transition in the west and at a seepage structure, likely to be methane gas (Garcia-Gil et al., 2002), that leads to a reduced seafloor conductivity. Transitions between sandy mud and mud, as indicated in the sedimentological map of Garcia-Garcia et al. (2004) (Figure 6-6) vary smoothly, indicating gradual changes in sediment texture or as local bathymetric trough, filled with mud. In summary, electromagnetic profiling indicates that muddy sediments within the Ria de Vigo are dominated by long periodic gradual changes in porosity, stepwise increasing susceptibility with lowest values in the inner Ria and local phenomena addressed to bathymetric troughs, gravel deposits, gas seepage or buried magnetic and/or conductive objects. 


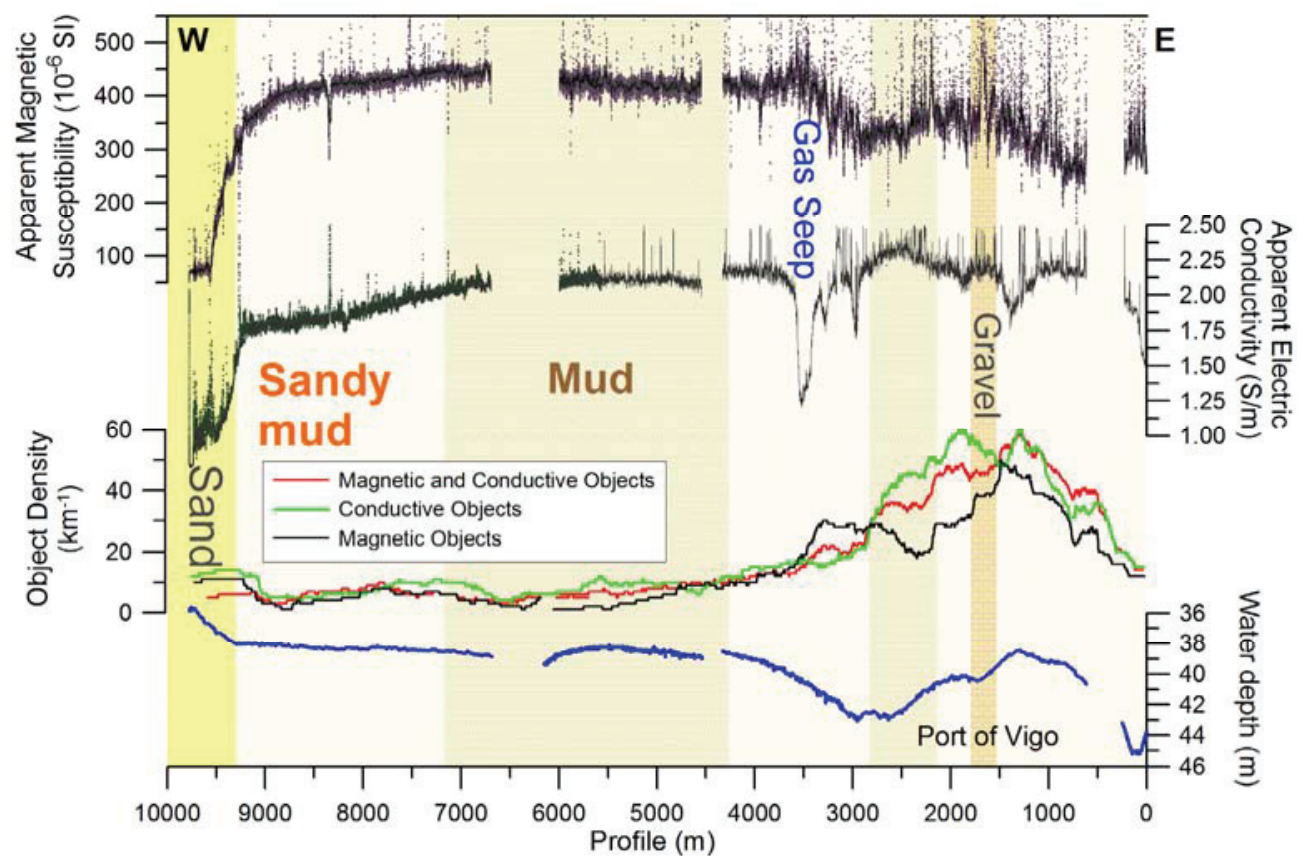

Figure 6-6. East-West profile through the Ria de Vigo (modified after Chapter 4: Rey et al. 2008). The Object density classifies electromagnetic peaks as ferrous objects (red), non-ferrous but conductive objects (green) and magnetic, low-conductive objects, e.g. granites (grey). Background colors represent the lithologic zones according to Garcia-Garcia et al. (2004).

The cross-plot of apparent magnetic susceptibility versus apparent porosity of the acquired profiles (Figure 6-7) reveals that the main sediment facies of sand, mud gravel and sandy mud could be classified by electromagnetic sensing. However, the bandwidth of EM values within each facies class indicates that the signal is not exclusively explained by sedimentology. 


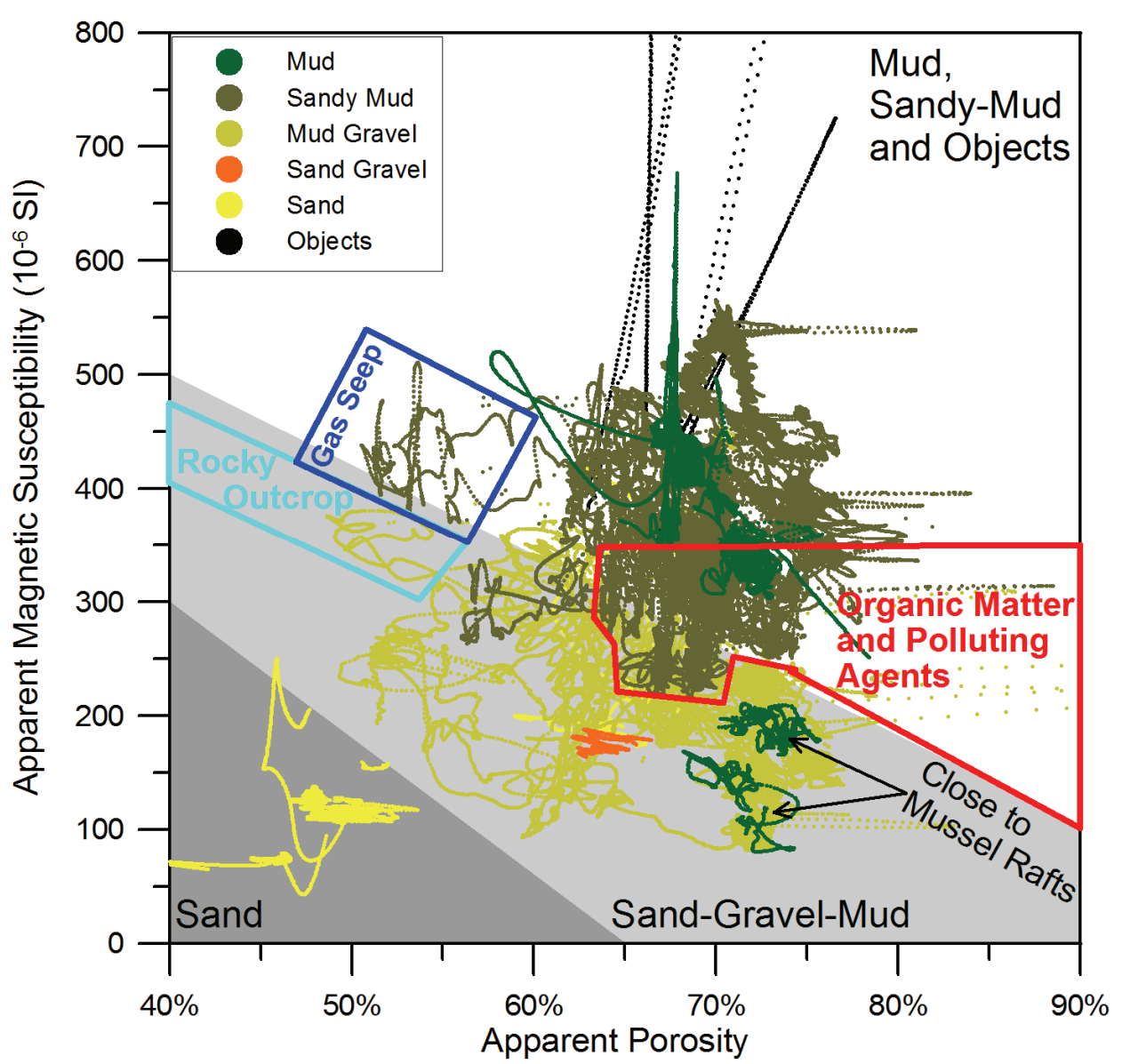

Figure 6-7. Apparent susceptibility and porosity cross-plot of the 2007 Ria de Vigo EM profiles.

\subsubsection{Discussion and Conclusion}

During the first marine survey, the novel CSEM profiler provided high quality magnetic susceptibility and electric conductive data of the seafloor. The general susceptibility trends agree with the known, sample based susceptibility distribution of the Ria de Vigo (LopezRodriguez et al., 2000; Rey et al., 2000). The high spatial coverage of the application also provides means to investigate the heterogeneity of the sediment properties and anthropogenic metal pollution. However, the survey also demonstrated the inherent difficulties of coastal operations in areas of high economic use. Frequent collisions with unmarked fishing nets and various obstacles on the seafloor and a towing vessel with simple infrastructure greatly reduced the total length of profiles. Future operations of that kind will need improved logistics, e.g. to clear study areas of illegal fishing, and provide pre-surveying with acoustic methods (swath sounder or sidescan sonar). Once such methods are fully developed, combination of this method with local geochemical analyzes, and hydrodynamic modeling provides a high potential to become an excellent tool of coastal management. 


\subsubsection{References}

Archie, G. E., 1942, The electrical resistivity log as an aid in determining some reservoir characteristics: Journal of Petroleum Technology, 5, 1-8.

Chan, L. S., S. L. Ng, A. M. Davis, W. W. S. Yim, and C. H. Yeung, 2001, Magnetic properties and heavy-metal contents of contaminated seabed sediments of Penny's Bay, Hong Kong: Marine Pollution Bulletin, 42(7), $569-583$

Cheesman, S. J., L. K. Law, and B. St. Louis, 1993, A porosity survey in Hecate Strait using a seafloor electromagnetic profiling system: Marine Geology, 110, 245-256.

Emiroglu, S., N. Petersen, and D. Rey, 2004, Magnetic properties of sediments in the Ría de Arousa (Spain): Dissolution of iron oxides and formation of iron sulphides: Physics and Chemestry of the Earth, 29, 947959.

García-García, A., S. García-Gil, F. Vilas, 2004, Echo characters and recent sedimentary processes as indicated by high-resolution sub-bottom profiling in Ría de Vigo (NW Spain): Geo-Marine Letters, 24, 32-45.

García-Gil S, Vilas F, García-García A (2002) Shallow gas features in incised-valley fills (Ría de Vigo, NW Spain): a case study: Continental Shelf Research, 22, 2303-2315.

Lopez-Rodríguez, N., D. Rey, B. Rubio, and F. Vilas, 2000, Correlación negativa entre susceptibilidad magnética y el contenido en metales pesados de origen antropogénico en un medio litoral: Geotemas, 1, $111-116$

Rey, D., N. López-Rodríguez, B. Rubio, F. Vilas, K. J. Mohamed, O. Pazos, and M. F. Bógalo, 2000, Propiedades magnéticas de los sedimentos de tipo estuarino. El caso de las Rías Baixas: Cuadernos de Geología Ibérica, 26, 115-126.

Rey, D., K. J. Mohamed, A. Bernabeu, B. Rubio, and F. Vilas, 2005, Early diagenesis of magnetic minerals in marine transitional environments: Geochemical signatures of hydrodynamic forcing: Marine Geology, 215, 215-236.

Rubio, B., K. Pye, J. E. Rae, D. Rey, 2001, Sedimentological characteristics heavy metal distribution and magnetic properties in subtidal sediments, Ria de Pontevedra, NW Spain: Sedimentology, 48 (6), $1277-$ 1296.

Scoullos, M., and F. Oldfield, 1985, Heavy metal-magnetic relationships in particulates and sediments: 5th Heavy Metals in the Environment International Conference, 2, 363-365.

Spassov, S., R. Egli, F. Heller, D. K. Nourgaliev, and J. Hannam, 2004, Magnetic quantification of urban pollution sources in atmospheric particulate matter: Geophysical Journal International, 159(2), 555-564.

Won, I. J., D. A. Keiswetter, D. R. Hanson, E. Novikova, and T. M. Hall, 1997, GEM-3: A Monostatic Broadband Electromagnetic Induction Sensor: Journal of Environmental and Engineering Geophysics, 2 (1), 53-64. 


\title{
Uso de sensores electromagnéticos para la estimación de las propiedades físicas y calidad ambiental de sedimentos superficiales en el medio marino. Resultados preliminares.
}

\author{
Using electromagnetic sensors to estimate physical properties and environmental quality of \\ surface sediments in the marine environment. Preliminary results
}

\author{
D. Rey ${ }^{1}$, H. Müller ${ }^{2}$, B. Rubio ${ }^{1}$, T. von Dobeneck ${ }^{2}$, F. Vilas ${ }^{1}$, C. Hilgenfeldt ${ }^{2}$, A. Bernabeu ${ }^{1}$, T. Frederichs ${ }^{2}$, \\ S.Fernández ${ }^{1}$, K.J. Mohamed ${ }^{1}$ y Grupo GEOMA ${ }^{1 *}$. \\ 1 Dpto. Geociencias Marinas, Facultad de Ciencias del Mar, Universidad de Vigo,36310 Vigo. danirey@uvigo.es \\ 2 Research Center “Ocean Margins”, University of Bremen. Postfach 330440 D-28331 Bremen. Alemania. \\ hendrik.mueller@uni-bremen.de \\ Grupo GEOMA (P. Abilleira, P. Álvarez-Iglesias, A. Andrade, A. Ares, I. Pérez, I.R. Germade)
}

\begin{abstract}
Resumen: Los sistemas litorales, en muchos casos, se encuentran sometidos a una alta presión antrópica, lo que hace necesario el desarrollo de técnicas que permitan evaluar los impactos ambientales provocados por dicha actividad humana. Se presentan los primeros resultados obtenidos durante el periodo de desarrollo e implementación de un nuevo equipo de prospección geofísica submarina orientado a la gestión integral de zonas costeras (ICZM). Se basa en el arrastre en contacto con el fondo de un submarino, dotado de un sensor electromagnético que permite la medida de la susceptibilidad magnética y conductividad eléctrica de los sedimentos superficiales de forma continua y con una capacidad de penetración de hasta $40 \mathrm{~cm}$. Este sistema, una vez perfeccionado, permitirá obtener información muy valiosa para la monitorización de la calidad ambiental de las zonas litorales.
\end{abstract}

Palabras clave: Contaminación marina, susceptibilidad, sensor electromagnético.

\begin{abstract}
The coastal systems, are often subjected to high anthropogenic pressure, which makes it necessary to develop new techniques to assess the environmental impacts caused by such human activity This paper presents the first results obtained during the development and implementation of a new equipment of submarine geophysics survey oriented to integrated coastal zone management (ICZM). It is based on the drag of a submarine in contact with the sea-bottom. The submarine is equipped with an electromagnetic sensor which allows the measurement of the magnetic susceptibility and electrical conductivity of the surface sediments continuously and to a depth of sediment of $40 \mathrm{~cm}$. This system, once improved, will allow us to obtain valuable information for monitoring the environmental quality of coastal areas.
\end{abstract}

Key words: Marine pollution, susceptibility, electromagnetic sensor.

\section{INTRODUCCIÓN}

Las rías de Galicia constituyen unos espacios singulares de una gran riqueza natural y un importante valor económico, que vienen conviviendo con asentamientos urbanos y actividades industriales de cierta entidad. Así, un $40 \%$ de la población gallega vive cercana a las Rías y los principales complejos industriales se localizan próximos al área portuaria. El deterioro en la calidad de sus aguas y sedimentos a lo largo del tiempo causado por los aportes continuados de materia orgánica $\mathrm{y}$ metales asociados a estas actividades, o a otras de nueva implantación como los cultivos marinos, hace necesaria la utilización y desarrollo de instrumentos adecuados que permitan monitorizar, evaluar y gestionar sus consecuencias potencialmente perniciosas.
La química, biogeodinámica y biodisponibilidad de los metales en los ecosistemas marinos costeros es especialmente interesante, desde el punto de vista de control y prevención de los efectos dañinos de estos contaminantes. Este tipo de datos pueden adquirirse mediante técnicas químicas y geoquímicas costosas y muy laboriosas y, por tanto, es necesario el desarrollo de otras tecnologías más baratas y rápidas, que permitan definir niveles de contaminación y estimar los posibles patrones de dispersión de contaminantes con mayor periodicidad y resolución espacial. Esto permitirá valorar su tendencia temporal a corto y medio plazo con mayor precisión espacio-temporal. En este sentido, algunas propiedades magnéticas tales como la susceptibilidad magnética (k) o la SIRM, y cuya determinación es rápida, barata $\mathrm{y}$ no destructiva, muestran correlaciones significativas con las concentraciones de metales en la fracción fina de los sedimentos (Scoullos y Olfield, 1985; Chan et al., 2001; 
Spassov et al., 2004). Dicha asociación puede explicarse debido al papel que juega el tamaño de grano y los óxidos de $\mathrm{Fe}$ en el control de las concentraciones metálicas, lo que les confiere un valor considerable como herramienta en los estudios de calidad ambiental.

Por todo ello, este trabajo expone el desarrollo de un nuevo equipo de medida de susceptibilidad magnética y conductividad in situ, que una vez perfeccionado permitirá valorar de forma indirecta una serie de parámetros físicos y químicos del sedimento claves en la determinación de la calidad ambiental de una determinada zona. El equipo consiste en un submarino dotado con un sensor electromagnético (EM) que determinará la susceptibilidad magnética y conductividad eléctrica mientras es arrastrado por el fondo de la zona de estudio. Se ha seleccionado la Ría de Vigo como zona de estudio porque ha sido muy estudiada desde el punto de vista magnetoquímico (Rubio et al., 2001; Emiroglu et al., 2004; Rey et al., 2005). Estos trabajos, ponen de manifiesto relaciones entre la susceptibilidad y la concentración de metales donde los valores bajos de susceptibilidad coinciden con áreas de gran sensibilidad a la acumulación y biodisponibilidad de metales.

El desarrollo de este equipo es el resultado de una estrecha colaboración entre el RCOM de la Universidad de Bremen, quienes desarrollan la base tecnológica, y el grupo GEOMA de la Universidad de Vigo, quienes lo implementan a problemas medioambientales. Aspira a convertirse en un elemento clave en lo que hoy denominamos Gestión Integral de la Zona Costera (ICZM), ya que proporcionará una herramienta idónea para detectar y monitorizar la contaminación marina en zonas litorales. Asimismo permitirá valorar a medio y largo plazo la susceptibilidad de la contaminación de estas zonas, lo que contribuiría a establecer una técnica objetiva de valoración del impacto ambiental potencial en las mismas con una clara aplicación comercial.

\section{ZONA DE ESTUDIO}

La Ría de Vigo es la más meridional de las Rías Baixas de Galicia. Presenta forma de triángulo con bisectriz de $33 \mathrm{~km}$ de longitud en dirección NE (ápice)SO (base). La profundidad se incrementa a lo largo de este eje desde $7 \mathrm{~m}$ en su zona interna hasta $53 \mathrm{~m}$ en la zona externa. El extremo occidental está definido por una elevación estructural que da origen al archipiélago de las Islas Cíes. Estas islas actúan como apantallamiento ante los temporales atlánticos, condicionando de este modo la distribución de la energía del oleaje en el interior de la ría y, por tanto, la distribución de sedimentos superficiales (Vilas et al., 1995). En líneas generales los sedimentos más gruesos, de alto contenido en gravas bioclásticas carbonatadas, se concentran hacia los márgenes de la ría y su zona externa. Los sedimentos más finos se depositan preferentemente en el eje central, más profundo y hacia las zonas internas (Vilas et al., 1995).
Los trabajos previos en el área (López-Rodríguez et al., 2000; Rey et al., 2000) sugirieron que la distribución de la susceptibilidad magnética del sedimento superficial estaba determinada en gran medida por la interrelación entre las características hidrodinámicas y texturales de la ría. De este modo, los valores más bajos de este parámetro se encontrarán en los márgenes y zonas más someras, más ricos en sedimentos gruesos cabonáticos de origen biogénico. Por el contrario los niveles más altos se concentran en el eje fangoso central, donde los carbonatos biogénicos son menos abundantes, y hacia la zona más externa, de condiciones más oxidantes. A lo largo de este eje, los valores disminuyen hacia las zonas internas.

\section{MATERIAL Y MÉTODOS}

En este trabajo se presentan los primeros resultados en el desarrollo de una herramienta útil en la gestión integral de los sedimentos marinos someros de zonas costeras contaminadas. El equipo presentado consiste en un submarino especialmente diseñado para su arrastre por el fondo $y$ en el que se instala un sensor electromagnético (Geophex GEM 3) capaz de determinar el valor de la susceptibilidad magnética y de la conductividad de los $20-40 \mathrm{~cm}$ superficiales. Esto permite valorar la calidad ambiental de los sedimentos de fondo con gran resolución espacial.

El submarino es de fibra de aramid con refuerzos de resinas especiales, goma y aluminio en las zonas del casco más expuestas a los golpes y al desgaste durante su arrastre por el fondo. En su interior se sitúan un CTD para la determinación de la conductividad del agua de mar, un altímetro que da la profundidad a la que se encuentra el submarino, un flotador de rescate hinchable que actúa como sistema de flotación, una esfera bentónica presurizada que contiene los equipos de navegación que determinan la posición, inclinación y velocidad del submarino (brújula y sensor de inclinación), y el dispositivo electrónico de la sonda. En la parte posterior del submarino, y también protegidas del agua y de la presión, mediante una carcasa presurizada, se sitúan las bobinas encargadas de la generación del campo electromagnético que permite calcular la susceptibilidad y la conductividad.

El submarino es apoyado en superficie por una embarcación neumática ligera de 5,4 m de longitud. En ella se instalan las botellas de oxígeno que operan los flotadores del submarino, un ordenador con un sistema GPS diferencial (DGPS) un sistema de comunicación inalámbrico para el intercambio de datos con el barco encargado del arrastre (WLAN) y para la adquisición de los datos obtenidos con la sonda electromagnética multifrecuencia (Geophex GEM 3) y las baterías que la abastecen. La lancha y el submarino se comunican mediante un cable, que transmite al ordenador los datos recogidos por la sonda y una manguera que conduce aire presurizado al sistema de flotación del submarino. 


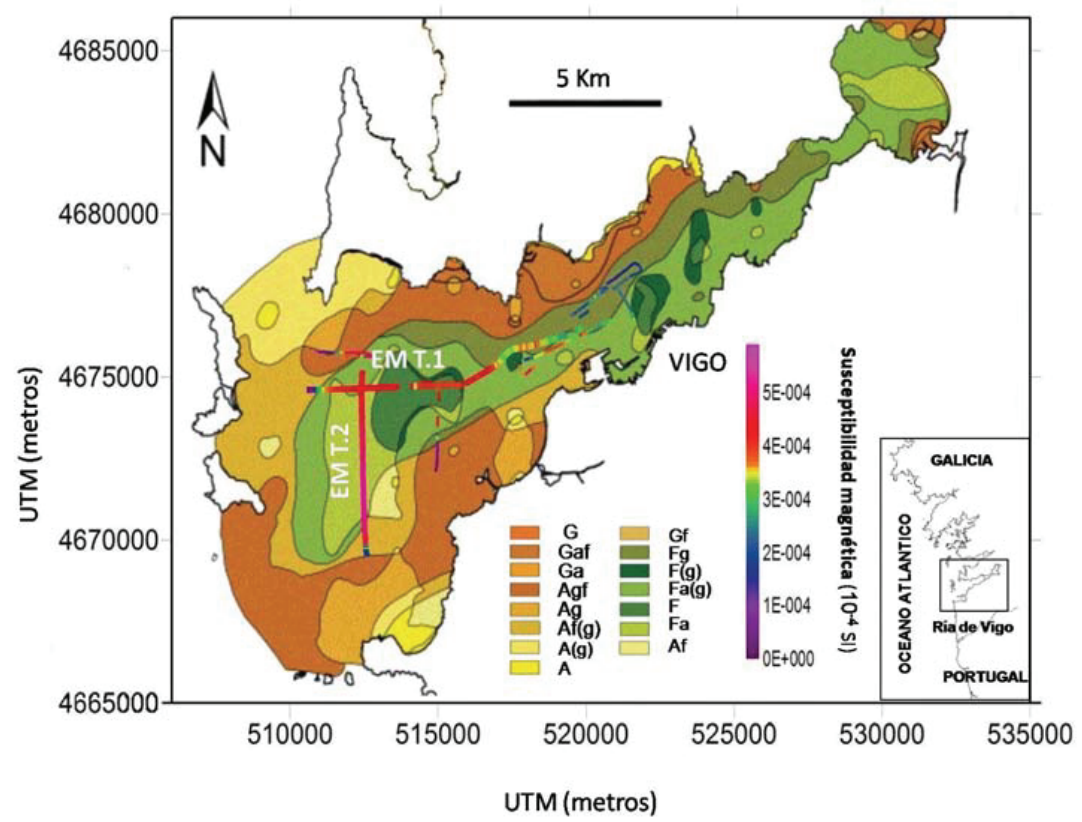

FIGURA 1. Mapa de distribución de los sedimentos superficiales y susceptibilidad magnética en la Ría de Vigo, tomado de Vilas et al. 2005. Las líneas perpendiculares muestran la situación de los transectos seguidos en este trabajo.

El equipo se completa con una embarcación encargada del arrastre de la lancha y del submarino, y que equipada con una ecosonda, un cabestrante, un WLAN de comunicaciones con la lancha y un DGPS. El arrastre se lleva a cabo a una velocidad no superior a 2 nudos durante el funcionamiento de los equipos, manteniendo en todo momento al submarino en la perpendicular de la lancha.

Para la obtención de los datos en las salidas de campo, una vez todo el equipo está preparado y a flote, la lancha y el submarino son arrastradas hasta el punto inicial de cada perfil, donde con la embarcación en línea y a una distancia de $180 \mathrm{~m}$ se abren las válvulas del aire y los flotadores del submarino se vacían para que se sumerja. Cuando llega al fondo comienza el arrastre hasta alcanzar la velocidad requerida, momento en el cual se empieza a medir con la sonda electromagnética usando un espectro de frecuencias de 75, 175 y 4725 Hz. Para cada una de estas frecuencias se obtienen una serie de datos en fase y cuadratura que proporcionan los valores de susceptibilidad y conductividad, respectivamente.

La prospección se realizó a través de una serie de transectos, cuya localización se basó en las características del fondo. Se consideraron preferentemente zonas donde no existiesen rocas que pudiesen dañar al submarino y en las que aparecieran fangos donde los elevados valores de susceptibilidad esperados, permitiesen también validar las medidas del equipo. Para ello se dispusieron las medidas iniciales a lo largo de dos transectos perpendiculares entre sí. El primero (Track 1) de dirección W-E es paralelo al eje central de la ría, mientras el segundo (Track 2) de dirección N-S y próximo a la boca, es transversal a la misma (Fig.1).
La campaña consistió en ocho salidas durante las que se realizaron siete perfiles en dirección E-W a lo largo del eje Track 1 y dos N-S en una zona más externa siguiendo el Track 2, resultando un total de 16:48 h de medidas y una longitud final de los perfiles de $35178 \mathrm{~m}$.

\section{RESULTADOS Y DISCUSIÓN}

Los valores de susceptibilidad obtenidos por el sensor EM aumentan de este a oeste, a medida que se aleja de las fuentes de materia orgánica y metales (Fig. 2). En las zonas fangosas más internas del eje central de la ría se aprecia una reducción de la susceptibilidad atribuida a la disolución diagenética de los minerales magnéticos, debido a las condiciones más reductoras provocadas por el aumento de carbono orgánico en esa región. Los resultados son consistentes con el modelo de distribución de la susceptibilidad en la ría de Vigo propuesto por López-Rodríguez et al., (2000) y Rey et al., (2000), basados en la medición de muestras discretas.

Los datos de susceptibilidad de las zonas próximas muestran niveles altos de ruido debido a la presencia de residuos metálicos, cables submarinos y ruido electromagnético de la industria portuaria de la zona, cuya importancia disminuye hacia el oeste, a medida que nos alejamos de la ciudad y su puerto. Las medidas de conductividad expresan los cambios de porosidad que presentan los sedimentos superficiales, proporcionando los valores de conductividad más altos en las zonas de mayor porosidad y viceversa. Este parámetro proporciona información acerca de las variaciones del tamaño de grano. Los datos de conductividad presentan descensos bruscos que se interpretan como debidos a la presencia de gravas o materiales de relleno y desecho en ciertos puntos de la trayectoria del submarino (Fig. 2). 
La susceptibilidad y conductividad muestran diferencias de comportamiento en las transiciones litológicas de fango a arenas, de forma que dichos cambios litológicos son indicados por variaciones bruscas en los valores de conductividad, mientras que la susceptibilidad sufre un descenso gradual. Esto se debe, en el caso de la conductividad, a las diferencias de porosidad que presentan las distintas litologías. Para la susceptibilidad, las variaciones vendrán motivadas por la mezcla de diferentes tamaños de grano que provocan un descenso gradual del contenido en minerales magnéticos.

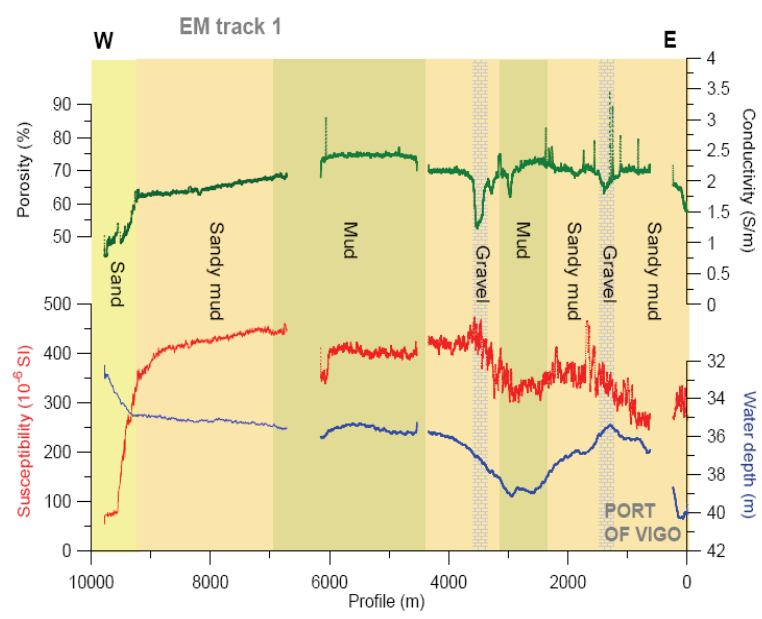

FIGURA 2. Datos se Conductividad $(S / m)$ y Susceptibilidad $\left(10^{-6}\right.$ SI) obtenidos de los transectos realizados en el eje central de la Ría.

\section{CONCLUSIONES Y PERSPECTIVAS FUTURAS}

En este trabajo se introduce una nueva metodología, basada en un submarino equipado con la sonda electromagnética Geophex GEM 3, como una nueva herramienta para la adquisición de datos sobre las propiedades magnéticas de los sedimentos superficiales en las zonas costeras, lo que permitirá la elaboración de mapas con importante información medioambiental. Estos datos se obtienen en mayor cantidad y más rápido que con los métodos tradicionales, y una vez que la técnica esté completamente perfeccionada podremos correlacionar los datos obtenidos de este modo con datos de concentración de metales pesados y susceptibilidades determinados según las técnicas geoquímicas habituales, con el objetivo de validar los resultados, y de esta forma definir una relación señalcalidad ambiental. Su futuro uso combinado con datos de modelización hidrodinámica se convertirá en una excelente herramienta de gestión, ya que permitirá determinar el estado redox y su límite subsuperficial en 3-D, y por tanto distinguir entre zonas en las que un determinado vertido puede ser remineralizado de forma segura o por el contrario ser expuesto a un proceso de transformación posterior al vertido que favorezca su incorporación a la cadena trófica.

\section{AGRADECIMIENTOS}

Este trabajo constituye una contribución a los proyectos PGDIT06TAM31201PR de la Xunta de Galicia y CTM2007-61227/MAR del Ministerio de Ciencia y Tecnología, y recursos propios de investigación del RCOM de la Universidad de Bremen (publicación \# 0565) y GEOMA de la Universidad de Vigo.

\section{REFERENCIAS}

Chan, L.S., Ng, S.L., Davis, A.M., Yim, W.W.S. y Yeung, C.H. (2001): Magnetic properties and heavymetal contents of contaminated seabed sediments of Penny's Bay, Hong Kong. Marine Pollution Bulletin. 42(7), 569-583.

Emiroglu, S., Petersen, N. y Rey, D., (2004). Magnetic properties of sediments in the Ría de Arousa (Spain): Dissolution of iron oxides and formation of iron sulphides. Physics and Chemestry of the Earth. 29 (13-14 SPEC.ISS.), 947-959.

Lopez-Rodríguez, N., Rey, D., Rubio, B. y Vilas, F. (2000). Correlación negativa entre susceptibilidad magnética y el contenido en metales pesados de origen antropogénico en un medio litoral. Geotemas. 1, 111-116.

Rey, D., López-Rodríguez, N., Rubio, B., Vilas, F., Mohamed, K., Pazos, O. y Bógalo, M.F. (2000). Propiedades magnéticas de los sedimentos de tipo estuarino. El caso de las Rías Baixas. Cuadernos de Geología Ibérica. 26, 115-126.

Rey, D., Mohamed, K.J., Bernabeu, A., Rubio, B., Vilas, F., (2005). Early diagenesis of magnetic minerals in marine transitional environments: Geochemical signatures of hydrodynamic forcing. Marine Geology. 215 (3-4), 215-236.

Rubio, B., Pye, K., Rae, J.E., Rey, D. (2001) Sedimentological characteristics heavy metal distribution and magnetic properties in subtidal sediments, Ria de Pontevedra, NW Spain. Sedimentology. 48 (6), 1277-1296.

Scoullos, M. y Oldfield, F. (1985). Heavy metalmagnetic relationships in particulates and sediments. 5th Heavy Metals in the Environment International Conference. 2, 363-365.

Spassov, S., Egli, R., Heller, F., Nourgaliev, D.K. y Hannam, J. (2004). Magnetic quantification of urban pollution sources in atmospheric particulate matter. Geophysical Journal International. 159(2), 555-564.

Vilas, F., Nombela, M.A., García-Gil, E., García-Gil, S., Alejo, I., Rubio, B. y Pazos, O. (1995). Cartografía de Sedimentos Submarinos. La Ría de Vigo. Escala 1:50.000. Memoria y Mapas. Xunta de Galicia, Consellería de Pesca, Marisqueo e Acuicultura, Madrid. 40 p. 


\subsection{EM survey on the Galician Shelf}

During EUROPROX-Expedition P-366/3 with (2008) the novel EM profiler GEM Shark was deployed for the first time on a shelf sea. The system was operated by the $61 \mathrm{~m}$ long RV Poseidon. During ten deployments in water depth of up to $270 \mathrm{~m}$ and mission durations of 6-8 hours, about $300 \mathrm{~km}$ of sub-meter resolution susceptibility and conductivity profiles were gathered. The in-situ data will be interpreted in combination with sedimentological, geochemical and rock magnetic parameters based on 54 grab samples, 27 giant box cores, 21 vibro cores and 4 gravity cores. 


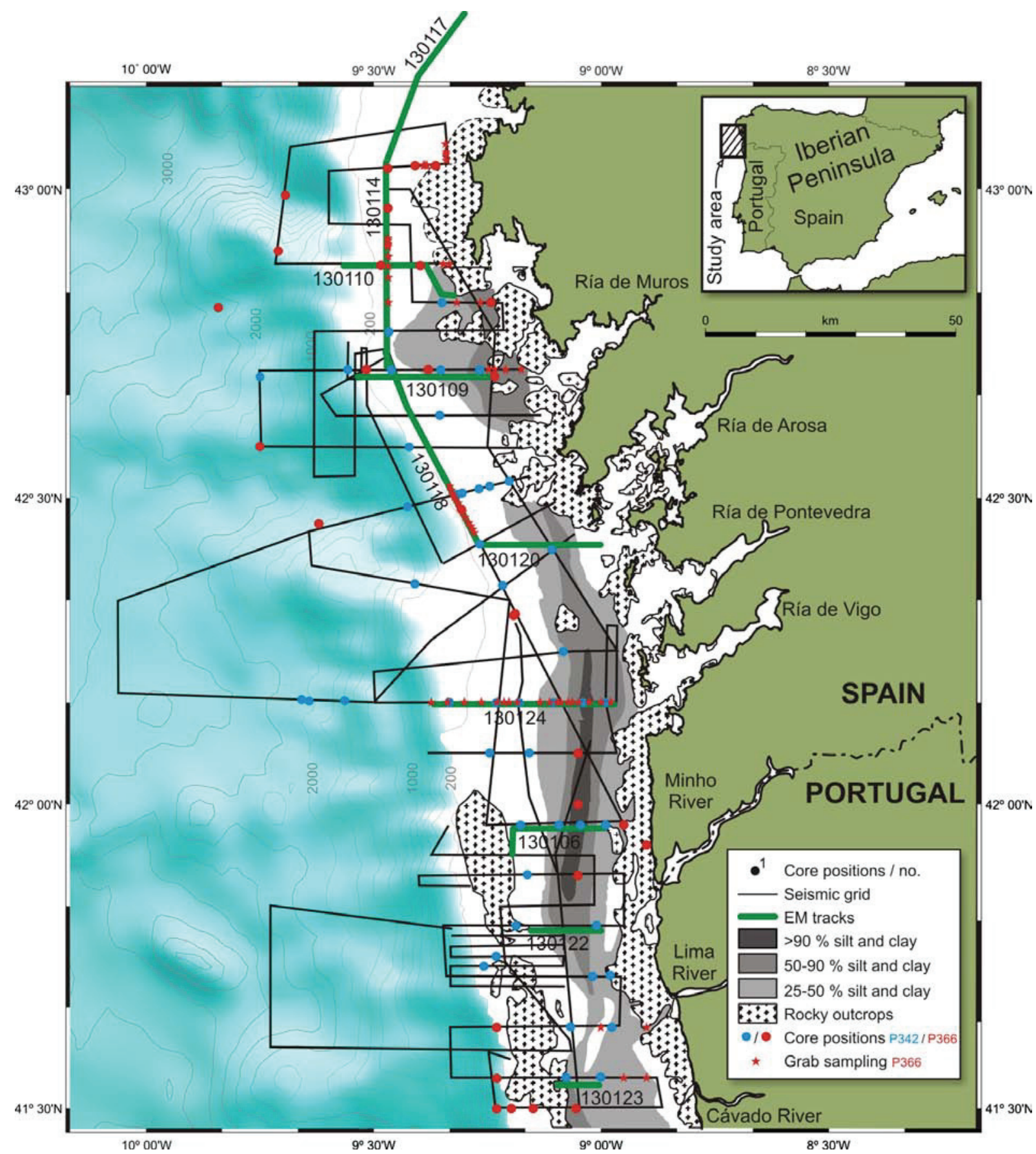

Figure 6-8. The Galician shelf mud belt. EM survey lines, Boomer sections, core and grab sampler positions. Map, seismic profiles and sampling locations according to Lantzsch et al. (2009); silt and clay concentration according to Dias et al. (2002). 


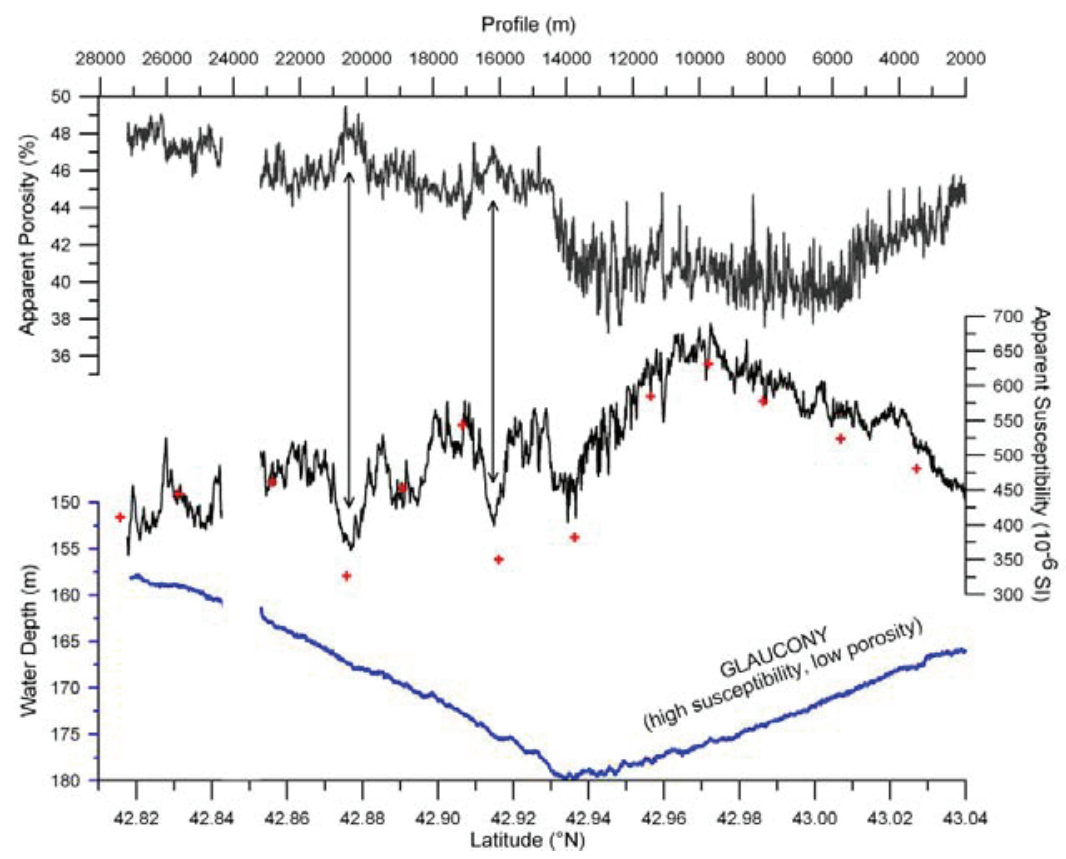

Figure 6-9. Exemplary profile GeoB 130114 from the northern Galician shelf. The sandy sediment is characterized by a generally low apparent porosity (39-49\%). Grab-sample susceptibility (red crosses) correlates well with EM susceptibility. Further sediment analysis revealed that paramagnetic glaucony sand controls the magnetic signal. The profiled depression is marked by asymmetry of the two flanks. The northern flank has generally a low porosity and maximum susceptibility, indicating well sorted glaucony sand. The southern flank is also characterized by relict sands, but more heterogeneous and probably worse sorted.

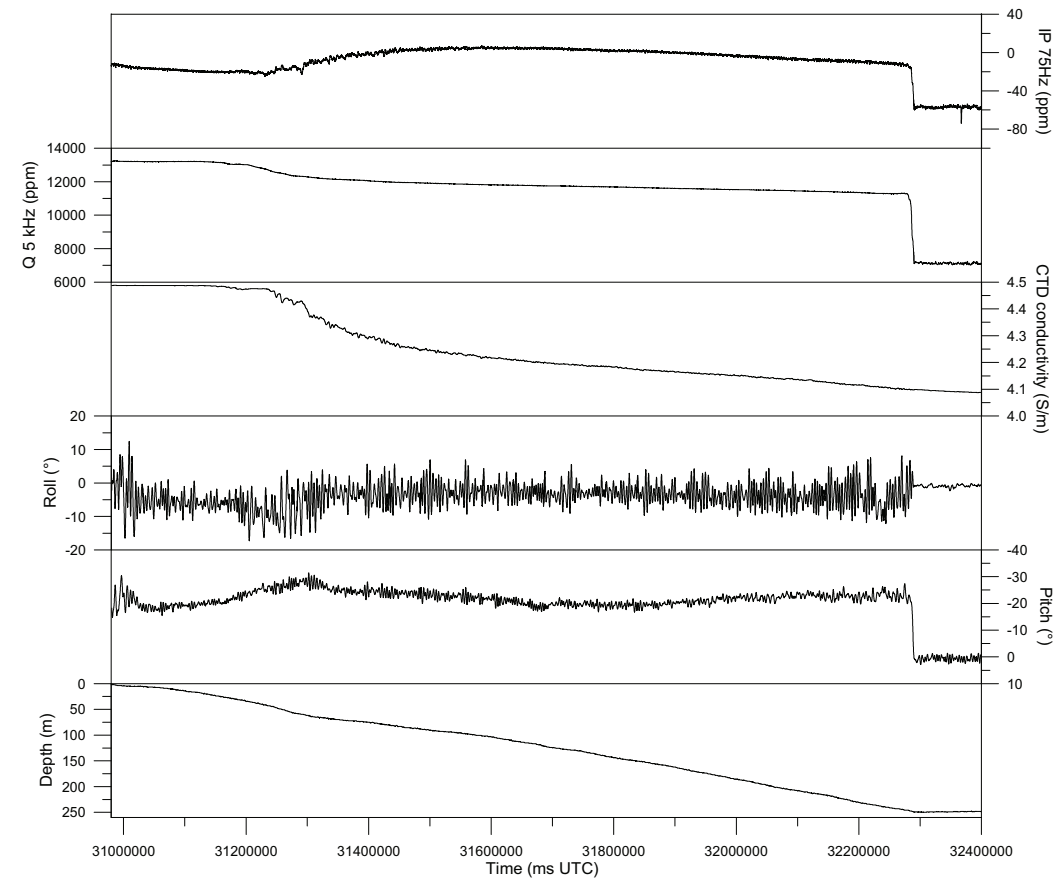

Figure 6-10. RAW data landing procedure. The diving to about $250 \mathrm{~m}$ water depth lasted 18 minutes. Ground contact is clearly indicated by the change in the pitch level (from $25^{\circ}$ to $0^{\circ}$ tilt), a CTD water depth equal to the bathymetry, decay in the EM $5 \mathrm{kHz}$ quadraure (Q) and $75 \mathrm{~Hz}$ in-phase (IP) component. 


\subsection{EM survey on the Uruguayan Shelf}

In June 2009 the optimized GEM Shark was deployed on the Uruguayan Shelf, during Cruise M78/3 by RV Meteor. Within the scopes of the expedition we investigated sediment transport and depositional patterns on the shelf by means of combined hydroacoustic, seismic and electromagnetic mapping as well as geological sampling. Our main objective during this cruise was electromagnetic mapping of the magnetic susceptibility ( terrigenous content) and electrical conductivity ( porosity) of near-surface sediments $(0-50 \mathrm{~cm})$ on the shelf and upper slope at water depths down to about $200 \mathrm{~m}$. Little was previously known about the transport and dumping of fine sediments originating from the Rio de la Plata plume.

Strong wind and currents and the new adoption of the EM system to RV Meteor's winch and tow-cable system were demanding issues during this cruise. Despite the fact of an early and unrecoverable lost of the system, the real-time communication over $10 \mathrm{~km}$ coax cable, the new LabView software that records and visualizes all sensor data in a single control software, and the optimizations of the GEM Shark, also offering mission durations of up to 15 hours, were successful results of the cruise.

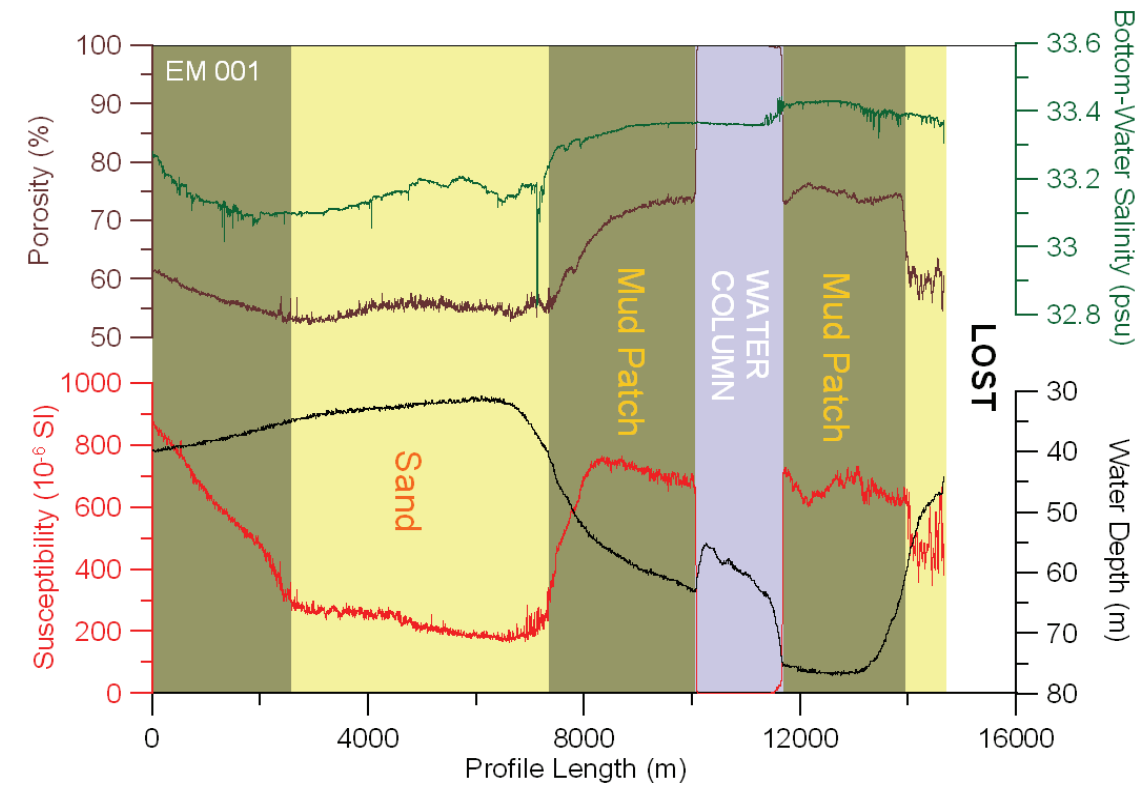

Figure 6-11. GEM Shark profile, taken on the shelf of Uruguay (SE-NW profile). The profiler was deployed in about $40 \mathrm{~m}$ water depth (black line) on sediments of relatively high magnetic susceptibility (red) and porosity (brown). More sandy sediments dominate the seafloor between 2.500 and $7.500 \mathrm{~m}$ profile length. The Uruguayan mud patch is situated in a morphologic low with sediments characterized by high susceptibility and porosity. At a profile length of about $10.000 \mathrm{~m}$, the sled lifted off the seafloor, until further release of the tow-cable enables bottom-contact. The NW part of the mud patch is characterized by a steep slope in bathymetry and abrupt changes in susceptibility and porosity to lower values, which is typical for sand. A collision with an unknown barrier of relict sediments caused the loss of the system in about $45 \mathrm{~m}$ water depth on the Shelf. 


\subsection{LabVIEW data acquisition environment}

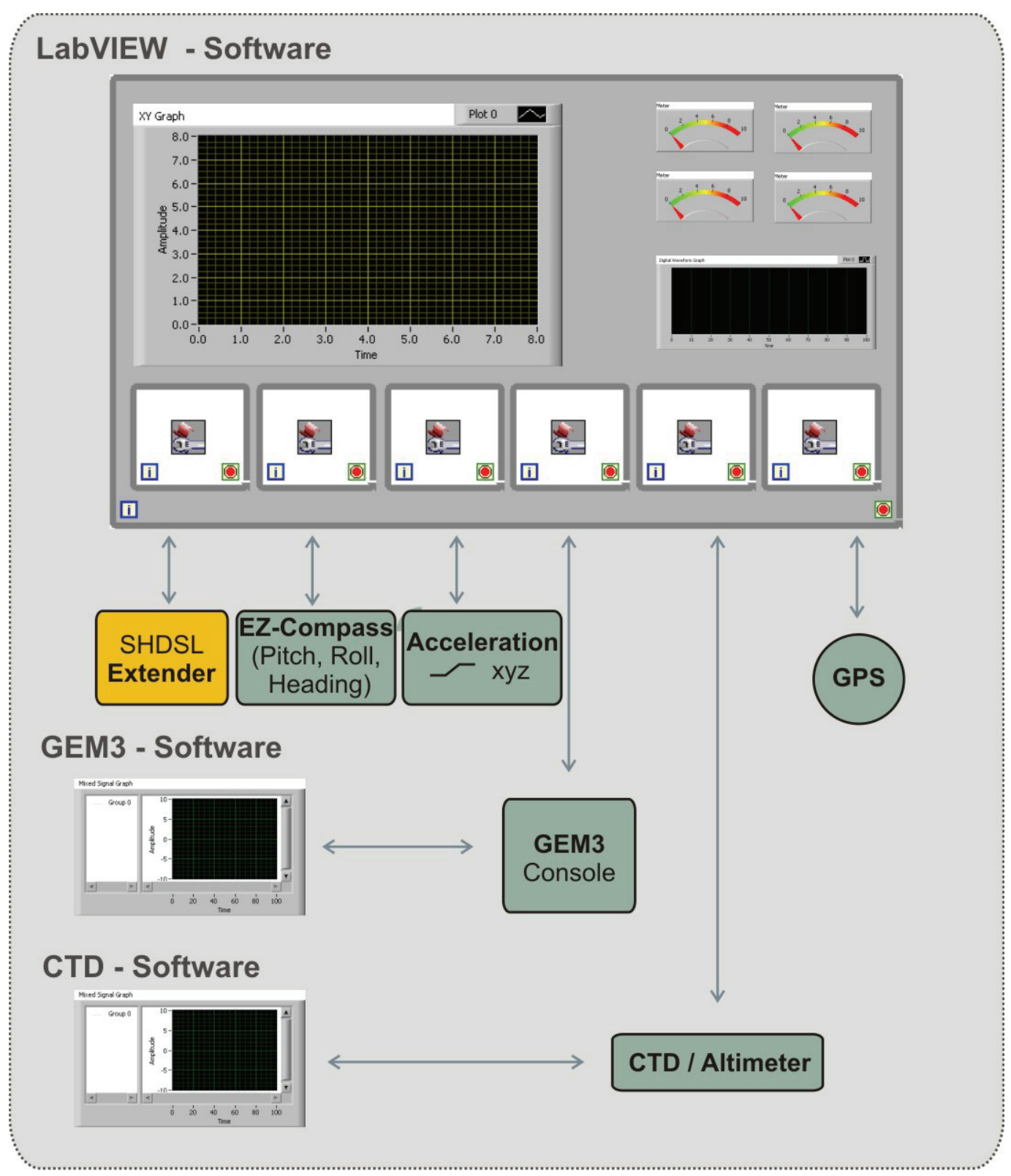

Figure 6-12. Scheme of the LabVIEW data acquisition environment used for real-time control and recording of sensors within the GEM Shark. 


\subsection{Matlab functions}

\subsubsection{N-Layer GEM-3 response}

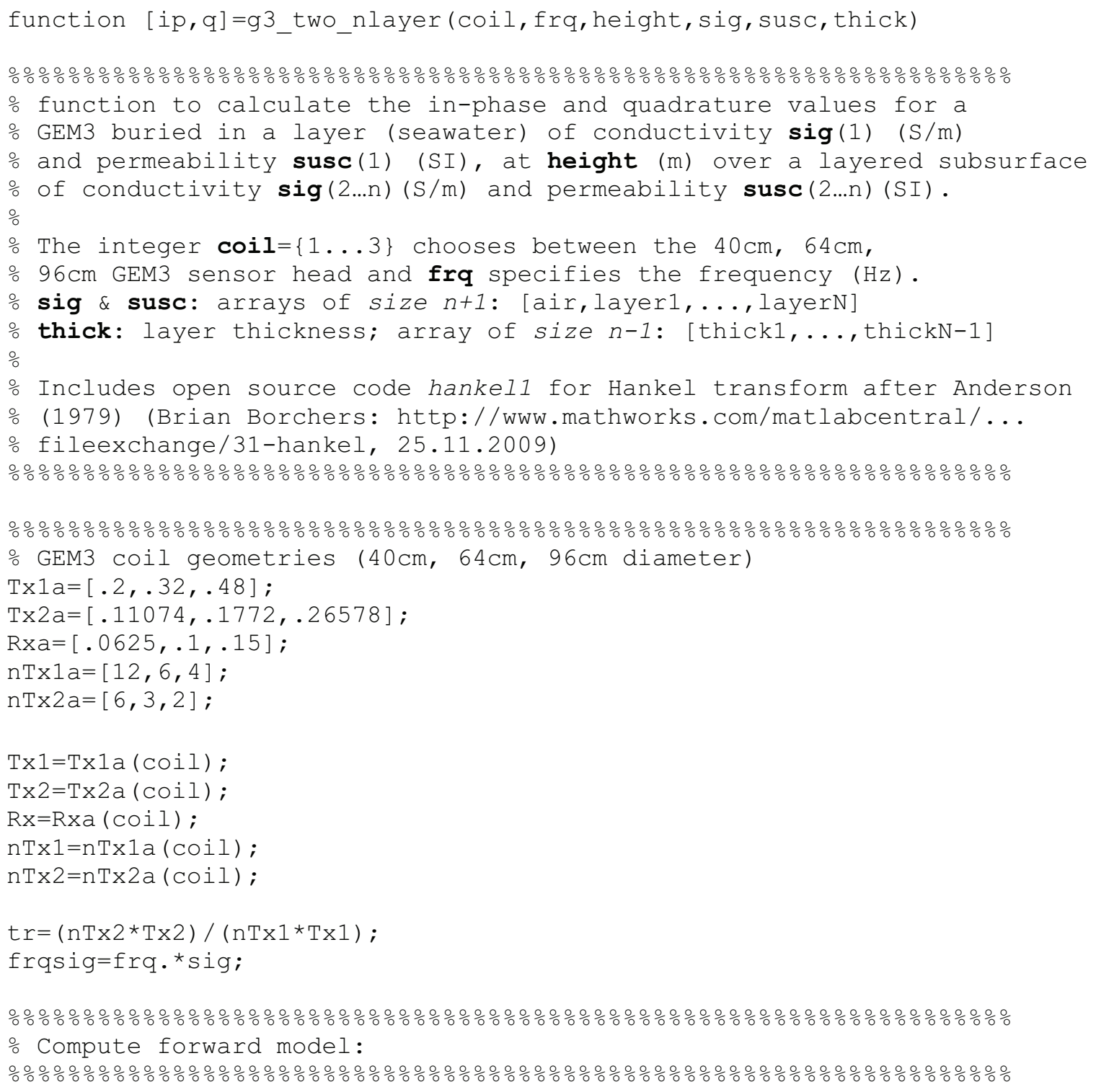




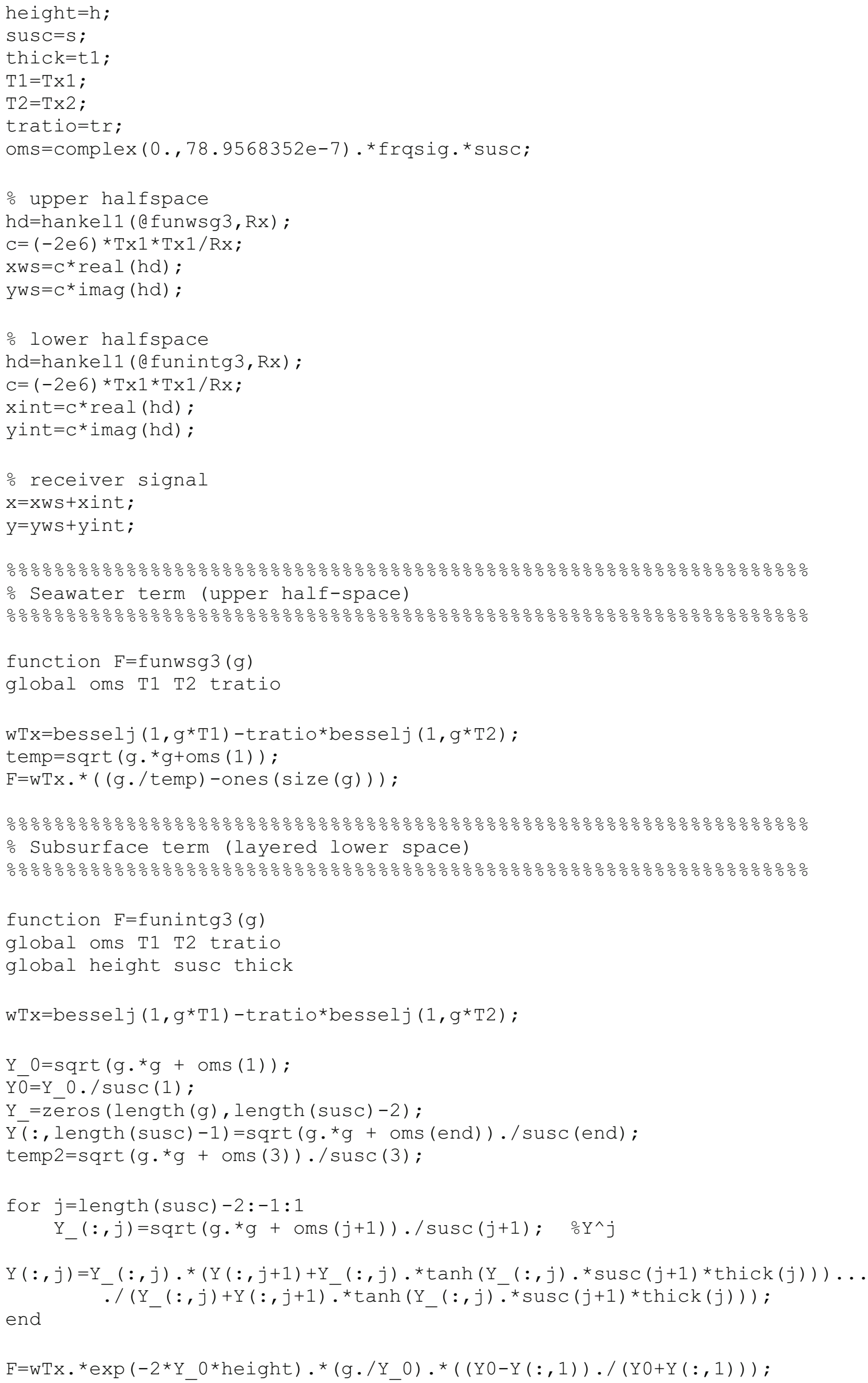




\subsubsection{Half-space inversion algorithm}

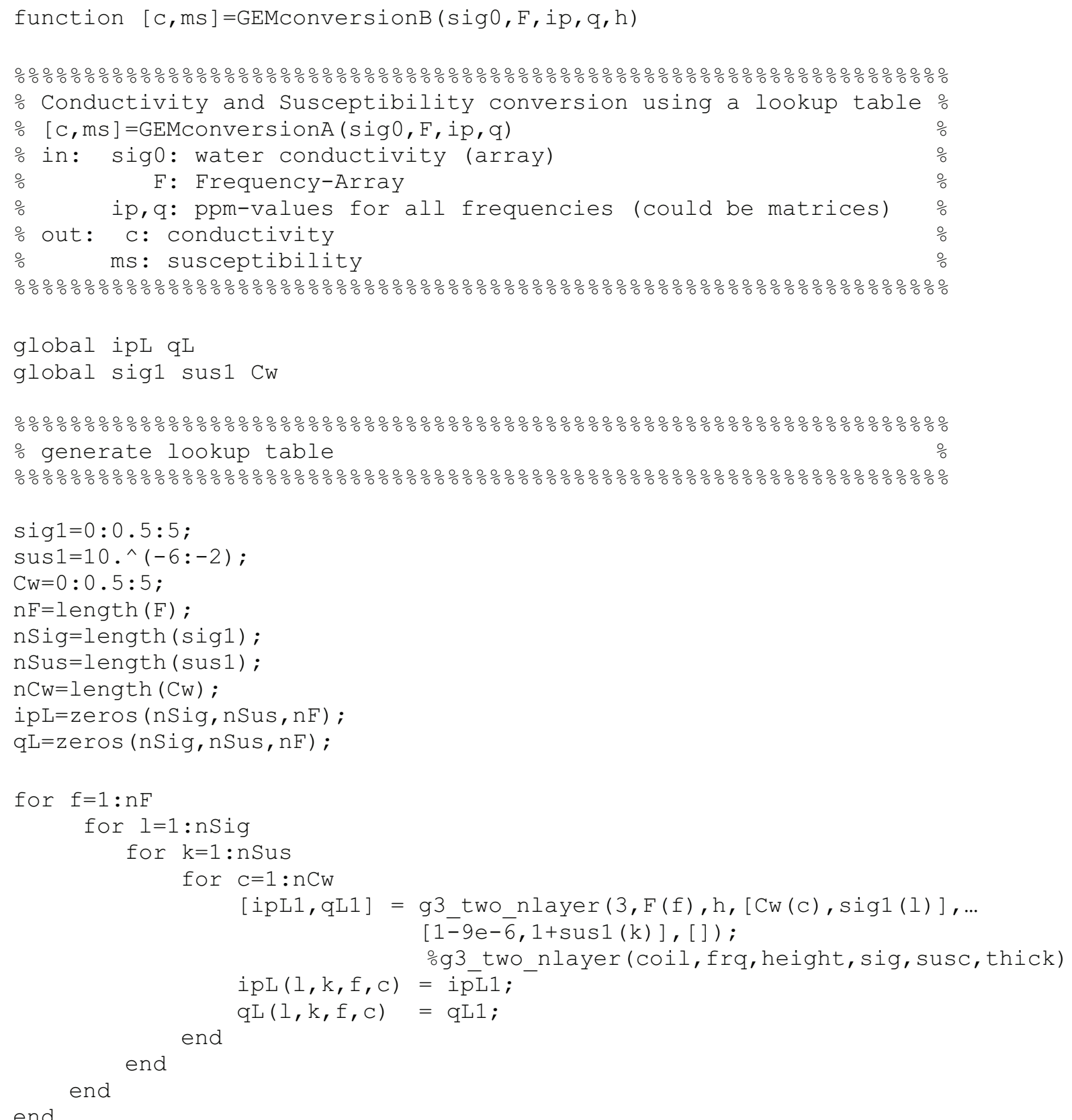

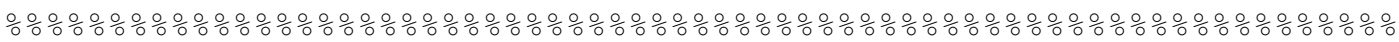

\% Conversion (susceptibility by lowest frequency) 응

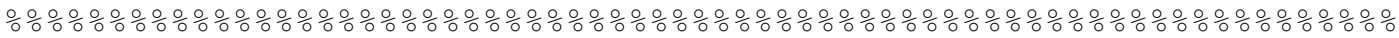

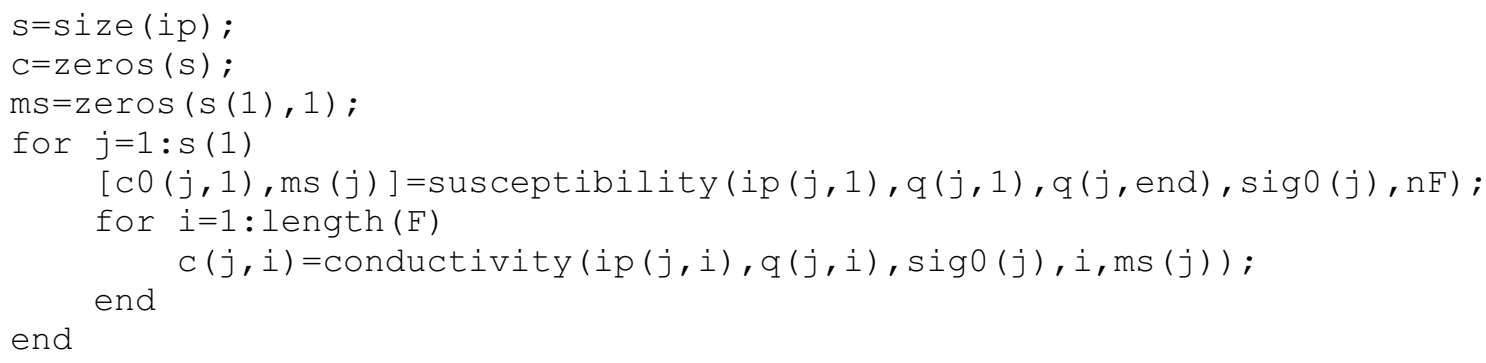




\section{ㅇ Subfunctions}

function [C,ms]=susceptibility (ipLow, qLow, qHigh, sig0, Fx)

global ipL qL

global sigl sus1 $\mathrm{Cw}$

qCwL=spline (Cw, qL ( : , : Fx, : ), sig0) ;

qCwL0 = spline $(\mathrm{Cw}, \mathrm{qL}(:,:, 1,:), \operatorname{sig} 0)$;

ipCwL=spline $(\mathrm{Cw}, \mathrm{ipL}(:,:, 1,:), \operatorname{sig} 0)$;

$\mathrm{c}=$ spline (qCwL $(:, 1), \mathrm{sigl,qHigh)}$;

C=spline (qCwLO $(:, 1), \operatorname{sig} 1$, qLow $)$;

IP=interp1 ( sig1, ipCwL (: , :), c, 'linear', 'extrap') ;

ms=spline (IP, susl, ipLow);

function $c=$ conductivity (ipX, qX, sig0, nF, sus75)

global qL

global sigl susl $\mathrm{CW}$

$\mathrm{qCwL}=\mathrm{spline}(\mathrm{Cw}, \mathrm{qL}(:, \mathrm{:}, \mathrm{nF},:), \operatorname{sig} 0)$;

$\mathrm{Q}=$ interpl ( $\operatorname{sus} 1, \mathrm{qCwL}\left(:, \mathbf{y}^{\prime}\right)$ ', sus 75, 'linear', 'extrap') ;

$\mathrm{C}=\operatorname{spline}(\mathrm{Q}, \mathrm{sig} 1, \mathrm{qX})$; 


\section{Curriculum Vitae}

\section{PERSONAL DETAILS}

Name:

Hendrik Müller

Born:

05.05.1976 in Hannover, Germany

Nationality:

German

Marital status:

Married, one child

\section{EMPLOYMENT HISTORY}

\begin{tabular}{|c|c|c|}
\hline $\begin{array}{l}\text { Since } \\
11 / 2008\end{array}$ & $\begin{array}{l}\text { Research assistant in marine geophysics and environmental } \\
\text { magnetism }\end{array}$ & $\begin{array}{l}\text { University of Bremen, } \\
\text { Germany }\end{array}$ \\
\hline $\begin{array}{l}10 / 2008 \\
- \\
11 / 2005\end{array}$ & $\begin{array}{l}\text { PhD position in geophysics: "Acquisition processes and new } \\
\text { investigative techniques of magnetic signatures in aquatic } \\
\text { sediments" }\end{array}$ & $\begin{array}{l}\text { MARUM - Center for } \\
\text { Marine Environmental } \\
\text { Sciences }\end{array}$ \\
\hline $\begin{array}{l}11 / 2004 \\
- \\
08 / 2004 \\
\end{array}$ & $\begin{array}{l}\text { Scientist: „Impact of physical processes, related to early } \\
\text { diagenesis, on the magnetic remanence of aquatic Sediments“ }\end{array}$ & $\begin{array}{l}\text { University of Bremen, } \\
\text { Department of Geosciences }\end{array}$ \\
\hline $\begin{array}{l}06 / 2004 \\
- \\
04 / 2004 \\
\end{array}$ & $\begin{array}{l}\text { Internship: „Development and application of magnetic } \\
\text { 'online' quantification methods of the paramagnetic mineral } \\
\text { Rinneit in the salt mining industry“ }\end{array}$ & $\begin{array}{l}\mathrm{K}+\mathrm{S} \text { Group - Research and } \\
\text { development in salt mining }\end{array}$ \\
\hline $\begin{array}{l}03 / 2004 \\
- \\
01 / 2004\end{array}$ & $\begin{array}{l}\text { Project work: „Laboratory experiments on the magnetic } \\
\text { remanence acquisition of deep sea sediments“ }\end{array}$ & $\begin{array}{l}\text { University of Bremen, } \\
\text { marine Geophysics }\end{array}$ \\
\hline $\begin{array}{l}12 / 2003 \\
- \\
11 / 2003\end{array}$ & $\begin{array}{l}\text { Scientist: „Feasibility study and requirements analysis for } \\
\text { the magnetic quantification of paramagnetic salt in the potash } \\
\text { mining industry“ }\end{array}$ & $\begin{array}{l}\text { University of Bremen, } \\
\text { in collaboration of the } \mathrm{K}+\mathrm{S} \\
\text { Group }\end{array}$ \\
\hline
\end{tabular}

EXAMINATIONS

2005 Scientific Diver (Berufsgenossenschaft Tiefbau, Germany)

2003 Diploma in geophysics at the University of Bremen, Germany

1999 Associate degree in physics at the University of Goettingen, Germany

1995

General qualification for university entrance at the Georg-Christoph-Lichtenberg Schule, Goettingen, Germany

\section{LECTURES}

WS 2009/10 Magnetic methods in exploration Geophysics (including data processing)

SS $2009 \quad$ Multisensor core logging (Sedimentkernpraktikum)

WS 2008/09 Magnetic methods in exploration Geophysics

WS 2008/09 Magnetic field survey and data processing with GEOSOFT Oasis Montaj 


\section{EXPEDITIONS}

\begin{tabular}{|c|c|c|l|l|}
\hline Time & Ship & Job & Region & Topic \\
\hline $\begin{array}{c}\text { 19.05. }- \\
\text { 13.06.2009 }\end{array}$ & RV Meteor & PL & $\begin{array}{l}\text { Uruguayan and Argen- } \\
\text { tine Shelf (Montevideo } \\
\text { - Montevideo) }\end{array}$ & $\begin{array}{l}\text { Electromagnetic imaging of sediment } \\
\text { deposits and physical property } \\
\text { measurements of sediment cores }\end{array}$ \\
\hline $\begin{array}{c}\text { 23.07. - } \\
\text { 31.07.2008 }\end{array}$ & RB Polarfuchs & CL & $\begin{array}{l}\text { Eckernfoerde Bay, } \\
\text { Baltic Sea (Kiel - Kiel) }\end{array}$ & Electromagnetic imaging of cold seeps \\
\hline $\begin{array}{c}\text { 02.06. - } \\
\text { 18.06.2008 }\end{array}$ & $\begin{array}{c}\text { RV Poseidon } \\
\text { (cruise P366-3) }\end{array}$ & PL & $\begin{array}{l}\text { Galician shelf, Spain } \\
\text { (Vigo - Vigo) }\end{array}$ & $\begin{array}{l}\text { Electromagnetic imaging of sediment } \\
\text { transport processes }\end{array}$ \\
\hline $\begin{array}{c}25.09 .- \\
11.10 .2007\end{array}$ & RB ARAO & CL & $\begin{array}{l}\text { Ria de Vigo, Spain } \\
\text { (Vigo-Vigo) }\end{array}$ & $\begin{array}{l}\text { Electromagnetic mapping of sedimen- } \\
\text { tation processes and pollution pathways }\end{array}$ \\
\hline $\begin{array}{c}08.08 .- \\
01.09 .2006\end{array}$ & RB Polarfuchs & CL & $\begin{array}{l}\text { Eckernfoerde Bay, } \\
\text { Baltic Sea (Kiel - Kiel) }\end{array}$ & $\begin{array}{l}\text { Deep towed magnetic mapping sediment } \\
\text { sampling at cold seeps }\end{array}$ \\
\hline $\begin{array}{c}30.05 .- \\
01.06 .2006\end{array}$ & RB Polarfuchs & CL & $\begin{array}{l}\text { Eckernfoerde Bay, } \\
\text { Baltic Sea (Kiel - Kiel) }\end{array}$ & $\begin{array}{l}\text { Magnetometer und acoustic mapping of } \\
\text { basement structures and cold seeps }\end{array}$ \\
\hline $\begin{array}{c}09.06 .- \\
01.07 .2005\end{array}$ & $\begin{array}{c}\text { RV Meteor (cruise } \\
\text { M65/1) }\end{array}$ & MSP & $\begin{array}{l}\text { NW-Afrika } \\
\text { (Dakar - Dakar) }\end{array}$ & $\begin{array}{l}\text { Climate history and sedimentation } \\
\text { processes }\end{array}$ \\
\hline $\begin{array}{c}25.05 .- \\
27.05 .2005\end{array}$ & $\begin{array}{c}\text { RV Professor } \\
\text { Albrecht Penck }\end{array}$ & PL & $\begin{array}{l}\text { Baltic Sea } \\
\text { (Saßnitz - Rostock) }\end{array}$ & $\begin{array}{l}\text { Magnetic property assessment at } \\
\text { monitoring stations }\end{array}$ \\
\hline $\begin{array}{c}16.08 .- \\
16.09 .2000\end{array}$ & $\begin{array}{c}\text { RV Sonne (cruise } \\
\text { SO149) }\end{array}$ & SA & $\begin{array}{l}\text { Cascadia basin } \\
\text { (Victoria-Victoria) }\end{array}$ & $\begin{array}{l}\text { Seismic and thermal investigation of } \\
\text { seepage structures }\end{array}$ \\
\hline
\end{tabular}

[CL: cruise leader; PL: project leader; MSP: member of scientific party; SA: student assistant] 


\section{Danksagung}

Mein ganz besonderer Dank gilt meinem Doktorvater, Chef, Mentor und Erstgutachter Professor Dr. Tilo von Dobeneck. Insbesondere möchte ich ihm für das in mich gesetzte Vertrauen, die Chance meine Ideen auch seinen eigenen Vorstellungen vorzuziehen und die vielen Stunden des technischen und wissenschaftlichen Gesprächs danken.

Professor Dr. Tobias Mörz gilt ein besonderer Dank, für die Anfertigung des zweiten Gutachtens.

Ein ganz spezieller Dank gilt meinem geschätzten Kollegen und technischen Mentor Christian Hilgenfeldt. Selbstverständlich wäre ohne ihn die technische und praktische Realisierung dieser Arbeit unmöglich gewesen. Darüber hinaus hat unser freundschaftliches Verhältnis in unserem sub-Team wesentlich zum Durchhalten in so manch verzweifelter Stunde beigetragen. Auch gilt mein Dank Thomas Frederichs für sein offenes Ohr, seine Projektunterstützung, die mittägliche Zusammenfassung des WK-Lokalteils und für vieles mehr. Liane Brück danke ich herzlich für den Expeditions-Support und für die Bereitschaft, als „Mädchen für alles“ allseits präsent zu sein.

Ich möchte weiterhin allen aktuellen und ehemaligen Mitgliedern der Arbeitsgruppe Marine Geophysik in Bremen danken, mit denen ich hier eine aufregende Zeit in freundschaftlicher Atmosphäre verbracht habe (Heike Piero, Dave Heslop, Cletus Itambi, Melanie Dillon, Frank Schmieder, Ulrich Bleil, Daniela Hofmann, Marion Milling-Goldbach, Martina Braun, Linda Garmin, Wiebke Nehmiz, Christine Franke, Cornelia Köhler, Mathias Höcker, Anne Witt, Andreas Steinbach, Janna Just, Vera Bender, Yanzhe Fu, Sebastian Razik, Firoz Badesab, Bastian Wichand und Johannes Brock).

Prof. Dr. Daniel Rey und Belén Rubio, möchte ich vielmals für die tolle Kooperation danken, die dieses Projekt erst ermöglicht hat. Insbesondere hat mich ihre unglaubliche Gastfreundschaft sowie die generelle freundschaftliche Beziehung sehr inspiriert. Dies trifft natürlich ebenfalls und in ganz besonderem Masse für das Arao-Kernteam: Alba Andrade, Irene Pérez und Ana Ares zu. Sara Fernández gilt mein spezieller Dank für die Arbeit die sie zur Publikation des Ría de Vigo EM Einsatz geleistet hat. Auch ist es dankenswert, dass sie in ihrer Masterarbeit die EM Profile der Ría de Vigo erfolgreich in geochemische und magnetische Untersuchungen eingebunden und mich mit ihren Fragen zum EM Prinzip zum nachdenken angeregt hat. Im Weiteren gilt mein Dank den Mitgliedern der Arbeitsgruppe 
„Environmental Geology” der Universität Vigo für die interessante und abwechslungsreiche Zeit in Galizien (Ana Bernabeu, Kais Mohamed, Frederico Vilas, Paula Abilleira, Paula Álvarez-Iglesias, Isabell Germade und David Campos).

Für die Unterstützung und Anregungen während meiner ersten Erfahrungen als ,Fahrtleiter auf FB Polarfuchs möchte ich Holger Meier und Helmut Schramm danken. Ebenso gilt mein Dank Tom Müller und Maike Heinitz von der Koordinierungsstelle für Forschungsschiffe des IFM-GEOMAR, die den Polarfuchseinsatz unterstützt und sich für eine effektive Zeitzuteilung eingesetzt haben.

Die erfolgreiche Realisierung des ersten Groß-Schiffseinsatzes auf der Expedition P366/3, sowie die erfolgreiche Rettung des Systems nach einem Abriss, verdanken wir Kapitän Schneider, seinen Offizieren und der Besatzung der FS Poseidon.

Katrin Schwalenberg (BGR) und Marion Jegen (IFM-GEOMAR) danke ich für die freundschaftliche Aufnahme in den Kreis der marinen EM-community. Ihr Rat zu Beginn des Projektes sowie die Unterstützung in der Endphase dieser Arbeit, waren von enormer Hilfe und haben mich stets als Teil einer tollen Gemeinschaft fühlen lassen.

I.J. Won, Bill SanFillipo, Alex Oren, Frank Funak und Joe Seibert von Geophex Ltd. (Raleigh, USA) gilt mein Dank und Respekt für die fundamentale Unterstützung zur Realisierung unserer marinen Version ihres GEM-3 EM Sensors - auch unter schwierigen Bedingungen und enormen Zeitdruck.

Nebst beruflicher/wissenschaftlicher Unterstützung wäre ich ohne den Beistand meiner Eltern Ilse und Klaus Müller nicht in den Genuss gekommen, diese Arbeit anfertigen zu können. John Ingram danke ich für die ,native speaker‘ Tipps und Korrekturen zum Kapitel 3 dieser Arbeit. David Wolf-Rooney gilt mein Dank für seine großartige Hilfe bei den Korrekturen in der Endphase dieser Arbeit. Die größte und schwerste Last hatten aber meine Frau Kerstin und mein im Januar dieses Jahres geborener Sohn Theo, insbesondere in den letzten Monaten dieser Arbeit. Ihnen möchte ich in aller Liebe diese Doktorarbeit widmen. 